\title{
O impacto da virtualização no desempenho de aplicações distribuídas baseadas em SOA e a sua influência nos modelos de desempenho
}

\section{Luís Cézar Darienzo Alves}

Orientador: Prof. Dr. Marcos José Santana

Tese apresentada ao Instituto de Ciências Matemáticas e de Computação - ICMC-USP, como parte dos requisitos para obtenção do título de Doutor em Ciências - Ciências de Computação e Matemática Computacional. VERSÃO REVISADA. 
o impacto da virtualização no desempenho de aplicações distribuídas baseadas em SOA e a sua influência nos modelos de desempenho / Luís Cézar Darienzo Alves; orientador Marcos José Santana. -São Carlos, 2013. $158 \mathrm{p}$.

Tese (Doutorado - Programa de Pós-Graduação em Ciências de Computação e Matemática Computacional) -Instituto de Ciências Matemáticas e de Computação, Universidade de São Paulo, 2013.

1. Arquitetura orientada a serviços. 2. Web Services. 3. Virtualização. 4. Modelos de desempenho. I. Santana, Marcos José, orient. II. Título. 
À minha querida esposa Wilnice que tem sido uma fonte inesgotável de paciência e compreensão e que continua me ensinando a olhar a vida pelo seu lado mais doce, presenteando-me com o nosso filho Dante, que está no sétimo mês de gestação. 



\section{Agradecimentos}

Agradeço primeiramente à Deus, por me apresentar oportunidades e me orientar nas decisões.

À Wilnice, minha esposa, pela paciência, compreensão e incentivo. Sem ela este trabalho não teria sido desenvolvido.

Ao meu filho Dante, que ainda está no sétimo mês de gestação, mas que já é uma fonte inesgotável de inspiração e motivação.

Ao Prof. Dr. Marcos Santana, pela orientação e confiança durante o desenvolvimento deste trabalho, principalmente durante a fase de finalização.

À Prof. Dra. Regina, pelas contribuições sugeridas, sendo de fundamental importância para as decisões tomadas neste trabalho. Além da amizade e dos ensinamentos transmitidos.

À prof. Dra. Agma, pelo apoio prestado durante o desenvolvimento deste trabalho e pelo empenho exemplar nos trâmites administrativos.

Aos amigos Lucas e Matheus pelas orientações constantes e apoio durante todo o desenvolvimento deste trabalho.

À minha família por estarem presentes nos momentos importantes da minha vida, pelo apoio e carinho.

À minha irmã Francislaine pela motivação, apoio e atenção dedicada, principalmente, nos últimos meses.

Ao casal Wilson e Larenice, que sempre me receberam com atenção e carinho.

Ao Prof. Dr. Monaco, por seus ensinamentos e pela amizade desenvolvida, incentivando-me nos momentos mais difíceis deste trabalho.

Aos demais professores do LaSDPC, que de maneira direta ou indireta, contribuíram para este trabalho.

Aos meus colegas e amigos da USP e do LaSDPC, cujos nomes omitirei para não cometer a injustiça de esquecer algum, que através das reuniões do grupo ou até mesmo em conversas informais, teceram comentários importantes para o desenvolvimento deste trabalho 
Aos funcionários do ICMC-USP, pelo convívio amigo e descontraído. Em especial Caroline e Ana Paula que sempre me atenderam de maneira exemplar.

Aos meus colegas do Tribunal Regional Eleitoral que de forma direta ou indireta contribuíram para o desenvolvimento deste trabalho, principalmente aos amigos Franklâneo, Ailton, Cândido, Fábio, Rodrigo, Maikon, Ludmilla, Rafael, Dilma e Rose.

Ao diretor geral do TRE-MT, Mauro Diogo, pelo apoio na divulgação do artigo publicado no XI WCGA.

Aos meus colegas do Instituto de Computação da Universidade Federal de Mato Grosso, cujos nomes omitirei para não cometer a injustiça de esquecer algum, que compreenderam o momento e flexibilizaram o meu trabalho nessa instituição, permitindo, assim que este trabalho fosse concluído.

À CAPES pelo apoio financeiro durante a fase inicial deste trabalho. 
"Não exijas dos outros qualidades que ainda não possua."

Chico Xavier 



\section{Resumo}

ALVES, L. C. D. O impacto da virtualização no desempenho de aplicações distribuídas baseadas em SOA e a sua influência nos modelos de desempenho. Tese (Doutorado) ICMC, USP, São Carlos, 2013.

Esta tese de doutorado analisa o impacto gerado pela virtualização assistida por hardware, de terceira geração, no desempenho de aplicações baseadas em SOA do tipo CPU-bound e memory-intensive, bem como nas operações de marshalling e unmarshalling de mensagens SOAP executadas nas bibliotecas dos servidores de aplicação. A partir dessa análise, concluiu-se que os recursos disponibilizados pela plataforma de hardware, principalmente no gerenciamento de memória, eliminam a sobrecarga gerada pela virtualização baseada em tradução binária, elevando os hypervisores bare-metal a um novo patamar, onde aplicações executadas sobre tais virtualizadores obtêm, frequentemente, desempenho superior àquelas executadas em plataformas não virtualizadas. Assim, modificações nos modelos de desempenho de aplicações baseadas em SOA atualmente em uso são propostas, de acordo com a análise desenvolvida, para que reflitam os resultados obtidos de forma realista.

Palavras-chave: SOA, Web Services, virtualização e modelo de desempenho. 



\section{Abstract}

ALVES, L. C. D. . Thesis (PHd) - ICMC, USP, São Carlos, 2013

This $\mathrm{PhD}$ thesis analyzes the impact caused by third generation hardware-assisted virtualization on the performance of CPU-bound and memory-intensive SOA-based applications, as well as the impact caused on the marshaling and unmarshalling operations of the SOAP messages executed on the libraries of the application servers. From this analysis is concluded that the resources provided by the hardware platform, mainly considering the memory management, eliminate the overload generated by virtualization based on binary translation, raising the bare-metal hypervisors to a new level, where applications running on these hypervisors reach better performance when compared to those applications running on platforms not virtualized. Thus, modifications on the performance models for SOAbased applications currently in use are proposed accordingly to the analysis developed, aiming at reflecting the results obtained in a realistic fashion.

Keywords: Web Services, Virtualization and Performance Model 



\section{Lista de Figuras}

1.1 Variação do varejo on-line no Brasil em bilhões [E-COMMERCE, 2013]. . . . 2

1.2 Variação na quantidade de consumidores on-line (e-consumidores) no Brasil. Em milhões $[$ E-COMMERCE, 2013] . . . . . . . . . . . . . . 3

2.1 Mapeamento de processos de negócios em softwares utilizando diferentes tecnologias $[\mathrm{ERL}, 2005] \ldots \ldots \ldots \ldots \ldots$

2.2 Organização e colaborações entre os componentes SOA [ENDREI et al., 2004]. 10

2.3 Uso de objetos e componentes, organizados em camadas, no desenvolvimento de soluções baseadas em SOA [ENDREI et al., 2004]. . . . . . . . . . 11

2.4 Infraestrutura dos elementos constituintes de uma arquitetura orientada a serviço [ENDREI et al., 2004]. . . . . . . . . . . . . . . . . 12

2.5 Esquema de uma composição de serviços, em que serviços de diferentes entidades são compostos, juntamente com um serviço utilitário, a fim de compor um serviço complexo denominado serviço-tarefa [ERL, 2009] . . . . 15

3.1 Arquitetura dos Web Services [TAVARES, 2009]. . . . . . . . . . . . . . . 24

3.2 Estrutura de um envelope SOAP [W3C, 2007] . . . . . . . . . . . . 31

4.1 Níveis de privilégio da plataforma X86 [TROYER, 2007] . . . . . . . . . . . 43

4.2 Virtualização total através de tradução binária [TROYER, 2007]. . . . . . . . 44

4.3 Abordagem de virtualização através da paravirtualização [TROYER, 2007]. . 45

4.4 Abordagem utilizando virtualização assistida por hardware [TROYER, 2007]. 46

4.5 Diagrama do sistema de gerenciamento de memória [BHATIA, 2009]: a) sistemas nativos e b) sistemas virtualizados. . . . . . . . . . . . . 47

4.6 Abordagem Ballooning para recuperação de memória pelo hypervisor [GUO,

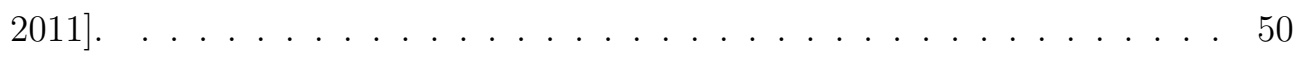

4.7 Comunicação via rede física utilizando a tecnologia VMDq [CHINNI; HIREMANE, 2013]. . . . . . . . . . . . . . . . . . . . 53 
5.1 Quadrante mágico de 2011 desenvolvido pelo grupo Gartner que reporta os principais competidores no mercado de servidores de aplicação corporativo [PEZZINE et al., 2011] . . . . . . . . . . . . . . . 56

5.2 Quadrante mágico de 2012 desenvolvido pelo grupo Gartner que reporta os principais competidores no mercado de virtualizadores X86 [BITTMAN et al., 2012]. . . . . . . . . . . . . . . . . . . 57

5.3 Desempenho obtido pelas aplicações CPU-bound e memory-intensive de carga baixa ao serem executadas sobre o servidor de aplicação Glassfish com $25 \%$ de utilização dos processadores: a) Tempo médio de resposta e b) Perda de desempenho. . . . . . . . . . . . . . . . . . . . . . . . 59

5.4 Desempenho das aplicações $C P U$-bound e memory-intensive de carga baixa ao serem executadas sobre servidor Glassfish: a) Tempo médio de resposta com 50\% de utilização dos processadores, b) Perda de desempenho com 50\% de utilização dos processadores, c) Tempo médio de resposta com 75\% de utilização das CPUs e d) Perda de desempenho com $75 \%$ de utilização das CPUs. . . . . . . . . . . . . . . . . . . . . 62

5.5 Desempenho das aplicações $C P U$-bound e memory-intensive de carga baixa ao serem executadas sobre servidor Glassfish com 100\% de utilização dos processadores: a) Tempo médio de resposta e b) Perda de desempenho. . .

5.6 Desempenho das aplicações memory-intensive com carga variando de moderada à alta ao serem executadas sobre servidor Glassfish com $25 \%$ de utilização das CPUs: a) Tempo médio de resposta e b) perda de desempenho.

5.7 Desempenho das aplicações memory-intensive de carga variando entre moderada e alta ao serem executadas sobre servidor Glassfish: a) Tempo médio de resposta com $50 \%$ de utilização dos processadores, b) Perda de desempenho com $50 \%$ de utilização dos processadores, c) Tempo médio de resposta com $75 \%$ de utilização das CPUs e d) Perda de desempenho com $75 \%$ de utilização dos processadores. . . . . . . . . . . . . . . . .

5.8 Perda de desempenho sofrida pelas aplicações memory-intensive com carga variando de moderada à alta ao serem executadas em plataformas virtualizadas e hospedadas no servidor de aplicação Glassfish com 100\% de utilização dos processadores. . . . . . . . . . . . . . . . . . .

5.9 Resultados obtidos ao executar aplicações distribuídas baseadas em SOA do tipo CPU-bound e memory-intensive de carga baixa implantadas no servidor de aplicação JBoss com $25 \%$ de ocupação dos processadores disponibilizados: a) Tempo médio de resposta. b) Perda de desempenho. . . . 
5.10 Resultados obtidos ao executar aplicações distribuídas baseadas em SOA do tipo CPU-bound e memory-intensive de carga baixa implantadas no servidor de aplicação JBoss: a) Tempo médio de resposta com 50\% de utilização dos processadores; b) Perda de desempenho com 50\% de utilização dos processadores; c) Tempo médio de resposta com $75 \%$ de utilização das CPUs e d) Perda de desempenho com $75 \%$ de utilização das CPUs. . . . . 72

5.11 Resultados obtidos ao executar aplicações distribuídas baseadas em SOA do tipo CPU-bound e memory-intensive de carga baixa implantadas no servidor de aplicação JBoss com 100\% de ocupação dos processadores disponibilizados: a) Tempo médio de resposta e b) Perda de desempenho.

5.12 Resultados obtidos ao executar aplicações distribuídas baseadas em SOA do tipo memory-intensive de carga moderada e alta implantadas no servidor de aplicação JBoss com 25\% de utilização dos processadores disponibilizados:

a) Tempo médio de resposta e b) Perda de desempenho. . . . . . . . . . . 75

5.13 Resultados obtidos ao executar aplicações distribuídas baseadas em SOA do tipo memory-intensive de carga moderada e alta implantadas no servidor de aplicação JBoss: a) Tempo médio de resposta com 50\% de utilização dos processadores; b) Perda de desempenho com $50 \%$ de utilização dos processadores; c) Tempo médio de resposta com $75 \%$ de utilização das CPUs e d) Perda de desempenho com 75\% de utilização das CPUs. . . . . 77

5.14 Resultados obtidos ao executar aplicações distribuídas baseadas em SOA do tipo memory-intensive de carga moderada e alta implantadas no servidor de aplicação JBoss com $100 \%$ de utilização dos processadores disponibilizados: a) Tempo médio de resposta e b) Perda de desempenho. . . . . . . . . . . 80

6.1 Resultados obtidos pelas plataformas baseadas em Glassfish durante as operações de unmarshalling de mensagens SOAP com 25\% de utilização dos processadores: a) Tempo médio de resposta e b) Perda de desempenho. 84

6.2 Resultados obtidos pelas plataformas baseadas em Glassfish durante as operações de unmarshalling de mensagens SOAP com taxa de utilização de processadores de 50\%: a) Tempo médio de resposta e b) Perda de desempenho. . . . . . . . . . . . . . . . . . 86

6.3 Perdas de desempenho sofridas pelas plataformas virtualizadas baseadas em Glassfish durante as operações de unmarshalling de mensagens SOAP: a) $75 \%$ de utilização das CPUs e b) $100 \%$ de utilização das CPUs. . . . . . 87

6.4 Resultados obtidos pelas plataformas baseadas em Glassfish durante as operações de unmarshalling de mensagens SOAP com cem caracteres por elemento XML e taxa de utilização de processadores de 25\%: a) Tempo médio de resposta e b) Perda de desempenho. . . . . . . . . . . . . . . . . 
6.5 Resultados obtidos pelas plataformas baseadas em Glassfish durante as operações de unmarshalling de mensagens SOAP formada por elementos XML de cem caracteres: a) Tempo médio de resposta com 50\% de utilização dos processadores, b) Perda de desempenho com 50\% de utilização dos processadores, c) Tempo médio de resposta com $75 \%$ de utilização dos processadores e d) Perda de desempenho com $75 \%$ de utilização dos processadores. . . . . . . . . . . . . . . . . . . . . . . . . . 92

6.6 Resultados obtidos pelas plataformas baseadas em Glassfish durante as operações de unmarshalling de mensagens SOAP com cem caracteres por elemento XML e taxa de utilização de CPU de 100\%: a) Tempo médio de resposta e b) Perda de desempenho. . . . . . . . . . . . . . . . . . . . . . 94

6.7 Resultados obtidos pelas plataformas baseadas em Glassfish durante as operações de unmarshalling de mensagens SOAP com mil caracteres por elemento XML e taxa de utilização de CPU de 25\%: a) Tempo médio de resposta e b) Perda de desempenho. . . . . . . . . . . . . . . . . . . 95

6.8 Resultados obtidos pelas plataformas baseadas em Glassfish durante as operações de unmarshalling de mensagens SOAP com mil caracteres por elemento XML e taxa de utilização de CPU de 50\%: a) Tempo médio de resposta e b) Perda de desempenho. . . . . . . . . . . . . . . . . . . . 97

6.9 Perdas de desempenho sofridas pelas aplicações distribuídas ao realizar operação de unmarshalling com mil caracteres por elemento XML: a) 75\% de utilização dos processadores e b) $100 \%$ de utilização dos processadores. . 98

6.10 Resultados obtidos pelas aplicações distribuídas ao realizar operação de marshalling com dez caracteres por elemento XML em plataformas com taxa de utilização de CPUs em 25\%: a) Tempo médio de resposta e b) Perda de desempenho. . . . . . . . . . . . . . . . . . . . . . 100

6.11 Resultados obtidos pelas aplicações distribuídas ao realizar operação de marshalling com dez caracteres por elemento XML em plataformas com taxa de utilização de CPUs em 50\%: a) Tempo médio de resposta e b) Perda de desempenho.

6.12 Resultados obtidos pelas aplicações distribuídas ao realizar operação de marshalling com dez caracteres por elemento XML: a) Tempo médio de resposta com taxa de utilização de CPUs $75 \%$, b) Perda de desempenho com taxa de utilização de CPUs de $75 \%$, e c) Tempo médio de resposta com taxa de utilização de CPUs 100\%, d) Perda de desempenho com taxa de utilização de CPUs de 100\% . . . . . . . . . . . . . . . . . . . . . . 104 
6.13 Resultados obtidos pelas aplicações distribuídas ao realizar operação de marshalling com cem caracteres por elemento XML e com $25 \%$ de utilização dos processadores disponíveis: a) Tempo médio de resposta e b) Perda de desempenho. . . . . . . . . . . . . . . . . . 106

6.14 Resultados obtidos pelas aplicações distribuídas ao realizar operação de marshalling com cem caracteres por elemento XML: a) Tempo médio de resposta com taxa de utilização de CPU 50\%, b) Perda de desempenho com taxa de utilização de CPU de 50\%, c) Tempo médio de resposta com taxa de utilização de CPU $75 \%$ e d) Perda de desempenho com taxa de utilização de CPU de $75 \%$. . . . . . . . . . . . . . . . . . . . . . 108

6.15 Resultados obtidos pelas aplicações distribuídas ao realizar operação de marshalling com cem caracteres por elemento XML e com100\% de utilização dos processadores disponíveis: a) Tempo médio de resposta e b) Perda de desempenho. . . . . . . . . . . . . . . . . . . . . . . 110

6.16 Resultados obtidos pelas aplicações distribuídas ao realizar operação de marshalling com mil caracteres por elemento XML e com 25\% de utilização dos processadores disponíveis: a) Tempo médio de resposta e b) Perda de desempenho. . . . . . . . . . . . . . . . . . . . . 112

6.17 Resultados obtidos pelas aplicações distribuídas ao realizar operação de marshalling com mil caracteres por elemento XML e com 50\% de utilização dos processadores disponíveis: a) Tempo médio de resposta e b) Perda de desempenho. . . . . . . . . . . . . . . . . . . . 113

6.18 Resultados obtidos pelas aplicações distribuídas ao realizar operação de marshalling com mil caracteres por elemento XML: a) Tempo médio de resposta com taxa de utilização de CPU 75\%, b) Perda de desempenho com taxa de utilização de CPU de 75\%, c) Tempo médio de resposta com taxa de utilização de CPU 100\% e d) Perda de desempenho com taxa de utilização de CPU de 100\% . . . . . . . . . . . . . . . . . . . . . . . . . 114

7.1 Definição da capacidade adequada [MENASCE; ALMEIDA, 2003] . . . . . . . 118

7.2 Metodologia para o planejamento de capacidade proposto em [MENASCE; ALMEIDA, 2003].

7.3 Parâmetros relacionados ao processo de modelagem da disponibilidade [MENASCE; ALMEIDA, 2003]. . . . . . . . . . . . . . . . . . . . . . . . 124

7.4 Categorias de recursos caracterizados em redes de filas: a) Recurso independente de carga, b) recurso dependente de carga e c) recurso de atraso. Adaptado de [MENASCE; AlMEIDA, 2003]. . . . . . . . . . . . . . . 127

7.5 Modelo de desempenho R-Capriccio proposto em [ZHANG et al., 2007]. . . . 128 
7.6 Modelo de desempenho apresentado em [LIU et al., 2008] considerando sistemas dividido em camadas e com múltiplas threads: a) Modelo de rede de filas e b) arquitetura de comunicação entre as camadas um e dois e c) arquitetura de comunicação entre as camadas dois e três. . . . . . . . . . 129

7.7 Processo básico do modelo de desempenho apresentado em [TEIXEIRA et al., 2009]. . . . . . . . . . . . . . . . . . . . . 132

7.8 Framework de um modelo lógico de serviço [KARGUPTA; BLACK, 2012]. . . 133

7.9 Modelo baseado em rede de filas que representa uma máquina física cujo sistema operacional é executado diretamente sobre o hardware. . . . . . . . 136

7.10 Modelo baseado em rede de filas que representa uma máquina virtual executando sobre um virtualizador do tipo bare-metal. . . . . . . . . . . 138

7.11 Modelo de um servidor de aplicação baseado em redes de filas. . . . . . . . 139

7.12 Modelo baseado em rede de filas que representa servidores de aplicação executados sobre ambientes virtualizados. . . . . . . . . . . . . . . . . 141 


\section{Lista de Tabelas}

5.1 Tempo médio, em ms, consumido ao alocar memória DRAM em blocos de tamanho previamente estabelecidos no servidor de aplicação Glassfish. . . . 60

5.2 Razão entre o tempo médio de resposta quando a taxa de ocupação de processamento é de $100 \%$ e $75 \%$.

5.3 Tempo médio, em ms, consumido ao alocar memória DRAM em blocos de tamanho previamente estabelecidos no servidor de aplicação JBoss. . . . . 71

5.4 Redução nos tempos médios de resposta ao substituir o servidor de aplicação Glassfish pelo JBoss. . . . . . . . . . . . . . . . . . . . . . . 76

6.1 Quantidade média de memória alocada em 25 iterações de consumo por taxa de utilização de CPUs. . . . . . . . . . . . . . . . . . . . . . 88

6.2 Razão entre os tempos médios de resposta com taxa de utilização de CPU em $75 \%$ e $50 \%$.

6.3 Quantidade média de memória alocada em 25 iterações de consumo por taxa de utilização de CPUs, considerando mensagens SOAP com cem caracteres por elemento XML. . . . . . . . . . . . . . . . . . . . 93

6.4 Quantidade média de memória alocada em 25 iterações de consumo por taxa de utilização de CPUs, considerando mensagens SOAP com mil caracteres por elemento XML. . . . . . . . . . . . . . . . . . . . . 96

6.5 Razão entre os tempos médios de resposta com taxa de utilização de CPU em $100 \%$ e $75 \%$ ao processar mensagens SOAP com mil caracteres por elemento XML.

6.6 Quantidade média de memória alocada ao realizar operações de marshalling por taxa de utilização de CPUs, considerando 25 iterações e mensagens SOAP com dez caracteres por elemento XML. . . . . . . . . . . . . . . . . 101

6.7 Razão entre os tempos médios de resposta das aplicações distribuídas ao considerar mil e cem caracteres por elemento XML e taxa de utilização de 
7.1 Classificação dos sistemas de acordo com a disponibilidade [MENASCE; ALMEIDA, 2003]. 
1 Introdução 1

1.1 Contextualização . . . . . . . . . . . . . . . . . . . . . 1

1.2 Motivação e objetivos . . . . . . . . . . . . . . . . . . . . . 4

1.3 Organização dos capítulos . . . . . . . . . . . . . . 6

2 Arquitetura Orientada a Serviços $\quad 7$

2.1 Considerações iniciais . . . . . . . . . . . . . . . . . . . 7

2.2 Definição . . . . . . . . . . . . . . . . . . . . 8

2.3 Componentes e cooperação . . . . . . . . . . . . . . . . 8

2.4 Estrutura . . . . . . . . . . . . . . . . . . . . . 11

2.5 Composição de serviços . . . . . . . . . . . . . . . . . . . . . . . 14

2.5.1 Membros da composição . . . . . . . . . . . . . . . . . 15

2.5 .2 Composição mínima . . . . . . . . . . . . . . . . . 16

2.5.3 Inconvenientes das composições . . . . . . . . . . . . . . . . 17

2.6 Características das arquiteturas orientadas a serviços . . . . . . . . . 18

2.6.1 Vantagens . . . . . . . . . . . . . . . . . . . . . 19

2.7 Considerações finais . . . . . . . . . . . . . . . . . . . . . . 20

3 Web Services $\quad 21$

3.1 Considerações iniciais . . . . . . . . . . . . . . . . . . . . . . . 21

3.2 Definição . . . . . . . . . . . . . . . . . . . . . . . . . . 21

3.3 Arquitetura, protocolos e padrões . . . . . . . . . . . . . . . . 22

3.3 .1 Tecnologias base . . . . . . . . . . . . . . . . 23

3.3.2 Camada de transporte . . . . . . . . . . . . . . . . . . . . . . 29

3.3.3 Camada de mensagens . . . . . . . . . . . . . . . . . . . 30

3.3 .4 Camada de descrição . . . . . . . . . . . . . . . . . . . . 34

3.3.5 Camada de descoberta . . . . . . . . . . . . . . . . . 35

3.3 .6 Demais camadas . . . . . . . . . . . . . . . . 37

3.4 Considerações finais . . . . . . . . . . . . . . . . . . . . . . . 39 
4 Virtualização $\quad 41$

4.1 Considerações iniciais . . . . . . . . . . . . . . . . . . . . . . . . . 41

4.2 Processadores . . . . . . . . . . . . . . . . . . . . . 42

4.2 .1 Virtualização através de tradução binária . . . . . . . . . . . . . . 44

4.2.2 Virtualização auxiliada por sistema operacional ou paravirtualização 44

4.2 .3 Virtualização assistida por hardware . . . . . . . . . . . . . . 45

4.3 Memória . . . . . . . . . . . . . . . . . . . . . 46

4.3.1 Recuperação de memória pelo hypervisor . . . . . . . . . . . . . . . 49

4.4 Entrada/Saída . . . . . . . . . . . . . . . . . . . . 52

4.5 Considerações finais . . . . . . . . . . . . . . . . . . . . . . . 54

5 Virtualização e o tempo de processamento $\quad 55$

5.1 Considerações iniciais . . . . . . . . . . . . . . . . . . 55

5.2 Metodologia . . . . . . . . . . . . . . . . . 55

5.2 .1 Plataformas . . . . . . . . . . . . . . . . 56

5.2 .2 Carga de trabalho . . . . . . . . . . . . . . . . . 58

5.3 Organização da análise da Influência da virtualização . . . . . . . . . . . 59

5.4 Aplicações CPU-Bound e memory-intensive de carga baixa . . . . . . . . . 59

5.5 Aplicações memory-intensive de carga moderada e alta . . . . . . . . . . . 64

5.6 Servidor de aplicação . . . . . . . . . . . . . . . . . . . . . . . . . 69

5.6.1 Aplicações CPU-bound e memory-intensive de carga baixa . . . . 70

5.6.2 Aplicações memory-intensive de carga moderada e alta . . . . . . . 74

5.7 Considerações finais . . . . . . . . . . . . . . . . . . . . . . . 81

6 Virtualização e a manipulação de envelopes SOAP 83

6.1 Considerações iniciais . . . . . . . . . . . . . . . . . . . 83

6.2 Operação unmarshalling . . . . . . . . . . . . . . . . . . . . 83

6.2 .1 Caracteres por elemento XML . . . . . . . . . . . . . . . . 90

6.3 Operação marshalling . . . . . . . . . . . . . . . . . . . . . . . 100

6.3.1 Variação no tamanho dos elementos XML . . . . . . . . . . 106

6.4 Considerações finais . . . . . . . . . . . . . . . . . . . . . 115

7 Virtualização e os modelos de desempenho 117

7.1 Considerações iniciais . . . . . . . . . . . . . . . . . . . . . 117

7.2 Capacidade adequada . . . . . . . . . . . . . . . . . . . 118

7.3 Planejamento de capacidade . . . . . . . . . . . . . . . . . . . . 119

7.3.1 Modelo de carga de trabalho . . . . . . . . . . . . . . . 120

7.3 .2 Modelo de custos . . . . . . . . . . . . . . . . . . . . . 123

7.3 .3 Modelo de disponibilidade . . . . . . . . . . . . . . . . . 123

7.3 .4 Modelo de desempenho . . . . . . . . . . . . . . . . . . . 126 
7.4 A influência da virtualização nos modelos de desempenho disponíveis . . 128

7.4.1 Modelo modular proposto . . . . . . . . . . . . . . . . 135

7.5 Considerações finais . . . . . . . . . . . . . . . . . . . . 141

8 Conclusões 143

8.1 Considerações finais . . . . . . . . . . . . . . . . . . . . . . . . 143

8.2 Contribuições . . . . . . . . . . . . . . . . . . . . . . . . . . . . . 149

8.3 Sugestões para trabalhos futuros . . . . . . . . . . . . . . . 152

$\begin{array}{ll}\text { Referências bibliográficas } & 153\end{array}$ 



\section{Capítulo \\ 1 \\ Introdução}

\subsection{Contextualização}

Desde o seu surgimento, em 1989 no CERN (European Organization for Nuclear Research), a World Wide Web, ou simplesmente Web, tem modificado a forma como as pessoas lidam com a informação, como elas se relacionam e consomem produtos. Presenciou-se o surgimento do vídeo sob demanda, das bibliotecas digitais, do aprendizado a distância, das redes sociais e até mesmo de mundos virtuais [MENASCE; ALMEIDA, 2003]. Da mesma forma, houve o surgimento do comércio eletrônico, também conhecido como e-business, que representa uma mudança de paradigma no modo como as empresas disponibilizam seus produtos [MARZULLO, 2009].

Neste tipo de comércio a transação ocorre totalmente na Web, em sistemas desenvolvidos para tal finalidade, denominados sistemas Web. Tal forma de negociação permite que, a partir de investimentos reduzidos, seja possível realizar transações comerciais em escala global. Essa característica levou e ainda leva muitas empresas a adotarem esse modelo de negócio. Todavia, ao implantar sistemas Web muitas empresas não substituem seu software legado, obrigando a coexistência dos mesmos. Sendo assim, faz-se necessário o desenvolvimento de novas tecnologias de integração e migração de plataformas de software. Tal necessidade também está presente em transações de compras ou fusões de empresas.

Apesar das dificuldades em disponibilizar e integrar plataformas, tanto de hardware quanto de software, essa nova modalidade de comércio tende a aumentar, uma vez que estão surgindo novos dispositivos móveis, como os smartphones e tablets, que associados à interface amigável da Web permitem acesso facilitado a esses sistemas. Outro fator relevante é o aumento no número de pessoas com acesso à Internet, além da elevação no 
nível de confiança neste tipo de comércio por parte da população [MARZULLO, 2009].

Tal fato pode ser comprovado na Figura 1.1 que apresenta a evolução das vendas on-line no varejo brasileiro entre 2001 e 2012. Essas estatísticas foram registradas pela organização e-commerce [E-COMMERCE, 2013].

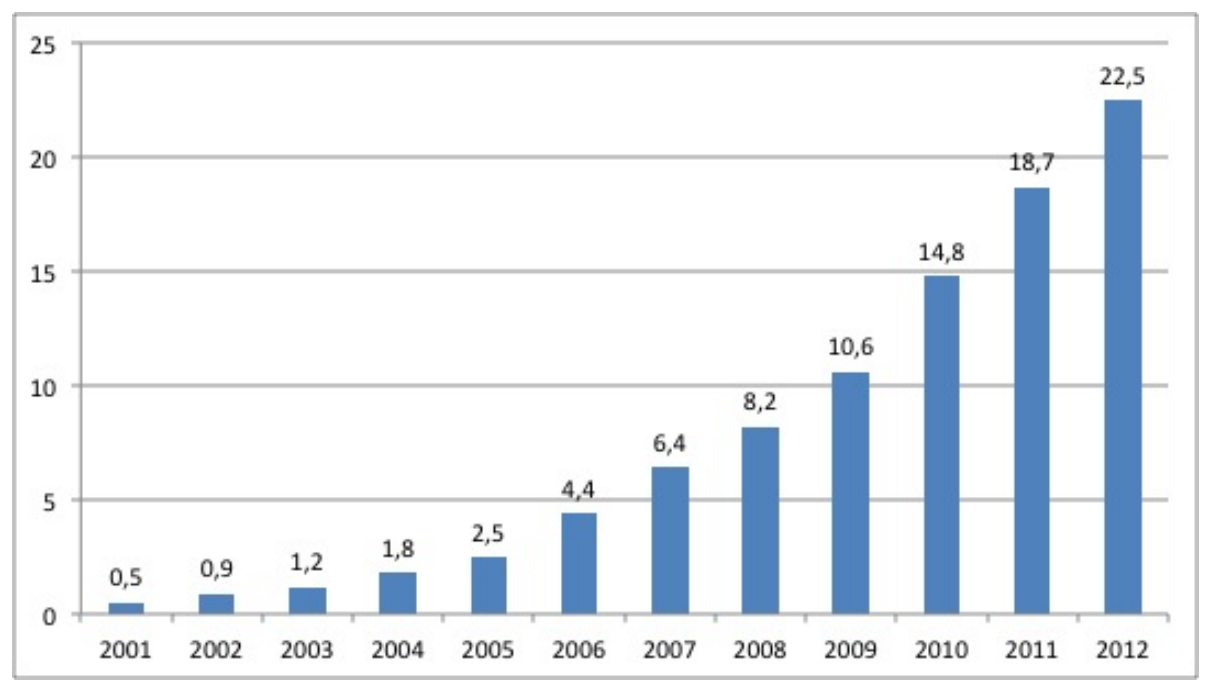

Figura 1.1: Variação do varejo on-line no Brasil em bilhões [E-COMMERCE, 2013].

A partir da Figura 1.1, percebe-se que o faturamento passou de 0,54 bilhões de reais em 2001 para 22,5 bilhões em 2012, com faturamento de 26 bilhões previsto para o ano de 2013, sendo que tais valores não consideram vendas de automóveis, passagens aéreas e leilões on-line. Ao analisar tal variação, percebe-se que as vendas realizadas em 2001 representam, aproximadamente, apenas 2,2\% daquelas realizadas em 2012.

Outro fator que comprova a aumento de confiança no comércio eletrônico pode ser observado na Figura 1.2, que apresenta a evolução do número de compradores on-line no Brasil. Esses compradores também são conhecidos como e-consumidores.

Diante desse crescimento, não é raro que sites populares recebam milhões de solicitações por dia, o que pode elevar extremamente os tempos de respostas, frustrando muitos usuários da Web, além de gerar um grande problema para as equipes de desenvolvimento e suporte. Tais equipes precisam dimensionar a plataforma de hardware, bem como utilizar diferentes tecnologias de software, para entregar os serviços requisitados com os níveis de qualidade negociado [ZHANG et al., 2007].

Neste cenário de evolução e transformação, duas soluções estão se tornando essenciais: Arquiteturas Orientadas a Serviços (SOA) e a consolidação de servidores, obtida através do processo de virtualização e, recentemente, da computação em nuvem, principalmente a categorizada como Infraestrutura como Serviço (IaaS), fundamentada sobre o processo de virtualização [BAUN et al., 2011]. 


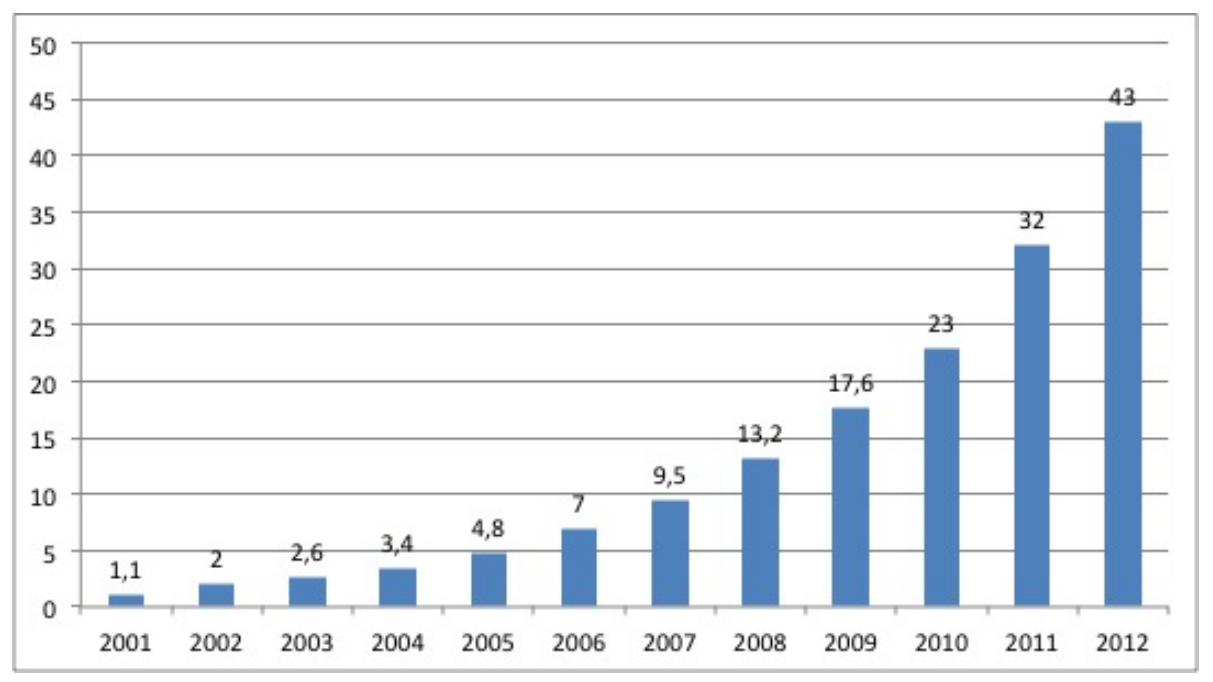

Figura 1.2: Variação na quantidade de consumidores on-line (e-consumidores) no Brasil. Em milhões [E-COMMERCE, 2013]

A arquitetura orientada a serviço, através da adoção de Web Services, permite separar as regras de negócio e as tecnologias de desenvolvimento de software, aproximando, assim, as áreas de gestão e TI (Tecnologia da Informação). Este fato, por si só, permite que softwares sejam desenvolvidos de maneira mais eficiente, em espaços de tempos menores que aqueles obtidos ao utilizar as metodologias tradicionais [ENDREI et al., 2004]. Tal arquitetura permite, também, que softwares desenvolvidos em diferentes linguagens e plataformas sejam integrados de forma transparente, uma vez que há uma interface bem definida, baseada em padrões abertos, que permite a descoberta e posterior invocação dos diferentes serviços disponibilizados.

Já a virtualização de hardware permite que múltiplas máquinas virtuais sejam instanciadas sobre um mesmo hardware, compartilhando os recursos físicos existentes entre os vários sistemas operacionais, denominados convidados, instalados sobre as máquinas virtualizadas. Assim, essa tecnologia permite que o dimensionamento de hardware seja totalmente direcionado à necessidade de processamento, armazenamento e comunicação do sistema operacional convidado, permitindo, inclusive, que uma máquina virtual seja transferida de um servidor físico para outro sem a necessidade de reinício. Essa tecnologia constitui a base para a computação em nuvem, mais especificamente para soluções do tipo IaaS, onde as característica de provisionamento sob demanda, no estilo self-service, pool de recursos, elasticidade e mensuração automatizada estão presentes. [BAUN et al., 2011; Peter Mell and Tim Grance, 2011]

Assim, ao considerar as soluções em uso atualmente, percebe-se que uma grande quantidade de aplicações baseadas em SOA estão sendo implantadas em ambientes virtualizados e que o dimensionamento adequado da infraestrutura de TI, a fim de cumprir SLAs (Service-Level Agreement) previamente estabelecidos, tornou-se mais complexo, eviden- 
ciando a necessidade do uso de modelos de desempenho que permitam prever, com base em projeções de cargas futuras, o comportamento da plataforma analisada, permitindo, assim, que a sua saturação seja evitada [MENASCE; ALMEIDA, 2003].

\subsection{Motivação e objetivos}

Muitos trabalhos estão sendo desenvolvidos considerando modelos e metodologias de aferição de desempenho e, consequentemente, planejamento de capacidade. Em [PRAPHAMONTRIPONG et al., 2007] os autores propõem um modelo de desempenho destinado à análise de desempenho de servidores Web implementados com mecanismos assíncronos encapsulados no padrão Proactor. Em [SHIMIZU et al., 2009] é apresentada uma abordagem genérica para modelar o uso de recursos pelas aplicações e suas correlações, sendo essa abordagem genérica o suficiente para ocultar as heterogeneidades de hardware, porém, não a heterogeneidade dos conjuntos de instruções. Assim, segundo os autores, é possível prever tempos de resposta de transações, poder de processamento, tamanho da memória cache entre outras informações, sem que seja necessário modificar o aplicativo analisado.

Esses trabalhos, no entanto, não consideram as aplicações baseadas em SOA, que são abordadas em [ESTRELLA et al., 2008], onde os autores apresentam diretrizes importantes para a avaliação de desempenho em Web Services, destacando os problemas com as especificações dos padrões utilizados, o que influencia, de forma negativa, na provisão da qualidade de serviço. Em [TEIXEIRA et al., 2011] é proposto um modelo, através de redes de Petri [KARTSON et al., 1994], cujo objetivo é analisar o consumo de recursos e a degradação nos níveis de serviço de aplicações baseadas em SOA.

Ainda considerando os modelos de desempenho, tendo como referência as aplicações baseadas em SOA, os autores do trabalho [ZHANG et al., 2007], de uma maneira mais específica, consideram as organizações em múltiplas camadas desses sistemas, apresentando metodologias para prever o impacto de cargas futuras em sistemas de múltiplos nós, porém, sem considerar a existência de múltiplas threads, destacado em [LIU; HEO; SHA, 2005; LIU et al., 2008]. Em [LU et al., 2010], os autores apresentam uma nova política para o controle de admissão, baseada em sessões, para sistemas de Web Services estruturados em múltiplas camadas, denominada AWAIT, permitindo reduzir, para o mínimo, a quantidade de sessões abortadas. Em [ROY et al., 2011] os autores descrevem uma abordagem híbrida para o planejamento de capacidade de sistemas multicamadas baseados em componentes que, através de heurísticas, determina a menor quantidade de recursos que deve ser alocada para um determinado componente. Em [HUANG et al., 2011] é proposta uma abordagem adaptativa, baseada em traces, que permitem descrever as características de grandes aplicações comerciais durante o seu tempo de execução, não partindo da fase de modelagem. 
Já em [KARGUPTA; BLACK, 2012] os autores desenvolveram fórmulas e padrões para representar uma grande quantidade de característica de Web Services, relacionando o desempenho dessas aplicações ao retardo de seus componentes. Em [MEZGHANI; HALIMA, 2012] é proposto um framework reconfigurável dinamicamente, denominado DRF4SOA, destinado a projetar aplicações SOA autônomas atendendo aos ciclos de fase MOPE (Monitoring, Analysis, Planning and Execution), sendo esse framework destinado a atender os contratos de SLA. Em [POTENA, 2013] os autores propõem uma metodologia para tratar o desempenho de sistemas baseados em SOA ao serem expandidos e adaptados, no entanto, essa metodologia parte dos novos requisitos e da descrição do sistema, culminando na nova arquitetura a ser adotada.

De maneira análoga, o desempenho de plataformas virtualizadas e seus modelos de desempenho têm sido objetos de estudos recentemente, assim como as plataformas de computação em nuvem do tipo IaaS. Em [KUNDU et al., 2010] os autores identificaram um conjunto de fatores independentes que influenciam, diretamente, no desempenho de plataformas virtualizadas e, consequentemente, em um conjunto de aplicações executadas sobre essas plataformas. A partir desse conjunto de fatores, os autores desenvolveram um modelo de desempenho iterativo, baseado em redes neurais. Em [IOSUP et al., 2011] os autores analisam o desempenho de sistemas comerciais de computação em nuvem ao executar aplicações científicas, destacando, principalmente, o impacto da elasticidade. Em [CHI et al., 2011] é apresentado um novo framework, denominado SLA-Tree, utilizado na tomada de decisão para cumprimento de SLAs. Em [RAO et al., 2011] é proposto um mecanismo de provisionamento auto adaptativo de máquinas virtuais, comprovando a eficiência da solução através de um protótipo executado sobre a plataforma Xen.

A partir da análise dos trabalhos presentes na literatura, é possível perceber que há uma lacuna importante a ser preenchida, uma vez que os estudos atuais não tratam o desempenho de aplicações baseadas em SOA, em especial as desenvolvidas com Web Services, ao serem inseridas em ambientes virtualizados, principalmente após a inserção de recursos no hardware destinados a ambientes virtualizados, como a tabela dupla de páginas e as "large-pages". As tabelas dupla de páginas permitem o mapeamento das páginas virtuais, utilizadas pelas aplicações, diretamente na tabela de páginas do sistema operacional hospedeiro, de forma transparente ao sistema operacional convidado, já as "large-pages" permitem ao sistema operacional hospedeiro alocar páginas até quinhentas vezes maiores que as páginas tradicionais utilizadas no sistema operacional convidado.

Assim, este trabalho propõe desenvolver uma análise aprofundada das características que influenciam o desempenho de aplicações CPU-bound e memory-intensive, com carga de memória variando de baixa à alta, ao serem implantadas em ambientes virtualizados, com o objetivo de descrever os relacionamentos existentes entre os recursos de virtualização existentes nos hardwares de terceira geração, os virtualizadores do tipo bare-metal e as suas eficiências no gerenciamento de recursos e os servidores de aplicação, responsáveis pela 
virtualização em nível de aplicação. Adicionalmente, este trabalho analisará os modelos de desempenho mais expressivos, com o objetivo destacar os pontos em que devem ser adaptados ou modificados, permitindo, assim, realizar o planejamento de capacidade das plataformas consideradas.

\subsection{Organização dos capítulos}

Esta tese se encontra organizada como descrito a seguir.

O capítulo 2 aborda a arquitetura orientada a serviços, definindo-a como um modelo direcionado ao mapeamento de regras de negócio em softwares, denominados serviços. Ao descrevê-la, são apresentados seus componentes e as interações existentes entre eles, utilizando para isso uma estrutura de padrões, organizada em camadas. Esse capítulo descreve ainda, a composição de serviços, cujo objetivo é permitir o reuso de software.

O capítulo 3 apresenta a tecnologia de Web Services que é, atualmente, a mais utilizada para a concretização da SOA. Assim, será descrita a linguagem XML (eXtensible Markup Language), bem como seus documentos de validação, que juntos constituem a base para a definição das demais camadas, as quais também serão descritas nesse capítulo, dando maior ênfase para as camadas de mensagem, descrição e descoberta.

O capítulo 4 descreve o processo de virtualização de processadores, memória e dispositivos de entrada e saída, destacando os tipos de virtualizadores e os recursos de virtualização de terceira geração, existentes nos hardwares atuais.

O capítulo 5 apresenta os resultados obtidos ao executar aplicações distribuídas baseadas em SOA, do tipo CPU-bound e memory-intensive, em ambientes virtualizados, destacando a influência gerada pelo sistema de virtualização no tempo de processamento dessas aplicações, bem como a influência do servidor de aplicação e da taxa de utilização dos processadores.

O capítulo 6 aborda a influência da virtualização sobre as bibliotecas de codificação e decodificação de envelopes SOAP utilizadas pelos servidores de aplicações e, também, pelas aplicações distribuídas baseadas em SOA ao realizar as operações de marshalling e unmarshalling. Neste capítulo é destacado a influência do sistema de coleta de lixo, da quantidade de memória DRAM (Dynamic random access memory) consumida e seu gerenciamento pelos sistemas gerenciadores de máquinas virtuais.

O capítulo 7 apresenta uma análise crítica dos principais modelos de desempenho encontrados na literatura, destacando suas falhas ao modelar aplicações distribuídas baseadas em SOA executadas sobre plataformas de virtualização total, com o objetivo de permitir que tais modelos sejam modificados para que reflitam, de maneira realista, o desempenho das plataformas estudadas.

Finalmente, no capítulo 8 serão apresentadas as conclusões obtidas nesta tese, destacando as principais contribuições alcançadas e sugestões para trabalhos futuros. 


\section{Arquitetura Orientada a Serviços}

\subsection{Considerações iniciais}

De acordo com [ENDREI et al., 2004], os executivos da área de TI necessitam reduzir custos enquanto maximizam a utilização das estruturas de TI disponíveis, porém, sem reduzir a qualidade do serviço prestado. Este comportamento permite que as empresas tornem-se mais competitivas e lucrativas.

Ainda de acordo com [ENDREI et al., 2004], há duas questões envolvidas na situação descrita anteriormente. A primeira refere-se à heterogeneidade das plataformas existentes nos ambientes de TI, enquanto a segunda refere-se à necessidade de mudanças ágeis dos modelos de negócio, permitindo que empresas continuem competitivas.

A heterogeneidade, tanto de hardware quanto de software, é uma consequência direta da evolução no desenvolvimento das soluções de TI. À medida que novos padrões e tecnologias são criados, diferentes empresas formatam produtos com determinadas características para que sejam aplicadas a um nicho de mercado. Todavia, é comum que as tecnologias anteriormente implantadas ainda permaneçam em uso. Sendo assim, não é raro observar diferentes tecnologias sendo utilizadas em uma mesma empresa, bem como a presença de produtos de diferentes fornecedores.

Já a necessidade de mudança, está diretamente relacionada ao avanço da competição entre as empresas, acirrada pelo surgimento do comércio eletrônico. Atualmente, é comum pequenas empresas precisarem concorrer com grandes corporações e, não menos comum, é a disputa entre duas ou mais corporações por um segmento de mercado. Esta disputa leva a menores ciclos de desenvolvimento de produtos e a busca constante por mercado consumidor.

Para resolver tal situação é necessário que novas metodologias de desenvolvimento de 
software sejam desenvolvidas, devendo permitir um melhor alinhamento entre as equipes de negócio e aquelas do setor de TI, além de permitir a integração de diferentes tecnologias, bem como ofertar a facilidade de adaptação às constantes mudanças.

Neste cenário, destaca-se a arquitetura orientada a serviços, que se apresenta como uma evolução da orientação a objetos e da componentização dos mesmos. Tal arquitetura permite sanar as necessidades anteriormente citadas, através do fraco acoplamento, transparência de localização e a independência de protocolos.

Desta forma, este capítulo definirá os conceitos utilizados em SOA, apresentando essa arquitetura que está sendo considerada como um dos maiores avanços na área de engenharia de software atualmente registrada [MARZULLO, 2009].

\subsection{Definição}

SOA pode ser definida como um estilo de arquitetura de TI que dá suporta à transformação de um negócio em um conjunto de serviços, encadeados, que podem ser acessados através de uma rede [ENDREI et al., 2004].

É importante observar que SOA é uma arquitetura conceitual, que define serviço como um processo de negócio implementado em software, que a partir de um conjunto de entradas fornece um conjunto de saídas, baseado em uma função de transformação. Esta função é conhecida pelo solicitante, uma vez que é descrita através de uma interface formal. Este conceito pode ser observado na Figura 2.1.

Como é possível observar na Figura 2.1, um serviço contém três camadas:

- Camada de negócios: Define os serviços mediante as necessidades da organização, independente das tecnologias que serão utilizadas. É nesta camada que é realizada a descrição das composições dos serviços.

- Camada de interface: Descrevem o serviço, sendo estas publicadas em um serviço de registro, tornando-se disponível para os consumidores.

- Camada de implementação: Contém a implementação do software posteriormente mapeado em serviço. Tais aplicações podem ser desenvolvidas em diferentes plataformas de desenvolvimento e estar distribuídas em diferentes provedores.

\subsection{Componentes e cooperação}

A organização dos elementos que compõem a SOA, bem como as interações permitidas e necessárias para seu correto funcionamento, podem ser visualizados na Figura 2.2.

Como é possível observar na Figura 2.2, SOA é organizada em três elementos distintos [ROCHA, 2006]: 


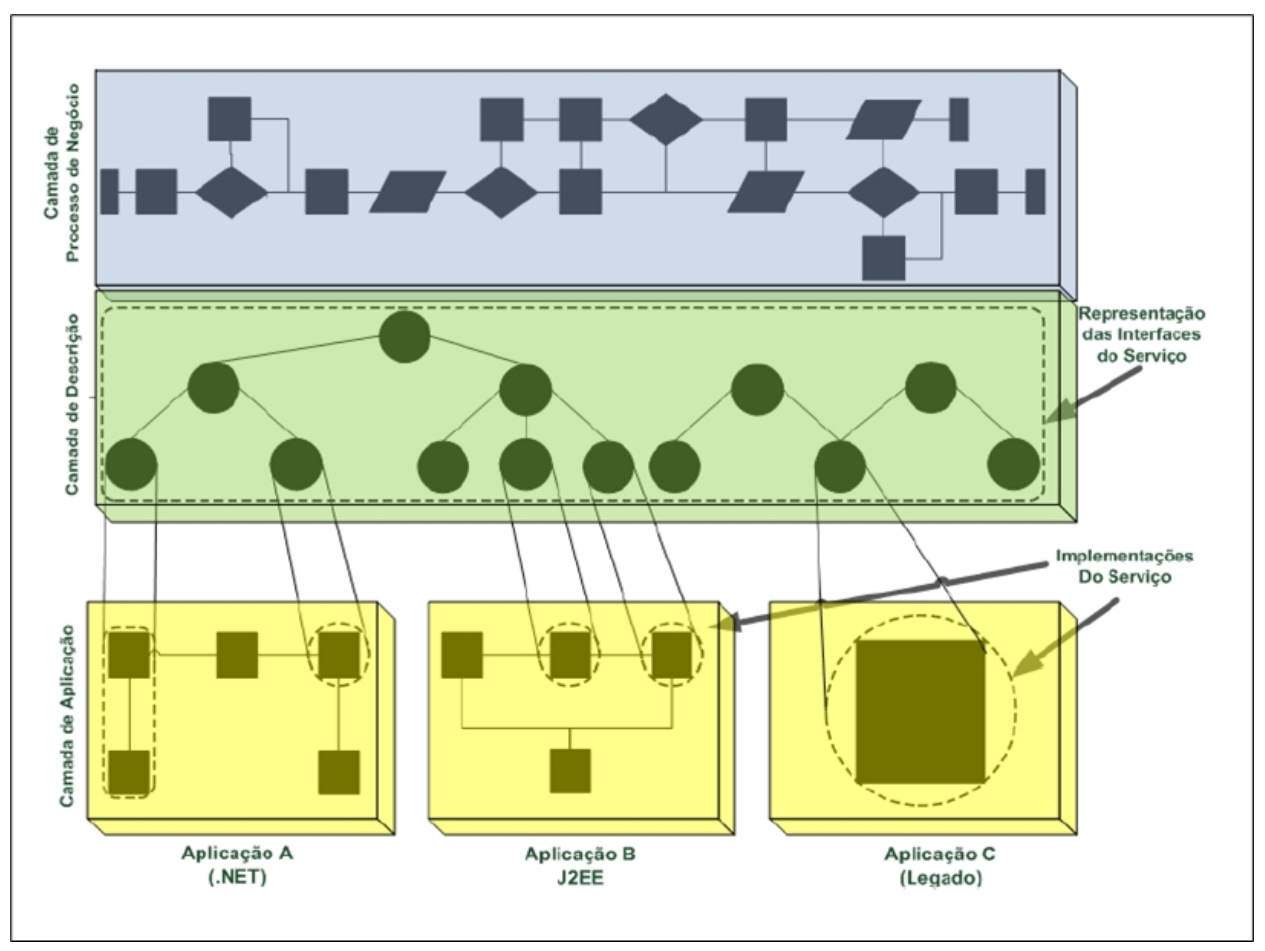

Figura 2.1: Mapeamento de processos de negócios em softwares utilizando diferentes tecnologias [ERL, 2005].

- Provedor de serviço: Responsável pela prestação do serviço. Esta entidade é responsável por receber solicitações e executar os serviços publicados. Para tal, deve manter os meios de comunicação necessários, seja para atender ambientes externos ou internos à sua infra-estrutura de acesso. Caso haja a presença de um cluster de servidores, cabe ao provedor receber a solicitação do cliente e, posteriormente, encaminhá-la para o nó responsável pelo escalonamento. Esse mesmo comportamento é esperado em casos de composição de serviços, descrita na Seção 2.5.

- Consumidor de serviços: Representa o solicitante de um serviço, sendo concretizado por uma pessoa, organização, máquina ou outro componente de software. Cabe ao consumidor compreender a descrição do serviço fornecida, bem como o correto envio dos parâmetros necessários para a execução do mesmo.

- Registro de serviço: Esta entidade possui duas tarefas distintas:

1. Registrar serviços: Nesta tarefa, o registro disponibiliza uma interface de comunicação para os provedores, a fim de que possam tornar públicos os serviços prestados. Esta publicação é realizada através de uma linguagem de definição de serviços, sendo esta específica de cada tecnologia que implementa SOA.

2. Responder consultas sobre serviços: Nesta tarefa, o registro deve fornecer outra 


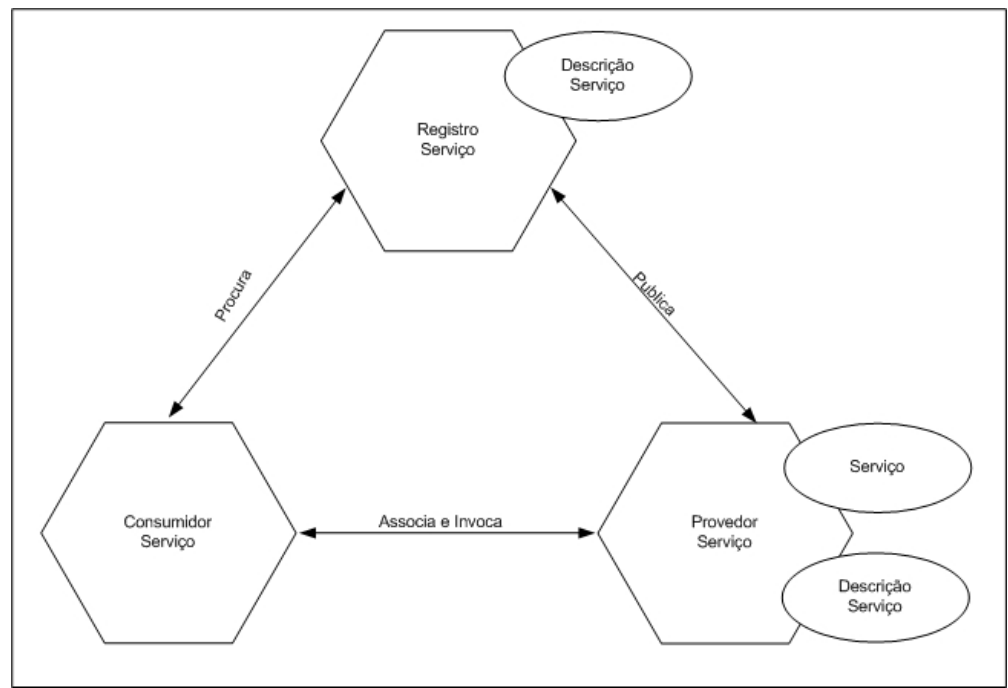

Figura 2.2: Organização e colaborações entre os componentes SOA [ENDREI et al., 2004].

interface de comunicação, permitindo aos consumidores solicitar informações sobre os serviços desejados. Nesta atividade é utilizada a mesma linguagem de definição de serviços utilizada na publicação.

As informações que o registro pode armazenar estão divididas em três categorias, denominadas páginas brancas, verdes e amarelas:

1. Páginas brancas: Armazenam informações diretamente relacionadas ao negócio, como nome, descrição e contato;

2. Páginas verdes: Armazenam informações técnicas sobre a implementação do serviço, por exemplo, linguagem de programação utilizada, infra-estrutura de acesso entre outras;

3. Páginas amarelas: Armazenam informações sobre o serviço, tais como as operações disponibilizadas, os parâmetros de entrada e saída entre outros.

Ao desenvolver um serviço, o provedor deverá descrevê-lo através de uma linguagem de descrição de serviço, comunicando, posteriormente, como a interface de publicação do registro. A partir desse momento, o serviço torna-se público e acessível para os consumidores. É importante ressaltar que ao tornar um serviço público, deve ser possível restringir quais os consumidores podem descobri-lo.

Posteriormente, cabe ao consumidor se comunicar com a interface de pesquisa do registro para solicitar informações sobre o serviços desejados. Podendo tal pesquisa ser executada manual ou automaticamente. A partir desse momento, o consumidor possui a localização correta do provedor de serviço, bem como os parâmetros necessários para a prestação do mesmo. Sendo assim, cabe ao consumidor interagir diretamente com o provedor, utilizando para isso um protocolo de comunicação, também conhecido a priori. 
Caso seja necessário utilizar novamente o serviço, não se faz mais necessário entrar em contato com o registro, podendo, o consumidor, enviar a solicitação diretamente ao provedor. A menos que o provedor tenha desativado o serviço, ou esteja indisponível por alguma falha ou desativação, o serviço será prestado.

\subsection{Estrutura}

Conforme mencionado anteriormente, os softwares baseados em serviços são fundamentados sobre a teoria de componentes, que por sua vez utilizam a orientação a objetos para defini-los. Tal organização pode ser visualizada na Figura 2.3.

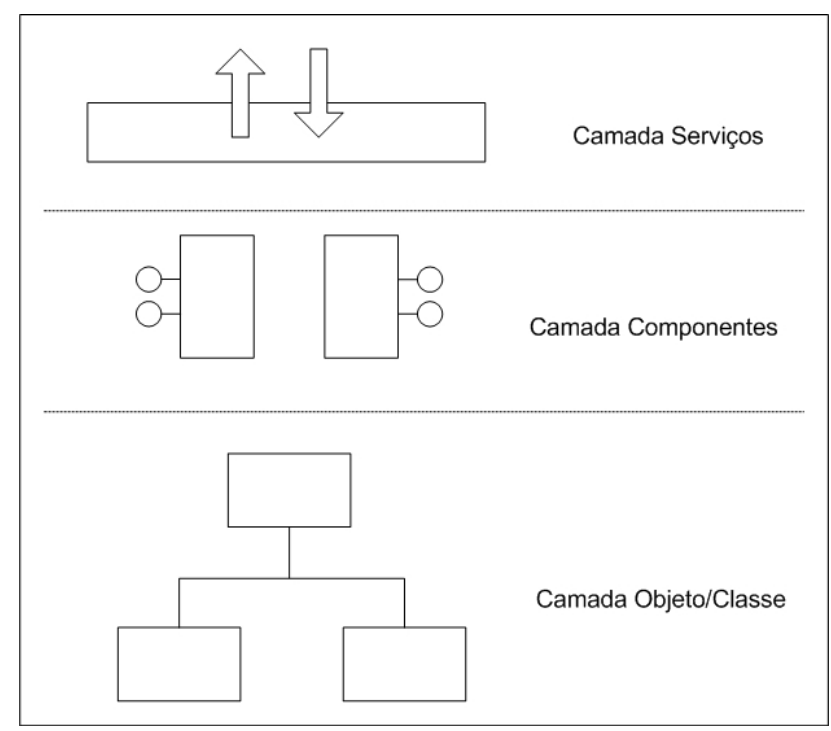

Figura 2.3: Uso de objetos e componentes, organizados em camadas, no desenvolvimento de soluções baseadas em SOA [ENDREI et al., 2004].

No desenvolvimento orientado a objetos, o projeto de software é focado nos dados, uma vez que estes refletem objetos do mundo real, assim, há um mapeamento entre os objetos reais e aqueles utilizados no sistema desenvolvido. Esses objetos possuem métodos, que podem ser interpretados como funções que executam ações sobre os atributos de cada objeto instanciado. Alguns objetos podem permitir a reutilização de código através do desenvolvimento de componentes, que possuem uma interface de comunicação bem definida. Essa característica permite acelerar o processo de desenvolvimento de software, além de prevenir falhas recorrentes, uma vez que sempre que possível são utilizados componentes já testados.

Todavia, ao utilizar o desenvolvimento baseado em objetos, em ambientes de comércio eletrônico, ou ainda, de maneira mais genérica, em ambientes de negócios, percebeu-se que seria mais natural tratar serviços ao invés de objetos ou componentes, sendo assim, inseriu-se mais uma camada de abstração em que serviços podem ser implementados por 
um conjunto de componentes, como apresentado na Figura 2.3. Tal medida desvincula as soluções empregadas dos conceitos computacionais.

A partir dessa ampliação do nível de abstração, desenvolveu-se uma estrutura baseada em duas categorias, funcionalidade e qualidade de serviço, para fornecer uma abordagem adequada para o desenvolvimento de soluções orientadas a serviço. Tal estrutura pode ser observada na Figura 2.4.

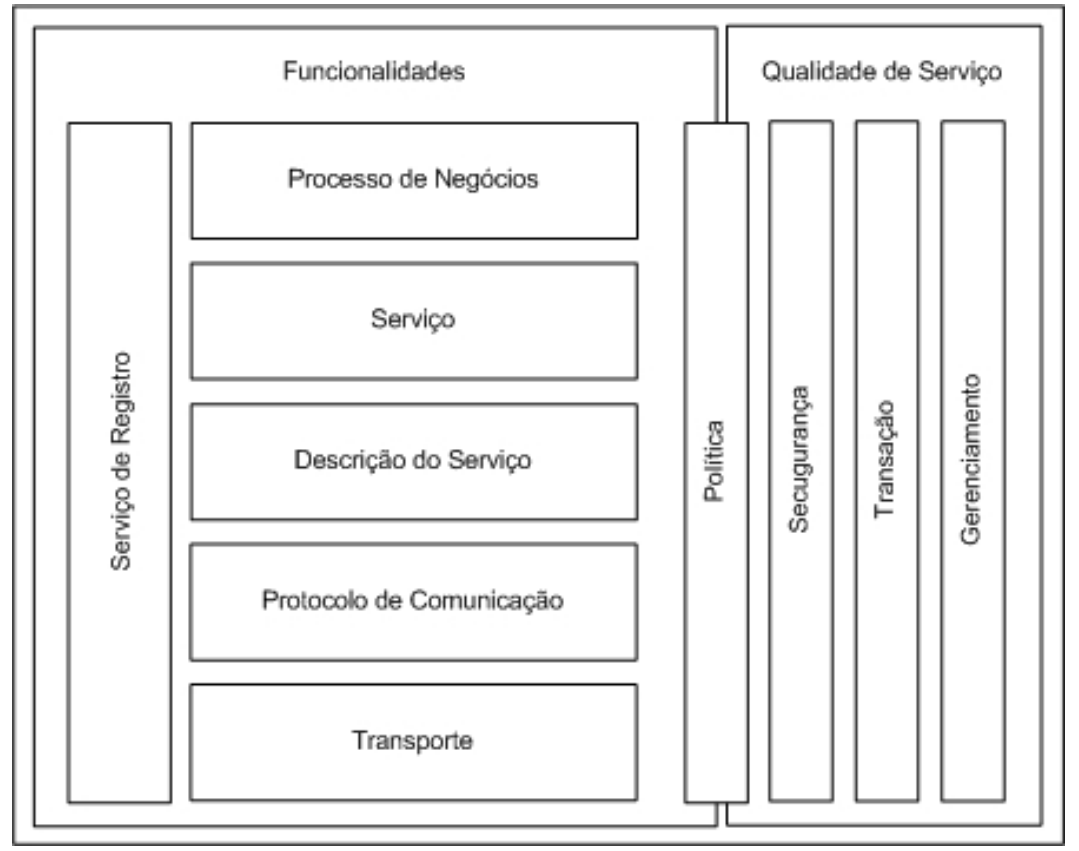

Figura 2.4: Infraestrutura dos elementos constituintes de uma arquitetura orientada a serviço [ENDREI et al., 2004].

Na Figura 2.4, é possível visualizar a separação entre os itens envolvidos com a funcionalidade propriamente da solução, e aqueles envolvidos com a qualidade de serviço prestada aos consumidores. De acordo com [ENDREI et al., 2004], na fronteira entre os aspectos funcionais e aqueles relacionados à qualidade, encontram-se as políticas que podem ser definidas como um conjunto de regras impostas pelo provedor de serviço ao consumidor, para que o serviço seja efetivamente prestado.

O aspecto funcional é composto pelas seguintes camadas [ENDREI et al., 2004]:

- Transporte: Define o mecanismo responsável pela transmissão das mensagens enviadas em ambas às direções, tanto aquelas partindo do provedor para o consumidor e vice-versa. Esta camada também é responsável pela entrega das mensagens eventualmente trocadas entre o registro e produtores ou o registro e consumidores.

A função desta camada se assemelha àquela empregada pela camada de transporte em redes de computadores, cujos protocolos TCP (Transmission Control Protocol) e UDP (User Datagram Protocolo) são os mais conhecidos e atualmente utilizados, 
devido ao sucesso da pilha de protocolos TCP/IP (Transmission Control Protocol/Internet Protocol). Todavia, é importante observar que, na prática, os protocolos envolvidos na camada de transporte de SOA são protocolos da camada de aplicação, especificada no modelo de referência ISO/OSI(International Organization for Standardization/Open Systems Interconnection), uma vez que, ao desenvolver aplicações baseadas em serviços, considera-se que os meios de comunicação estão presentes.

- Protocolo de comunicação: É o protocolo utilizado para a troca de informações entre os prestadores e os consumidores de serviço. Este protocolo define padrões de formatação de mensagens que permite, tanto ao provedor, quanto ao consumidor, interpretar corretamente o que está sendo solicitado ou respondido.

Novamente aqui cabe uma comparação com os protocolos envolvidos com as redes de computadores. A tarefa realizada pelo protocolo de comunicação é semelhante àquela prestada pelas camadas de apresentação e aplicação do modelo ISO/OSI. Uma vez que a camada de transporte é responsável por realizar o transporte fima-fim, ou seja, desde a origem até o destino, há a necessidade de um protocolo de camada superior que permita a comunicação entre as aplicações, uma vez que a camada de transporte apenas entrega os pacotes enviados.

No contexto da SOA o mesmo cenário ocorre. O protocolo de transporte, descrito anteriormente, apenas garante a entrega das mensagens enviadas entre o provedor e o consumidor, todavia, há a necessidade de um padrão de comunicação entre os serviços, permitindo a correta interpretação da mensagem trocada.

- Descrição do serviço: Esta camada é responsável por definir a forma como os serviços são descritos e invocados, destacando os dados necessários para a correta execução do mesmo. É nesta camada que ocorre a padronização de como os serviços são descritos, permitindo que os mesmos sejam publicados pelo provedor em um repositório e, posteriormente, consultados pelo consumidor, que se necessário pode invocar o serviço desejado.

- Serviço: Descrição do serviço disponível para o consumidor, através do padrão explicitado no item anterior.

- Processo de negócios: É uma coleção de serviços que representam um requisito de negócio. Os serviços envolvidos no processo de negócio devem ser invocados através de uma regra bem definida, uma vez que somente assim, será possível mapear um conjunto de serviços em um processo de negócio.

Outro fator interessante refere-se ao fato de um processo de negócio poder ser tratado como um serviço, servindo de composição para um processo de negócio mais abrangente e de certa forma global. 
- Serviço de registro: Conforme descrito na seção 2.3, o serviço de registro é caracterizado por um repositório, constituído de duas interfaces bem definidas, que são utilizadas para publicação de serviços por parte dos provedores e por posteriores buscas provenientes de consumidores.

Com relação aos aspectos direcionados à qualidade de serviço têm-se:

- Segurança: Constitui regras, implementadas no provedor, que permitem identificar consumidores, bem como autenticá-los, a fim de autorizar acesso a determinados serviços. Esta camada não se faz necessária em serviços disponibilizados publicamente. Todavia, mesmo nessa categoria, algumas medidas são necessárias para evitar seu uso incorreto, sendo implementadas na camada de políticas.

- Transação: Constitui regras destinadas a entrega de resultados consistentes. Assim, antes da execução, as informações utilizadas por um serviço se encontram em um estado consistente, devendo permanecer assim após o término da execução.

- Gerenciamento: Constitui um conjunto de atributos que são utilizados para gerenciar tanto provedores quando consumidores.

A partir da descrição da estrutura utilizada em SOA, é importante destacar que essa estrutura deve ser interpretada de maneira análoga àquela utilizada pelo modelo de referência ISO/OSI, uma vez que diferentes tecnologias de implementação de arquitetura orientada a serviço, como os Web Services, podem tratar tais informações de maneira ligeiramente diferentes, excluindo, unindo e, inclusive, ampliando a quantidade de camadas utilizadas.

\subsection{Composição de serviços}

A composição de serviços advém da teoria da separação das preocupações, acrescida do reuso de software [ERL, 2009].

$\mathrm{Na}$ teoria de separação das preocupações, divide-se um grande problema em problemas menores, denominados unidades, que poderão posteriormente ser agrupadas, recompostas, de forma a resolver o problema inicial. Tal técnica é utilizada desde os primórdios da programação, uma vez que problemas menores são mais fáceis de resolver. Essa teoria é popularmente conhecida como "dividir para conquistar".

$\mathrm{Na}$ teoria de reuso de software, as unidades decompostas do problema inicial tendem a ser organizadas de forma a permitir a recomposição para resolver novos problemas. Essa técnica popularizou-se no advento das bibliotecas de vinculação dinâmicas DLL's ( $D y$ nanmic Link Library), pelo fato de elas terem tornado altamente acessível a separação de unidades reusáveis de lógica, em arquivos de bibliotecas genéricas com interfaces públicas. 
Assim como na orientação a objetos, em que objetos de classes podem ser associados a fim de realizarem uma determinada tarefa, na orientação a serviços é possível decompor a lógica de negócio em partes menores e independentes, de forma que combinadas possam tratar problemas maiores como representado na Figura 2.5.

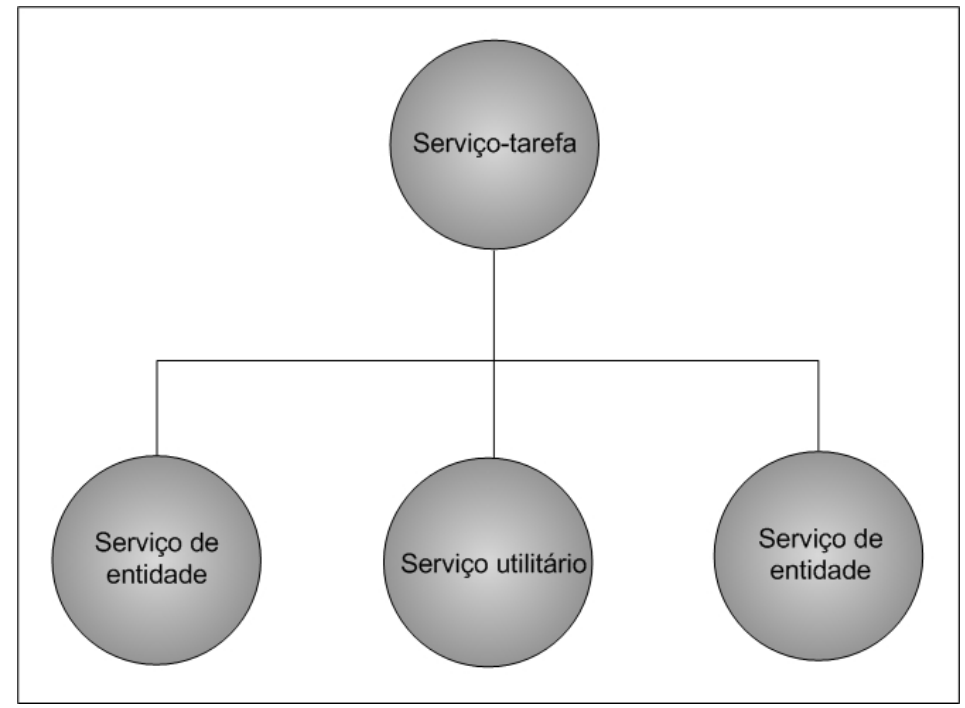

Figura 2.5: Esquema de uma composição de serviços, em que serviços de diferentes entidades são compostos, juntamente com um serviço utilitário, a fim de compor um serviço complexo denominado serviço-tarefa [ERL, 2009].

Todavia, há diferença entre a composição de serviço configurada estaticamente, em tempo de projeto, e a instância realmente executada. Ao executarmos uma regra de negócio composta, é possível que não seja necessário ativar todos os serviços membros ${ }^{1}$ que a compõem, uma vez que a composição deve estar preparada para tratar todas as possibilidades existentes, que pode não ocorrer em todas as execuções da composição.

\subsubsection{Membros da composição}

Observando a Figura 2.5, é possível deduzir que nas composições de serviço há sempre serviços identificados como controladores, que são responsáveis pela orquestração das requisições. É possível que uma composição possua subcomposições, assim, haverá também a presença de subcontroladores.

A tarefa de controlar uma composição pode ser atribuída a qualquer serviço, todavia, é comum o desenvolvimento de serviços que serão controladores, uma vez que a exigência de alto desempenho é muito grande nestes elementos.

Desta forma, de acordo com [ERL, 2005] é comum que os controladores possuam as seguintes características:

\footnotetext{
${ }^{1}$ Serviços membros são aqueles que não são controladores e subcontroladores
} 
- Lógica específica destinada a tratar apenas a regra de negócio a qual a composição está destinada a realizar.

- Uma vez que o reuso não é uma característica fundamental para uma SOA, apesar de desejada e incentivada, é comum ao controlador não ser desenvolvido como um serviço reutilizável, apesar desta abordagem não ser obrigatória. Todavia, devido às necessidade de alto desempenho, torna-se complexo torná-lo genérico suficiente para poder ser empregado em outras composições, destinadas a outras regras de negócio.

- Dependência de estados: diferentemente dos demais serviços, os controladores podem ficar dependentes de estados, tendo "conhecimento" da existência dos demais serviços.

Os demais componentes de uma composição são denominados membros da composição, e não possuem considerações especiais de desenvolvimento além daquelas destinadas à SOA, relacionadas na seção 2.6 .

Há ainda o papel destinado aos iniciadores de composição. Este papel cabe àquele serviço que realiza a chamada inicial ao controlador de uma composição, sendo caracterizado normalmente pelo consumidor. É a partir da invocação realizada pelo iniciador que a execução de uma composição passa a ser executada. Todavia, é possível que um subcontrolador, membro de uma composição maior, receba uma invocação de um serviço membro da composição a qual ele também é um membro, assim, o serviço membro, que invocou o subcontrolador, será caracterizado como iniciador da nova instância de composição.

\subsubsection{Composição mínima}

Devido ao recente surgimento da SOA e das composições de serviços, é mais frequente a ocorrência de troca de dados na modalidade ponto a ponto, que não caracterizam uma conexão. Este fato se deve ao número elevado de soluções que utilizam a SOA como integradora de soluções legadas e aquelas que a utilizam como pontos de contato, geralmente utilizadas para sincronização de base de dados [ERL, 2009].

Em uma troca do tipo ponto a ponto, somente dois serviços são envolvidos no processo de comunicação, sendo esses representados pelo provedor e pelo consumidor. Sendo assim, comunicações ponto a ponto não constituem uma composição de serviço, visto que uma composição mínima é caracterizada pelo envolvimento de pelo menos dois serviços e seu consumidor. Desta forma, o consumidor é tratado como iniciador, o serviço que recebe a primeira mensagem é identificado como controlador e o segundo serviço invocado pelo controlador é dito membro.

A partir dessas informações, é possível afirmar que uma composição mínima é representada por todos os seus participantes, com exceção do iniciador de composição. 


\subsubsection{Inconvenientes das composições}

Em uma composição, de acordo com a quantidade de serviços que constituem, bem como com o nível de interação entre os serviços, é possível classificá-las como primitivas ou complexas.

Não há um limite formal para classificar as composições, todavia, categoriza-se como primitivas aquelas mais simples, implementadas nas primeiras etapas de implantação de uma arquitetura orientada a serviço. Como exemplo podem-se citar as composições mínimas, descritas anteriormente. Já as complexas, são aquelas mais sofisticadas que envolvem uma grande quantidade de serviços membros e, possivelmente, subcontroladores. Tais composições são utilizadas para automatizar processos de negócios maiores e de maior abrangência [ENDREI et al., 2004].

Sendo assim, em cenários cuja presença de composições complexas são realidade, algumas dificuldades passam a existir, apresentando-se como desvantagens inerentes as composições [ERL, 2005]:

- Falha em cascata: Apesar de SOA ser uma arquitetura distribuída, isso não a qualifica como descentralizada, uma vez que nas composições os serviços controladores são tido como elementos centralizados, e como tal aparecem como ponto único de falha. Esse fato é agravado por este serviço ser responsável pela coordenação de outros, o que causará falhas em cascata.

Para amenizar tal problema, devem-se utilizar as técnicas disponíveis de tolerância a falhas, tais como redundância e clusterização.

- "Gargalos": Presentes constantemente em sistemas distribuídos, este comportamento indesejado também está presente no tipo de ambiente aqui considerado. Serviços mal projetados ou sobrecarregados tendem a retardar o tempo de execução de uma composição, não permitindo explorar todos os recursos computacionais direcionados a ela. Sendo assim, mesmo que o controlador possua uma implementação mais complexa, e cuja implementação deva ser tal que permita que o mesmo tenha desempenho superior aos apresentados pelos demais serviços, é necessário dedicar atenção suficiente ao projeto dos serviços membros, além de empregar técnicas de redução de "gargalos", como clusterização.

- Complexidade de alteração de interfaces: Uma vez que serviços membros são projetados para o reuso, à medida que se aumenta a quantidade de composições na qual um membro participa, torna-se complexo alterar a sua interface, uma vez que esta estará sendo utilizada por um grande número de serviços. Assim, é possível concluir que à medida que aumenta a complexidade e a quantidade das composições presentes em um ambiente de TI, aumenta também o acoplamento entre os serviços e as composições. 
Apesar dos fatos descritos anteriormente serem mais críticos para composições complexas, em cenários onde somente as composições primitivas são realidade, tais inconvenientes são amenizados, porém presentes, podendo ser agravados por falhas de projetos e implementações.

\subsection{Características das arquiteturas orientadas a ser- viços}

Como destacado na seção 2.1, a SOA possui como características: a neutralidade de tecnologia, o acoplamento fraco e a transparência de localização.

A neutralidade de tecnologia garante que sistemas desenvolvidos em diferentes tecnologias possam ser integrados de maneira coerente e de forma transparente. Como será abordado no capítulo 5, normalmente tal característica é obtida através de barramentos de serviços.

O fraco acoplamento permite que o design e a lógica de um serviço possam evoluir independentemente de sua implementação, ao mesmo tempo em que garante a interoperabilidade básica com consumidores que se utilizam das capacidades do serviço [ERL, 2009].

Finalmente, a transparência de localização permite que um serviço seja acessado independentemente do local em que está armazenado. Para tal, faz-se necessário a existência de um repositório de registro que garanta ao cliente descobrir e invocar de maneira correta um dado serviço.

Para que tais características sejam obtidas, faz-se necessário que outras características estejam presentes nas soluções baseadas em SOA [HAU et al., 2008]:

- Orientação a interface: Esta característica demonstra que a orientação a serviços é uma evolução natural da orientação a objetos, uma vez que o uso de interfaces permite isolar a implementação da solução aplicada a um problema.

Desta forma, o usuário da solução não toma conhecimento de como a implementação foi realizada, permitindo que implementações sejam melhoradas e se necessário substituídas sem causar transtornos para o usuário da solução. Tal característica somente é possível se não houver alterações nos parâmetros de entrada e saída e se a interface for publicada em uma linguagem padronizada e livre de ambiguidades.

- Padronização: Uma vez que SOA é também direcionada para a integração de soluções desenvolvidas em diferentes tecnologias, faz-se necessário a existência de uma linguagem padronizada de comunicação que possa ser interpretada por aquelas implementações que compõem a solução. É necessário ainda que haja um padrão de 
comunicação entre os membros que formam o triângulo de cooperação da SOA. Essa característica garante a neutralidade de tecnologias.

- Autonomia e modularidade: Esta característica reflete o fraco acoplamento da SOA. Tal fato indica que um serviço deve ter autonomia para realizar o trabalho ao qual foi projetado, sem que seja necessário interagir com os outros serviços do sistema. Mesmo que tal interação seja necessária, os serviços devem continuar sendo implementados de forma independente.

- Orientação a negócios: Esta é outra característica que remete à orientação a objetos. Assim como os objetos desenvolvidos devem mapear aqueles da realidade, os serviços desenvolvidos devem mapear as regras de negócio envolvidas em um processo encontrado no mundo real.

\subsubsection{Vantagens}

Apesar do conceito envolvendo SOA não ser novo, algumas vantagens foram obtidas com a sua definição:

- Utilização de recursos existentes: Uma vez que o nível de abstração é elevado para o nível de negócios, é possível para a organização continuar utilizando os recursos obtidos com investimentos passados, reduzindo o custo total de propriedade [ENDREI et al., 2004].

- Redução da complexidade: Uma vez que a SOA providencia a transparência de implementação, realizar mudanças na infra-estrutura de software torna-se menos complexa, minimizando o seu impacto [TAVARES, 2009].

- Agilidade: A possibilidade de utilizar serviços existentes em novas composições permite à organização se adaptar rapidamente a novas necessidades de mercado [TAVARES, 2009]. Desta forma, há uma redução do volume de lógica em geral, uma vez que é possível reutilizar componentes para automatizar diversos processos de negócios, o que reduz consideravelmente o tempo gasto com desenvolvimento de novos componentes [ERL, 2005].

- Redução de custos: Como destacado anteriormente, através do reuso, o desenvolvimento de novos componentes de softwares tornam-se reduzidos, diminuindo também o custo envolvido no desenvolvimento de uma nova solução [ENDREI et al., 2004].

- Alinhamento entre negócio e TI: Uma vez que o conceito de serviços é comum tanto aos profissionais de TI, quanto àqueles de negócio, torna-se possível mapear, em uma abordagem top-down, os requisitos envolvidos nas regras de negócios com os recursos de TI disponíveis [MARZULLO, 2009]. 
- Interoperabilidade inerente: Uma vez que o desenvolvimento de software dá-se no sentido regra de negócio componente, através de definições padronizadas de interfaces, bem como a padronização dos meios utilizados para trocas de mensagens, é possível integrar diferentes tipos de aplicações, como já destacado no início do capítulo [ERL, 2005], [TAVARES, 2009].

\subsection{Considerações finais}

Neste capítulo abordou-se a arquitetura orientada a serviços, atualmente apresentada como uma das melhores soluções para a integração de sistemas, bem como para o alinhamento de interesses entre a equipe de negócios e a de TI.

Destacou-se que tal arquitetura baseia-se em três elementos principais: provedor, consumir e registro de serviços. Sendo que o processo de interação entre eles dá-se a partir do momento em que o provedor de serviços publica o mesmo em um repositório, utilizando para isso uma interface bem definida. A partir desse momento é possível ao consumir consultar o repositório utilizado pelo provedor, a fim de obter os serviços fornecidos, bem como a interface de comunicação que deverá ser utilizada.

Uma vez que se utilizam protocolos e métodos de troca de mensagem padronizados, tal arquitetura mantém-se isenta das tecnologias utilizadas na implementação dos sistemas, permitindo ainda a integração de sistemas legados, bem como aqueles desenvolvidos nas mais diferentes plataformas.

Destacou-se, ainda, a composição de serviços, que utiliza serviços relativamente genéricos, a fim de mapear um processo de negócio. Destacou-se, também, a necessidade da existência de um serviço gerenciador da composição, que é responsável pela orquestração da correta execução da instância da composição utilizada. Conforme destacado na seção 2.5.1, o controlador deve ser desenvolvido de maneira menos genérica, o que dificulta a sua reutilização, todavia, permite que o mesmo seja focado no alto desempenho.

Finalmente, destacaram-se as vantagens e desvantagens ao adotar a arquitetura orientada a serviços, que deve ser compreendida como um modelo de referência. Assim, para que a SOA seja aplicada na prática, faz-se necessário o uso de uma tecnologia que a implemente. Ao analisar os trabalhos desenvolvidos, percebe-se que a tecnologia atualmente mais utilizada é denominada Web Services. Por esse motivo, o próximo capítulo abordará essa tecnologia e seus aspectos relacionados. 


\section{Capítulo \\ 3 \\ Web Services}

\subsection{Considerações iniciais}

Apesar da existência de alguns middlewares destinados à integração de aplicações distribuídas, tais como CORBA(Common Object Request broker Architecture), DCOM (Diustribted Component Object model) e RMI (Remote method Invocation), foi somente com o advento dos Web Services que a computação baseada em serviços passou a ser fortemente adotada por companhias com a SUN Microsystems, IBM, Microsoft, BEA, Oracle e Borland [YU et al., 2008].

Este fato se deve a alguns inconvenientes apresentados pelas tecnologias existentes destacadas anteriormente, tais como: incompatilibidade com outros protocolos, dependência de linguagem ou de sistema operacional e utilização de modelos, tanto de objeto quando de passagem de mensagem, dependentes de fabricantes [MATOS, 2009].

Tais dificuldades são eliminadas com a adoção de Web Services, uma vez que estes são baseados em padrões e protocolos abertos e amplamente difundidos, permitindo que serviços sejam disponibilizados a clientes na Web independente da plataforma de hardware ou software utilizada.

\subsection{Definição}

De acordo com a W3C (World Wide Web Consortium), Web Services podem ser definidos como sistemas de software destinados à suportar a interação entre máquinas sobre uma rede de comunicação de dados. Tais sistemas utilizam a linguagem WSDL ( Web Services Description Language) para descrever as suas interfaces e trocam mensagens através do protocolo SOAP (Simple Object Access Protocol), baseado em XML, utilizando 
como camada de transporte os protocolos pertencentes à pilha TCP/IP, descritos para a Internet [SCHLIMMER, 2002].

Os principais recursos e características disponibilizados pelos Web Services são [ENDREI et al., 2004]:

- Autonomia: No lado cliente não há necessidade de softwares adicionais, com exceção do navegador e de uma implementação da pilha de protocolos TCP/IP, incluindo o HTTP. Já no lado servidor, é necessário apenas um servidor Web e um servidor de aplicação. Desta forma, é possível habilitar Web Services sem a necessidade de escrever linhas de código adicionais.

É importante ressaltar que a habilitação de um Web Service não garante a implementação das regras de negócio como serviços, uma vez que estes deverão ser descritos através de uma linguagem de programação adequada e disponibilizados.

- Auto-descrição: Tanto o lado cliente, quanto o servidor, não conhecem detalhes de implementação ou estruturais da extremidade oposta na comunicação. Sendo necessário que ambos consigam manipular apenas o formato das mensagens enviadas e recebidas, cuja descrição e formato são enviados juntamente com as mensagens trocadas. Tal recurso garante aos Web Services o fraco-acoplamento.

- Modularidade: Uma vez que os Web Services apenas provêem acesso para as funções de negócios na Web, é possível, e necessário, utilizar outros padrões para desenvolvêlos, tais como as plataformas JEE (Java Enterprise Edition) e Microsoft .Net, o que permite utilizar a teoria da separação das preocupações, a fim de modularizar o desenvolvimento de um dado sistema.

- Interoperabilidade: Partindo do mesmo princípio apresentado no item Modularidade, é possível integrar diferentes tecnologias em uma mesma solução, incluindo aplicações legadas desenvolvidas em linguagens como C, Cobol e Natural e em diferentes plataformas de hardware como, por exemplo, Mainframes e I386.

- Adaptabilidade: Uma vez que os Web Services implementam a SOA, eles permitem a formação de composições, permitindo o reuso de software e a rápida adaptação a novos negócios. Para tal, há a necessidade de projetos bem elaborados, visando o reuso, uma vez que, assim como descrito no capítulo 2, há a necessidade da generalização dos serviços desenvolvidos, permitindo que os mesmos sejam reaproveitados.

\subsection{Arquitetura, protocolos e padrões}

Assim como a maioria das tecnologias, as especificações de interoperabilidade dos Web Services são definidas por um conjunto de organizações. Dentre elas destaca-se a WS-I 
(Web Services Interoperability Organization), que constitui um consórcio aberto, composto aproximadamente por cento e cinquenta companhias de vários segmentos [ENDREI et al., 2004].

Um dos objetivos do WS-I é intermediar os diálogos entre empresas e os órgãos de regulamentação como W3C, OASIS (Advancing Open Standards for the Information Society, IETF (Internet Engineering Task Force) entre outras, a fim de promover a interoperabilidade entre as diferentes plataformas, através do uso de padrões abertos, além de encorajar o uso de Web Services e acelerar seu desenvolvimento.

A partir desse trabalho, duas gerações de Web Services foram padronizadas, sendo que cada uma dessas gerações é associada a um conjunto de padrões e especificações [ERL, 2009].

$\mathrm{Na}$ primeira geração foram definidas as tecnologias fundamentais para o completo funcionamento dos Web Services, estabelecendo-se que:

- A descrição do serviço deve ser realizada através da WSDL e esta validada através de XSD (XML Schema Definition), uma vez que tal linguagem é baseada em XML.

- A troca de mensagem deve ser realizada através do protocolo SOAP, utilizando o protocolo HTTP como camada de transporte.

- Os processos de publicação e descoberta devem ser definidos através de UDDI ( Universal Description, Discovery and Integration).

Já na segunda geração, definiram-se as características relacionadas à qualidade de serviço, segurança, transações e confiabilidade de comunicação. Itens ausentes na primeira geração, e de suma importância para a adoção dos Web Services nas corporações [TAVARES, 2009].

Para abordar tais itens, definiram-se várias extensões denominadas genericamente por WS-*, onde o asterisco diz respeito a uma característica abordada, como por exemplo, WS-ReliableMessaging [MARZULLO, 2009].

Sendo assim, na Figura 3.1 encontra-se a associação dos padrões dos Web Services de segunda geração agrupados em camadas, de acordo com suas funcionalidades.

\subsubsection{Tecnologias base}

Como é possível observar na Figura 3.1, a linguagem de marcação XML, bem como seus meios de validação, são essenciais para o desenvolvimento dos padrões utilizados na arquitetura de Web Services.

XML é uma linguagem de marcação, baseada na SGML (Standard Generalized Markup Language), que tem por objetivo criar linguagens de marcação que descrevam dados 


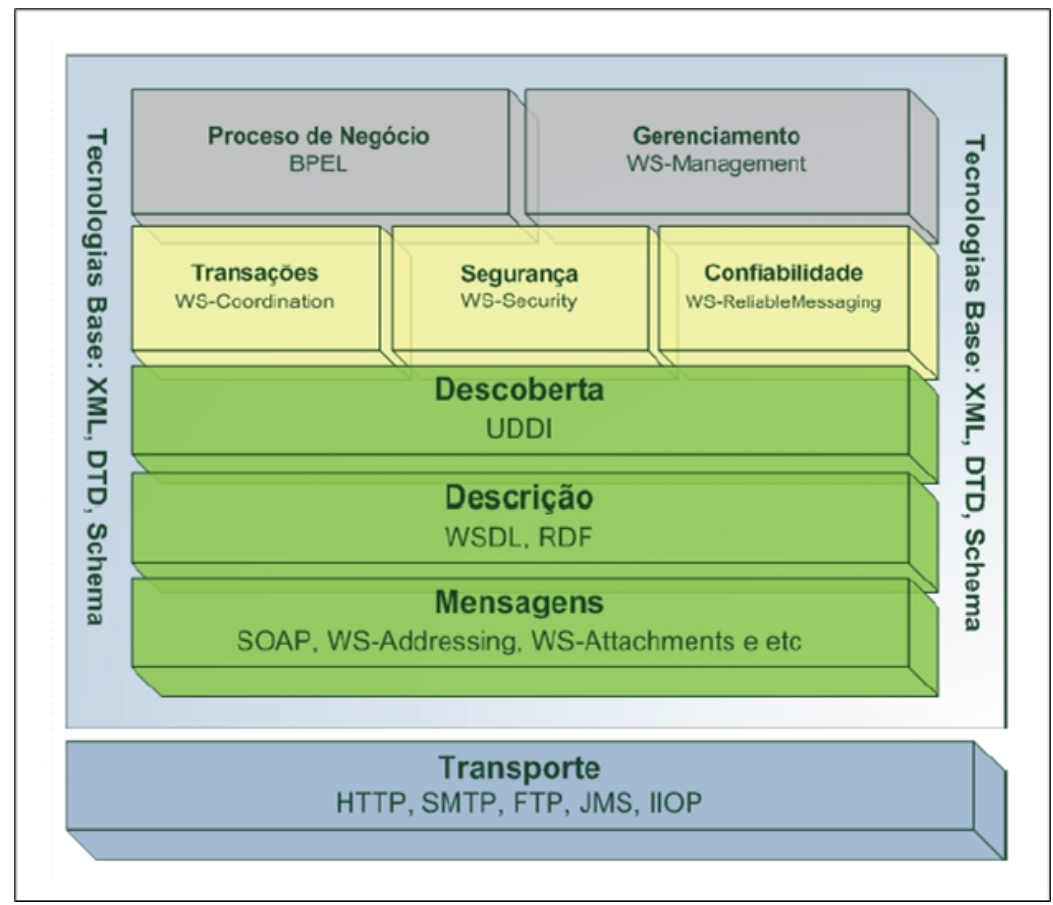

Figura 3.1: Arquitetura dos Web Services [TAVARES, 2009].

de todos os tipos. Sendo padronizada pelo W3C, ela oferece um formato de dados estruturado, extensível e flexível, permitindo especificar documentos abertos, apropriados para o intercâmbio de dados entre aplicações Web [DEITEL et al., 2003].

Devido às características citadas, tal linguagem é muito utilizada como padrão de armazenamento e transporte de dados, sendo, inclusive, capaz de trafegar todo e qualquer tipo de informação necessária num contexto de negócio [MARZULLO, 2009].

Os documentos XML, identificados pela extensão de mesmo nome, podem ser visualizados como uma árvore invertida, cujo elemento raiz situa-se na parte superior. Tal elemento é obrigatório para a descrição de um documento, sendo seguido por tags semelhantes às encontradas nos documentos HTML (HyperText Markup Language). As tags caracterizam elementos que podem ser vazios, simples ou conter outros elementos.

Assim como nas demais linguagens, para obter um documento XML válido, é necessário que o mesmo respeite algumas regras [MARZULLO, 2009], [DEITEL et al., 2003]:

- A primeira informação de um documento deve ser a declaração da versão da linguagem utilizada, identificada pela tag:

$\langle ? \mathrm{xml}$ version $=" 1.0 " ?\rangle$

- Como mencionado anteriormente, a presença de um elemento raiz é obrigatório, tal elemento deve conter os demais, sendo o elemento mais externo do documento. 
- Cada elemento pode conter atributos, assim como em HTML, sendo que cada atributo deve ser único em cada tag e deve ser limitado por aspas duplas.

- Cada elemento deve ter sua tag de fechamento.

Uma vez que um documento XML atenda às regras anteriormente descritas, diz-se que ele é bem formado, todavia, para que o mesmo seja válido, é necessário que ele seja validado perante uma gramática. As gramáticas, descritas através de DTD (Document Type Definition) ou XML-Schema, definem os tipos de dados que os elementos manipulam, além de descrever o comportamento de seus atributos, identificando o que representa efetivamente cada tag dentro de um documento XML.

Como exemplo de documento XML, considere o código a seguir que descreve um formulário de uma agência de locação de veículos, cuja interação com o usuário dá-se de forma multimodal, através dos dispositivos de entradas tradicionais, mouse e teclado, bem como através de comandos de voz [NETO et al., 2008].

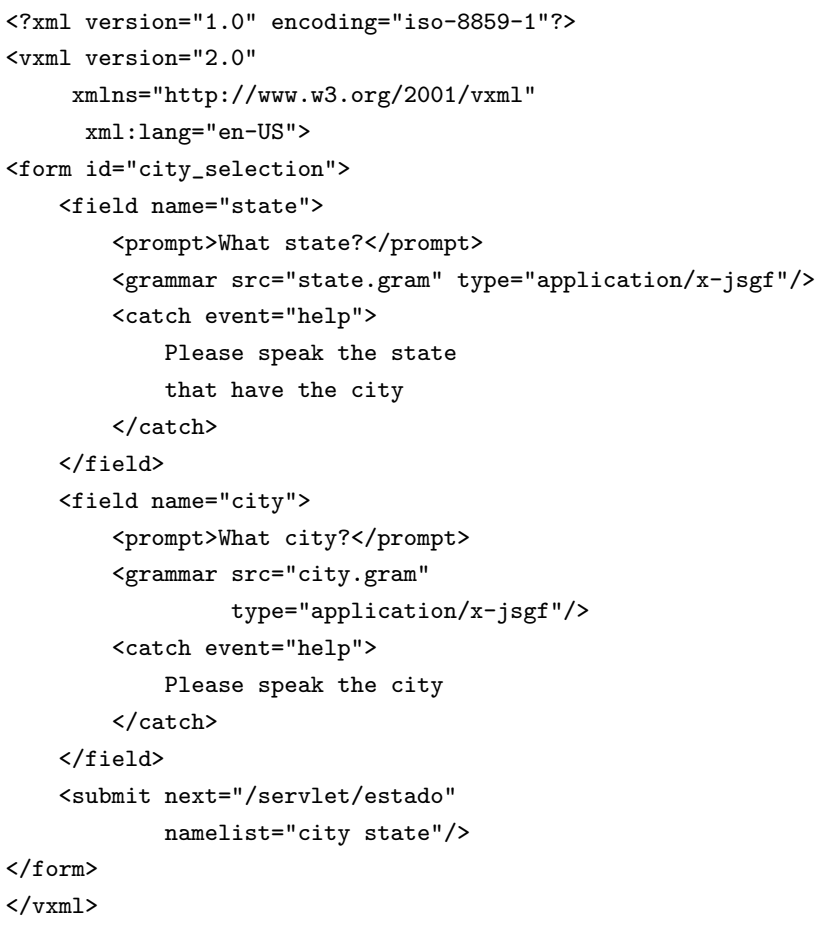

DTD

Apesar dos documentos XML não terem necessariamente que estar vinculados a um DTD, tal ação é frequentemente recomendada para garantir a conformidade do documento, especialmente em transações business-to-business (B2B), uma vez que um DTD tem por função definir a estrutura de um documento [DEITEL et al., 2003].

Os DTDs são definidos através da gramática EBNF (Extended Backus-Naur Form), cujas regras são utilizadas para determinar como os elementos devem ser definidos, além 
de especificar os valores possíveis para seus atributos e conteúdo [MARZULLO, 2009].

A vinculação de um DTD com um arquivo XML pode ser feita diretamente no arquivo XML ou em um arquivo externo. Na primeira situação, deve-se inserir as produções no início do arquivo, logo após a declaração inicial. O código a seguir, disponibilizado em [MARZULLO, 2009], ilustra tal situação:

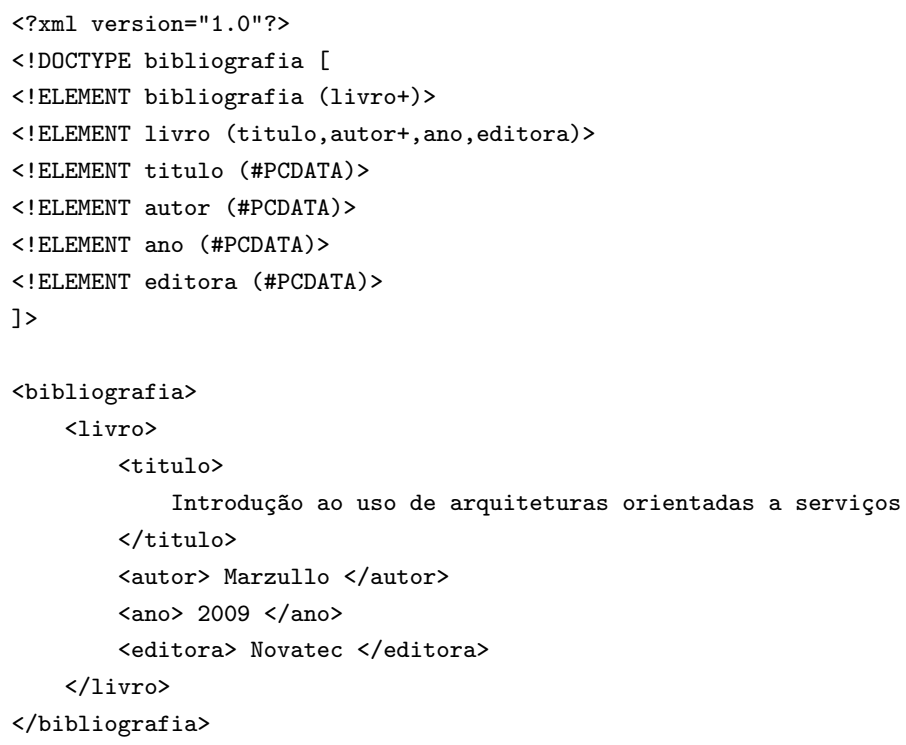

Já para vincular o documento XML a um DTD externo, deve-se utilizar o atributo SYSTEM, na declaração do tipo do documento XML, sendo assim, define-se o código em XML em um arquivo .xml e as produções do DTD em um arquivo .dtd. como exemplo, observe como ficaria o documento XML do exemplo anterior:

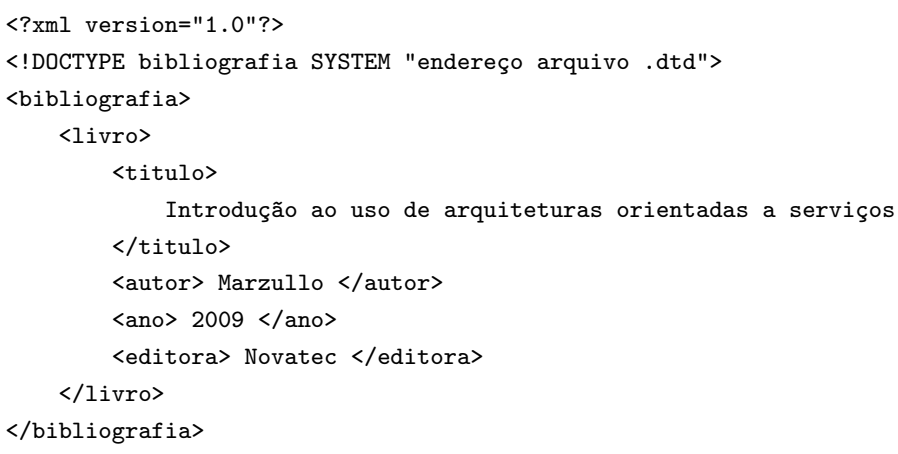

É possível ainda utilizar o atributo PUBLIC ao invés de SYSTEM, caso o arquivo de definição seja de domínio público. Neste caso, deve-se informar a URL (Uniform Resource Locator) do repositório do documento.

Como é possível observar nos exemplos apresentados anteriormente, a declaração de um elemento da-se pela declaração !ELEMENT (tipo), onde o tipo pode assumir os seguintes valores: 
- EMPTY: O elemento não poderá conter nenhum valor.

- ANY: O elemento poderá conter qualquer tipo de conteúdo.

- \#PCDATA: O elemento poderá abrigar outros elementos ou conter textos.

- \#CDATA: O elemento poderá conter somente textos.

Uma vez definidos os elementos, é possível definir seus atributos, devendo para isso utilizar a diretiva !ATTLIST $N_{e}, N_{a}$, tipo valor_padrão, onde $N_{e}$ é o nome do elemento ao qual o atributo pertece; $N_{a}$ define o nome do atributo; tipo pode assumir os mesmos valores definidos para os elementos e finalmente, valor_padrão indica como deverá ser tratado o conteúdo do atributo, podendo assumir os seguintes valores:

- \#DEFAULT valor: O atributo possui um valor padrão, caso o usuário não informe um, será atribuído o conteúdo identificado por valor.

- \#REQUIRED: O atributo definido é obrigatório, não podendo ser omitido.

- \#IMPLIED: Indica que o atributo é opcional.

- \#FIXED valor: O atributo possui um conteúdo fixo identificado por valor.

\section{XML-Schema}

O XML-Schema, ou XSD, além de ser um padrão da W3C, é apresentado como uma evolução natural ao DTD. Apesar de possuir os mesmos objetivos de um DTD, o XSD é mais flexível, uma vez que utiliza a sintaxe XML, permitindo que o mesmo seja pesquisado e transformado em diferentes representações. Esta última, através do uso de XSLT (eXtensible Stylesheet Language Transformations).

Adicionalmente, o XSD permite definir não somente a estrutura dos documentos XML, mas também a ordem das tags, o conteúdo que pode ser atribuído aos elementos e atributos e a definição dos tipos de dados que poderão ser utilizados [DEITEL et al., 2003].

Como exemplo, pode-se considerar o código a seguir, que apresenta uma versão em schema do documento de bibliografia definido anteriormente.

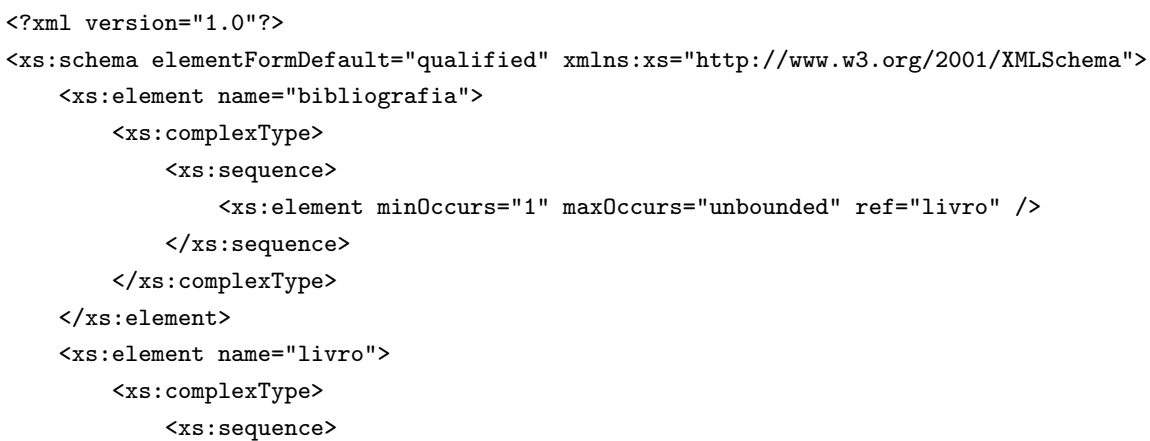




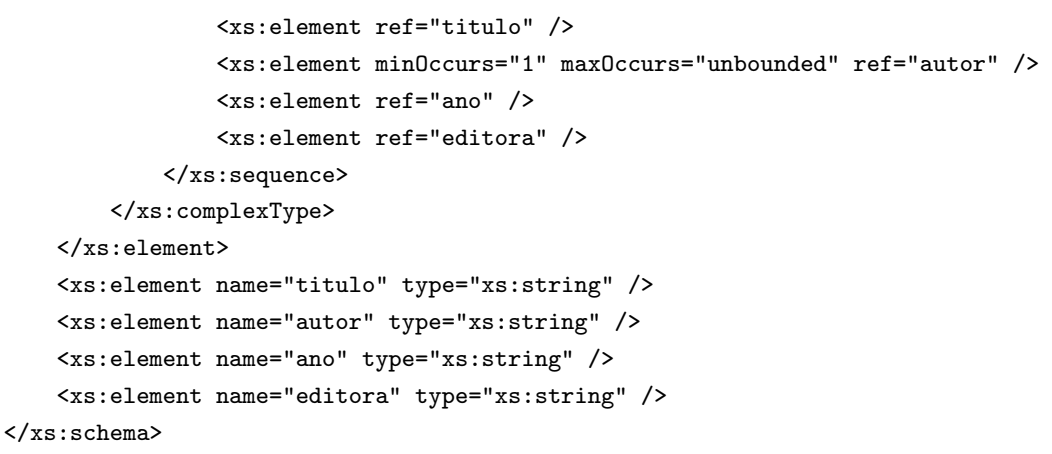

Analisando o código apresentado, é possível perceber que a tag $\langle x s: s c h e m a>$ é o elemento raiz de um XSD. Onde o prefixo xs indica o espaço de nome definido pelo atributo xmlns. O espaço de nomes, também conhecido como namespace, qualifica nomes de elementos e atributos a fim de evitar colisões de nomenclaturas em documentos de domínios diferentes [MARZULLO, 2009], [DEITEL et al., 2003].

Como exemplo considere-se o elemento ano; é fato que muitos documentos XML contêm essa tag, no entanto, para diferentes domínios de negócios. Assim, o espaço de nomes permite criar prefixos que evitem a ambigüidade. No caso do schema apresentado, definese o espaço de nomes xs, definido no documento XMLSchema do repositório www.w3.org. É importante lembrar que a definição dos espaços de nomes é realizada no elemento raiz.

Já o atributo elementFormDefault define que todos os elementos do documento schema devem ser qualificados pelo espaço de nomes, por esse motivo, todas as tags possuem o prefixo xs.

Com relação aos tipos de elementos, estes podem ser simples ou complexos. Os primeiros podem conter apenas valores textuais, enquanto os do segundo tipo pode conter outros elementos sendo definidos em quatro categorias: 1) Elemento vazio, 2) elemento que contém somente outros elementos, 3) elemento que contém somente valor textual e 4) elemento que contém tanto valor textual como outros elementos.

No caso do documento apresentado no exemplo, o tipo complexo considerado, é composto por uma sequência de elementos simples. Utilizaram-se também os atributos maxOccurs e minOccurs, que indicam qual a quantidade máxima e mínima que um dado elemento pode ser utilizado em um documento XML.

Finalmente, através do atributo type, é possível ajustar qual o tipo de dados aceito pelos elementos, sendo que entre os principais tipos permitidos encontram-se: string, int, double, date, datetime ...

Uma vez definido o Schema, pode-se vinculá-lo a um documento XML. Para tal, considerem-se o código a seguir:

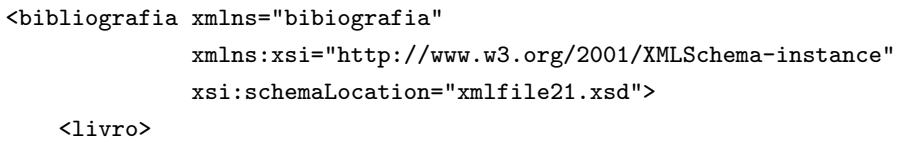




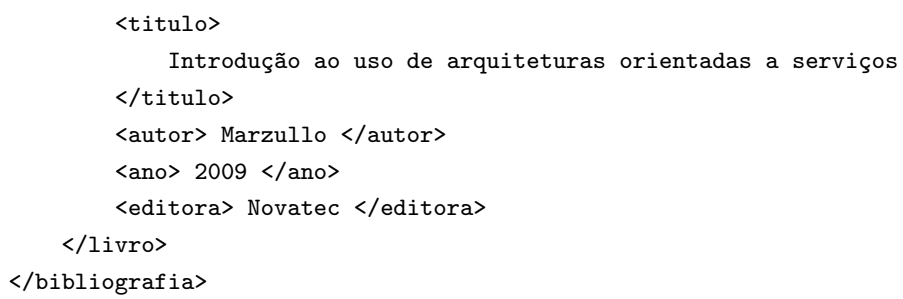

Observe que a vinculação é realizada através do atributo xsi:schemaLocation, cujo valor indica a localização do arquivo com a definição.

\subsubsection{Camada de transporte}

Os protocolos, utilizados como camada de transporte pelos Web Services, constituem protocolos da camada de aplicação da pilha de protocolos TCP/IP, sendo o HTTP o mais utilizado atualmente [TAVARES, 2009].

O HTTP pode ser caracterizado como um protocolo do tipo pedido/resposta, cujo cliente envia um pedido ao servidor na forma de um método de requisição, contendo a URI (Uniform Resource Identifier), a versão do protocolo e uma mensagem em formato tipo MIME(Multipurpose Internet Mail Extensions).

A resposta do servidor é enviada com uma linha de status que inclui: A versão do protocolo, um código de sucesso ou erro, seguido de uma mensagem do tipo MIME, que contém informações do servidor, metadados e corpo da mensagem.

Como pode ser observado, a versão do protocolo é fundamental na troca de informações entre cliente e servidor, uma vez que na versão 1.0 do protocolo HTTP, apenas um objeto é enviado por conexão TCP, enquanto que na versão 1.1, muitos objetos podem ser enviados, economizando tempo através da redução de handshakes de três vias executados.

O principal motivo para a sua rápida adoção, encontram-se no fato deste ser um protocolo amplamente utilizado, estando presente em uma vasta quantidade de servidores, e presente em todos os navegadores incluindo plataformas como celulares e smartphones [ENDREI et al., 2004]. Além do fato de ser transponível em praticamente todos os firewalls implementados. Todavia, deve-se observar que o tráfego normalmente liberado deve ser direcionado para a porta 80 ou 443.

Porém, algumas desvantagens são observadas, como o fato desse protocolo ser do tipo sem conexão (stateless) e não confiável, uma vez que, na concepção da Web, coube ao protocolo TCP prover a confiabilidade necessária [ENDREI et al., 2004].

Apesar da larga adoção do HTTP, outros protocolos também constituem a camada de transporte dos Web Services, tais como:

- SMTP (Simple Mail Transfer Protocol): Protocolo utilizado para envio e troca de mensagens entre MUA (Mail User Agents) e MTA (Mail Transfer Agents) e entre MTAs. 
- RMI/IIOP (RMI over IIOP): Consiste em executar o RMI (Java Remote Method Invocation) sobre o IIOP (Internet Inter-Orb Protocol). Este padrão foi criado para simplificar o desenvolvimento de aplicação Corba sem que se perdessem os benefícios que lhe são associados [MARZULLO, 2009].

- JMS (Java Message Service): Permite as aplicações Java trocarem mensagens de forma confiável, o que facilita o desenvolvimento de aplicações distribuídas, uma vez que a confiabilidade não fica a cargo do programador, como ocorre com o HTTP.

\subsubsection{Camada de mensagens}

Esta camada é responsável por prover a transmissão fim-a-fim entre Web Services, utilizando, como suporte, os protocolos HTTP e SMTP da camada de transporte descrita anteriormente.

Dentre os protocolos propostos, o SOAP é o mais utilizado atualmente, podendo ser definido como uma especificação para troca de informações estruturadas em ambientes descentralizados e distribuídos, utilizando o XML como linguagem de descrição das mensagens [MARZULLO, 2009].

A mensagem SOAP é composta pelo envelope XML, obrigatório, contendo dois elementos: Header e Body. O primeiro é de uso facultativo, enquanto o segundo é obrigatório. Tais elementos são definidos pela aplicação que utiliza o envelope e não pela definição do protocolo [W3C, 2007]. Um esquema da estrutura de um envelope SOAP pode ser observado na Figura 3.2.

\section{Envelope}

O envelope define a raiz, transformando uma mensagem XML em uma mensagem SOAP. Seu espaço de nomes é determinado pelo documento soap-envelop disponibilizado em www.w3.org/2001/12/. Outro fator importante é a definição do tipo de codificação, permitindo que o Web Service de destino interprete corretamente a mensagem.

O estilo de codificação utilizado também é padronizado e encontra-se no documento soap-encoding, disponível no mesmo repositório do arquivo soap-envelop. A codificação deve ser especificada no envelope, sendo aplicada a todo o documento. Todavia, é possível redefinir a codificação utilizada, tanto no cabeçalho, quanto no corpo da mensagem. A seguir, é apresentado a estrutura de um envelope SOAP.

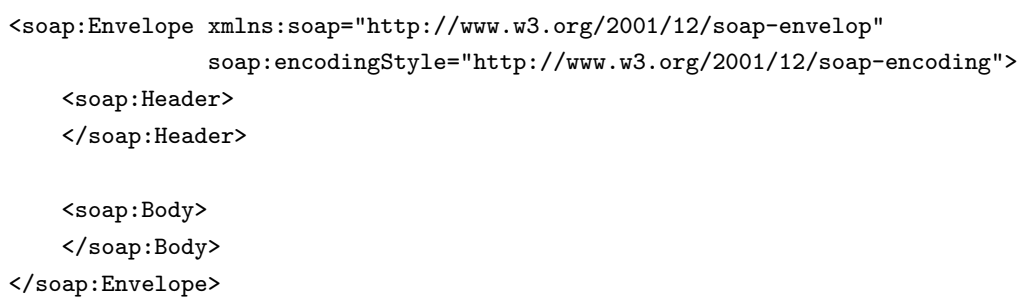




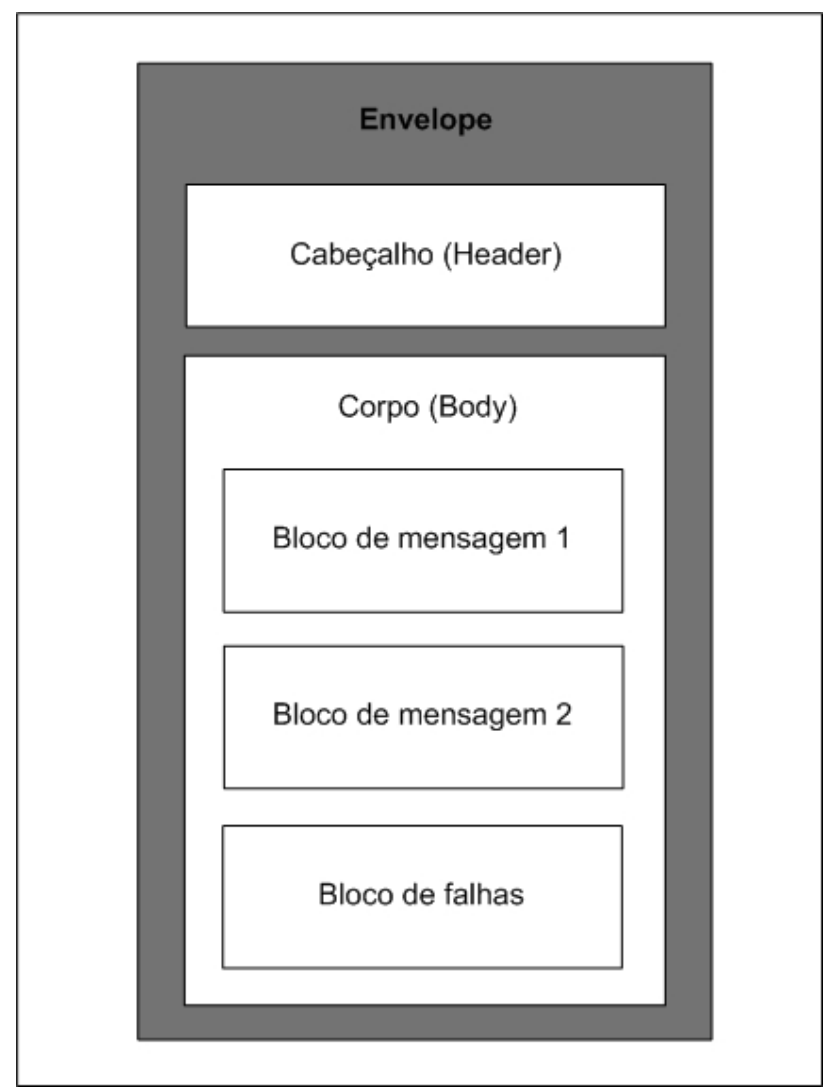

Figura 3.2: Estrutura de um envelope SOAP [W3C, 2007].

\section{Header}

A seção header é responsável por trafegar informações específicas da mensagem SOAP, que são independente dos dados trafegados pela aplicação do usuário na seção body. Tais dados incluem informações sobre autenticação, formas de pagamento, Web Services que devem interpretar a mensagem entre outros. É possível ainda trafegar regras de segurança específicas da mensagem SOAP [MARZULLO, 2009].

Esta seção possui ainda três atributos que são definidos no espaço de nomes soapenvelope, descrito anteriormente. Tais atributos podem ser inseridos em qualquer elemento interno a tag <header $>$. Tais atributos são [W3CSCHOOLS, 2010]:

- mustUnderstand: Este atributo pode assumir os valores "0" ou "1" e indica a obrigatoriedade do Web Service receptor processar o elemento que o contém.

Desta forma, se ao receber uma mensagem SOAP, cujo header contenha algum elemento com este atributo setado em "1", cabe ao Web Service interpretá-lo, caso isso não seja possível, uma mensagem de erro deverá ser retornada.

- actor: Este atributo lista qual Web Service deverá interpretar um determinado elemento do header. Desta forma, é possível que a mensagem seja roteada por diversos 
Web Services intermediários, sem que esses precisem interpretar as informações. Isso garante que uma mensagem não seja recusada por intermediários. Sua sintaxe é dada por:

soap: actor="URI"

- encodingStyle: Este atributo permite redefinir o tipo de codificação utilizado, sobrepondo aquela definida no envelope, sendo, no entanto, aplicável somente ao elemento header. Sua sintaxe é dada por:

soap: encodingStyle="URI"

\section{Body}

É nesta seção que será armazenado o documento da aplicação do usuário a ser transmitido para o Web Service. É neste elemento também que é inserida a codificação das falhas, usando para isso o elemento fault.

O atributo soap:encodingStyle também pode ser utilizado neste elemento, a fim de alterar o padrão de codificação utilizado, que pode ter sido declarado no envelope. Assim como no elemento header, a mudança de codificação, se utilizada, possui escopo local afetando apenas os dados internos a tag $<$ body $>$.

O elemento fault é utilizado para retornar qualquer tipo de erro ocorrido durante a comunicação envolvendo Web Services, sendo portanto opcional, uma vez que não há notificações de sucesso através deste elemento. Todavia, se este estiver presente em uma mensagem SOAP, ele deve ser único [MARZULLO, 2009].

A fim de reportar o erro da melhor forma possível, o elemento fault possui os seguintes elementos [W3CSCHOOLS, 2010]:

- faultcode: Identifica o erro ocorrido através dos seguintes códigos:

- VersionMismatch: Indica que o espaço de nomes utilizado no envelope SOAP não é válido.

- MustUnderstand: Este código de erro refere-se ao atributo de mesmo nome utilizado na seção header. Se este elemento contiver o valor "1", indica que o Web Service não conseguiu processar a informação obrigatória.

- Client: Indica que a mensagem enviada está mal formada, caracterizando um erro de construção da mensagem SOAP, sendo assim considerada um erro do aplicativo cliente.

- Server: Indica que o Web Service de destino não pode processar a solicitação.

- faultstring: Descrição do erro. 
- faultactor: Informação referentes ao causador do erro.

- detail: Detalhes específicos da aplicação, referindo-se aos erros ocorridos no elemento body. Para tal, a aplicação deve estar preparada para reportar esse erro.

Como é possível observar, o conteúdo do elemento body não possui um padrão com relação a seus elementos, com exceção das notificações de falhas. É nesta característica que se encontra uma das maiores vantagens dos Web Services tornando-se altamente flexíveis.

\section{Tipos de codificação}

Como descrito anteriormente, é possível ajustar o tipo de codificação que será utilizada nas mensagens SOAP. Tal recurso faz-se necessário pois os Web Services são utilizados para a troca de informações entre aplicações desenvolvidas em diferentes plataformas, como sistemas orientados a objetos e sistemas legados. Sendo assim, faz-se necessário que os dados sejam transformados em mensagens XML, na aplicação origem, inseridas na seção body e ao ser recebida no destino, elas sejam convertidas para o formato da aplicação local [COHEN, 2003].

Assim, alguns tipos de codificação foram padronizados, todavia, apenas três tornaramse populares:

- SOAP RPC (Remote Process Call): Realiza uma chamada a um método ou procedimento remotamente, através de um documento XML em uma mensagem SOAP. Esse método é o mais simples de ser implementado pelo desenvolver de uma aplicação, uma vez que cabe a pilha de protocolo SOAP converter a chamada, juntamente com seus parâmetros, em um documento XML. A esse processo dá-se o nome de serialização.

Da mesma forma, após receber o documento XML enviado, via protocolo HTTP ou SMTP, cabe à pilha SOAP realizar o trabalho inverso no receptor, deserializando o objeto.

- SOAP RPC-literal: Também utilizado para invocar um método remoto, como no caso anterior, porém, a conversão para XML é realizada pela aplicação que está invocando o método. Assim, a pilha SOAP necessita serializar apenas um elemento, que contém a codificação XML fornecida pela aplicação.

Como é possível concluir, esse método é mais complexo de ser implementado, todavia, permite ao sistema obter melhores taxas de desempenho.

- SOAP Document-style: Este tipo de codificação é utilizado quando se espera apenas a troca de informações entre aplicações, não sendo invocado nenhum método remoto. Assim, cabe à aplicação cliente construir o documento XML e enviá-lo à aplicação 
destino. Esta por sua vez precisa realizar o parser do documento para obter as informações enviadas.

Este tipo de codificação apresenta-se como o mais complexo para o desenvolvedor da solução, apresentando o melhor desempenho dentre os métodos citados.

Ao realizar requisições no estilo RPC, o protocolo SOAP define um conjunto de regras para realizar o processo de requisição-resposta. Tais regras definem que o elemento body contenha um elemento com o nome do método invocado, seguido de seus parâmetros, bem como valores de retorno. Ambos também identificados como elementos [COHEN, 2003].

\subsubsection{Camada de descrição}

A camada de descrição é responsável por definir a linguagem a ser utilizada no processo de publicação e descoberta de serviços, definindo como os Web Services são acessados e combinados.

Para cumprir esses objetivos, esta camada define a linguagem WSDL, responsável por manipular a semântica das interfaces, enquanto o RDF (Resource Description Framework) é utilizado para criar ontologias para categorizar mensagens e serviços.

A WSDL é uma gramática em XML, que tem o objetivo de descrever um Web Service como uma coleção de pontos de acesso, também denominados endpoints. Como ponto de acesso entende-se o destino final de uma mensagem SOAP, identificados por uma URL.

Assim, pode-se concluir que a WSDL é utilizada para definir, de forma abstrata, a interface de acesso de um Web Service concreto, descrevendo suas operações e métodos [MARZULLO, 2009].

Os elementos que compõem a estrutura básica da WSDL se encontram divididos em duas categorias: Abstratos e concretos. Os primeiros estão relacionados às mensagens, referindo-se ao conteúdo que é independente dos detalhes de implementação, enquanto o segundo grupo refere-se a informações de localização e detalhes de acesso dos serviços [TAVARES, 2009].

Tais elementos são inseridos em uma tag raiz < definitions $>$, que age como um container para a descrição do serviço. É neste elemento que se encontra grande parte do espaço de nomes, sendo o padrão definido pelo atributo targetNamespace.

Há ainda a possibilidade da existência de elementos import, que permitem separar os elementos de um serviço dentro de um documento independente, promovendo a modularização do documento, semelhante o que ocorre nas linguagens Java e C\# [MARZULLO, 2009].

\section{Elementos abstratos}

Este grupo é composto de três elementos principais e seu subelementos [MARZULLO, 2009], [TAVARES, 2009]: 
- types: Este elemento é utilizado para definir os tipos de dados que estarão presentes na tag $<$ message $>$, usando para isso a sintaxe de schemas apresentada na seção 3.3.1.

- message: Este elemento encapsula os dados, métodos e parâmetros, que são trocados em uma comunicação entre Web Services. Tais mensagens são compostas por um ou mais elementos part, que representa as partes de uma mensagem.

- portType: Este elemento define o local em que um Web Service está hospedado e as operações disponibilizadas por ele. As operações são disponibilizadas através do elemento operation, que possui os elementos input e output.

As operações, que representam serviços executados pelo Web Service, obedecem a padrões estabelecidos de envio e respostas a saber:

- Via-Única: Neste padrão o cliente envia uma mensagem e não aguarda resposta do serviço, sendo assim, somente o elemento input deve ser utilizado.

- Requisição-Resposta: O cliente envia uma solicitação ao serviço e aguarda uma resposta. Desta forma, deve-se utilizar os elementos input e output, sendo que aquele deverá aparecer antes deste na mensagem.

- Solicitação-Resposta: Ao contrário do padrão anterior, neste o serviço realiza uma solicitação e aguarda uma resposta do cliente. Neste padrão, o elemento output deverá ser inserido antes do elemento input.

- Notificação: Semelhante ao padrão de via-única, no entanto, em uma notificação, o serviço envia uma mensagem ao cliente e não aguarda por resposta. Desta forma, somente o elemento output deverá estar presente na mensagem.

\section{Elementos concretos}

Este grupo é composto por dois elementos:

- binding: Define o formato da mensagem e o protocolo de comunicação suportado. Os valores possíveis são: HTTP, SOAP e MIME.

- service: Especifica o serviço exposto, sendo compostos por um ou mais elementos port, que descrevem pontos de acesso. É possível ainda que o elemento service contenha um elemento documentation, que permite acrescentar informações sobre o ponto de acesso disponibilizado.

\subsubsection{Camada de descoberta}

Atualmente são utilizadas duas maneiras distintas para vincular um cliente a um $W e b$ Service. A primeira, denominada estática, é realizada em tempo de projeto, onde a 
interface e a descrição de um serviço encontram-se armazenadas localmente, excluindo a necessidade de um mecanismo de busca e descoberta.

Por outro lado, a vinculação dinâmica ocorre em tempo de execução, de forma automatizada, sendo que a aplicação cliente realiza a busca por um dado serviço e, posteriormente, realiza a vinculação de forma dinâmica, utilizando para isso a interface previamente publicada pelo provedor de serviços [ENDREI et al., 2004].

Apesar da preferência dos usuários pela busca manual, através de mecanismos de busca e portais especializados, caracterizando a vinculação estática, há uma necessidade crescente da automatização do processo de busca e descoberta de Web Services, cabendo ao UDDI prover tal solução [LU et al., 2007].

O UDDI é uma iniciativa da indústria para criar uma arquitetura livre de plataforma e capaz de propagar de forma eficiente seus serviços [MARZULLO, 2009].

O UDDI utiliza um conjunto de três registros que são responsáveis por dividir as informações e organizá-las em grupos semânticos, denominados páginas brancas, amarelas e verdes. Tal fato reflete a concretização do padrão modelado para as arquiteturas orientadas a serviços, descritas no Capítulo 2.

Para concretizar tal estrutura, o UDDI é formado por três entidades essenciais [MARZULLO, 2009], [ENDREI et al., 2004]:

- businessService: Representa uma classificação, a fim de descrever um conjunto de serviços oferecidos pela organização.

- businessEntity: Representa as páginas brancas definidas na SOA, contendo informações sobre o negócio, incluindo contato, categorização, descrição de relacionamentos com outros negócios.

Os relacionamentos com outros negócios, ou seja, com outras entidades businessEntity, deverá utilizar uma entidade publisherAssertion.

- bindingTemplates: Representam as páginas verdes, contendo informações técnicas e pontos de acesso dos serviços. Essa entidade está relacionada diretamente com os elementos port descritos na WSDL.

Cada businessService pode possuir uma ou mais entidades bindingTemplates.

- tModel: Representa as páginas amarelas, descrevendo a especificação de um serviço a ser invocado. Tal entidade relaciona-se diretamente com o elemento portType da WSDL.

Cada entidade bindingTemplate pode conter um ou mais elementos tModel.

Juntamente com a estrutura anteriormente descrita, é definida uma API (Application Programming Interface) de busca, responsável por fornecer métodos para publicação e 
obtenção das informações armazenadas. Tal interface está dividida em dois níveis: Métodos de localização que possuem o padrão find_xxx, e métodos de obtenção, representados pelo padrão get_xxx.

Os métodos de localização procuram no registro o serviço e retornam o resultado qualificado, enquanto os métodos de obtenção permitem analisar os resultados, obtendo detalhes específicos de cada entidade [MARZULLO, 2009].

Há ainda uma API de publicação, que permite registrar novos serviços e atualizar os existentes. No entanto, para a localização e obtenção de informações sobre os serviços, não há a necessidade de autenticação do cliente, situação oposta à apresentada na publicação, em que a autenticação é necessária, exigindo um cadastramento prévio do provedor [MARZULLO, 2009].

Essa diferença de concepção influencia no protocolo de transporte utilizado. Para a localização e obtenção pode-se utilizar protocolos não seguros, como HTTP, enquanto que para o serviço de publicação deve-se dar prioridade para os protocolos que incluem camadas de segurança, como o HTTPS (HyperText Transfer Protocol Secure) [ERL, 2009].

\subsubsection{Demais camadas}

As camadas de transporte, mensagens, descrição e descoberta, descrevem o comportamento geral dos Web Services, todavia, como citado no início do capítulo, faz-se necessário definir outras camadas a fim de prover subsídios para itens como a qualidade de serviço, segurança e confiabilidade entre outros. Sendo assim, faz-se necessário descrevê-las.

\section{Camada de transações}

Esta camada é responsável por prover uma infra-estrutura de execução com protocolos de coordenação, a fim de permitir a orquestração de Web Services de maneira transparente.

No processo de orquestração, um conjunto de Web Services são ativados em conjunto, a fim de fornecer um serviço. Para tal, faz-se necessário um contexto de execução coordenado, que permita a propagação de atividade de um Web Service para outro.

Nesse contexto encontra-se o WS-Coordination, que constitui um framework para a coordenação e orquestração de Web Services. Todavia, para permitir a concretização desse ambiente, faz-se necessário mecanismos para controle de transação atômicas, que são obtidos através do padrão WS-AtomicTransaction, que define o commit de duas fases, em que os resultados obtidos pelos participantes registrados em uma transação, devem ser ou consistentes ou inconsistentes. Tal padrão garante ainda que todos os participantes sejam notificados do resultado obtido [MARZULLO, 2009]. 


\section{Camada de segurança}

Questões relacionadas à segurança estão presentes em todos os tipos de sistemas desenvolvidos, uma vez que a sua falta pode expor as regras de negócios de uma organização, permitindo, em alguns casos, que elas sejam alteradas, o que pode causar grandes prejuízos.

Essa situação torna-se mais crítica em sistemas de e-business, uma vez que estes são, na maioria dos casos, disponibilizados publicamente em uma rede cujas medidas de segurança são mínimas ou inexistentes, cabendo a cada organização o provimento da mesma se desejado [ENDREI et al., 2004].

Desta forma, no contexto de Web Services, o padrão WS-Security permite promover meios de integridade, confidencialidade e não repúdio entre outros requisitos de segurança. Todavia, é importante destacar que as questões relacionadas à segurança precisam ser tratadas também nas demais camadas da pilha de protocolos TCP/IP, como a utilização de VPNs (Virtual Private Networks) e protocolos seguros como HTTPS.

\section{Camada de confiabilidade}

O principal padrão utilizado nesta camada é o WS-ReliableMessaging. Esse padrão é utilizado como um header SOAP e define um protocolo de garantia de serviço, que especifica a completa execução de um processo de negócio como obrigatório.

Sendo assim, uma vez que uma mensagem é enviada, o destinatário deve acusar seu recebimento por um acknowledgement, ou enviar uma notificação de falha em caso de erros. Todavia, o WS-ReliableMessaging também provê mecanismos de retransmissão, caso a mensagem enviada não seja confirmada [MARZULLO, 2009], [TAVARES, 2009].

\section{Camada de processo de negócio}

Essa camada é responsável por compor Web Services, a fim de prover a implementação de um processo de negócio, como descrito na Seção 2.5. Assim, a camada de processo de negócio define os dados compartilhados entre serviços, os parceiros envolvidos no processo e as relações existentes entre eles [TAVARES, 2009].

Para esse processo destaca-se a linguagem BPEL (Business Process Execution Language), também conhecida como WS-BPEL ou BPEL4WS.

\section{Camada de gerenciamento}

Finalmente, a camada de gerenciamento é responsável por gerenciar o desempenho, a taxa de utilização, a disponibilidade dos Web Services, definindo para isso o padrão WS-Management, que provê, para os sistemas, formas de acesso comum as informações de infra-estrutura, permitindo que as mesmas sejam alteradas e atualizadas. 


\subsection{Considerações finais}

Este capítulo apresentou os Web Services como uma alternativa para a implementação de arquiteturas orientadas a serviços, sendo atualmente a mais utilizada.

Destacou-se que essa tecnologia se encontra organizada em camadas, tendo a linguagem XML como tecnologia de base. Sendo assim, é possível a um provedor desenvolver um serviço e utilizar a linguagem WSDL para publicá-lo em um repositório universal, denominado UDDI, cuja comunicação é realizada através do protocolo SOAP.

Esse protocolo é utilizado como camada de mensagens para a tecnologia, desta forma, toda troca de informação realizada entre componentes distribuídos deve utilizar o SOAP, sendo este encapsulado pelo protocolo HTTP, que apesar de ser um protocolo de aplicação da pilha TCP/IP, comporta-se, nos Web Services, como uma camada de transporte garantindo a transmissão fim-a-fim.

Para que uma solução implementada através de Web Services seja bem dimensionada, incluindo a arquitetura de hardware e a comunicação disponibilizada, faz-se necessário considerá-la no cenário global de execução, uma vez que é cada vez mais frequente a utilização de máquinas virtuais destinadas a suportar a execução dos sistemas operacionais e servidores de aplicação onde os Web Services são implantados. A virtualização, responsável pela consolidação de servidores, possui características de desempenho que são direta ou indiretamente refletidas nos tempos de execuções das aplicações desenvolvidas com Web Services e, também, nos consumos de recursos como, por exemplo, a memória DRAM.

Sendo assim, o capítulo a seguir apresentará a virtualização de sistemas operacionais, descrevendo, entre outras coisas, as várias técnicas e as características envolvidas ao virtualizar CPU, memória e dispositivos de entrada e saída. 


\section{Capítulo \\ 4 \\ Virtualização}

\subsection{Considerações iniciais}

A virtualização de sistemas operacionais pode ser entendida como a técnica de permitir que múltiplos sistemas operacionais sejam executados, como convidados, em um mesmo hardware com isolamento total entre eles, compartilhando recursos físicos como CPU, memória e dispositivos de entrada e saída [TROYER, 2007].

Nessa solução, é implantada, acima do hardware, uma camada de virtualização, também denominada sistema operacional hospedeiro, que é responsável por abstrair o hardware através da criação de gerenciadores de máquinas virtuais, fornecendo, assim, hardwares padronizados, permitindo que outros sistemas operacionais sejam instalados sobre ele.

A virtualização teve seu início ainda na década de 70 quando a IBM criou o sistema $\mathrm{VM} / 370^{\circledR}$, sendo composto de um monitor de máquina virtual, instalado diretamente sobre o hardware e implementando multiprogramação. Esse sistema fornecia máquinas virtuais como cópias reais do hardware existente, permitindo que múltiplos sistemas operacionais fossem executados como, por exemplo, os sistemas descendentes do OS/360 [TANENBAUM, 2009]. No entanto, com o avanço da computação e o barateamento do hardware, a virtualização deixou de ser uma tecnologia de destaque até 1998, quando a empresa VMWare ${ }^{\circledR}$ lançou o processo de virtualização para plataformas X86, até então considerada impossível [TROYER, 2007].

Até essa época, muitas empresas iniciaram a implantação de sistemas em máquinas servidoras independentes, o que ocasionou um crescimento exagerado no parque computacional à medida que novos sistemas foram surgindo. Ao implantar diferentes soluções como servidores Web, FTP (File Transfer Protocol) e correio eletrônico em diferentes máquinas físicas, os administradores garantiam, de certa forma, a tolerância a falhas, uma 
vez que as maioria das falhas são ocasionadas por problemas de software e não de hardware. Assim, apenas um serviço se tornaria indisponível ao invés de um conjunto deles [TANENBAUM, 2009].

Assim, na década de 90, a virtualização, através da consolidação de servidores, retornou como uma das principais soluções para os problemas de crescimento do parque computacional e da existência de ambientes mistos, onde diferentes sistemas operacionais são executados. O crescimento do parque computacional acarreta em consumo elevado de energia e, também, em gastos elevados com equipamentos e espaços de armazenamento dos servidores, além de gerar problemas de emissão de gases, contribuindo para o aquecimento global [CHIANG, 2012].

Adicionalmente, a virtualização se apresentou como uma das soluções da continuidade do negócio, uma vez que sistemas operacionais antigos podem ser executados na mesma estrutura que os novos, permitindo que softwares legados, que necessitam de tais sistemas, continuem em produção sem a necessidade de reimplementação. Tal fato se origina na característica inerente aos sistemas comerciais que possuem "ciclos de vida" elevados, enquanto sistemas operacionais e hardwares apresentam ciclos menores [TANENBAUM, 2009].

Outra vantagem apresentada pelo processo de virtualização, em relação à continuidade do negócio, refere-se à recuperação de desastres, uma vez que se torna possível a obtenção de um snapshot do sistema operacional convidado em execução, permitindo que o mesmo seja transportado para um segundo sistema operacional hospedeiro, em caso de problema com o primeiro.

Nesse contexto, dois tipos de virtualizadores se destacam. No primeiro, denominado hosted ou virtualizador do tipo 2, a camada de virtualização é instalada sobre um sistema operacional como uma aplicação. Assim, há uma clara separação entre o sistema operacional que suporta a plataforma de virtualização e virtualizador, sendo que aquele permite, inclusive, a execução de aplicações. Por outro lado, na segunda abordagem, denominada hypervisor bare-metal ou virtualizador do tipo 1, a camada de virtualização é instalada diretamente sobre o hardware, permitindo, assim, que o hypervisor tenha acesso direto à plataforma X86 [TROYER, 2007].

Como exemplo de plataformas do tipo 2 é possível destacar: VMWare server ${ }^{\circledR}$, VMWare player ${ }^{\circledR}$, Oracle Virtual Box ${ }^{\circledR}$ e Parallels ${ }^{\circledR}$, já como exemplo de hypervisores bare-metal destacam-se: VMWare ESX $^{\circledR}$ e ESXi ${ }^{\circledR}$, Microsoft Hyper-V ${ }^{\circledR}$ e o projeto Xen ${ }^{\circledR}$.

\subsection{Processadores}

A virtualização de processadores, juntamente com a virtualização de memória e de dispositivos de entrada e saída, constituem os principais desafios no processo de executar 
sistemas operacionais sobre uma máquina virtual baseada na tecnologia X86, uma vez que sistemas operacionais são projetados e desenvolvidos para executar diretamente sobre o hardware em um nível privilegiado.

Na arquitetura X86 há quatro níveis de privilégio, como pode ser observado na Figura 4.1. O anel zero corresponde ao nível de maior privilégio, onde são executados os sistemas operacionais. Nesse nível, o acesso ao hardware é total, incluindo o controle das interrupções, acesso à memória e aos dispositivos de entrada e saída. As aplicações de usuário, por outro lado, são executadas no anel três, que corresponde ao nível de menor prioridade, onde o acesso ao hardware deve ser realizado via o sistema operacional instalado no anel zero.

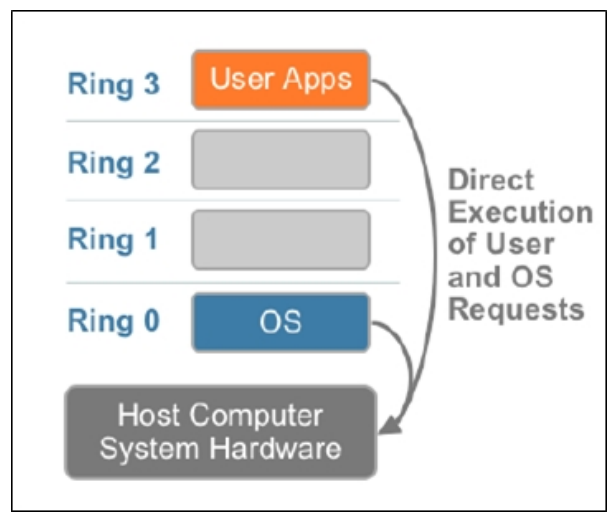

Figura 4.1: Níveis de privilégio da plataforma X86 [TROYER, 2007].

Ao considerar ambientes virtualizados do tipo bare-metal, a plataforma de virtualização é executada no anel zero, enquanto o sistema operacional convidado é executado no anel um. Assim, no momento em que o sistema operacional convidado tenta acessar o hardware, via uma instrução sensível, a instrução é ignorada, uma vez que partiu de um nível não privilegiado [TANENBAUM, 2009].

De acordo com [TANENBAUM, 2009], as instruções sensíveis são aquelas que devem ser executadas com nível de privilégio elevado, ou seja, no anel zero, enquanto instruções privilegiadas são aquelas capturadas por uma armadilha do hardware e enviadas ao software executando no nível zero para que sejam tratadas. Assim, no processo de virtualização, todas as instruções sensíveis deveriam ser privilegiadas, o que não ocorre na arquitetura X86 original. Por esse motivo, as instruções sensíveis, enviadas pelo sistema operacional convidado, são ignoradas, uma vez que esse é o comportamento padrão da arquitetura X86 quando tais instruções não partem do anel zero.

A partir desse contexto, três diferentes técnicas surgiram para tratar esse problema: Virtualização total com tradução binária, virtualização auxiliada por sistema operacional ou paravirtualização e virtualização assistida por hardware [TROYER, 2006]. 


\subsubsection{Virtualização através de tradução binária}

Nessa modalidade de virtualização não há a necessidade de alteração do sistema operacional convidado, uma vez que as instruções sensíveis são substituídas por instruções modificadas que produzem o efeito pretendido no hardware utilizado [TANENBAUM, 2009].

A esse processo de substituição das instruções dá-se o nome de tradução binária, sendo realizada ou de forma estática ou dinâmica. A forma estática é mais complexa de ser executada, uma vez que algumas partes do código executável podem ser acessadas apenas através de trechos indiretos de código, diferentemente da forma dinâmica, em que o código é analisado durante a sua carga.

A tradução binária é caracterizada pela substituição de blocos básicos de código por instruções que desviarão o fluxo de execução para o hypervisor que, após executar a instrução corretamente, manterá os resultados em cache para futura necessidade [CHIANG, 2012], como pode ser visualizado na Figura 4.2. Nesse caso, blocos básicos são aqueles em que nenhuma instrução interna é destino de uma instrução de salto ou aqueles onde apenas a sua última instrução é responsável por um salto, iniciando outro bloco de código.

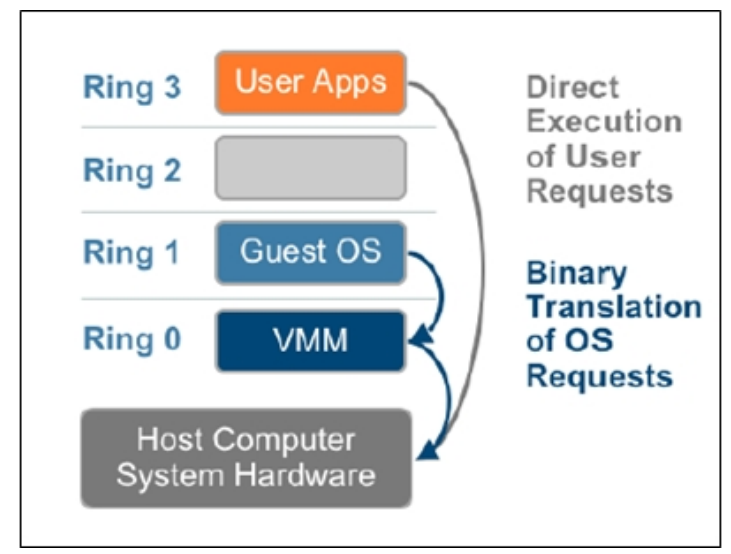

Figura 4.2: Virtualização total através de tradução binária [TROYER, 2007].

Como pode ser observado na Figura 4.2, nesse tipo de virtualização, também denominada virtualização total, as instruções em nível de usuário são executadas diretamente sobre o hardware, não sendo necessária nenhuma tradução pela camada de virtualização. Essa iniciativa visa acelerar o desempenho das aplicações que não necessitam de acesso à instruções sensíveis [TROYER, 2007].

\subsubsection{Virtualização auxiliada por sistema operacional ou para- virtualização}

A paravirtualização, como é mais conhecida a virtualização auxiliada por sistema operacional, tem como objetivo eliminar a tradução binária, retirando todas as instruções 
sensíveis do kernel do sistema operacional convidado, transformando-as em chamadas ao virtualizador, denominadas hypercalls [TANENBAUM, 2009], como pode ser visualizado na Figura 4.3.

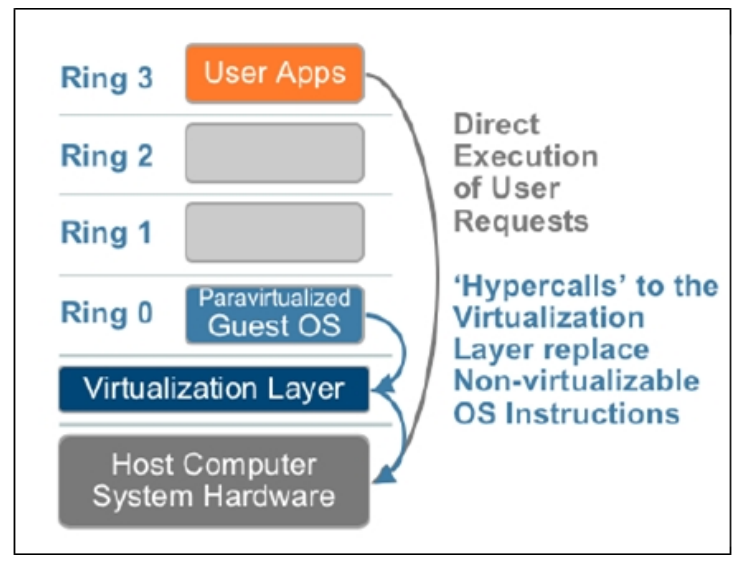

Figura 4.3: Abordagem de virtualização através da paravirtualização [TROYER, 2007].

Como é possível observar na Figura 4.3, ao implementar as hypercalls, o sistema operacional convidado passa a "conhecer" o fato de estar executando sobre um outro sistema operacional e que não executa diretamente sobre o anel zero [TROYER, 2006]. Assim, é possível concluir que sistemas operacionais de "código fechado", como o Microsoft Windows ${ }^{\circledR}$, não podem ser executados sobre tais plataformas, uma vez que na paravirtualização, o núcleo do sistema convidado deve ser adaptado.

Uma vez que o sistema operacional convidado realiza chamadas para o sistema operacional hospeiro, também denominado microkernel, é natural que este forneça APIs ( $A p$ plication Programming Interfaces) para aquele, elevando, assim, o nível de acoplamento entre ambos.

Desta forma, uma vez que o objetivo da paravirtualização é ampliar o desempenho dos sistemas operacionais convidados, retirando a sobrecarga da tradução binária e das armadilhas de hardware, muitos hypervisores, como VMWare ESX ${ }^{\circledR}$, utilizam-se de técnicas de paravirtualização para ampliar o desempenho de alguns módulos, como ocorre com o driver de dispositivo de rede Vmxnet, que compartilha estruturas de dados com o hypervisor. Esse driver é instalado através dos kits de integração normalmente disponibilizados pelos fabricantes de plataformas de virtualização. No contexto da Microsoft, drivers implantados utilizando técnicas de paravirtualização são denominado sintéticos [CHINNI; HIREMANE, 2013].

\subsubsection{Virtualização assistida por hardware}

Com o crescimento da utilização da virtualização, os fabricantes de processadores começaram a inserir, no hardware, recursos de virtualização, permitindo tratar a falha 
existente na plataforma X86, em que instruções sensíveis, executadas fora do anel zero, são ignoradas. Assim, surgiram as tecnologias Intel Virtualization Tecnology ${ }^{\circledR}$, denominada VT-X, e $A M D$-Virtualization ${ }^{\circledR}$, denominada AMD-V [TROYER, 2007]. Tais tecnologias criam um nível de privilégio abaixo do anel zero, onde é executado o hypervisor. Assim, o sistema operacional convidado é executado no anel zero, conforme pode ser observado na Figura 4.4.

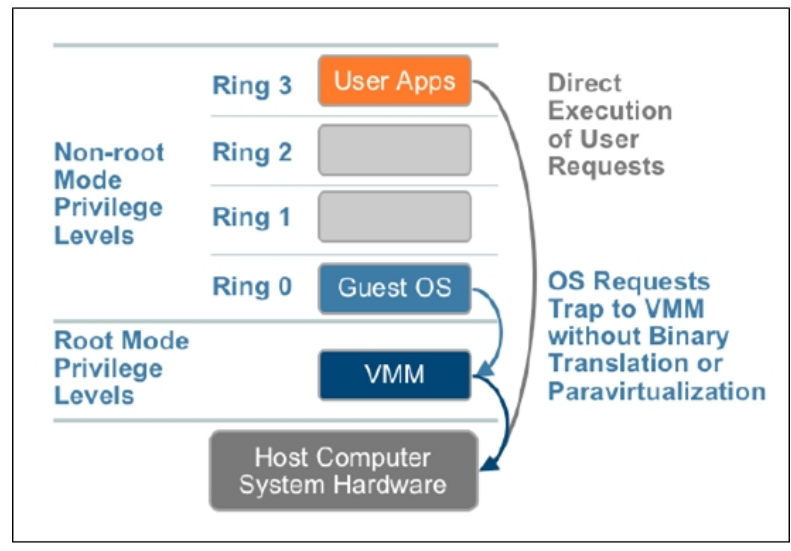

Figura 4.4: Abordagem utilizando virtualização assistida por hardware [TROYER, 2007].

Ao analisar a Figura 4.4, percebe-se que uma vez que o sistema operacional convidado é executado no nível de maior privilégio, as suas instruções sensíveis não serão mais ignoradas pelo hardware, que gera uma armadilha, armazenando seu conteúdo nas estruturas de dados compartilhadas com o virtualizador, denominadas pelos fabricantes Intel ${ }^{\circledR}$ e $\mathrm{AMD}^{\circledR}$, respectivamente, Virtual Machine Control Structures e Virtual Machine Control Blocks. Ao armazenar seus estados nessas estruturas, o controle é direcionado para o virtualizador, que trata as chamadas conforme necessário, eliminando, assim, a necessidade de tradução binária e paravirtualização.

\subsection{Memória}

Em ambientes não virtualizados, um sistema operacional fornece, para cada aplicação em execução, um conjunto de endereços virtuais lineares e contíguos. Tais endereços possuem a mesma base e limite para todas as aplicações consideradas e são divididos em páginas, sendo, então, convertidos, com o auxílio da MMU (Memory Management Unit) disposibilizada pelo hardware, em endereços físicos de memória, que são divididos em molduras de páginas de mesmo tamanho da página virtual, onde os dados estão realmente localizados [TANENBAUM, 2009]. Esse cenário pode ser visualizado na Figura 4.5.a.

Esse mesmo processo também é implementado pelos hypervisores, que disponibilizam, para os sistemas operacionais convidados, endereçamentos virtuais como se tais sistemas 


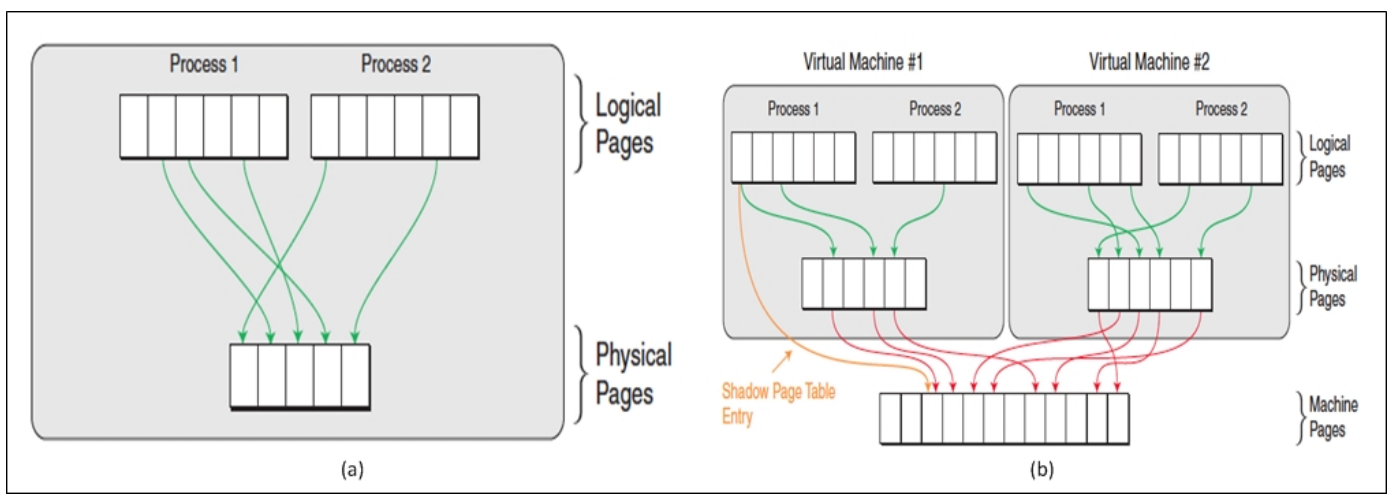

Figura 4.5: Diagrama do sistema de gerenciamento de memória [BHATIA, 2009]: a) sistemas nativos e b) sistemas virtualizados.

operacionais fossem aplicações convencionais. Posteriormente, esses endereços virtuais são mapeados em endereços físicos [GUO, 2011].

Asssim, pode-se definir três categorias de endereços nas plataformas virtualizadas:

- Memória virtual do convidado: Refere-se à memória virtual disponibilizada pelo SO convidado para as aplicações;

- Memória física do convidado: Refere-se à memória virtual do hypervisor disponibilizada para o SO convidado, que a trata como memória física;

- Memória física do hospedeiro: Refere-se à memória fisicamente instalada no hardware e disponibilizada para o hypervisor.

Desta forma, em ambientes virtualizados, existem dois níveis de mapeamento de páginas virtuais em páginas físicas, como pode ser observado na Figura 4.5.b. O primeiro nível corresponde à tradução da memória virtual do convidado para o endereçamento físico do convidado. Já o segundo nível corresponde à conversão do endereçamento físico do convidado para o endereçamento físico do hypervisor.

Uma vez que o sistema operacional convidado não tem "conhecimento" sobre a existência do virtualizador em sua base, ao executar operações de mapeamento de memória, ele realiza uma chamada sensível de manipulação da MMU e, também, da TLB (Translation Lookaside Buffer), que auxilia no ganho de desempenho nas operações de conversão de endereços. Assim, é necessário que essa operação seja capturada por uma armadilha de hardware e, posteriormente, enviada ao hypervisor para a substituição do endereço virtual do convidado pelo endereço físico do convidado, permitindo, assim, a correta resolução pelo sistema operacional convidado. No entanto, essa operação gera uma grande sobrecarga, reduzindo o desempenho das plataformas virtualizadas.

Nesse contexto, desenvolveu-se a solução SPT (Shadow Page Tables), utilizada em sistemas de virtualização total implementados com tradução binária e execução direta. 
Essa solução cria uma tabela extra, no contexto do hypervisor, que mapeia diretamente os endereços virtuais do convidado para endereços físicos do hospedeiro. Assim, quando uma solicitação de tradução de endereços é iniciada pelo sistema operacional convidado, apenas um nível de tradução é necessário [GUO, 2011].

No entanto, ao adotar a solução SPT, faz-se necessário que as tabelas extras estejam coerentes com as tabelas de mapeamento do convidado e do hospedeiro, porém, algumas operações de manipulação de tabela, no âmbito do convidado, não são sensíveis, e por isso não são capturadas pelas armadilhas do hardware. Assim, é necessário utilizar recursos que tornem sensíveis todas as operações realizadas nessa tabela. Um opção é tornar a tabela de páginas do convidado protegida contra escrita pelo hypervisor. Desta forma, todas as operações de escrita pelo convidado resultarão em uma falta de página, fazendo com que o controle seja alterado para a camada de virtualização, que emulará a operação necessária [DEVICES, 2008].

A partir da situação descrita, os fabricantes de hardware, especificamente a Intel $^{\circledR}$ e AMD ${ }^{\circledR}$, desenvolveram a terceira geração de suporte de hardware, disponibilizados nos processadores AMD Opteron ${ }^{\circledR}$ e Intel Xeon série $5500{ }^{\circledR}$. Entre os recursos disponibilizados se encontram o Intel EPT ${ }^{\circledR}$ (Extended Page Table) e AMD-V NPT ${ }^{\circledR}$ (Nested Page Tables) [DEVICES, 2008].

Ambos os recursos disponibilizam um segundo nível de tabelas de conversão de endereços em nível de hardware, fazendo com que o mapeamento do endereço virtual do convidado para o endereço físico do convidado seja realizado por um nível de tabelas e a conversão da tabela física do convidado para a tabela física do hypervisor seja realizada por um nível extra, eliminando a necessidade do hypervisor ter que interceptar todas as operações de manipulação de tabelas de páginas realizadas pelo sistema operacional convidado, uma vez que essas tabelas são sincronizadas pelo hardware, removendo, assim, toda a sobrecarga das SPTs. Atualmente, essa solução é utilizada pelos principais virtualizadores auxiliados por hardware, entre eles VMWare ESXi ${ }^{\circledR}$ e Microsoft Hyper- $\mathrm{V}^{\circledR}$.

Ampliando esse objetivo de aumentar o desempenho das plataformas virtualizadas, estabeleceu-se, também, a tecnologia denomiada large-pages ou super-pages. Nessa tecnologia os virtualizadores utilizam páginas de até $2 M B$, ao invés dos tradicionais $4 K B$, reduzindo, consideravelmente, o tamanho das tabelas de páginas, uma vez que um número menor de páginas são mapeadas [GUO, 2011].

Adicionalmente, ao ampliar em quinhentas vezes o tamanho das páginas e, consequentemente, das molduras de páginas, reduz-se as falhas de TLB e, também, o tempo de varredura, uma vez que a quantidade de entrada nessa tabela é reduzida na proporção direta em que o tamanho da página é ampliado.

É importante destacar que o virtualizador Hyper- ${ }^{\circledR}$ utiliza essa tecnologia mesmo quando o sistema operacional convidado utiliza apenas as páginas tradicionais de $4 \mathrm{~KB}$, diferentemente do VMWare $\mathrm{ESXi}^{\circledR}$, que habilita tal recurso à medida que o sistema 
operacional convidado também o faz.

\subsubsection{Recuperação de memória pelo hypervisor}

Ao desenvolver técnicas para otimizar o processo de alocação de memória pelo convidado, faz-se necessário, também, desenvolver métodos para a recuperação da memória pelo virtualizador, uma vez que, em ambientes virtualizados, é comum que a soma da quantidade de memória configurada para as máquinas virtuais seja superior à quantidade de memória física disponível, já que, em geral, os sistemas operacionais convidados não consomem toda a memória disponível simultâneamente.

Assim como o hardware não fornece interfaces para alocar e liberar memória, os gerenciadores de máquinas virtuais também não o fazem. Desta forma, é possível concluir que o processo de alocação e liberação de memória é inerente ao sistema operacional que manipula uma quantidade de memória física disponibilizada [GUO, 2011].

Nesse contexto, ao liberar páginas de memória, o sistema operacional convidado adiciona o seu índice na lista de páginas livres ou as retira da lista de páginas ocupadas, não enviando nenhuma informação para o hypervisor atualizar a sua tabela de páginas. Adicionalmente, é comum que o sistema operacional convidado não retire o mapeamento da página liberada, mantendo-a em cache/buffer, uma vez que, ao ser acessada novamente, será gerado apenas uma falta de página menor, ao invés de uma falta maior como ocorria se a página fosse enviada para o disco [ALVES, 2008].

Nesse contexto, quatro métodos devem ser destacados: compartilhamento transparente de páginas, Ballooning, compressão de memória e Swapping do Hypervisor.

\section{Compartilhamento transparente de páginas}

O compartilhamento transparente de páginas é uma técnica destinada a reduzir, através da eliminação de páginas duplicadas, a quantidade de molduras na memória física do hospedeiro. Em ambientes virtualizados, é comum a execução de máquinas virtuais com o mesmo sistema operacional convidado e, em alguns casos, as mesmas aplicações, proporcionando a existência de páginas com o mesmo conteúdo, mapeada na memória física do hypervisor [GUO, 2011; LARSON; CARBONE, 2009].

No entanto, comparar as páginas bit a bit elevaria significativamente o consumo de CPU, o que é indesejável. Assim, o hypervisor se utiliza de hashing para designar páginas potenciais para o compartilhamento. Sendo que, somente a partir da colisão do hashing, uma comparação bit a bit é realizada para evitar casos de falsos positivos. A partir do momento em que a igualdade das páginas candidatas é confirmada, apenas uma moldura de página permanece com o conteúdo da página. Adicionalmente, o hypervisor altera as tabelas de páginas dos sistemas convidados, cujas páginas foram remapeadas, para manter a coerência dos mapeamentos das memórias físicas dos convidados com a memória física 
do hypervisor.

Após o compartilhamento, caso um dos convidados altere o conteúdo da página, um mecanismo de cópia na escrita é ativado, fazendo com que a página seja novamente duplicada. Nesse contexto, é interessante observar que há uma sobrecarga imposta pelo compartilhamento se comparado ao cenário em que páginas não são compartilhadas.

Finalmente, é importante destacar que esse método deve ser evitado ao considerar ambientes de virtualização em que o recurso large-pages está ativado, uma vez que a comparação bit a bit, nesses casos, consome um tempo proibitivo, considerando que a plataforma já estará apresentando sobrecarga no sistema de memória [LARSON; CARBONE, 2009].

\section{Ballooning}

Diferentemente da técnica de compartilhamento transparente de páginas, a técnica ballooning recupera memória de um sistema operacional convidado em específico. Seu objetivo é transferir a "pressão" por memória DRAM do hypervidor para o sistema operacional convidado [GUO, 2011].

Essa técnica é realizada através da instalação de um pseudo-driver no núcleo do sistema operacional convidado, abrindo um ponto de comunicação entre o hypervisor e o sistema operacional convidado, uma vez que naturalmente, não há uma forma da plataforma de virtualização descobrir quais páginas estão realmente sendo ocupadas pelo convidado e quais estão sendo utilizadas como cache/buffer [GUO, 2011].

Ao necessitar de memória, o hypervisor "infla o balão" no interior do sistema operacional convidado, fazendo com que o mesmo aloque páginas, que inicialmente estavam no cache, para a aplicação balão, como pode ser visualizado na Figura 4.6.

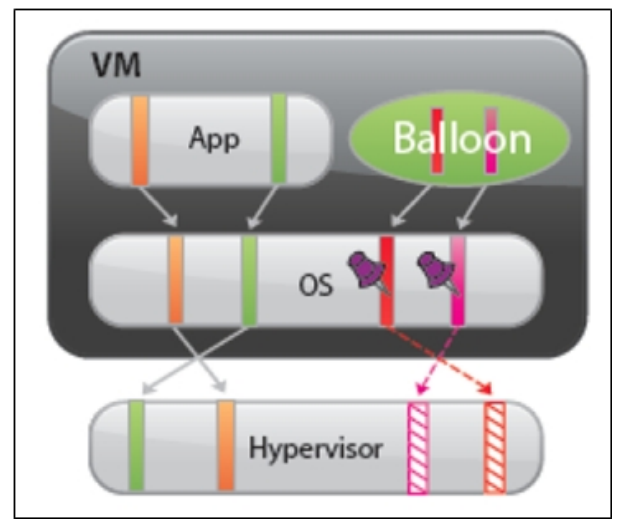

Figura 4.6: Abordagem Ballooning para recuperação de memória pelo hypervisor [GUO, 2011].

Ao analisar a Figura 4.6, é possível perceber que após alocada a memória permanece disponível para a aplicação balão, que não a utilizará para realizar tarefas. Assim, o hyper- 
visor poderá remover o mapeamento da sua tabela de páginas, considerando as molduras, anteriormente consumidas com dados de cache, disponíveis. À medida que a "pressão" por memória no contexto do sistema de virtualização é decrementada, o virtualizador comunica-se, através do driver, com a aplicação balão, solicitando que a mesma libere a memória anteriormente reservada, caracterizando a etapa de "desinflar".

Apesar de ser uma técnica de recuperação pontual de memória, o Ballooning deve ser aplicado com cautela, uma vez que ao "inflar" o balão no interior de sistemas operacionais convidados, cuja quantidade de páginas ativas seja muito elevada, pode-se ocasionar um grande número de falta de páginas maiores e, consequentemente, uma elevada taxa de swapping, levando o sistema operacional convidado ao estado de thrashing[TANENBAUM, 2009].

\section{Compressão de memória}

Diferentemente da técnica ballooning, que recupera memória em uma taxa lenta, a técnica de compressão é utilizada para recuperar memória rapidamente e evitar as operações de swapping no âmbito do hypervisor, uma vez que o acesso ao disco é extremamente mais lento que o tempo consumido ao comprimir páginas.

Ao necessitar disponibilizar memória DRAM para atender à novas requisições das máquinas virtuais, o hypervisor comprime um conjunto de páginas menos recentemente utilizadas, inserindo-as em um espaço na memória destinado à operações de cache. No entanto, para que espaços de memória sejam efetivamente liberados, é necessário que a taxa de compressão seja elevada. Assim, antes de comprimir uma página, o virtualizar analisa seu conteúdo para determinar a taxa de compressão, caso ela seja inferir ao limite estabelecido, a página é descartada e uma nova página é analisada [CHIANG, 2012].

Posteriormente, caso a página seja novamente acessada, ela deverá ser descomprimida e remapeada na memória, o que impõe uma sobrecarga de processamento ao sistema operacional convidado. No entanto, essa sobrecarga é inferior àquela apresentada pelo processo de swapping.

Adicionalmente, a memória destinada ao espaço de cache não é isolada dos demais endereços de memória do hypervisor, assim, ao necessitar de mais memória além daquela obtida com o processo de compressão, pode ser que as páginas em cache sejam enviadas para swap, no entanto, para isso, elas necessitam ser, primeiramente, descompactadas, o que eleva a sobrecargas da operação de swap. Após essa operação o virtualizador poderá atribuir a memória, anteriormente consumida com o espaço de cache, à uma máquina virtual [LARSON; CARBONE, 2009]. 


\section{Swapping do hypervisor}

O processo de swapping do hypervisor é semelhante ao processo convencional de swapping, a diferença reside no fato do sistema de virtualização selecionar páginas de uma máquina virtual específica para ser enviada ao disco, sendo tais páginas, inclusive, armazenadas em arquivos separados por máquinas virtuais. Apesar de ser uma técnica de obtenção de páginas rápida, ela somente deve ser utilizada após as demais apresentadas, devido à baixa velocidade de acesso ao disco e aos problemas ocasionados pela falta de informação do hypervisor com relação ao sistema operacional convidado [TROYER, 2007].

Essa falta de informação pode ocasionar inconvenientes no momento de seleção da páginas a ser enviada para o disco, uma vez que o hypervisor pode selecionar páginas cuja taxa de acesso é elevada, impondo, ao sistema operacional convidado, uma elevada sobrecarga gerada pelo processo de retirada da página do disco e remapeamento da tabela de página do virtualizador. Adicionalmente, é possível que uma página enviada para o disco pelo hypevisor seja, também, selecionada pelo sistema operacional convidado para participar do processo de swapping. Assim, faz-se necessário que o virtualizador retire a página do disco, realize o remapeamento em sua tabela de páginas, sendo que, logo em sequência, a página será novamente enviada para o disco, no entanto pelo sistema operacional convidado. Nesse contexto, a fim de minimizar tais problemas, alguns virtualizadores, como o VMWare ESXi ${ }^{\circledR}$, selecionam páginas a partir de números pseudo-aleatórios [GUO, 2011].

\subsection{Entrada/Saída}

A virtualização de dispositivos de entrada e saída são, de certa forma, mais simples de serem tratados, uma vez que as operações de entrada e saída iniciadas pelos sistemas operacionais virtualizados são executadas por instruções sensíveis e privilegiadas, permitindo que o hardware as capture via uma armadilha, transferindo o controle para o hypervisor [TANENBAUM, 2009].

Ao virtualizar os dispositivos de entrada e saída, o hypervisor fornece para os sistemas operacionais convidados dispositivos padronizados, permitindo que o hardware evolua sem, no entanto, afetar o sistema operacional convidado. Nesse cenário, cabe ao virtualizador converter as instruções padronizadas para o novo tipo de hardware instalado.

Nesse contexto, a virtualização das interfaces de rede são os dispositivos de entrada e saída de maior interesse para este projeto, uma vez que as plataformas de virtualização permitem que redes inteiras sejam estabelecidas apenas virtualmente, através da utilização de switches e interfaces virtuais, permitindo que a composição dos Web Services sejam realizadas apenas por essas interfaces. Nessa configuração, os virtualizadores não disponibilizam placas físicas para atender o sistema operacional convidado, sendo o tráfego encaminhado internamente na estrutura do hypervisor [TROYER, 2007]. 
No entanto, ao estabelecer, nas máquinas virtuais, interfaces de rede que se conectam à uma rede física, o hypervisor deve acionar o modo promíscuo na sua interface física de rede, uma vez que múltiplos endereços IP (Internet Protocol) são utilizados pelos sistemas operacionais convidados, bem como múltiplos endereços MAC (Media Access Control), o que obriga o hypervisor a coletar pacotes destinados a múltiplos endereços de rede [LARSON; CARBONE, 2009].

De maneira análoga ao presenciado na virtualização de processadores e memória, os fabricantes de hardware, também, implementaram recursos destinados à comunicação via interfaces de rede, uma vez que ao tratar os pacotes que entram e saem das interfaces, os hypervisores consomem recursos elevados de processamento com a classificação e roteamento dos pacotes, uma vez que cada máquina virtual possui uma interface virtual com buffers independentes, sendo interligadas à interface física por um switch virtual instanciado no hypervisor [CHINNI; HIREMANE, 2013].

Entre os principais recursos, destaca-se o VMDq (Virtual Machine Device Queues) desenvolvido pela Intel ${ }^{\circledR}$. Essa tecnologia disponibiliza múltiplas filas de algoritmos de ordenação em nível de hardware, como pode ser observado na Figura 4.7, retirando a sobrecarga de processamento.

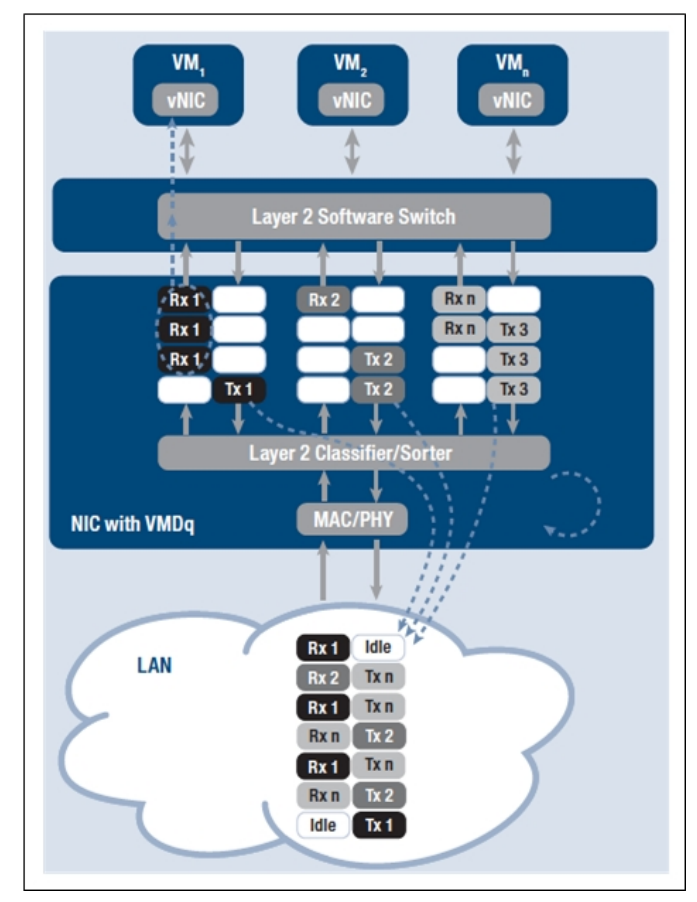

Figura 4.7: Comunicação via rede física utilizando a tecnologia VMDq [CHINNI; HIREMANE, 2013].

Ao receber fluxos de tráfego originados na rede e destinados às máquinas virtuais, o VMDq analisa os destinos dos pacotes, inserindo-os em filas separadas, destinadas à cada máquina virtual, para que sejam entregues pelo hypervisor diretamente. De ma- 
neira análoga, ao enviar dados, o virtualizador encaminha os pacotes das placas virtuais de cada sistema operacional convidado para as filas correspondentes no VMDq, que se responsabiliza por encaminhá-los através de uma política Round-Robin.

\subsection{Considerações finais}

Este capítulo abordou a virtualização de sistemas operacionais que, através da consolidação de servidores, apresenta-se como uma solução para as demandas atuais de serviços, reduzindo a quantidade de máquinas físicas instaladas nos parques computacionais das empresas e garantindo a continuidade do negócio.

Entre as características abordadas se destacou a virtualização de processadores, principalmente ao considerar ambientes de virtualização total, uma vez que essa técnica elimina a necessidade de modificações no núcleo do sistema operacional convidado. Nesse contexto, ressaltou-se as soluções baseadas em tradução binária e, principalmente, as auxiliadas por hardware, uma vez que ao implementar em hardware algumas características do processo de virtualização, elimina-se, ou se reduz consideravelmente, a sobrecarga ocasionada pela virtualização desenvolvida em software.

Neste contexto, ao tratar virtualização da memória, destacou-se as tecnologias de terceira geração baseada em hardware, principalmente as tabelas estendidas de páginas e as "large-pages". As tabelas estendidas permitem resolver, de forma eficiente, o mapeamento de endereços entre a memória virtual do convidado e a memória física do hypervisor, enquanto as "large-pages" reduzem o tempo de percorrer as tabelas de mapeamento de páginas e aumenta a taxa de acerto da TLB.

Desta forma, ao considerar as tecnologias de virtualização de processador e de memória baseadas em hardware, juntamente com o recurso VMDq, espera-se que as aplicações baseadas em SOA, executadas sobre essas tecnologias, possuam desempenho similar e, em alguns casos, superior ao obtido pelas aplicações executadas em ambientes não virtualizados. Assim, os dois próximos capítulos abordarão o desempenho dessas aplicações em plataformas virtualizadas baseadas em hypervisores largamente utilizados, principalmente ao tratar as operações de marshalling e unmarshalling de envelopes SOAP em redes totalmente virtualizadas. 


\section{Capítulo \\ 5 \\ Virtualização e o tempo de processamento}

\subsection{Considerações iniciais}

Com o objetivo de facilitar a compreensão dos resultados obtidos, este capítulo se encontra dividido em quatro seções. A primeira seção apresenta a metodologia utilizada nos experimentos e análises realizadas neste capítulo e no próximo. As duas seções seguintes tratam a influência da virtualização no tempo de processamento de aplicações distribuídas baseadas em SOA, sendo tratadas na primeira seção as aplicações do tipo CPU-bound e memory-intensive de carga baixa e na segunda as aplicações predominantemente memoryintensive de carga moderada e alta. Em ambas as seções as aplicações são executadas sobre o servidor de aplicação Glassfish. Assim, a quarta seção apresenta a influência da troca do servidor de aplicação, uma vez que as mesmas aplicações, utilizadas nas seções dois e três, são executadas sobre o servidor de aplicação JBoss.

\subsection{Metodologia}

Para avaliar a influência da virtualização no desempenho de aplicações baseadas em SOA, desenvolveu-se Web Services que representam aplicações CPU-bound, memory-intensive e network-bound, sendo os mesmos implantados em servidores de aplicação executados em diferentes plataformas de virtualização.

Complementarmente, desenvolveu-se um software cliente multithread responsável pelo consumo dos Web Services e pelas aferições dos tempos de resposta, adotando-se confiança de $95 \%$ e mantendo-se $10 \%$ das submissões como warm-up [JAIN, 1991]. 
Assim, para uma completa compreensão da metodologia adotada, nas subseções a seguir serão descritas as plataformas e as cargas de trabalho utilizadas.

\subsubsection{Plataformas}

Ao total foram estabelecidos dois conjuntos de três plataformas computacionais nas quais as aplicações SOA foram implantadas. Todas são formadas pela mesma configuração de hardware: dois processadores Intel Xeon ${ }^{\circledR}$ X5675, com seis núcleos de $3,07 \mathrm{GHz}, 12 \mathrm{MB}$ de cache e $64 \mathrm{~GB}$ de memória DRAM.

O primeiro conjunto considera a implantação dos Web Services em servidores de aplicação Oracle Glassfish ${ }^{\circledR}$, enquanto o segundo conjunto, por sua vez, utiliza o servidor de aplicação JBoss AS ${ }^{\circledR}$. A escolha do servidor de aplicação Oracle Glassfish ${ }^{\circledR}$, denominado a partir deste ponto apenas como Glassfish, foi motivada pelo fato dessa implementação ser a referência para a arquitetura JEE (Java Enterprise Edition) [MARZULLO, 2009]. Já a opção pelo servidor de aplicação JBoss $\mathrm{AS}^{\circledR}$, denominado a partir deste ponto apenas por JBoss, foi incentivada por essa plataforma ser amplamente utilizada em ambientes corporativos e por ser, de acordo com o grupo Gartner, um dos líderes no ramo de servidores de aplicação corporativos, como pode ser visualizado na Figura 5.1, que demonstra o quadrante mágico de 2011, desenvolvido anualmente por esse grupo.

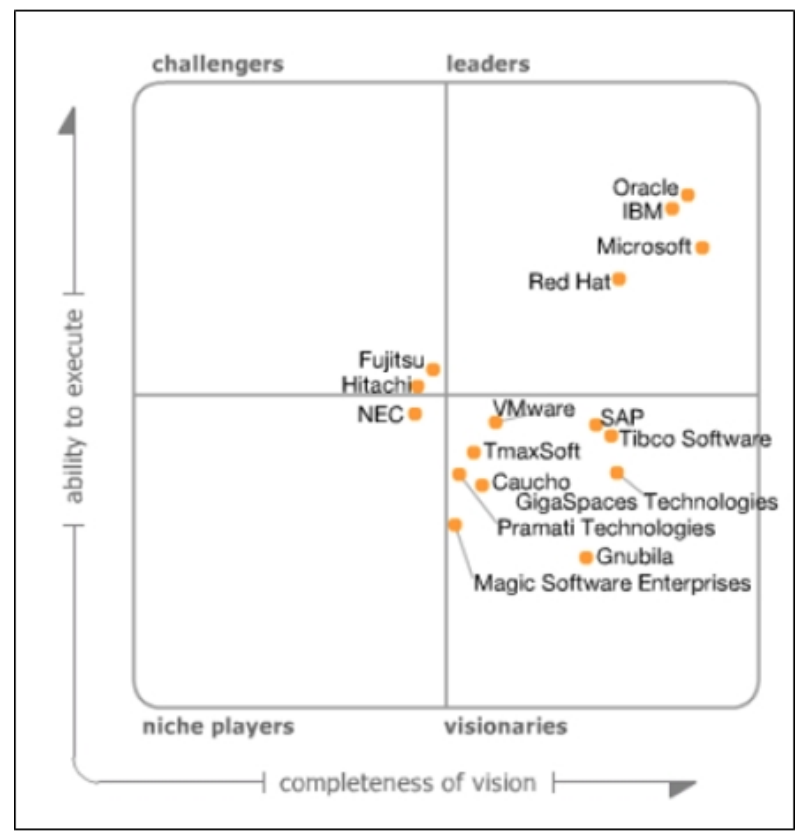

Figura 5.1: Quadrante mágico de 2011 desenvolvido pelo grupo Gartner que reporta os principais competidores no mercado de servidores de aplicação corporativo [PEZZINE et al., 2011].

Para ambos os conjuntos há três variações de plataformas, sendo a primeira de- 
nominada plataforma de referência, constituída pela instalação do sistema operacional GNU/Linux, denominado a partir deste momento apenas como Linux, diretamente sobre o hardware, não havendo, assim, a presença de gerenciadores de máquinas virtuais. As duas outras plataformas de cada conjunto utilizam os virtualizadores VMWare ESXi ${ }^{\circledR}$ e Microsoft Hyper-V 2008 R2 ${ }^{\circledR}$, denominados, a partir deste momento, apenas como VMWare e Hyper-V, respectivamente.

Assim como a escolha do servidor de aplicação JBoss, a escolha dos gerenciadores de virtualização foi baseada nas pesquisas realizadas pelo grupo Gartner, que demonstram ambos os virtualizadores como líderes de mercado na categoria de plataformas de virtualização X86, como pode ser observado na Figura 5.2. Adicionalmente, esses virtualizadores são amplamente utilizados no desenvolvimento de soluções de computação em nuvem do tipo IaaS (Infrastructure as a service) [BAUN et al., 2011]

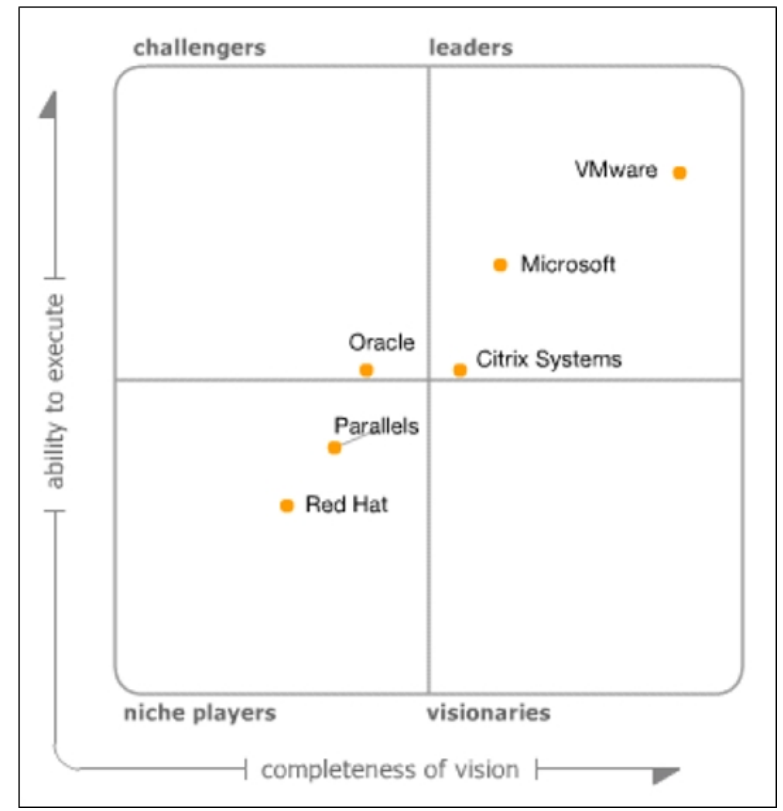

Figura 5.2: Quadrante mágico de 2012 desenvolvido pelo grupo Gartner que reporta os principais competidores no mercado de virtualizadores X86 [BITTMAN et al., 2012].

As plataformas de referência são denominadas PRef.G e PRef.J. PRef.G é caracterizada pela utilização do servidor de aplicação Glassfish, enquanto PRef.J pelo servidor de aplicação JBoss. De maneira análoga, as plataformas virtualizadas são denominadas, P1.G, P2.G, P1.J e P2.J. As plataformas P1.G e P2.G são compostas pelo servidor de aplicação Glassfish e os sistemas de virtualização VMWare e Hyper-V, repectivamente. Já as plataformas P1.J e P2.J são compostas pelo servidor de aplicação JBoss e os gerenciadores de máquinas virtuais VMWare e Hyper-V, respectivamente. 


\subsubsection{Carga de trabalho}

A partir da metodologia utilizada em [XIAO; CHEN; ZHANG, 2002; SHIMIZU et al., 2009; UENO; TATSUBORI, 2006; TEIXEIRA et al., 2011], onde algoritmos reais são utilizados para representar categorias de aplicações, optou-se por desenvolver três Web Services que, a partir de quatro operações, implementam os algoritmos selecionados nos trabalhos citados com o objetivo de representar as classes de aplicações CPU-bound, memory-intensive e network-intensive[ALVES et al., 2009].

1. Ordenação de vetores: O primeiro Web Service é composto por uma única operação que realiza a ordenação de vetores pelo método Quick Sort. De acordo com [XIAO; CHEN; ZHANG, 2002], os algoritmos de ordenação de vetores são importantes representantes das classes de aplicação $C P U$-bound e memory-intensive. A seleção desse algoritmo, especificamente, ocorreu devido à sua classificação como eficiente e por ser amplamente utilizado [ZIVIANI, 2011]. Como configuração, utilizou-se $100.000 \leq N \leq 500.000$, onde $N$ representa a quantidade de elementos a serem ordenados. Nesta configuração, à medida que o valor de $N$ aumenta, a aplicação deixa de ser classificada unicamente como CPU-bound se tornando, também, memory-intensive de carga baixa.

2. Multiplicação de matrizes: Este Web Service é composto de uma operação de multiplicação de matrizes quadradas, sendo que $500 \leq O \leq 2000$, onde $O$ representa a ordem das matrizes. Nesse tipo de aplicação, para matrizes de ordem pequena, a carga de trabalho é considerada $C P U$-bound e memory-intensive de carga moderada. No entanto, à medida que a ordem das matrizes é incrementada, a carga passa a ser considerada, além de $C P U$-bound, como memory-intensive de carga elevada.

3. Processamento de envelopes SOAP: Com o objetivo de aferir, separadamente, o impacto da virtualização no tempo de execução das aplicações e no tempo de codificação/decodificação de mensagens SOAP, este Web Service implementa duas operações que representam as tarefas de marshalling e unmarshalling, enviando e recebendo, respectivamente, envelopes SOAP cujos tamanhos, denotado por $S$, variam entre $2 M B$ e $10 M B$.

Adicionalmente, com o objetivo de avaliar o impacto da quantidade de elementos XML (eXtensible Markup Language) por mensagem SOAP, definiu-se que as mensagens possuiriam entre 10 e 1000 caracteres por elemento. Sendo assim, o tamanho do corpo do envelope SOAP permanece o mesmo, mas a quantidade de elementos XML a ser processada varia consideravelmente, uma vez que à medida que se aumenta a quantidade de caracteres por elemento, diminui-se a quantidade de elementos presentes na mensagem. 


\subsection{Organização da análise da Influência da virtuali- zação}

O estudo do impacto da virtualização, ao executar aplicações baseadas em SOA em ambientes virtualizados, foi dividido em duas etapas: A primeira trata a influência da virtualização, através da virtualização de processadores e memória, e dos servidores de aplicação nos tempos de resposta das aplicações $C P U$-bound e memory-intensive, enquanto a segunda, abordada no próximo capítulo, refere-se à influência da virtualização nos tempos de resposta ao processar mensagens SOAP, considerando, não somente a virtualização de processadores e memória, mas, também, dos dispositivos de entrada e saída.

Adicionalmente, como medida de comparação, utilizou-se a perda de desempenho obtida através da Equação 5.1, onde $t r_{v}$ é o tempo médio de resposta obtido por uma plataforma virtualizada e $t r_{r}$ é o tempo médio de resposta da plataforma de referência.

$$
P D=\frac{t r_{v}}{t r_{r}}
$$

\subsection{Aplicações $C P U$-Bound e memory-intensive de carga baixa}

Ao executar aplicações predominantemente $C P U$-bound e memory-intensive de carga baixa, representada pelo Web Service de ordenação de vetores, percebe-se que para uma pequena ocupação dos processadores disponibilizados, em torno de $25 \%$, as três plataformas, PRef.G, P1.G e P2.G, apresentam desempenho similar, conforme pode ser observado no gráfico da Figura 5.3.

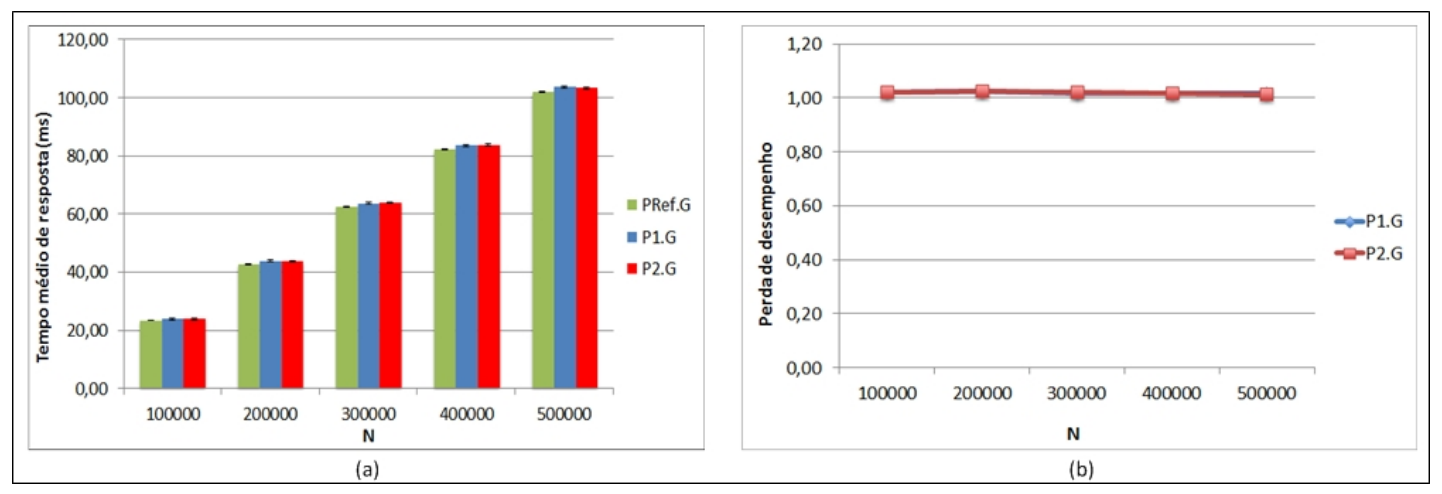

Figura 5.3: Desempenho obtido pelas aplicações $C P U$-bound e memory-intensive de carga baixa ao serem executadas sobre o servidor de aplicação Glassfish com $25 \%$ de utilização dos processadores: a) Tempo médio de resposta e b) Perda de desempenho.

Ao observar a figura 5.3.a, é possível perceber que houve a sobreposição das médias 
e intervalos de confiança para todos os valores de $\mathrm{N}$ analisados, indicando, assim, que a influência da virtualização no desempenho de aplicações baseadas em SOA, nesse cenário, é irrelevante. Isso ocorre devido à relação entre o tempo gasto no processamento da ordenação e o tempo de alocação de memória DRAM.

Ao executar as submissões de ordenação com $N=100.000$, é alocado, aproximadamente, 58 MB de memória DRAM, sendo que para cada iteração de requisição para o $W e b$ Service é gasto $390 \mathrm{~KB}$ de memória DRAM com o vetor a ser ordenado. Desta forma, a partir da tabela 5.1, é possível perceber que para alocar $50 \mathrm{MB}$, em blocos de $400 \mathrm{~KB}$, a Plataforma PRef.G consome, aproximadamente, 15, $65 \mathrm{~ms}$, enquanto as plataformas P1.G e P2.G consomem, respectivamente, 17, $95 \mathrm{~ms}$ e $14 \mathrm{~ms}$, o que permite concluir que para $N=100.000$, a Plataforma PRef.G consome, aproximadamente, apenas $33 \%$ do tempo total com o processamento da ordenação e, aproximadamente, $67 \%$ com o processo de alocação de memória. Já as plataformas virtualizadas P1.G e P2.G consomem, respectivamente, $25 \%$ e $41 \%$ do tempo total com o processamento e $75 \%$ e $59 \%$ no processo de alocação de memória DRAM.

\begin{tabular}{|c|c|c|c|c|}
\hline Quantidade memória & Tamanho bloco & PRef.G & P1.G & P2.G \\
\hline $50 \mathrm{MB}$ & $400 \mathrm{~KB}$ & 15,65 & 17,95 & 14 \\
\hline $150 \mathrm{MB}$ & $1024 \mathrm{~KB}$ & 48,30 & 54,20 & 42,35 \\
\hline $200 \mathrm{MB}$ & $1536 \mathrm{~KB}$ & 63,85 & 71,30 & 56,50 \\
\hline $200 \mathrm{MB}$ & $2048 \mathrm{~KB}$ & 64,95 & 72,35 & 57 \\
\hline
\end{tabular}

Tabela 5.1: Tempo médio, em ms, consumido ao alocar memória DRAM em blocos de tamanho previamente estabelecidos no servidor de aplicação Glassfish.

Isso demonstra que a plataforma P2.G consegue alocar blocos pequenos de memória com uma eficiência superior de, aproximadamente, $16 \%$ em relação à plataforma PRef.G. Assim, a sobrecarga imposta pelo virtualizador na execução das instruções de processamento é compensada pela eficiência no processo de alocação de memória, tornando equivalente o desempenho de ambas as plataformas. Essa eficiência é obtida através do recurso large page ativo na plataforma Hyper-V mesmo quando esse recurso não é solicitado pelo sistema operacional convidado e pela tabela de página estendida, disponibilizada pelos processadores utilizados nas plataformas estudadas, como descrito no capítulo 4 . Tais recursos permitem uma maior eficiência no acesso e manipulação da TLB e no mapeamento de páginas virtuais.

Por outro lado, a plataforma P1.G apresentou desempenho inferior à PRef.G no processo de alocação de pequenas quantidades de memória, no entanto, o tempo proporcionalmente gasto com processamento foi equivalente ao consumido por PRef.G, fazendo com que o tempo total gasto seja similar. Essa vantagem de P1.G, consumindo, aproximadamente, $13 \%$ menos tempo de processamento de instruções que PRef.G, deve-se ao fato da plataforma VMWare trabalhar com alocação garantida de memória. Assim, as faltas de páginas maiores ocorridas são tratadas com maior velocidade pela plataforma P1.G, 
uma vez que para o sistema operacional convidado, a página está sendo buscada no disco, enquanto, na realidade, ela está sendo tratada como uma falta menor pelo virtualizador, o que indica que a página já está na memória e nenhum acesso ao disco é necessário, diferentemente da plataforma de PRef.G em que o acesso ao disco se faz necessário.

Ao aumentar o valor de $N$ para 500.000 , fazendo com que as aplicações representadas sejam, além de $C P U$-Bound, também memory-intensive de carga baixa, percebe-se que as plataformas apresentam comportamento similar ao obtido com o valor de $N$ demonstrado anteriormente. Com essa configuração, é necessário, aproximadamente, $1.953 \mathrm{~KB}$ de memória DRAM para armazenar cada instância do vetor e um total de $220 M B$ durante as submissões pelo software consumidor. Sendo assim, ao consultar a tabela 5.1, percebe-se que a plataforma PRef.G gasta, aproximadamente, 64,95 ms para alocar $200 \mathrm{MB}$ de memória em blocos de $2 M B$, isso indica que PRef.G consome, aproximadamente, $36 \%$ do tempo total com o processamento, enquanto as plataformas P1.G e P2.G consomem, respectivamente, $30 \%$ e $44 \%$. Esses dados indicam que ao alterar o valor de $N$ de 100.000 para 500.000 ocorre uma variação de apenas $3 \%$ na porcentagem de tempo gasto com processamento e alocação de memória pelas plataformas mantendo o comportamento descrito quando $N=100.000$.

Já ao ampliar a porcentagem de CPUs utilizadas para $50 \%$ e 75\%, é possível perceber que a plataforma P1.G apresenta perdas de desempenho ocasionadas pela tarefa de gerenciamento dos processadores e da plataforma como um todo, como pode ser observado nos gráficos das Figuras 5.4.b e 5.4.d, que apresentam as perdas de desempenho sofridas pelas aplicações baseadas em SOA ao serem executadas sobre as plataformas virtualizadas com, respectivamente, $50 \%$ e $75 \%$ de utilização das CPUs disponíveis.

Ao observar o gráfico da Figura 5.4.b é possível perceber que a maior perda de desempenho registrada pela plataforma P1.G ocorre quando $N=100.000$, sendo de, aproximadamente, $6 \%$ enquanto a menor perda ocorre quando $N=500.000$ sendo de, aproximadamente, $1 \%$. Esse comportamento indica que à medida que a ordem do vetor é ampliada, a perda de desempenho sofrida pela plataforma é reduzida. Tal fato ocorre devido ao tempo de alocação de memória não aumentar à medida que se amplia a quantidade de CPUs utilizadas, uma vez que a máquina virtual JAVA aloca memória no heap da geração jovem com base na demanda. Assim, quando apenas uma CPU estava sendo utilizada, a alocação ocorria em blocos de, aproximadamente, $400 \mathrm{~KB}$ quando $N=100.000$ e $1.953 \mathrm{~KB}$ quando $N=500.000$. De maneira análoga, ao dobrar a quantidade de CPUs utilizadas, dobra-se, também, a quantidade de memória alocada no espaço Éden da JVM. No entanto, apesar da quantidade de memória alocada ser duplicada, o tempo gasto com a alocação apresenta uma variação extremamente baixa.

Uma vez que o tempo de alocação de memória não apresenta variações significativas, é possível concluir que, à medida que o valor de N aumenta, amplia-se, também, o tempo gasto com o processamento, fazendo com que o gerenciador de máquina virtuais VMWare 


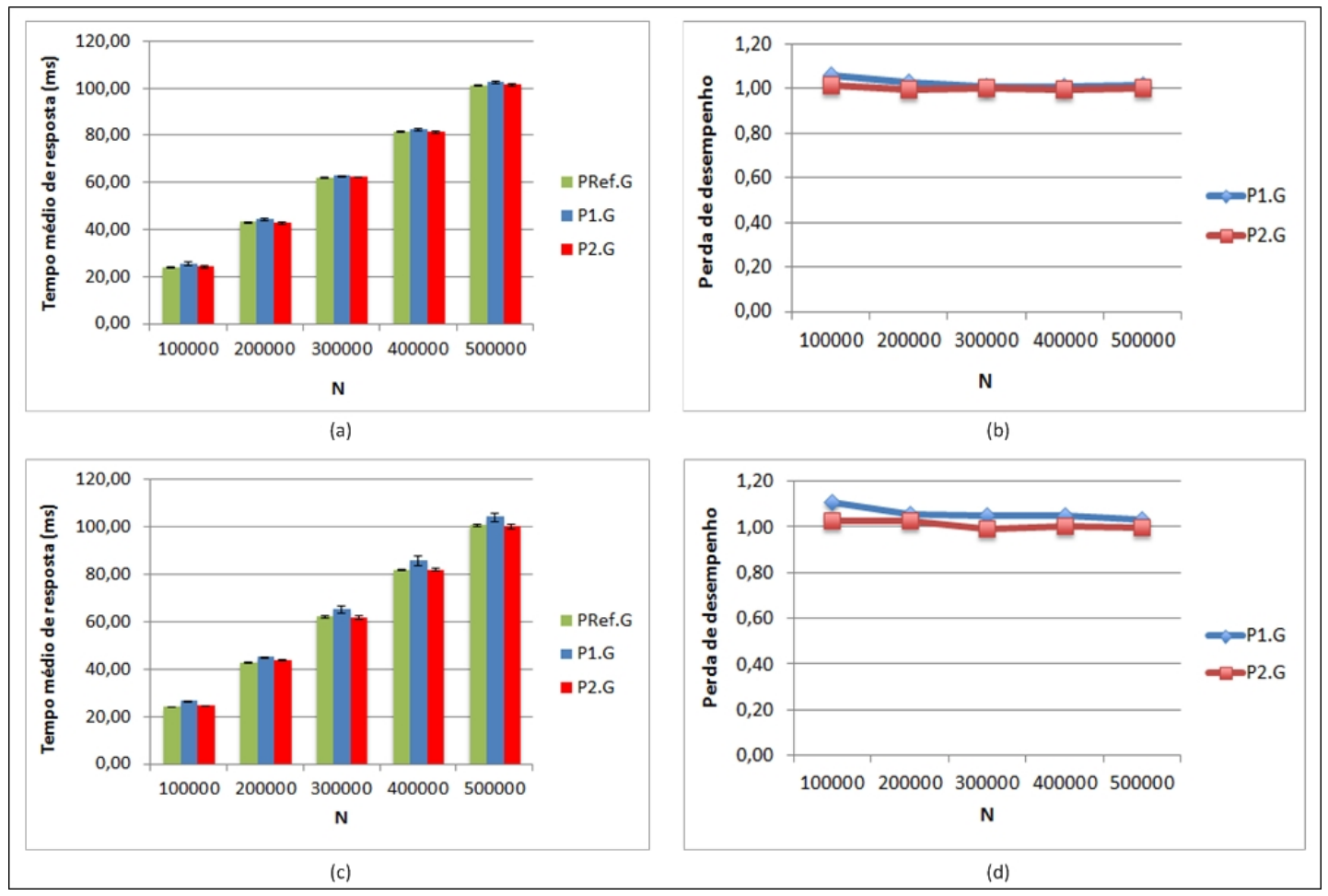

Figura 5.4: Desempenho das aplicações CPU-bound e memory-intensive de carga baixa ao serem executadas sobre servidor Glassfish: a) Tempo médio de resposta com $50 \%$ de utilização dos processadores, b) Perda de desempenho com $50 \%$ de utilização dos processadores, c) Tempo médio de resposta com $75 \%$ de utilização das CPUs e d) Perda de desempenho com $75 \%$ de utilização das CPUs.

apresente um desempenho mais próximo ao obtido pela plataforma de referência. Por outro lado, à medida que o valor de $\mathrm{N}$ diminui, menor torna-se o tempo destinado ao processamento, fazendo com que o virtualizador precise escalonar mais processos e threads, reduzindo o desempenho global da plataforma P1.G.

De maneira análoga, ao observar o gráfico da Figura 5.4.d, é possível concluir que a perda de desempenho registrada pela plataforma P1.G, ao ampliar a utilização das CPUs para $75 \%$, aumenta à medida que o valor de $\mathrm{N}$ diminui, sendo registrado, aproximadamente, $11 \%$ como a maior perda de desempenho e $3 \%$ como a menor, respectivamente, quando $N=100.000$ e $N=500.000$. O incremento de $6 \%$ para $11 \%$ registrado ao elevar a taxa de utilização dos processadores de $50 \%$ para $75 \%$, quando $N=100.000$, deve-se ao aumento de, aproximadamente, $5 \%$ no tempo total de processamento registrado pela plataforma P1.G, enquanto as demais plataformas mantiveram uma variação inferior à $1 \%$.

Com relação à plataforma P2.G, a mesma apresentou desempenho equivalente à plataforma PRef.G ao aumentar a quantidade de CPUs para 50\%, uma vez que houve sobreposição das médias e dos intervalos de confiança para todos os valores de $\mathrm{N}$ avaliados. 
Esse cenário é alterado, parcialmente, apenas quando a taxa de ocupação dos processadores é incrementada para $75 \%$, quando ocorrem sobreposição dos intervalos e médias apenas para $N \geq 300.000$. Tais fatos podem ser observados nas Figuras 5.4.a e 5.4.c, que apresentam o tempo médio de resposta das aplicações ao serem executadas sobre o servidor Glassfish nas três diferentes plataformas analisadas com taxa de utilização dos processadores de $50 \%$ e $75 \%$, respectivamente.

Apesar de não haver sobreposição dos intervalos de confiança e das médias para $N \leq 200.000$, as perdas de desempenho sofridas pelas aplicações executadas sobre a plataforma P2.G foram muito pequenas, variando entre $2 \%$ e $3 \%$, o que indica que a superioridade de, aproximadamente, $11 \%$ da plataforma P2.G em relação à PRef.G ao alocar memória, foi suficiente para reduzir consideravelmente as perdas de desempenho sofridas pelo gerenciamento das CPUs e escalonamento de threads.

Todavia, ao ampliar a taxa de utilização das CPUs para 100\%, não ocorrem mais as sobreposições nos tempos médios de resposta obtidos pelas plataformas PRef.G e P2.G, sendo, inclusive, registrados perdas de desempenho significativas pelas aplicações executadas sobre a plataforma P2.G. Tais fatos podem ser observados nas Figuras 5.5.a e 5.5.b que apresentam os tempos médios de respostas obtidos pelas aplicações ao serem executadas nas três plataformas aqui estudadas, bem como a perda de desempenho registradas nas plataformas virtualizadas, ambas as informações quando a taxa de utilização das CPUs é de $100 \%$.

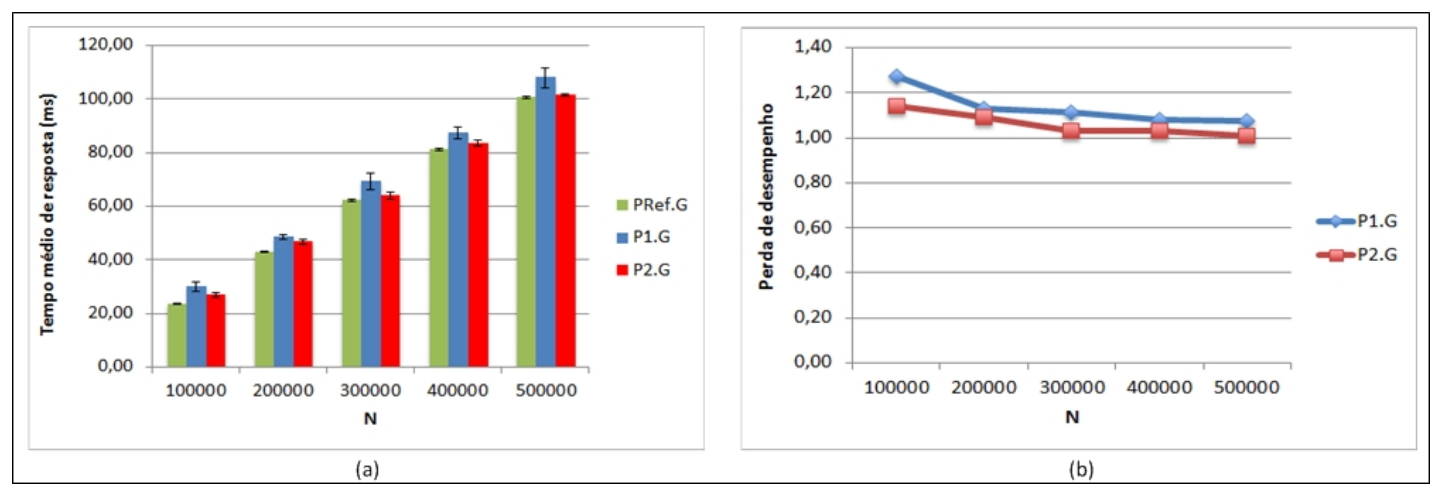

Figura 5.5: Desempenho das aplicações $C P U$-bound e memory-intensive de carga baixa ao serem executadas sobre servidor Glassfish com $100 \%$ de utilização dos processadores: a) Tempo médio de resposta e b) Perda de desempenho.

Ao analisar a Figura 5.5.b é possível perceber que a plataforma P1.G registrou a maior perda de desempenho quando $N=100.000$ e a menor quando $N=500.000$, respectivamente, $14 \%$ e 1\%. Essa perda de desempenho se deve à sobrecarga gerada pelo virtualizador durante o processo de escalonamento de threads e o gerenciamento das CPUs. Assim, quanto menor a ordem do vetor, mais frequente é o escalonamento das threads. Essa sobrecarga ampliou em, aproximadamente, $10 \%$ o tempo total de processamento das 
aplicações ao ampliar a taxa de utilização dos processadores de $75 \%$ para $100 \%$, quando $N=100.000$. No entanto, à medida que a ordem do vetor é incrementada maior se torna o tempo de processamento, reduzindo a carga de gerenciamento e escalonamento por parte do virtualizador, fazendo com que a perda de desempenho seja reduzida. Tal fato permitiu que a plataforma P2.G registrasse um aumento no tempo de processamento de apenas $1 \%$ ao ampliar a taxa de utilização das CPUs de $75 \%$ para $100 \%$, isto quando $N=500.000$

Da mesma forma, a plataforma P1.G, que já apresentava desempenho inferior quando a taxa de ocupação de CPUs era inferior à 100\%, passou a apresentar perdas de desempenho variando entre $7 \%$ e $27 \%$, sendo a maior registrada quando $N=100.000$ e a menor quando $N=500.000$, como pode ser observado no gráfico da Figura 5.5.b. De maneira análoga ao ocorrido com a plataforma P2.G, ao ampliar a taxa de utilização dos processadores de $75 \%$ para $100 \%$, a plataforma baseada em VMWare apresentou um aumento de, aproximadamente, $13 \%$ no tempo total de processamento das aplicações puramente CPU-bound quando $N=100.000$ e, aproximadamente, $4 \%$ quando $N=500.000$

\subsection{Aplicações memory-intensive de carga mode- rada e alta}

Diferentemente da situação observada com as aplicações predominantemente $C P U$ Bound, não houve sobreposições dos intervalos de confiança e dos tempos médios de resposta obtidos ao executar aplicações memory-intensive nas plataformas consideradas e com taxa de utilização dos processadores em $25 \%$, conforme pode ser observado no gráfico da Figura 5.6.a.

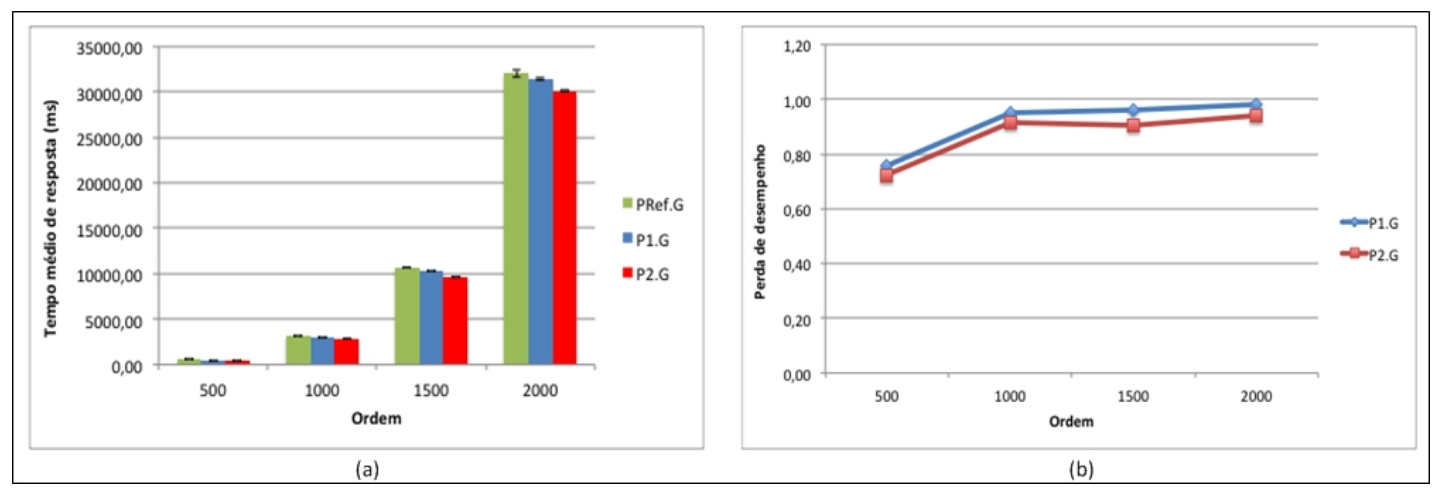

Figura 5.6: Desempenho das aplicações memory-intensive com carga variando de moderada à alta ao serem executadas sobre servidor Glassfish com $25 \%$ de utilização das CPUs: a) Tempo médio de resposta e b) perda de desempenho.

Ao observar o gráfico da Figura 5.6.a é possível perceber que independentemente da ordem da matriz adotada, o desempenho da plataforma PRef.G é inferior às demais pla- 
taformas consideradas. Tal fato é reforçado pelo gráfico da Figura 5.6.b, que demonstra as perdas de desempenho obtidas pelas aplicações ao serem executadas nas plataformas consideradas com taxa de utilização das CPUs em $25 \%$.

Nesse cenário, as plataformas que possuem sistema de gerenciamento de máquinas virtuais apresentaram ganhos de desempenho, sendo o maior ganho registrado quando $O=500$ e o menor ganho quando $O=2000$, com P1.G registrando ganhos variando de $2 \%$ à $24 \%$ e P2.G entre $6 \%$ e $28 \%$, sendo esta plataforma a mais eficiente para todas as ordens consideradas. No entanto, é possível perceber que há uma transição de fase quando $O \geq 1000$, onde os ganhos de desempenho de ambas as plataformas virtualizadas se tornam estáveis. Nessa fase, a plataforma P1.G apresenta uma variação de $3 \%$ no ganho de desempenho e a plataforma P2.G de 2\%. Esse fato indica que a perda ou ganho de desempenho gerada pelo processo de virtualização possui características distintas à medida que a aplicação deixa de ser predominantemtne memory-intensive de carga moderada e se torna de carga elevada.

Para aplicações memory-intensive de carga moderada, o tempo de processamento não é muito elevado, fazendo com que as submissões sejam executadas em um intervalo curto de tempo. Nesses intervalos, muitos objetos são instanciados e removidos na JVM, exigindo que a mesma aloque e desaloque uma grande quantidade de memória no heap, especificamente no espaço Éden, que é reservado aos novos objetos que ainda não "sobreviveram" a nenhuma operação de coleta de lixo.

Nesse processo de reservar e liberar memória repetidamente, uma grande quantidade de ausências de páginas é gerada no sistema operacional que dá suporte ao servidor de aplicações, sendo o mesmo obrigado a tratá-las com dados que em muitas ocasiões são provenientes do disco rígido, uma vez que por se tratar de aplicações memory-intensive de carga moderada, a quantidade de memória manipulada é significativa. Por outro lado, as plataformas P1.G e P2.G que possuem sistemas gerenciadores de máquinas virtuais não tratam a solicitação com páginas originadas no disco rígido, mas sim com páginas já alocadas previamente na memória em uma espaço de cache/buffer destinado à máquina virtual e ao sistema operacional convidado. Sendo assim, para o sistema operacional convidado, não há nenhuma diferença no tratamento da ausência de página maior, inclusive, no contexto do sistema operacional convidado, os dados são buscados do sistema de armazenamento em massa, no entanto, ao interceptar a instrução, o virtualizador trata a ausência com dados previamente alocados na memória.

Adicionalmente, as plataformas de hardware modernas, destinadas a servidores, são equipadas com os sistemas de mapeamento de páginas de nível duplo, denominado pela Intel de EPT e pela $A M D$ de RVI, como apresentado no Capítulo 4. Nessa tecnologia, o sistema operacional hospedeiro consegue mapear as páginas reservadas às aplicações que estão sendo executadas dentro do sistema operacional convidado, permitindo que o remapeamento e, consequentemente o tratamento das faltas de páginas, sejam tratados 
de formas ainda mais eficiente. A influência desses recursos presentes nessa nova fase da computação, destinados à consolidação de servidores e à computação em nuvem, pode ser observada ao analisar os resultados obtidos durante o processo de warm-up das avaliações. Durante essa fase, os tempos de resposta das aplicações executadas em ambientes virtualizados são relativamente maiores se comparados aos obtidos na plataforma não virtualizada, o que demonstra que esses recursos destinados à consolidação de servidores, disponibilizados tanto em hardware quanto em softwares, são capazes de reduzir e até mesmo eliminar a sobrecarga gerada pelo processo de virtualização, principalmente em ambientes de produção, onde as aplicações apresentam ciclos de vida regulares e longos.

No entanto, como é possível perceber pelo gráfico da Figura 5.6.b, a plataforma P2.G apresenta resultados ainda melhores que os obtidos pela plataforma P1.G. Esse fato se dá pela eficiência da plataforma P2.G em alocar memória. Como apresentado na tabela 5.1, esta plataforma é, aproximadamente, $11 \%$ mais eficiente que a plataforma física no processo de alocação repetitiva de memória e, aproximadamente, $20 \%$ mais eficiente que a plataforma P1.G.

Essa superioridade é obtida pelo sistema operacional hospedeiro Microsoft Windows Server 2008 R2 através de sua estrutura diferenciada de alocação de memória e, também, pelo uso do recurso denominado large page, suportado pelos processadores utilizados nos experimentos. Como destacado anteriormente, a plataforma P1.G também possui a implementação desse recurso, no entanto, ele é ativado nessa plataforma apenas quando o sistema operacional convidado solicita. De maneira similar, o sistema operacional GNU/Linux somente aloca páginas "largas" se a aplicação solicitar. Assim, para P1.G utilizar tal recurso, não somente o sistema convidado teria que ser configurado para tal mas, também, a máquina virtual Java utilizada como base para o servidor de aplicações. O virtualizador Hyper- $V$, por outro lado, utiliza páginas "largas" para tratar suas próprias páginas que são destinadas às máquinas virtuais.

Por outro lado, à medida que as aplicações se tornam memory-intensive de carga alta, os ciclos de criação e liberação de objetos, e consequentemente as ausências de páginas, tornam-se mais longos e o tempo de processamento se torna o principal fator nos tempos de resposta das aplicações, fazendo com que os ganhos de desempenho das aplicações, executadas nas plataformas virtualizadas, sejam reduzidos, no entanto, com a utilização da carga de processadores baixa, pouco recurso de escalonamento e gerenciamento é solicitado, fazendo com que os ganhos, provenientes da alocação de memória, ainda sejam significativos. Porém, à medida que a utilização da plataforma passa para 50\% e $75 \%$ dos processadores disponíveis, as reduções nos ganhos de desempenho apresentadas pelas plataformas virtualizadas se tornam evidentes. Como pode ser observado nos gráficos das Figuras 5.7.b e 5.7.d que apresentam as perdas de desempenho sofridas pelas aplicações memory-intensive de carga moderada e alta, ao serem executadas nas plataformas virtualizadas instanciadas no servidor Glassfish, respectivamente quando a taxa de utilização 
dos processadores é de $50 \%$ e $75 \%$.

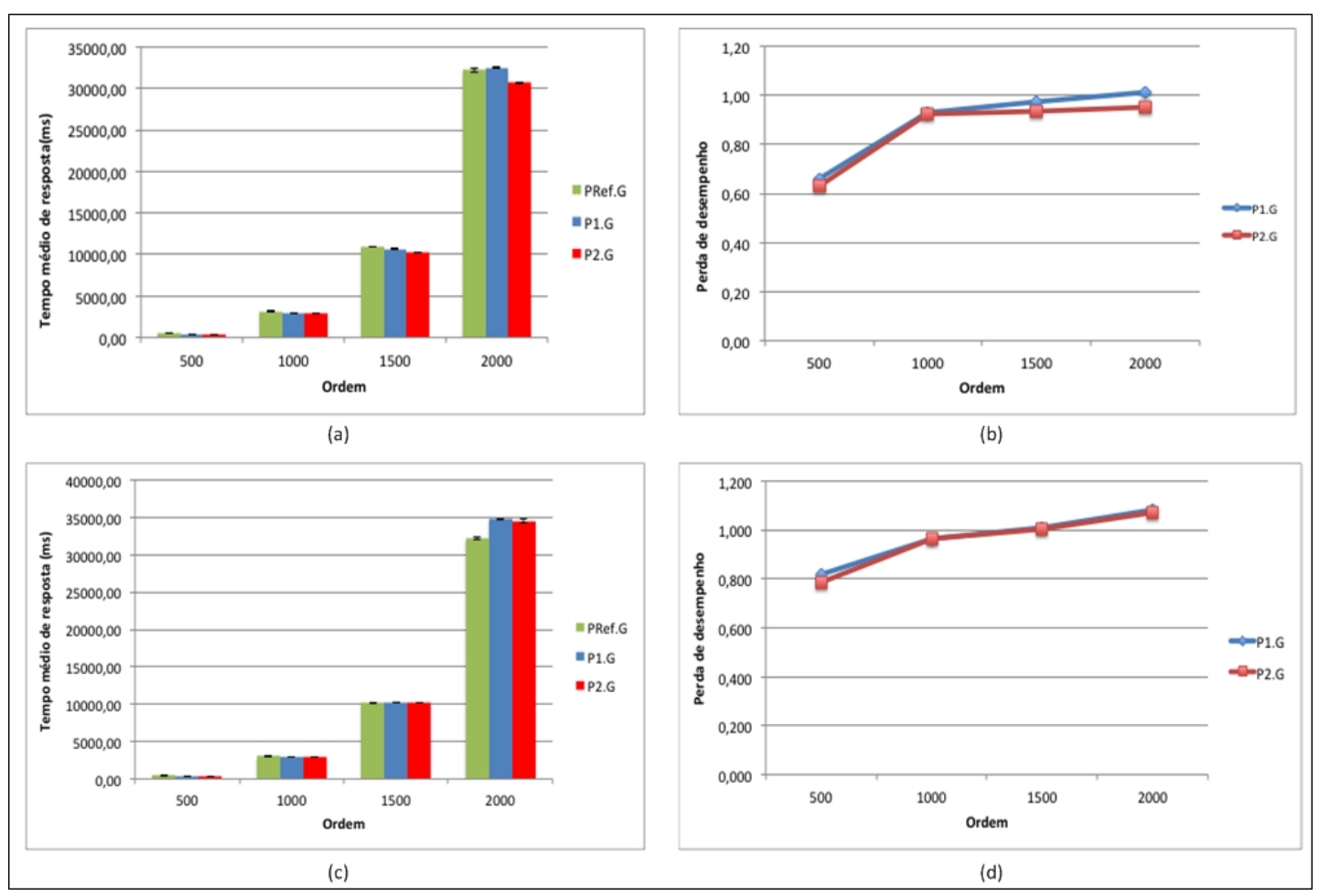

Figura 5.7: Desempenho das aplicações memory-intensive de carga variando entre moderada e alta ao serem executadas sobre servidor Glassfish: a) Tempo médio de resposta com $50 \%$ de utilização dos processadores, b) Perda de desempenho com $50 \%$ de utilização dos processadores, c) Tempo médio de resposta com $75 \%$ de utilização das CPUs e d) Perda de desempenho com $75 \%$ de utilização dos processadores.

Como é possível observar nos gráficos das Figuras 5.7.a e 5.7.c, não houve sobreposições dos intervalos de confiança e das médias para os casos estudados. Ao observar o gráfico da Figura 5.7.b, é possível perceber que para aplicações de carga predominantemente moderada, quando $O=500$, os ganhos de desempenho registrados pelas plataformas virtualizadas foram ainda mais significativos que aqueles registrados quando a taxa de utilização dos processadores era de $25 \%$. Esse fato ocorre, pois, a JVM aloca memória, na geração jovem, em blocos destinados a atender todas as requisições recebidas em um pequeno intervalo de tempo. Assim, ao ampliar a ocupação dos processadores das plataformas para $50 \%$, duas threads solicitam memória em intervalos muito pequenos de tempo, o que leva a JVM a aumentar o tamanho do bloco a ser alocado se comparado com aquele alocado quando a ocupação dos processadores era menor. Com o aumento no tamanho do bloco alocado, os recursos descritos anteriormente utilizados pelos virtualizadores se tornam ainda mais eficientes, uma vez que o tempo de execução de cada instância da aplicação é muito pequeno, aproximadamente, entre $300 \mathrm{~ms}$ e $500 \mathrm{~ms}$.

Por outro lado, à medida que a ordem das matrizes é ampliada, fazendo com que as 
aplicações deixem de ser memory-intensive de carga moderada para se tornarem memoryintensive de carga elevada, é possível perceber que os ganhos de desempenho das aplicações virtualizadas são reduzidos significativamente. Nesse contexto, quando a taxa de ocupação dos processadores é de 50\%, a plataforma P1.G apresentou ganhos de desempenho de, aproximadamente, $3 \%$ quando $N=1.500$, chegando a registrar uma pequena perda de desmpenho de, aproximadamente, $1 \%$ quando $N=2.000$. Para os mesmos valores de $N$, a plataforma P2.G apresentou ganho de desempenho de, aproximadamente, $6 \%$ e $5 \%$. Nesse contexto, ao comparar os resultados obtidos pelas plataformas virtualizadas com aqueles obtidos pelas mesmas plataformas quando apenas $25 \%$ dos processadores eram utilizados, percebe-se que a plataforma P1.G apresentou redução no ganho de desempenho variando entre $1 \%$ e $3 \%$ quando $N=\geq 1.500$, enquanto a plataforma P2.G apresentou reduções entre $1 \%$ e $4 \%$ para o mesmo intervalo de $N$ analisado.

Já ao ampliar a utilização dos processadores para 75\%, a redução no ganho de desempenho ocorreu para todos os valores de $O$ considerados, levando ambas as plataformas virtualizadas à registrarem perda de desempenho quando $O \geq 1.500$. Como pode ser observado no gráfico da Figura 5.7.d, a maior perda registrada para a plataforma P1.G foi de $8 \%$ e a menor de $1 \%$, quando $O=2.000$ e $O=1.500$, respectivamente. Para essa mesma plataforma, o maior ganho de desempenho ocorreu quando $O=500$ e o menor quando $O=1000$, respectivamente, $18 \%$ e $3 \%$. A plataforma P2.G, por outro lado, apresentou perdas de desempenho inferiores à $1 \%$ quando $O \geq 1.500$ e ganhos de $22 \%$ e $4 \%$, respectivamente, quando $O=500$ e $O=1.000$.

Finalmente, assim como ocorreu com as aplicações $C P U$-bound, ao ampliar a taxa de utilização dos processadores para $100 \%$, as plataformas virtualizadas deixaram de registrar ganhos e registraram perdas de desempenho, principalmente para aplicações memoryintensive de carga elevada. Tais resultados podem ser observados no gráfico da Figura 5.8 .

Como é possível perceber no gráfico da Figura 5.8, a menor perda de desempenho registrada para a plataforma P1.G foi de $2 \%$ e a maior de $8 \%$ quando $O=500$ e $O=2000$, respectivamente. Já a plataforma P2.G apresentou perdas de desempenho variando de $1 \%$ à $23 \%$, respectivamente, quando $O=500$ e $O=2000$. Ao analisar tais resultados, percebe-se que ambas as plataformas virtualizadas sofreram perda de desempenho mesmo para aplicações memory-intensive de carga moderada, quando $O=500$. Apesar da alocação pela JVM ser realizada em blocos, como descrito anteriormente, e a quantidade de threads executando simultaneamente ter sido ampliada, a sobrecarga gerada pelo gerenciamento dos processadores e escalonamento torna o desempenho das plataformas virtualizadas inferior à plataforma não virtualizada. Tal sobrecarga pode ser observada ao comparar a razão entre os tempos de resposta obtidos pela execução das aplicações com carga de processadores em 100\% e 75\%. Tais informações são apresentadas na Tabela 5.2.

Ao observar a Tabela 5.2, é possível perceber que quando $O \leq 1.000$, os tempos médios 


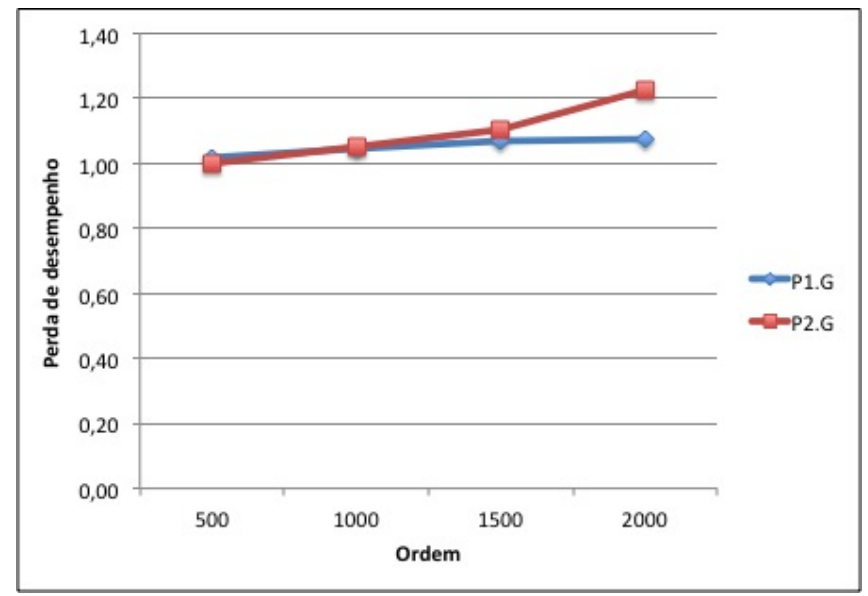

Figura 5.8: Perda de desempenho sofrida pelas aplicações memory-intensive com carga variando de moderada à alta ao serem executadas em plataformas virtualizadas e hospedadas no servidor de aplicação Glassfish com 100\% de utilização dos processadores.

\begin{tabular}{|c|c|c|c|}
\hline Ordem da matriz & PRef.G & P1.G & P2.G \\
\hline 500 & 0,82 & 1,02 & 1,04 \\
\hline 1.000 & 0,92 & 1,00 & 1,01 \\
\hline 1.500 & 1,09 & 1,15 & 1,19 \\
\hline 2.000 & 1,01 & 1,00 & 1,15 \\
\hline
\end{tabular}

Tabela 5.2: Razão entre o tempo médio de resposta quando a taxa de ocupação de processamento é de $100 \%$ e $75 \%$.

de resposta obtidos pela plataforma PRef.G, com taxa de utilização de CPUs em 100\%, são inferiores àqueles obtidos quando o taxa de utilização é de $75 \%$. Essa redução se deve à quantidade de threads sendo executadas simultaneamente, no entanto, as plataformas virtualizadas apresentam tempos médios de resposta superiores ou equivalentes, sendo a plataforma P2.G a que apresenta o maior acréscimo no tempo médio de processamento, chegando à $19 \%$ quando $O=1500$. Isso indica que esta plataforma é muito sensível à taxas muito elevadas de ocupação de processadores, principalmente na presença de aplicações memory-intensive de carga elevada.

\subsection{Servidor de aplicação}

Ao substituir o servidor de aplicação Glassfish pelo JBoss, é possível perceber que para aplicações $C P U$-bound e memory-intensive de carga baixa, a relação de desempenho apresentou o mesmo tipo de comportamento. No entanto, ao ampliar a quantidade de memória utilizada pelas aplicações, tornando-as memory-intensive de carga moderada e elevada, há uma mudança no desempenho global à medida que se aumenta a porcentagem de processadores utilizados. 


\subsubsection{Aplicações CPU-bound e memory-intensive de carga baixa}

Como destacado, ao considerar as aplicações $C P U$-bound e memory-intensive de carga baixa, é possível perceber que, de uma forma geral, as perdas de desempenho sofridas pelas aplicações distribuídas implantadas no servidor de aplicação JBoss, executado sobre plataformas virtualizadas, possuem as mesmas características daquelas obtidas ao utilizar o servidor de aplicação Glassfish. Sendo que, as maiores perdas de desempenho são obtidas para pequenos valores de $N$ e à medida que o valor de $N$ aumenta, a perda de desempenho reduz, no entanto, em nenhum cenário estudado houve ganho de desempenho. Sendo que, apenas em algumas configurações, as plataformas estudadas apresentaram desempenhos similares.

Para uma ocupação de CPU reduzida, em torno de $25 \%$, diferentemente dos resultados obtidos com o servidor de aplicação Glassfish, em que, para todos os valores de $N$ considerados, o desempenho das plataformas foram similares, ao considerar o servidor de aplicação Jboss, apenas o desempenho das plataformas PRef.J e P2.J são equivalentes, como pode ser comprovado ao analisar as sobreposições das médias e intervalos de confiança apresentados no gráfico da Figura 5.9.a, que apresenta os tempos médios de resposta obtidos ao executar aplicações $C P U$-bound e memory-intensive de carga baixa, implantadas no servidor de aplicação JBoss.
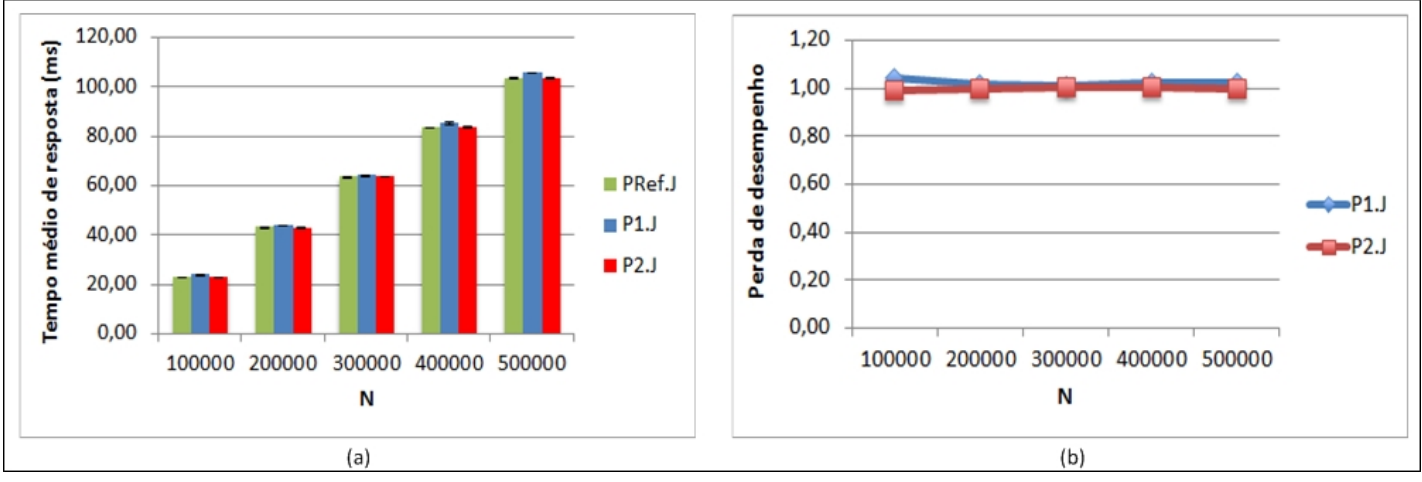

Figura 5.9: Resultados obtidos ao executar aplicações distribuídas baseadas em SOA do tipo CPU-bound e memory-intensive de carga baixa implantadas no servidor de aplicação JBoss com 25\% de ocupação dos processadores disponibilizados: a) Tempo médio de resposta. b) Perda de desempenho.

Nesse cenário, a maior perda de desempenho observada para a plataforma P1.J foi de $4 \%$ e o menor de $2 \%$, respectivamente quando $N=100.000$ e $N=500.000$. Tais perdas podem ser observadas no gráfico da Figura 5.9.b e possuem suas origens nas reduções dos tempos de processamento obtidos pelas plataformas PRef.J e P2.J ao comparar os tempos obtidos nas execuções ao substituir o servidor de aplicação Glassfish pelo JBoss. Quando $N=100.000$, a plataforma PRef.J apresentou redução de $2 \%$ no tempo de processamento 
em relação à plataforma PRef.G, enquanto a plataforma P2.J reduziu em 5\% o tempo de ocupação de CPU em relação à plataforma P2.G. Já a plataforma P1.J apresentou o mesmo desempenho obtido pela plataforma P1.G.

Apesar dessa perda de desempenho obtida pela plataforma P1.J, é possível perceber que para esse cenário, de baixa utilização dos processadores disponibilizados, em torno de $25 \%$, o recurso de carga de classes sob demanda privilegia as plataformas virtualizadas durante o processo de alocação de memória. Ao considerar a Tabela 5.3, que demonstra o tempo de alocação de blocos de memória de tamanhos predefinidos, nota-se que para todas as quantidades de memória analisadas, a plataforma PRef.J consome mais tempo que aquele gasto pela plataforma PRef.G, com a maior relação, aproximadamente 8\%, sendo obtida para um total de $50 \mathrm{MB}$ alocados em blocos de $400 \mathrm{~KB}$. Essa quantidade de memória corresponde à memória consumida ao ordenar vetores com 100.000 elementos.

Por outro lado, para as demais quantidades de memória DRAM analisadas, a plataforma PRef.J consome, de forma constante, aproximadamente, $3 \%$ mais tempo se comparado aos tempos obtidos pela plataforma Pref.G, no entanto, as plataformas P1.J e P2.J consomem, no máximo, o mesmo tempo que as plataformas P1.G e P2.G, chegando, em alguns casos, a consumirem até $3 \%$ menos tempo, como pode ser observado na Tabela 5.3 ao considerar a plataforma P1.J com memória de $50 M B$ e blocos de $400 K B$.

\begin{tabular}{|c|c|c|c|c|}
\hline Quantidade memória & Tamanho bloco & PRef.J & P1.J & P2.J \\
\hline $50 \mathrm{MB}$ & $400 \mathrm{~KB}$ & 16,90 & 17,40 & 14 \\
\hline $150 \mathrm{MB}$ & $1024 \mathrm{~KB}$ & 49,95 & 54,30 & 42 \\
\hline $200 \mathrm{MB}$ & $1536 \mathrm{~KB}$ & 65,65 & 71,30 & 56,50 \\
\hline $200 \mathrm{MB}$ & $2048 \mathrm{~KB}$ & 66,35 & 72 & 56,25 \\
\hline
\end{tabular}

Tabela 5.3: Tempo médio, em ms, consumido ao alocar memória DRAM em blocos de tamanho previamente estabelecidos no servidor de aplicação JBoss.

Tais diferenças, nos tempos globais de alocação, reduziram as perdas de desempenho de alocação da plataforma P1.J em relação à plataforma PRef.J e ampliaram o ganho de desempenho da plataforma P2.J em relação à mesma plataforma de referência. A perda de desempenho no tempo de alocação de P1.J, em relação à PRef.J, foi reduzida, aproximadamente, entre $3 \%$ e $12 \%$ se comparado às perdas registradas por P1.G em relação à PRef.G. A maior redução ocorreu ao alocar $50 \mathrm{MB}$ de memória em blocos de 400, sendo que para as demais configurações, a redução permaneceu constante, variando entre 3\% e $4 \%$ aproximadamente. De maneira análoga, a plataforma P2.J ampliou os ganhos de desempenho entre $2 \%$ e $7 \%$, sendo a maior ampliação registrada ao alocar $50 M B$ de memória em blocos de $400 K B$.

Ao ampliar a taxa de ocupação dos processadores disponibilizados nas plataformas para, aproximadamente, 50\%, não somente as plataformas PRef.J e P2.J apresentaram reduções nos tempos globais de execução em relação àqueles obtidos pelas plataformas PRef.G e P2.G. A plataforma P1.J, também, obteve tempos menores de execução, com 
variação entre $1 \%$ e $5 \%$, sendo que, apenas para $N=300.000$, o tempo de resposta foi semelhante ao obtido pela plataforma P1.G. A plataforma P2.J apresentou reduções entre $1 \%$ e $4 \%$, enquanto a plataforma PRef.J registrou reduções entre $3 \%$ e $5 \%$.

Para essa taxa de utilização das CPUs, houve sobreposição dos intervalos de confiança e das médias apenas entre as plataformas PRef.J e P2.J quando $N \geq 400.000$, diferentemente do caso anterior, ao considerar o servidor de aplicação Glassfish, em que para todos os valores de $N$ o desempenho de ambas as plataformas eram similares. Já a plataforma P1.J apresentou desempenho inferior as demais plataformas baseadas em JBoss. Tais fatos podem ser observados no gráfico da Figura 5.10.a, que apresenta os tempos médios de respostas obtidos pelas aplicações implantadas nas três plataformas analisadas com taxa de $50 \%$ de utilização dos processadores.

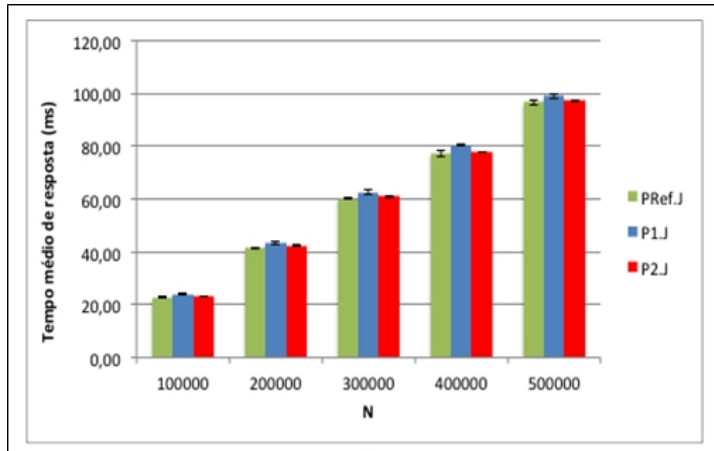

(a)

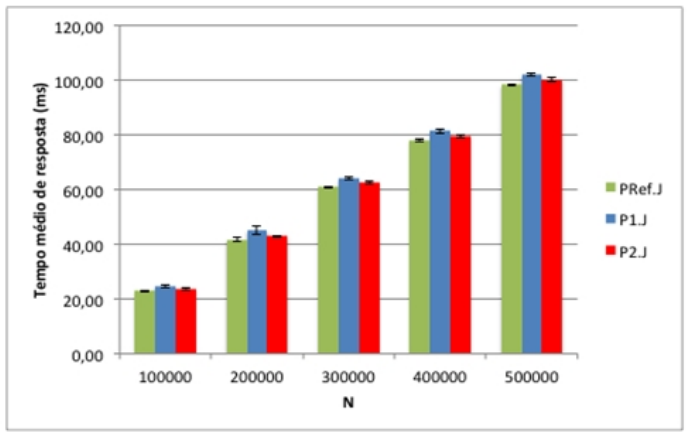

(c)

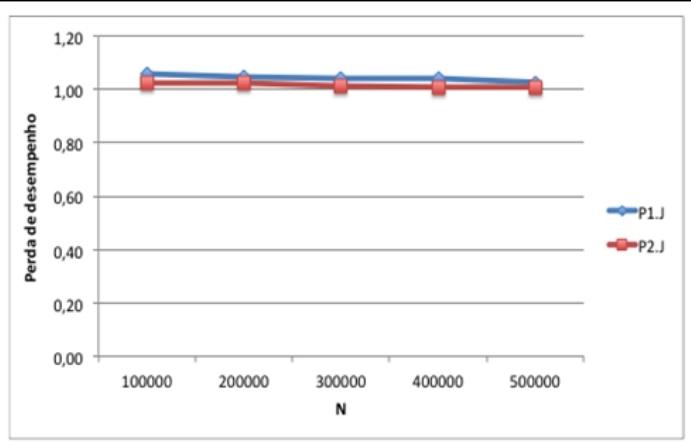

(b)

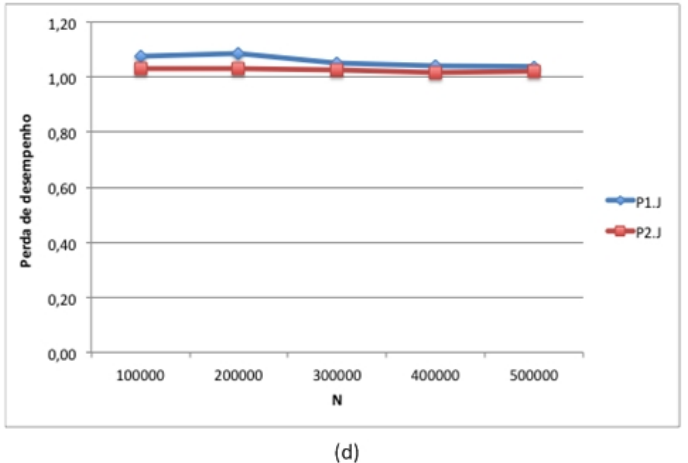

Figura 5.10: Resultados obtidos ao executar aplicações distribuídas baseadas em SOA do tipo CPU-bound e memory-intensive de carga baixa implantadas no servidor de aplicação JBoss: a) Tempo médio de resposta com $50 \%$ de utilização dos processadores; b) Perda de desempenho com $50 \%$ de utilização dos processadores; c) Tempo médio de resposta com $75 \%$ de utilização das CPUs e d) Perda de desempenho com $75 \%$ de utilização das CPUs.

Já ao observar no gráfico da Figura 5.10.c, que apresenta os tempos médios de resposta obtidos ao executar as aplicações com $75 \%$ de utilização dos processadores, é possível perceber que para todos os valores de $N$ observados, não há mais sobreposição dos intervalos de confiança e das médias obtidos pelas plataformas estudadas. Isso indica que à medida 
que a taxa de utilização dos processadores se eleva, as técnicas de alocação de memória como as large pages presentes na plataforma P2.J, a reserva de memória e a não liberação da memória no sistema operacional hospedeiro, a partir da liberação do sistema operacional convidado, tornam-se menos influentes no resultado global.

Tal fato se deve à característica de alocação de memória da JVM baseadas em blocos, como destacado anteriormente. Assim, à medida que a taxa de utilização de CPUs aumenta, incrementa-se, também, o tamanho de bloco de memória alocado por vez pela máquina Java, fazendo com que em apenas uma operação de alocação de memória física, seja alocada a memória necessária por todas as instâncias dos Web Services em execução. Tal fato amplia a relação entre tempo de processamento e tempo de alocação, fazendo com que este seja menor que aquele, incrementando as perdas de desempenho sofridas pelas aplicações, que podem ser visualizadas nas Figuras 5.10.b e 5.10.d, quando as taxas de ocupação de processadores são de, respectivamente, $50 \%$ e $75 \%$.

Ao observar o gráfico da Figura 5.10.b, percebe-se que a menor perda de desempenho registrada pela plataforma P1.J foi de $3 \%$ e a maior de $6 \%$, respectivamente quando $N=500.000$ e $N=100.000$. Ao comparar tais resultados com aqueles obtidos pela plataforma P1.G, percebe-se que para $N \geq 200.000$, a plataforma baseada em JBoss apresenta perdas de desempenho superiores àquelas obtidas pela plataforma baseadas em Glassfish. Tal fato se deve à redução no tempo global de processamento da plataforma P1.J destacado anteriormente.

Ao analisar os resultados obtidos pela plataforma P2.J, é possível perceber que as perdas de desempenho sofridas foram inferiores àquelas obtidas pela plataforma baseada em VMWare, variando entre $1 \%$ e $2 \%$, apresentando-se estáveis para os valores de $N$ em que não houve sobreposição dos intervalos de confiança e das médias entre PRef.J e P2.J.

Essa estabilidade se repete ao elevar a taxa de utilização dos processadores para $75 \%$, apresentando uma variação de apenas $1 \%$, fazendo com que as perdas de desempenho permaneçam entre $2 \%$ e $3 \%$. Com essa configuração, os resultados obtidos pela plataforma P2.J são semelhantes aos obtidos pela plataforma P2.G quando $N \leq 200.000$, uma vez que para valores maiores de $N$, a plataforma P2.G apresentou resultados semelhantes à plataforma PRef.G, conforme destacado no gráfico da Figura 5.4.c.

Para essa mesma taxa de utilização dos processadores, a plataforma P1.J registrou uma elevação na perda de desempenho de $2 \%$, em média, se comparado aos resultados obtidos quando a taxa de utilização de CPUs era de 50\%. A maior perda de desempenho registrada foi de $8 \%$ quando $N=100.000$ e a menor de $4 \%$ quando $N=500.000$. Todavia, é importante destacar que a partir dessa taxa de utilização dos recursos de processamento, a substituição do servidor de aplicação apresenta um decremento significativo nas perdas de desempenho registradas pelas plataformas baseadas em VMWare, diferentemente dos resultados obtidos nas plataformas baseadas em Hyper-V, em que a substituição do servidor de aplicação apresentou resultados similares apenas quando a 
utilização dos processadores se encontra em sua taxa máxima.

Com $75 \%$ de utilização dos processadores, a maior perda de desempenho registrada na plataforma P1.G foi de $11 \%$ enquanto a menor perda foi de $3 \%$, respectivamente quando $N=100.000$ e $N=500.000$, o que indica que a troca do servidor de aplicação reduziu em até $3 \%$ a perda de desempenho para o pior caso. Já ao sobrecarregar as plataformas utilizando $100 \%$ das CPUs disponíveis, a redução na perda de desempenho gerada pela substituição do servidor de aplicação, nas plataformas baseadas em VMWare, chegou a 16\%. Como pode ser observado no gráfico da Figura 5.11 .b.

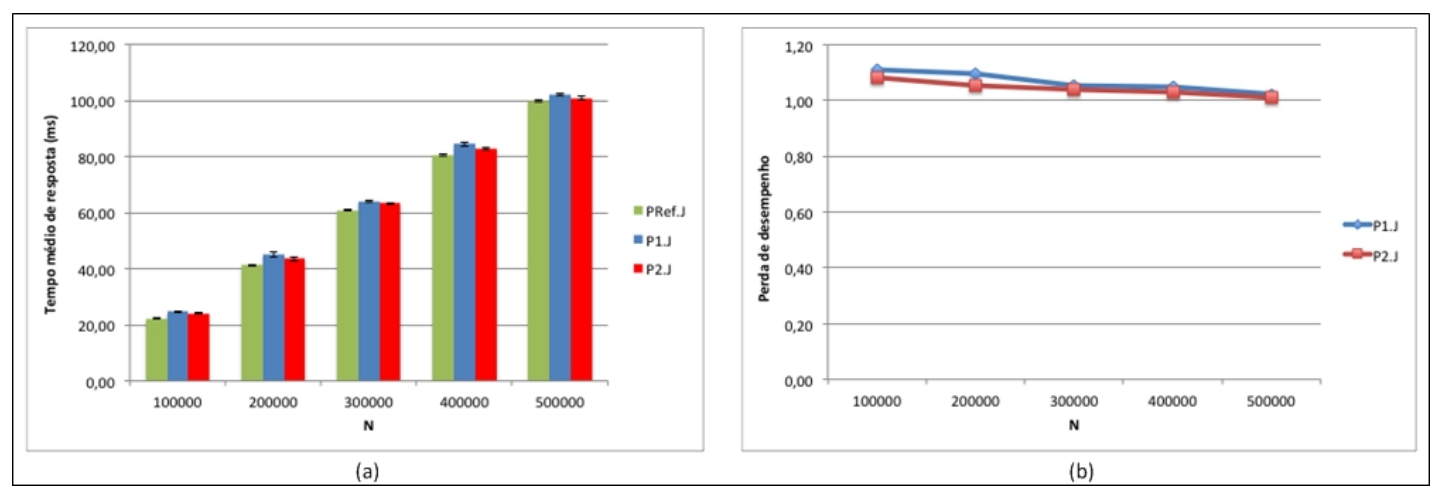

Figura 5.11: Resultados obtidos ao executar aplicações distribuídas baseadas em SOA do tipo CPU-bound e memory-intensive de carga baixa implantadas no servidor de aplicação JBoss com 100\% de ocupação dos processadores disponibilizados: a) Tempo médio de resposta e b) Perda de desempenho.

Ao observar o gráfico da Figura 5.11.b, percebe-se que as perdas de desempenho registradas em ambas as plataformas virtualizadas aumentam à medida que o valor de $N$ é decrementado, sendo registrado perdas de desempenho variando entre $2 \%$ e $11 \%$ pela plataforma P1.J e entre 1\% e $8 \%$ pela plataforma P2.J. Tais resultados apresentam uma redução entre $5 \%$ e $16 \%$ ao considerar os resultados obtidos pelas plataformas baseadas em VMWare utilizando ambos os servidores de aplicação e de até $6 \%$ ao considerar as plataformas baseadas em Hyper-V. Essa menor redução obtida pela plataforma P2.J se deve ao fato das plataformas baseadas em Hyper-V apresentarem os melhores resultados nos tempos de alocação de memória, independentemente do servidor de aplicação utilizado.

\subsubsection{Aplicações memory-intensive de carga moderada e alta}

Ao considerar aplicações memory-intensive que utilizam a memória DRAM de forma moderada e elevada, percebe-se que para cenários de baixa utilização das CPUs disponíveis, em torno de $25 \%$, as perdas de desempenho registradas pelas plataformas P1.J e P2.J apresentam comportamentos distintos daqueles obtidos ao utilizar o servidor de aplicação Glassfish, diferentemente do obtido com o aplicações CPU-bound e memory-intensive de carga baixa em que o comportamento registrado foi similar. 
Para a taxa de ocupação de processadores supracitada, à medida que a ordem da matriz é incrementada, diminui-se as perdas de desempenho sofridas pelas aplicações distribuídas, sendo que para $O \geq 1.500$, as aplicações deixam de registrar perda de desempenho e passam a registrar ganhos, como pode ser observado no gráfico da Figura 5.12.b.

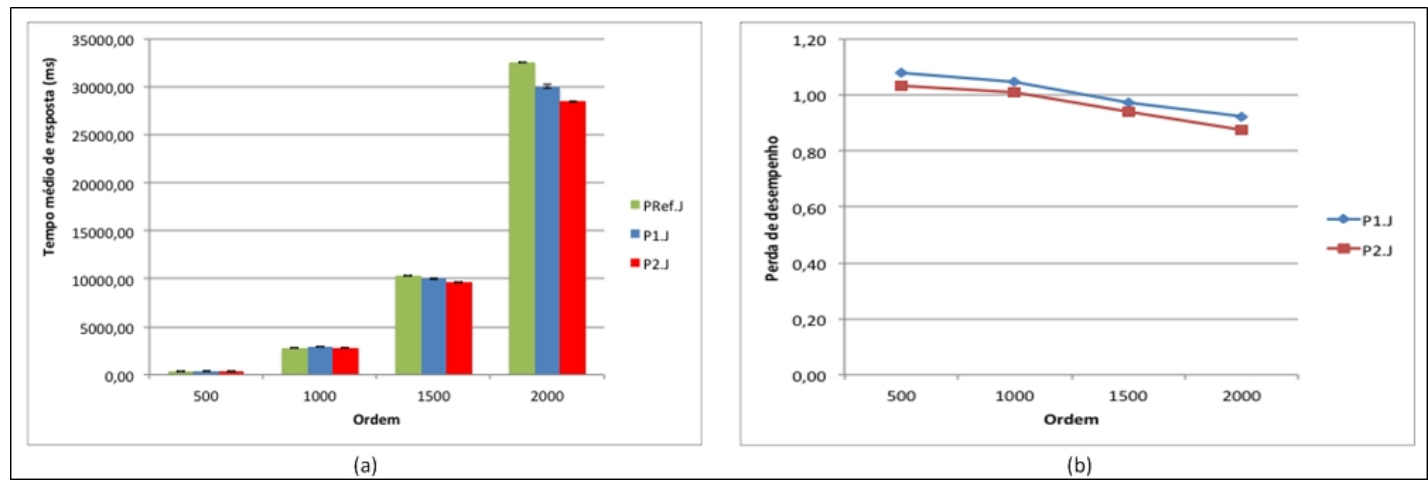

Figura 5.12: Resultados obtidos ao executar aplicações distribuídas baseadas em SOA do tipo memory-intensive de carga moderada e alta implantadas no servidor de aplicação JBoss com 25\% de utilização dos processadores disponibilizados: a) Tempo médio de resposta e b) Perda de desempenho.

Ao analisar o gráfico da Figura 5.12.b, percebe-se que a maior perda de desempenho registrada para a plataforma P1.J foi de $8 \%$ quando $O=500$, sendo, também de $8 \%$ o maior ganho de desempenho registrado, ocorrendo quando $O=2000$. De maneira similar, a plataforma P2.J obteve, aproximadamente, $3 \%$ como a maior perda de desempenho e $12 \%$ como o maior ganho, respectivamente para os mesmos valores de $O$ considerados em P1.J.

Ao considerar os resultados obtidos com o servidor de aplicação JBoss e compará-los com os registrados com o servidor de aplicação Glassfish, percebe-se que para $O \leq 1.000$, as perdas de desempenho registradas pelas aplicações foram superiores entre $12 \%$ e $42 \%$ ao considerar plataforma P1.J e entre $9 \%$ e $40 \%$ ao analisar os resultados registrados com a plataforma P2.J. No entanto, à medida que a ordem das matrizes é incrementada, as plataformas baseadas em JBoss registraram redução nas perdas de desempenho em, aproximadamente, $9 \%$.

Esse comportamento possui sua origem no recurso de carregamento paralelo e sob demanda de classes, presente no servidor JBoss, fazendo com que o tempo global de processamento seja reduzido como pode ser observado no gráfico da Figura 5.12.a.

Ao comparar os resultados obtidos nesse gráfico com aqueles registrados no gráfico da Figura 5.6.a, percebe-se que para $O<2.000$ a plataforma Pref.J apresentou reduções superiores nos tempos globais de processamento se comparado com aquelas obtidas pelas plataformas virtualizadas, conforme pode ser observado na Tabela 5.4, que apresenta a razão entre os tempos médios de resposta obtidos pelas aplicações aos serem executadas 
nas plataformas baseadas em JBoss e os tempos médios obtidos ao serem executadas sobre as plataformas baseadas em Glassfish.

\begin{tabular}{|c|c|c|c|}
\hline O & Plataforma PRef.J & Plataforma P1.J & Plataforma P2.J \\
\hline 500 & 0,63 & 0,89 & 0,89 \\
\hline 1.000 & 0,89 & 0,98 & 0,98 \\
\hline 1.500 & 0,96 & 0,97 & 1,00 \\
\hline 2.000 & 1,02 & 0,96 & 0,95 \\
\hline
\end{tabular}

Tabela 5.4: Redução nos tempos médios de resposta ao substituir o servidor de aplicação Glassfish pelo JBoss.

Ao analisar a Tabela 5.4 e considerando $500 \leq O \leq 1.500$, percebe-se que a maior redução registrada pela plataforma PRef.J foi de $37 \%$ e a menor foi de $4 \%$, respectivamente, quando $O=500$ e $O=1.500$. Já as plataformas virtualizadas registraram, ambas, 11\% como a maior redução, sendo que apenas P1.J registrou redução para o maior ordem, do intervalo considerado, sendo de, aproximadamente, 3\%. Já a plataforma P2.J obteve tempo médio de resposta equivalente ao obtido pela plataforma P2.G quando $O=1.500$.

No entanto, quando $O=2.000$, apenas a plataforma PRef.J apresentou tempo de processamento mais elevado, sendo que as plataformas P1.J e P2.J apresentaram redução, aproximada, de $4 \%$ e $5 \%$, respectivamente.

Ao realizar carga de classes sob demanda, os Web Services iniciam a execução do método estático main() mais rapidamente, ampliando a razão entre o tempo total de processamento e o tempo de preparação do container. Adicionalmente, durante as execuções dos métodos, há uma redução na sobrecarga gerada pelo carregamento de classes, uma vez que ela ocorre em paralelo, fazendo com que o servidor de aplicação apresente um melhor aproveitamento dos múltiplos núcleos disponibilizados na plataforma. No entanto, à medida que o tempo de processamento aumenta, o tempo gasto com a carga das classes deixa de ser significativo, fazendo com que os recursos de gerenciamento de memória, disponibilizados pelas plataformas de virtualização, sejam significativos, reduzindo as diferenças entre os tempos totais de processamento obtidos pelas plataformas virtualizadas e aqueles obtidos pela plataforma que não possui gerenciador de máquinas virtuais.

No entanto, quando a quantidade de processadores utilizados é incrementado para $50 \%$ e $75 \%$, o comportamento global das plataformas passa a ser similar àquele obtido pelas plataformas baseadas em Glassfish, sendo que à medida que se amplia a ordem das matrizes, incrementa-se, também, as perdas de desempenho sofridas pelas aplicações baseadas em SOA ao serem executadas em plataformas virtualizadas, como pode ser observado nos gráficos das Figuras 5.13.b e 5.13.d.

Ao observar o gráfico da Figura 5.13.b, percebe-se que para $O=500$, o desempenho das três plataformas consideradas são equivalentes, o que pode ser confirmado ao analisar o gráfico da Figura 5.13.a, que demonstra a sobreposição dos intervalos de confiança e das 


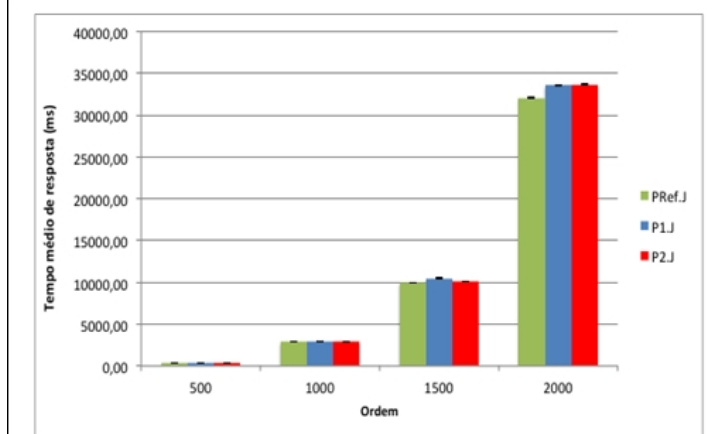

(a)

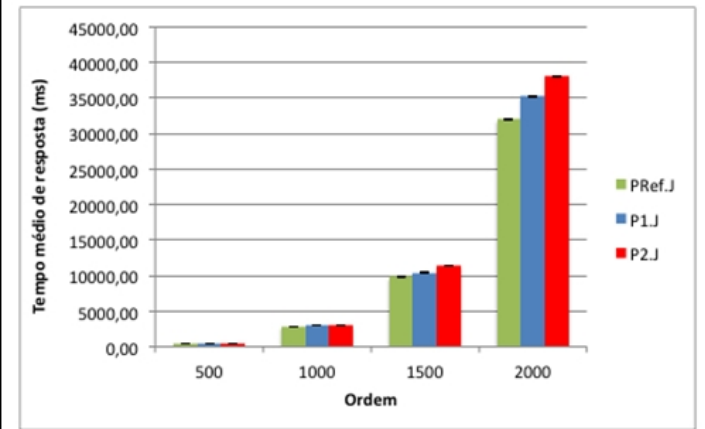

(c)

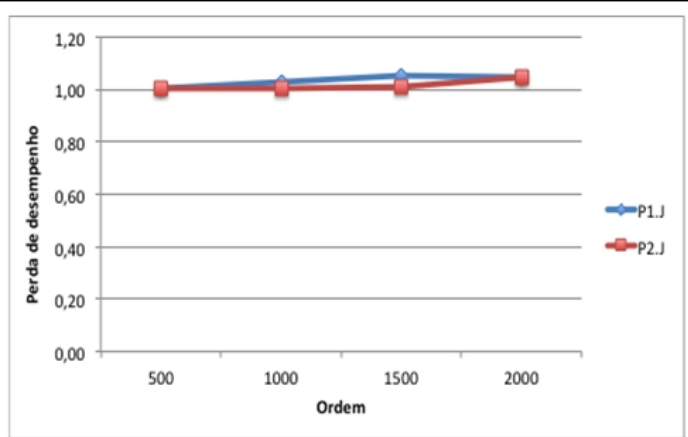

(b)

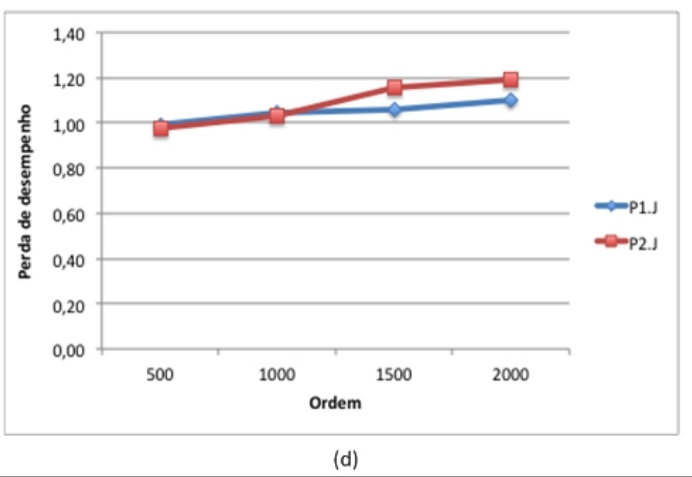

Figura 5.13: Resultados obtidos ao executar aplicações distribuídas baseadas em SOA do tipo memory-intensive de carga moderada e alta implantadas no servidor de aplicação JBoss: a) Tempo médio de resposta com 50\% de utilização dos processadores; b) Perda de desempenho com $50 \%$ de utilização dos processadores; c) Tempo médio de resposta com $75 \%$ de utilização das CPUs e d) Perda de desempenho com $75 \%$ de utilização das CPUs.

médias das plataformas destacadas. No entanto, à medida que a ordem das matrizes é ampliada para mil, apenas as plataformas PRef.J e P2.J apresentam desempenho semelhante, sendo registrado para a plataforma baseada em VMWare uma perda de desempenho de, aproximadamente, $3 \%$, sendo que ao incrementar ainda mais a ordem das matrizes, a perda registrada por essa plataforma atinge, aproximadamente, $5 \%$. Essa mesma perda é a maior registrada para a plataforma baseada em Hyper-V. Porém, essa situação somente ocorre com a plataforma P2.J quando $O=2.000$, enquanto que, na plataforma P1.J, tal situação já é registrada a partir de um estágio anterior, quando $O=1.500$, permanecendo constante ao ampliar a ordem das matrizes para o valor máximo considerado.

Ao ampliar a taxa de utilização dos processadores para, aproximadamente, 75\%, percebe-se que para aplicações predominantemente memory-intensive de carga moderada, onde $O=500$, as plataformas virtualizadas apresentam ganhos de desempenho de $1 \%$ e $2 \%$ para as plataformas P1.J e P2.J, respectivamente. Assim como ocorreu com os resultados obtidos ao considerar as plataformas baseadas em Glassfish, no entanto, em uma ordem de grandeza muito inferior, já que as plataformas P1.G e P2.G apresentaram ganhos de, 
aproximadamente, $44 \%$ e $37 \%$, respectivamente.

Porém, à medida que as aplicações deixam de ser exclusivamente memory-intensive de carga moderada e progridem para se tornar de carga elevada, onde $1.000 \leq O \leq 1.500$, ambas as plataformas deixam de registrar ganhos de desempenho, passando a impor as aplicações perdas de desempenho de até $6 \%$ na plataforma P1.J e de até $16 \%$ na plataforma P2.J, diferentemente dos resultados obtidos pelas plataformas virtualizadas baseadas em Glassfish para os mesmos valores de $O$ analisados. Nestas plataformas, foram registrados ganhos de desempenho quando $O=1.000$ e perdas muito pequenas, inferiores à $1 \%$, quando $O=1.500$. Esse comportamento obtido pelas plataformas baseadas em JBoss, deve-se, principalmente, ao aumento na frequência de execução do Garbage Collector da máquina virtual Java.

Apesar da máquina virtual Java utilizada nas plataformas baseadas nos servidores de aplicação Glassfish e JBoss ser a mesma, os servidores atribuem parâmetros ao iniciarem a JVM que melhor atendem aos requisitos dos projetos de ambos os servidores, sendo essa característica ressaltada ao habilitar o parâmetro server, que indica a ambos os servidores de aplicação que a JVM é destinada à um ambiente de produção e que o desempenho deve ser priorizado. Assim, é natural que a frequência de execução do Garbage Collector seja diferente nas diferentes plataformas consideradas.

Ao instanciar um objeto, a JVM o aloca em um espaço do heap denominado geração Jovem, que é divida em 3 partes. A primeira parte, denominada Éden, armazena os objetos instanciados recentemente e à medida que esse espaço é ocupado em uma certa porcentagem, uma coleta menor ocorre, fazendo com que os objetos que ainda possuam referências ativas sejam copiados para uma outra área denominada Survivor. Diferentemente do Éden que não recebe objetos de outros espaços de memória ou de outras gerações, o espaço Survivor recebe tanto objetos armazenados anteriormente no espaço Éden, quanto envia objetos para a geração Velha. Uma vez que o espaço sobrevivente possui uma grande movimentação de objetos, é necessário que o mesmo seja ordenado para facilitar a busca, sendo, assim, dividido em duas áreas iguais. Na primeira execução do coletor de lixo, apenas a primeira área recebe objetos, sendo a segunda área mantida totalmente livre. Em uma segunda execução, todos os dados da primeira área são copiados para a segunda área juntamente com os novos objetos recebidos do espaço Éden. Essa técnica auxilia a manter o espaço Survivor sempre ordenado.

No entanto, ao tratar aplicações que utilizam uma quantidade muito grande de memória e cujos objetos permanecem com referências ativas por tempo significativo, essa técnica eleva o tempo global de processamento das aplicações, uma vez que para executar as coletas menores, em que os dados são manipulados apenas na geração Jovem, uma grande quantidade de memória deve ser copiada entre as áreas do espaço Survivor.

Adicionalmente, ao considerar o servidor de aplicação JBoss, percebe-se que as plataformas virtualizadas apresentam uma maior frequência na execução de coletas de lixo, 
uma vez que o servidor de aplicação em questão analisa, também, a quantidade total de memória DRAM disponível, sendo essa inferior nas plataformas virtualizadas. Essa sobrecarga exercida pelos operações de coleta de lixo são ampliadas, ainda mais, quando as aplicações passam a ser exclusivamente memory-intensive de carga elevada, como aquelas representadas quando $O=2.000$. Nessa configuração, ao considerar a taxa de ocupação de $75 \%$ dos processadores, as perdas de desempenho registradas pelas plataformas baseadas em virtualizadores foram de, aproximadamente, $10 \%$ e $19 \%$ ao considerar P1.J e P2.J, respectivamente.

Ao comparar as perdas registradas quando $N=2.000$ e com taxa de processadores variando entre $50 \%$ e $75 \%$, é possível perceber que para uma menor taxa de utilização das CPUs disponíveis, as perdas de desempenho são inferiores em $5 \%$ e 14\%, ao considerar, respectivamente, os resultados obtidos por P1.J e P2.J. Isso ratifica a influência da operação de coleta de lixo, uma vez que à medida que se amplia a quantidade de processadores utilizados, aumenta-se, também, a quantidade de memória alocada em cada intervalo de tempo, fazendo com que seja necessário mais tempo para transferir os dados entre as áreas do espaço Survivor.

Apesar da sobrecarga gerada pelo incremento da frequência em que a tarefa de coleta de lixo é executada nas plataformas baseadas em JBoss, principalmente nas plataformas virtualizadas, os tempos médios de resposta obtidos por essas plataformas são inferiores aos obtidos pelas plataformas baseadas em Glassfish, como pode ser observado ao se comparar os resultados obtidos nos gráficos das Figuras 5.13.a e 5.13.c com aqueles registrados nos gráficos das Figuras 5.7.a e 5.7.c, respectivamente.

Ao considerar os resultados obtidos quando a taxa de utilização dos processadores é de $50 \%$, percebe-se que apenas quando $O=2.000$ as plataformas P1.J e P2.J apresentam tempos médios de resposta superiores aos obtidos pelas plataformas P1.G e P2.G, respectivamente, $3 \%$ e $10 \%$. Sendo que esses resultados permanecem ao incrementar a quantidade de processadores utilizados para $75 \%$.

Isso indica que os recursos ativados pelo servidor de aplicação JBoss impõem um desempenho superior às aplicações baseadas em SOA se comparado aos recursos ativos pelo servidor de aplicação Glassfish, sendo tal vantagem superada, apenas, quando a quantidade de memória alocada é muito elevada, bem como o "tempo de vida" dos objetos utilizados. No entanto, à medida que a taxa de utilização dos processadores atinge $100 \%$, os tempos médios de resposta, obtidos pelas plataformas baseadas em JBoss, passam a ser, frequentemente, inferiores aos registrados pelas plataformas baseadas em Glassfish, como pode ser observado no gráfico da Figura 5.14.a.

Ao observar os resultados apresentados na Figura 5.14.a e compará-los com aqueles obtidos pelas plataformas baseadas em Glassfish, percebe-se que à medida que a carga de trabalho deixa de ser memory-intensive de carga moderada e passa a ser de carga elevada, sendo $O \geq 1.500$, as redução nos tempos totais de processamento obtidos pelas 


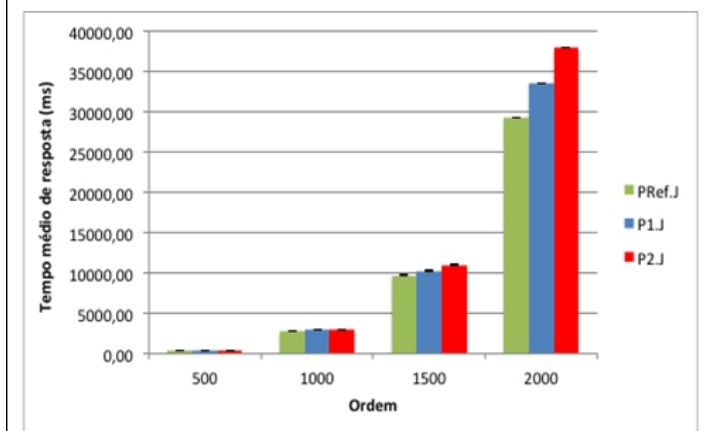

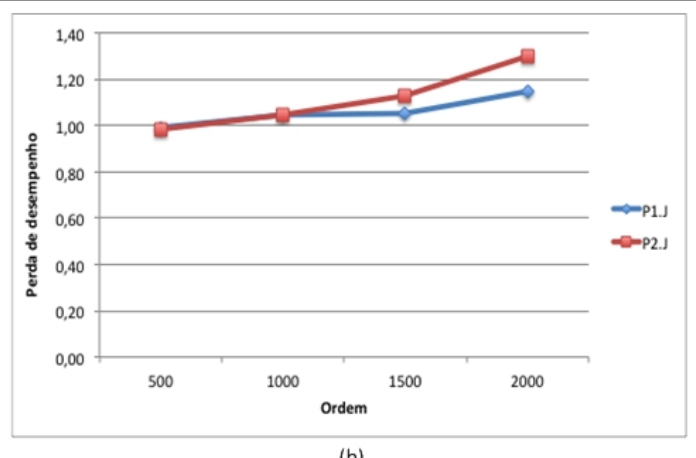

(b)

Figura 5.14: Resultados obtidos ao executar aplicações distribuídas baseadas em SOA do tipo memory-intensive de carga moderada e alta implantadas no servidor de aplicação JBoss com 100\% de utilização dos processadores disponibilizados: a) Tempo médio de resposta e b) Perda de desempenho.

plataformas baseadas em JBoss são maiores que aquelas obtidas quando a ordem das matrizes são inferiores, o que caracteriza a superioridade do servidor de aplicação JBoss e da gestão de threads desse container de Web Services.

Ao observar a plataforma PRef.J, é possível perceber que a redução no tempo global de processamento em relação à plataforma PRef.G foi em média, de, aproximadamente, $9 \%$, sendo essa a maior redução registrada, uma vez que as plataformas P1.J e P2.J, apresentaram redução, em relação às plataformas P1.G e P2.G, respectivamente, de, 8,5\% e $7 \%$.

Essa redução superior no tempo total de processamento, obtido pela plataforma de referência, reflete nas perdas de desempenho registradas pelas aplicações distribuídas executadas nas plataformas virtualizadas, como pode ser observado no gráfico da Figura 5.14.b, onde a plataforma P1.J registrou perdas de desempenho de até $15 \%$ em relação à plataforma PRef.J, sendo essa perda registrada quando $O=2.000$. Já para aplicações memory-intensive de carga moderada, em que $O=500$, a plataforma P1.J apresentou ganho de desempenho de, aproximadamente, $1 \%$. Essa perda elevada quando $O=2.000$ também foi registrada pela plataforma P2.J, cuja perda de desempenho foi de, aproximadamente, $30 \%$.

De maneira análoga ao ocorrido nas plataformas P1.G e P2.G, ao analisar as perdas de desempenho registradas pelas plataformas P1.J e P2.J, percebe-se que a plataforma baseada em Hyper- $\mathrm{V}$ apresenta dificuldades em gerenciar os recursos virtualizados em cenários de carga de trabalho elevada, levando essa plataforma a registrar perdas de desempenho extremamente elevadas, deixando de ser a plataforma mais eficiente dentre as virtualizadas.

Esse resultado negativo da plataforma P2.J é incrementado pelo servidor de aplicação JBoss, que ao ampliar a taxa de execuções do coletor de lixo, eleva muito a perda de desem- 
penho da plataforma. Tal fato pode ser comprovado ao comparar a perda de desempenho sofrida pelas aplicações ao serem executadas na plataforma P2.G e aquela registrada na plataforma P2.J, quando $O=2.000$. Nessa plataforma a perda foi de, aproximadamente, $30 \%$, enquanto naquela foi de, aproximadamente, $23 \%$. Essa mesma situação ocorre com a plataforma baseada em VMware, uma vez que a plataforma P1.J registrou perda de desempenho, em relação à plataforma de referência, de, aproximadamente, $7 \%$ superior àquela registrada pela plataforma P1.G.

\subsection{Considerações finais}

Este capítulo apresentou a análise da influência da virtualização no desempenho de aplicações distribuídas baseadas em SOA, do tipo CPU-bound e memory-intensive, ao serem executadas sobre os gerenciadores de máquinas virtuais VMWare e Hyper-V. Desta forma, foi possível destacar as características da virtualização que influenciam direta ou indiretamente no desempenho dessas aplicações, a fim de que sejam consideradas no momento de tomada de decisão da escolha da plataforma e na adaptação de modelos de planejamento de capacidade existentes para que reflitam, de forma realista, o cenário abordado.

Demonstrou-se neste capítulo que a virtualização possui forte influência no desempenho de aplicações distribuídas, principalmente as memory-intensive de carga moderada e elevada, permitindo, inclusive, que as aplicações executadas sobre plataformas virtualizadas obtivessem melhor desempenho que aquelas executadas sobre plataformas não virtualizadas. Essa superioridade é obtida mediante a exploração eficiente, pelos virtualizadores, dos recursos presentes nos hardwares atualmente em uso, como a tabela dupla de páginas e as large pages, e, também, pela implementação dos hypervisores, como a alocação garantida, explorada pelo VMWare, e a eliminação de páginas zeradas implementada pelo Hyper-V.

Demonstrou-se, ainda, que a substituição do servidor de aplicação altera significativamente o desempenho das aplicações baseadas em SOA, mesmo a máquina virtual Java utilizada sendo a mesma para ambos os cenários analisados. Tal fato se deve aos parâmetros enviados pelos servidores de aplicação à JVM e ao método de carregamento de classes, sendo esse mais eficientemente realizado pelo servidor de aplicação JBoss.

No entanto, a fim obter um melhor entendimento sobre o desempenho de aplicações distribuídas baseadas em SOA, faz-se necessário avaliar a influência da virtualização nas bibliotecas de codificação e decodificação de mensagens SOAP, uma vez que tais mensagens são fundamentais para a arquitetura orientada à serviço. Assim, o próximo capítulo realizará tal avaliação. 
Capítulo

6

\section{Virtualização e a manipulação de envelopes SOAP}

\subsection{Considerações iniciais}

De maneira análoga ao adotado no Capítulo 5, os resultados apresentados neste capítulo serão divididos em duas seções. A primeira abordará a influência da virtualização no desempenho de aplicações distribuídas baseadas em SOA ao realizarem operações de unmarshalling de mensagens SOAP, sendo tais aplicações instanciadas em conteineres do servidor de aplicação Glassfish. Também utilizando o servidor de aplicação Glassfish, a segunda seção analisará o desempenho das aplicações ao executar operações de marshalling de mensagens SOAP.

\subsection{Operação unmarshalling}

A operação de unmarshalling é realizada pelo Web Service no momento em que ele recebe uma mensagem SOAP, enviada pelo software consumidor, convertendo os elementos XML presentes no envelope, para objetos armazenados na memória DRAM, sendo essa operação também conhecida como deserialização de objetos. Todavia, essa nomenclatura mais popular é, de certa forma, mais genérica, pois se refere a qualquer processo que realiza a transformação de uma série de bytes em objetos. No entanto, para o contexto deste trabalho, ambos os termos, unmarshalling e deserialização, serão utilizados como sinônimos, uma vez que todas as séries de dados analisadas são provenientes de mensagens SOAP.

Como descrito no capítulo 5, as operações de unmarshalling de mensagens SOA ocor- 
rem nos Web Services à medida que eles recebem envelopes SOAP enviados pelo software consumidor. Tais envelopes, mais especificamente a seção body, são formados por elementos XML constituídos de dez, cem ou mil caracteres, constituindo mensagens onde $2 M B \leq S \leq 10 M B$, sendo que $S$ representa o tamanho aproximado da mensagem enviada.

Nesse contexto, é possível observar no gráfico da Figura 6.1.a os tempos médios de resposta obtidos pelas plataforma baseadas no servidor de aplicação Glassfish, quando a taxa de utilização das CPUs disponíveis é de $25 \%$.

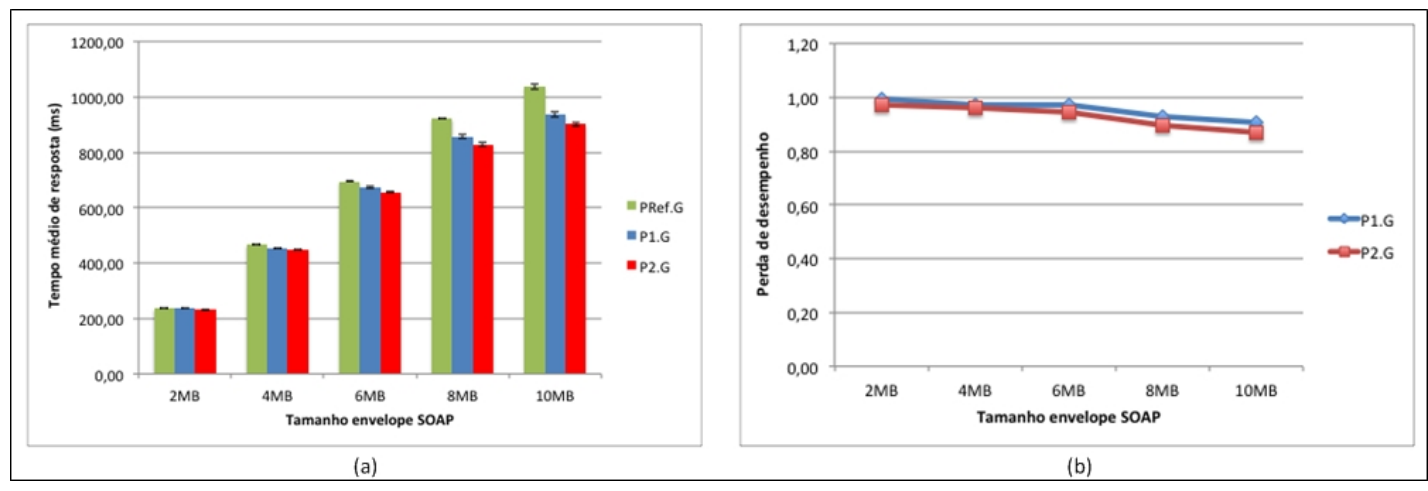

Figura 6.1: Resultados obtidos pelas plataformas baseadas em Glassfish durante as operações de unmarshalling de mensagens SOAP com $25 \%$ de utilização dos processadores: a) Tempo médio de resposta e b) Perda de desempenho.

Como é possível perceber ao analisar a Figura 6.1.a, não ocorreram sobreposições dos intervalos de confiança e das médias para os valores de $S$ considerados, no entanto, percebe-se que à medida que o tamanho da mensagem SOAP é incrementado, ampliase, também, o intervalo de confiança obtido. Esse comportamento demonstra que por se tratar de um processo baseado na alocação de memória e construção de objetos, o que exige pouca potência computacional da unidade de processamento, as operações de unmarshalling apresentam resultados com variações significativas nos tempos de resposta, uma vez que, para valores elevados de $S$, ocorre a execução de coletas de lixo, fazendo com que os tempos médios de resposta sejam maiores nesses momentos, principalmente pelo processo de compactação do espaço Survivor, ampliando, assim, os intervalos de confiança.

A execução do Garbage Collector para valores elevados de $S$ se deve à quantidade de memória DRAM necessária para processar tais mensagens. Uma única operação de unmarshalling de uma mensagem SOAP de $2 M B$, consome, aproximadamente, $24 M B$ de memória no conteiner de Web Services, já para uma mensagem de $10 M B$, são consumidos, aproximadamente, $90 M B$. No entanto, a progressão da quantidade de memória à medida que se amplia o número de submissões não é linear, ou seja, ao se considerar 25 submissões, de mensagens SOAP de $2 M B$, seria possível ponderar que deveriam ser necessários $600 M B$ de memória DRAM, no entanto, são consumidos, aproximadamente, 403 MB, o 
que corresponde a uma diferença de, aproximadamente, $32 \%$.

Essa diferença tende a aumentar à medida que o tamanho da mensagem SOAP é ampliada. Para mensagens onde $S=10 M B$ são necessários, aproximadamente, $1.367 M B$, o que corresponde a uma diferença de $39 \%$ com relação ao valor obtido pela multiplicação do consumo de memória de apenas uma única operação pela quantidade de submissões, o que corresponderia a um total de $2.250 \mathrm{MB}$ de memória DRAM.

No entanto, analisando os valores citados, é possível perceber que ao ampliar o tamanho da mensagem SOAP de $2 M B$ para $10 M B$, considerando 25 submissões, há um incremento de $375 \%$ na quantidade de memória DRAM alocada pelo conteiner do servidor de aplicação. Essa elevação faz com que o ganho de desempenho obtido pelas plataformas virtualizadas, em relação à plataforma de referência, seja ampliado à medida que se incrementa o tamanho da mensagem SOAP, como pode ser observado no gráfico da Figura 6.1.b.

Para todos os valores de $S$ analisados, a plataforma P2.G apresentou o melhor desempenho dentre as plataformas consideradas. O menor ganho de desempenho dessa plataforma, em relação à plataforma de referência, foi de, aproximadamente, $3 \%$ quando $S=2 M B$ e o maior de, aproximadamente, $13 \%$, quando $S=10 M B$. Já a plataforma P1.G apresentou ganhos de desempenhos, em relação à mesma plataforma de referência, variando entre $1 \%$ e $10 \%$, também, quando $S=2 M B$ e $S=10 M B$, respectivamente.

Esse ganho de desempenho obtido pela plataforma P1.G se deve, principalmente, ao recurso de manter as páginas de memória liberadas pelo sistema operacional convidado mapeadas na memória física do sistema operacional hospedeiro, permitindo que ausências maiores de páginas sejam tratadas rapidamente. Como a quantidade de memória reservada para a máquina virtual do sistema operacional convidado é menor que a quantidade de memória presente no virtualizador, praticamente toda memória requerida pelo sistema operacional convidado já se encontra alocada e disponível no virtualizador de máquinas virtuais VMWare.

Já a plataforma P2.G se utiliza dos recursos Large Pages e compressão de páginas zeradas para ampliar o desempenho do sistema operacional convidado. Tais recursos fazem com que as alocações de páginas sejam mais rápidas, uma vez que páginas maiores que as tradicionais são alocadas pelo virtualizador, fazendo com que cada página alocada, no sistema operacional hospedeiro, corresponda à quinhentas páginas no sistema operacional convidado.

Adicionalmente, ambas as plataformas fazem uso do recurso de tabela de páginas duplas, disponibilizado pelos processadores utilizados nas plataformas, permitindo com que os gerenciadores de máquinas virtuais tenham mapeados em suas tabelas de páginas as páginas utilizadas pelas aplicações virtualizadas, o que, também, reduz o tempo de tratamento de falta de páginas.

Porém, à medida que a taxa de processadores utilizados é ampliada para 50\%, a pla- 
taforma P2.G deixa de apresentar o melhor desempenho quando $S>2 M B$. Ao ampliar a taxa de utilização das plataformas, torna-se necessário alocar blocos maiores de memória em cada etapa de consumo devido às submissões paralelas realizadas pelas threads consumidoras, permitindo que os tempos médios de resposta obtidos pelas plataformas virtualizadas sejam inferiores aos tempos obtidos quando a taxa de utilização dos processadores era de 25\%, como pode ser observado no gráfico da Figura 6.2.a.

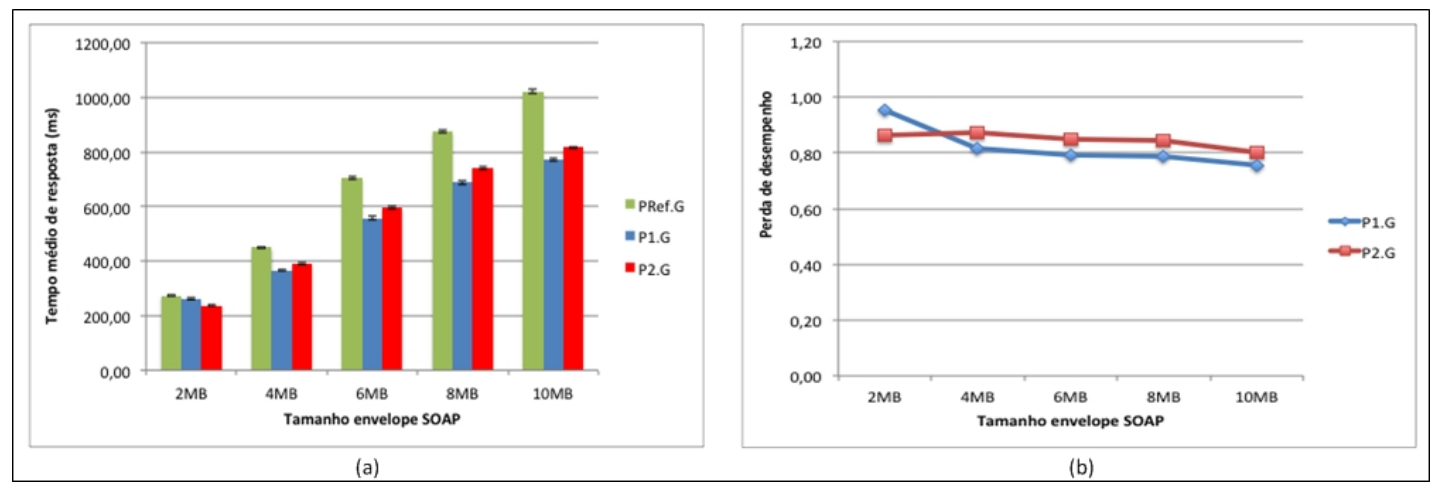

Figura 6.2: Resultados obtidos pelas plataformas baseadas em Glassfish durante as operações de unmarshalling de mensagens SOAP com taxa de utilização de processadores de 50\%: a) Tempo médio de resposta e b) Perda de desempenho.

No entanto, como pode ser observado ao comparar os resultados disponibilizados no gráfico da Figura 6.1.a com os resultados do gráfico da Figura 6.2.a, percebe-se que para o primeiro valor de $S$ analisado, há um aumento nos tempos médios de resposta, ocasionados pela sobrecarga gerada nos servidores de aplicação ao alocar threads simultâneas para tratar as requisições. Esse tempo de alocação das threads é relativamente elevado se comparado ao tempo necessário para realizar as operações de unmarshalling.

Nesse contexto, a plataforma P2.G apresentou uma elevação de apenas 3\% no tempo médio de resposta, o que justifica o seu melhor desempenho dentre as plataformas analisadas, enquanto as plataformas PRef.G e P1.G registraram, respectivamente, 15\% e $11 \%$.

Assim, quando a taxa de utilização dos processadores é de $50 \%$, o menor ganho de desempenho registrado pela plataforma P1.G, em relação à plataforma de referência, foi de $4 \%$, enquanto o maior foi de $24 \%$, respectivamente, quando $S=2 M B$ e $S=10 M B$. Já a plataforma P2.G apresentou ganhos de desempenho crescentes, variando entre $13 \%$ e $20 \%$, à medida que o tamanho da mensagem SOAP é ampliada. Tais resultados podem ser observados no gráfico da Figura 6.2.b.

Desta forma, é possível perceber a inversão de desempenho das plataformas virtualizadas com relação à plataforma de referência, sendo que, para $S>2 M B$, a plataforma P1.G apresentou o melhor desempenho dentre as plataformas analisadas. Tal fato se deve à presença de operações de coleta de lixo para o tamanho das mensagens consideradas, 
sendo que tais coletas fazem com que os sistemas operacionais convidados das plataformas virtualizadas, e o próprio sistema operacional da plataforma PRef.G, liberem a memória DRAM destinada ao espaço Éden, uma vez que o tempo de vida dos objetos utilizados é relativamente pequeno. Nesse cenário, o gerenciador de máquinas virtuais VMWare não libera a memória DRAM no virtualizador, fazendo com que as próximas alocações sejam mais eficientes que as realizadas nas outras duas plataformas, uma vez que as páginas já estão previamente mapeadas nas tabelas duplas de páginas do recurso EPT.

Esse cenário se mantém à medida que se amplia a taxa de utilização de CPUs para $75 \%$ e 100\%, como pode ser observado nos gráficos da Figura 6.3.a e 6.2.b, que apresentam as perdas de desempenho sofridas pelas aplicações distribuídas ao serem executadas sobre as plataformas baseadas em Glassfish, com taxa de utilização de CPUs de $75 \%$ e $100 \%$, respectivamente.

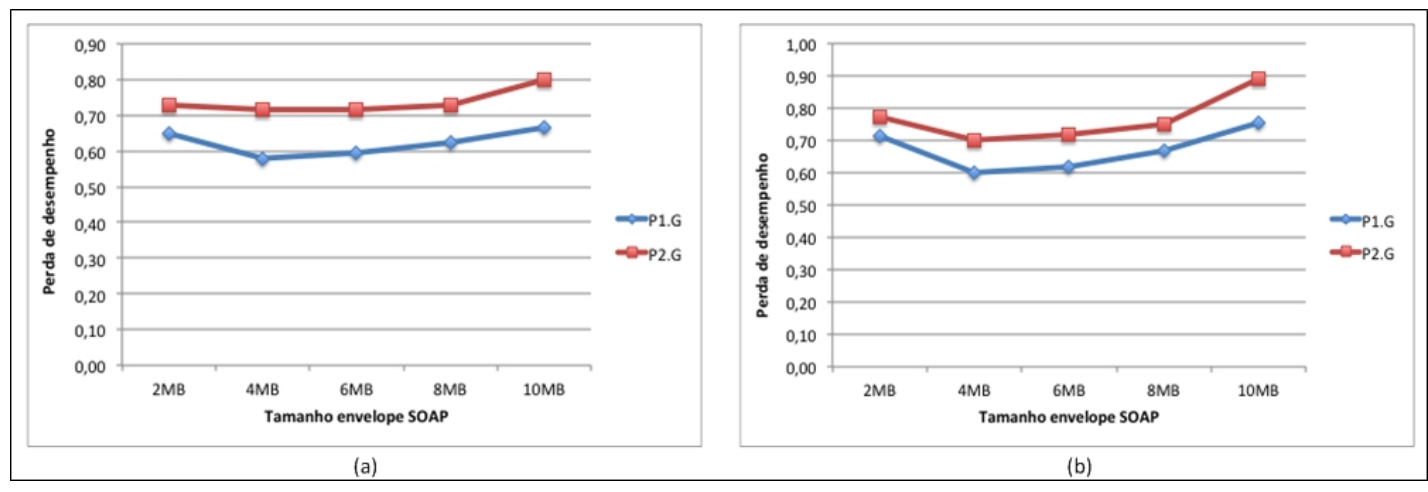

Figura 6.3: Perdas de desempenho sofridas pelas plataformas virtualizadas baseadas em Glassfish durante as operações de unmarshalling de mensagens SOAP: a) 75\% de utilização das CPUs e b) $100 \%$ de utilização das CPUs.

Quando a taxa de utilização das CPUs é de $75 \%$, o menor ganho de desempenho observado na plataforma P1.G foi de 34\%, em relação à plataforma de referência, já o maior ganho foi de $42 \%$, respectivamente, quando $S=10 M B$ e $S=4 M B$. Isso indica que o ganho de desempenho deixou de apresentar um comportamento crescente à medida que o tamanho das mensagens SOAP foi ampliado, como ocorreu nos casos anteriores, quando a taxa de utilização das CPUs era menor.

Esse mesmo comportamento foi apresentado pela plataforma P2.G, sendo o menor ganho de desempenho registrado quando $S=10 M B$ e o maior quando $S=4 M B$, respectivamente, $20 \%$ e $28 \%$.

Esse fato se deve basicamente ao aumento das operações de coleta de lixo para grandes blocos de memória alocados e a redução na quantidade de memória necessária, para alguns valores de $S$, à medida que se amplia a taxa de utilização dos processadores e, consequentemente, a quantidade de threads requisitando e liberando memória da geração Jovem da JVM. Esta característica pode ser observada na Tabela 6.1. 


\begin{tabular}{|c|c|c|c|c|}
\hline \multirow{2}{*}{ Tamanho envelope SOAP } & \multicolumn{4}{|c|}{ Taxa de utilização das CPUs } \\
\cline { 2 - 5 } & $\mathbf{2 5 \%}$ & $\mathbf{5 0 \%}$ & $\mathbf{7 5 \%}$ & $\mathbf{1 0 0} \%$ \\
\hline $2 \mathrm{MB}$ & $403 \mathrm{MB}$ & $407 \mathrm{MB}$ & $414 \mathrm{MB}$ & $408 \mathrm{MB}$ \\
\hline $4 \mathrm{MB}$ & $821 \mathrm{MB}$ & $822 \mathrm{MB}$ & $830 \mathrm{MB}$ & $825 \mathrm{MB}$ \\
\hline $6 \mathrm{MB}$ & $1.082 \mathrm{MB}$ & $1.235 \mathrm{MB}$ & $1.235 \mathrm{MB}$ & $599 \mathrm{MB}$ \\
\hline $8 \mathrm{MB}$ & $1.309 \mathrm{MB}$ & $1.019 \mathrm{MB}$ & $893 \mathrm{MB}$ & $632 \mathrm{MB}$ \\
\hline $10 \mathrm{MB}$ & $1.367 \mathrm{MB}$ & $1.367 \mathrm{MB}$ & $976 \mathrm{MB}$ & $976 \mathrm{MB}$ \\
\hline
\end{tabular}

Tabela 6.1: Quantidade média de memória alocada em 25 iterações de consumo por taxa de utilização de CPUs.

Ao analisar os dados da Tabela 6.1, percebe-se que há uma redução na quantidade de memória consumida quando $S \geq 8 M B$ ao elevar a taxa de utilização das CPUs de $50 \%$ para $75 \%$. Sendo assim, se ao ampliar a taxa de utilização das CPUs as plataformas apresentassem o mesmo comportamento registrado quando a taxa de utilização era de $50 \%$, o maior ganho de desempenho registrado ocorreria quando $S=6 M B$, já que para esse tamanho de mensagem SOAP, a quantidade de memória a ser alocada seria a maior dentre as submissões realizadas. No entanto, quando $\geq 6 M B$, as plataformas baseadas em Glassfish registraram atividades de coleta de lixo devido aos grandes blocos de memória alocados e as reduções nos tempos médios de resposta, elevando, assim, a influência do tempo consumido com a execução do Garbage Collector.

Essa redução nos tempos médios de resposta das aplicações distribuídas pode ser observada na Tabela 6.2, que apresenta a razão entre os tempos médios de resposta obtidos ao realizar submissões aos Web Services com taxa de utilização das CPUs em $75 \%$ e aqueles obtidos com taxa de consumo de $50 \%$.

\begin{tabular}{|c|c|c|c|}
\hline S & Plataforma PRef.G & Plataforma P1.G & Plataforma P2.G \\
\hline $2 \mathrm{MB}$ & 0,88 & 0,59 & 0,74 \\
\hline $4 \mathrm{MB}$ & 1,02 & 0,73 & 0,84 \\
\hline $6 \mathrm{MB}$ & 1,02 & 0,77 & 0,86 \\
\hline $8 \mathrm{MB}$ & 1,02 & 0,81 & 0,88 \\
\hline $10 \mathrm{MB}$ & 0,97 & 0,85 & 0,97 \\
\hline
\end{tabular}

Tabela 6.2: Razão entre os tempos médios de resposta com taxa de utilização de CPU em $75 \%$ e $50 \%$.

Analisando os dados da Tabela 6.2, percebe-se que apenas a plataforma PRef.G não apresentou redução para todos os tempos médios de resposta ao incrementar a taxa de utilização de CPUs, uma vez que essa plataforma não possui otimizações para alocar e desalocar uma grande quantidade de memória DRAM em intervalos reduzidos de tempo.

Ao observar os resultados obtidos pelas plataformas virtualizadas, é possível concluir que à medida em que se incrementa o tamanho da mensagem SOAP enviada pelo consumidor, aumenta-se a razão obtida entre as duas taxas de utilização de CPU, mesmo reduzindo o tamanho do bloco de memória a ser alocado, como demonstrado na Tabela 
6.1. Essa característica é obtida uma vez que para $S \leq 6 M B$ a quantidade de memória necessária aumenta à medida que $S$ é incrementado, no entanto, apesar dessa quantidade de memória reduzir a partir do momento em que a mensagem atinge $8 M B$ de tamanho, a tarefa de coleta de lixo é ampliada devido ao tamanho das mensagens, fazendo com que se reduza a diferença entre os tempos de resposta para ambas as utilizações de CPU. Esse fato demonstra o elevado impacto gerado pelo Garbage Collector presente na JVM.

De maneira análoga, ao ampliar a taxa de utilização de CPU para $100 \%$, percebese, através do gráfico da Figura 6.3.b, que o menor ganho de desempenho apresentado pela plataforma P1.G, em relação à plataforma PRef.G, foi de $25 \%$, enquanto o maior foi de $40 \%$, respectivamente, quando $S=10 M B$ e $S=4 M B$. Para os mesmos valores de $S$ descritos, a plataforma P2.G registrou $11 \%$ e $30 \%$ como menor e maior ganho de desempenho, respectivamente.

Nesse cenário de utilização máxima da quantidade de processadores disponíveis, também ocorre redução na quantidade de memória DRAM necessária para executar as submissões, uma vez que a quantidade de memória alocada por interação é ainda maior que aquela necessária quando $75 \%$ dos processadores estavam sendo utilizados. Como pode ser observado na Tabela 6.1, essa redução ocorre a partir de mensagens SOAP com tamanho de $6 M B$, diferentemente do registrado no caso anterior, em que essa redução ocorreu quando $S \geq 8 M B$.

Sendo assim, a maior quantidade de memória consumida, sem a execução de coleta de lixo, ocorre quando $S=4 M B$, o que justifica o maior ganho de desempenho das plataformas virtualizadas serem obtidos com esse valor de $S$. Já a maior quantidade de execuções do Garbage Collector ocorreu quando $S=10 M B$, fazendo com que as plataformas baseadas em virtualizados obtivessem o menor ganho de desempenho em relação à plataforma de referência.

Ao se ampliar a taxa de utilização de processadores de $75 \%$ para $100 \%$, os tempos médios de resposta das plataformas analisadas foram ampliados, diferentemente do apresentado anteriormente quando a taxa de utilização de CPUs era menor. Com a utilização total dos processadores, os sistemas operacionais, que suportam as aplicações distribuídas, concorrem com os servidores de aplicação na utilização dos processadores, elevando os tempos de resposta, que inclui, entre outros valores, o tempo de escalonamento pelo sistema operacional e o de alocação de recursos e threads pelo servidor de aplicação.

Nesse contexto, a maior ampliação nos tempos médios de resposta registrada pela plataforma PRef.G foi de $32 \%$ quando $S=10 M B$, sendo que para $S=2 M B$ essa plataforma registrou redução de 3\%. Já P1.G e P2.G registraram, respectivamente, $50 \%$ e $47 \%$ como o maior aumento nos tempos de resposta, também, quando $S=10 M B$, o que demonstra a sobrecarga gerada pela alocação de grandes blocos de memória por iteração do software consumidor. 


\subsubsection{Caracteres por elemento XML}

Ao ampliar de dez para cem a quantidade de caracteres por elemento XML nas mensagens SOAP, considerando a taxa de ocupação dos processadores em $25 \%$, diminui-se os tempos médios de resposta registrados pelas aplicações distribuídas ao realizarem unmarshalling das mensagens, como pode ser observado nos resultados apresentados no gráfico da Figura 6.4.a, que apresenta os tempos médios de resposta registrados pelas aplicações distribuídas durante as operações de unmarshalling com cem caracteres por elemento XML e taxa de utilização dos processadores supracitada.

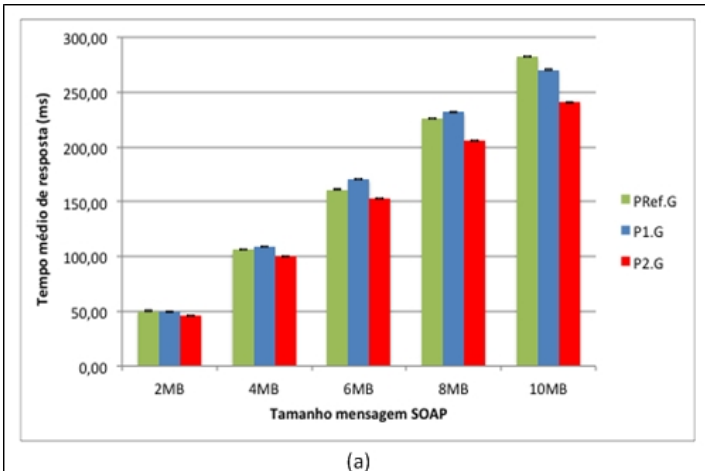

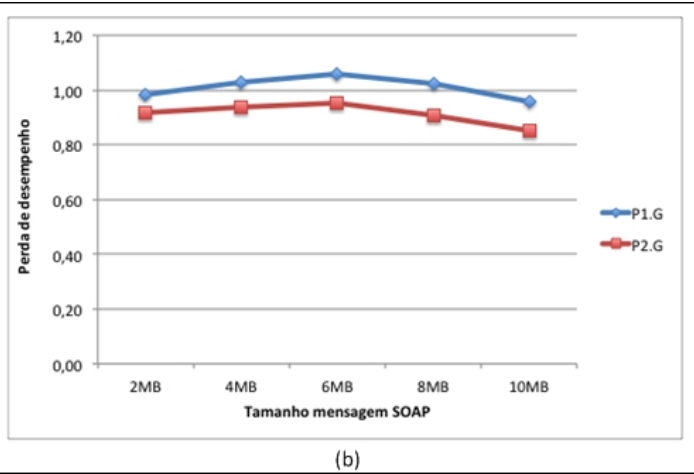

(b)

Figura 6.4: Resultados obtidos pelas plataformas baseadas em Glassfish durante as operações de unmarshalling de mensagens SOAP com cem caracteres por elemento XML e taxa de utilização de processadores de 25\%: a) Tempo médio de resposta e b) Perda de desempenho.

Ao se comparar os resultados apresentados no gráfico da Figura 6.4.a com aqueles demonstrados no gráfico da Figura 6.1.a, que apresenta os tempos médios de resposta obtidos pelas aplicações distribuídas ao realizar a deserialização de mensagens SOAP com dez caracteres e a mesma taxa de utilização dos processadores, é possível perceber que, em média, quando $S=2 M B$, a redução nos tempos de resposta é de, aproximadamente, $79 \%$, enquanto, para $S=10 M B$ a redução é de, aproximadamente, $72 \%$.

De maneira análoga, também ocorreu redução nas quantidades de memória DRAM utilizadas pelo servidor de aplicação para atender as requisições recebidas, independentemente da plataforma, sendo que à medida que o tamanho da mensagem é ampliado, reduz-se a razão entre a quantidade de memória consumida ao processar mensagens com cem e dez caracteres por elemento XML.

Ao considerar $S=2 M B$, a redução foi de, aproximadamente, $68 \%$, uma vez que ao processar mensagens com dez caracteres, o servidor de aplicação alocou, através da JVM, $403 M B$ de memória DRAM, já ao ampliar a quantidade de caracteres, a quantidade de memória consumida foi de, apenas, $130 \mathrm{MB}$. Ao considerar $S=10 \mathrm{MB}$, foram consumidos $1.367 M B$ e $630 M B$, respectivamente, para as mesmas quantidade de caracteres por mensagem XML consideradas anteriormente. 
Tal fato indica que a quantidade de atributos a ser instanciado e, consequentemente, preenchidos pelo servidor de aplicação, possui maior influência no desempenho em operações de unmarshalling de envelopes SOAP do que o tamanho desses objetos, uma vez que ao ampliar a quantidade de caracteres por elemento XML, reduz-se a quantidade de elementos presentes nas mensagens, já que o tamanho total da mensagem é preservado.

Essa característica se reflete na perda ou ganho de desempenho sofridos pelas aplicações distribuídas executadas sobre as plataformas virtualizadas, como pode ser observado no gráfico da Figura 6.4.b, que apresenta a perda de desempenho ao considerar elementos XML com cem caracteres e taxa de utilização de CPU de $25 \%$.

Ao observar a Figura 6.4.b, percebe-se que há duas fases de perda de desempenho: a primeira fase, que compreende os resultados obtidos quando $2 M B \leq S \leq 6 M B$, exibe um aumento nas perdas de desempenho à medida que o tamanho da mensagem SOAP é incrementado, sendo que para o menor tamanho considerado, ambas as plataformas apresentam ganho de desempenho de $2 \%$ e $8 \%$, considerando as plataformas P1.G e P2.G, respectivamente. Porém, quando $S \geq 4 M B$, mas inferior ao limite de tamanho estipulado nessa primeira fase, apenas a plataforma baseada em Hyper- $V$ permanece obtendo ganhos de desempenho, já a plataforma baseada em VMWare registra perdas de desempenho que atingem até $6 \%$.

A segunda fase, onde $8 M B \leq S \leq 10 M B$, no entanto, indica que as plataformas baseadas em virtualizadores apresentam reduções nas perdas de desempenho, possibilitando a plataforma P1.G registrar ganhos de desempenho de, aproximadamente, $4 \%$ quando $S=10 M B$, enquanto a plataforma P2.G apresentou tempos médios de resposta $15 \%$ inferiores aos obtidos pela plataforma de referência. Sendo assim, apesar da primeira fase compreender em aumento das perdas de desempenho, para nenhum valor de $S$ analisado, a plataforma P2.G registrou tempos de resposta maiores que a plataforma PRef.G.

Esse comportamento, dividido em fases, deve-se à redução da quantidade de memória DRAM alocada na geração Jovem da JVM e de sua relação com o tempo total de processamento. Quando $S \leq 6 M B$, a quantidade máxima de memória alocada no heap Éden foi de, apenas, $383 M B$, fazendo com que os recursos otimizados de gerência de memória não fossem tão efetivos como ocorreu quando a quantidade de caracteres por mensagem SOAP era menor. Ao ampliar o tamanho da mensagem, a quantidade de memória necessária passa a ser de, aproximadamente, $507 \mathrm{MB}$ e $630 \mathrm{MB}$, respectivamente, quando $S=8 M B$ e $S=10 M B$, ampliando a efetividade dos recursos de gestão de memória existentes nas plataformas virtualizadas.

Ao ampliar a taxa de utilização dos processadores disponibilizados nas plataformas para $50 \%$ e $75 \%$, é possível concluir que a efetividade dos recursos de gestão de memória, presentes nas plataformas baseadas em virtualizadores, é relativamente ampliada, como pode ser observado nos gráficos das Figuras 6.5.b e 6.5.d.

Nesse contexto, como pode ser observado na Tabela 6.3, a quantidade de memória 


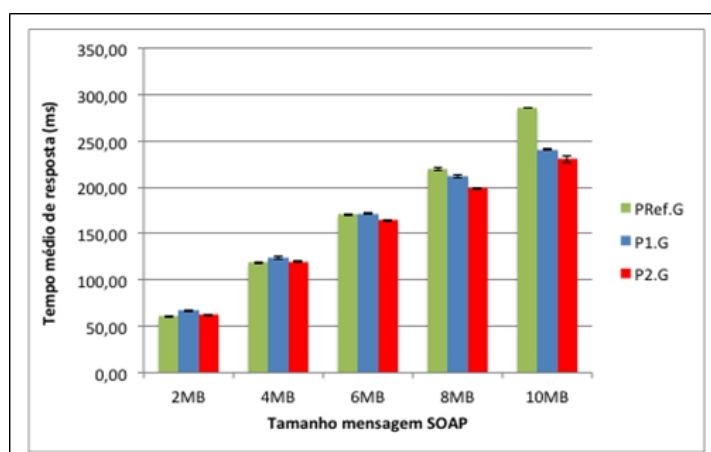

(a)

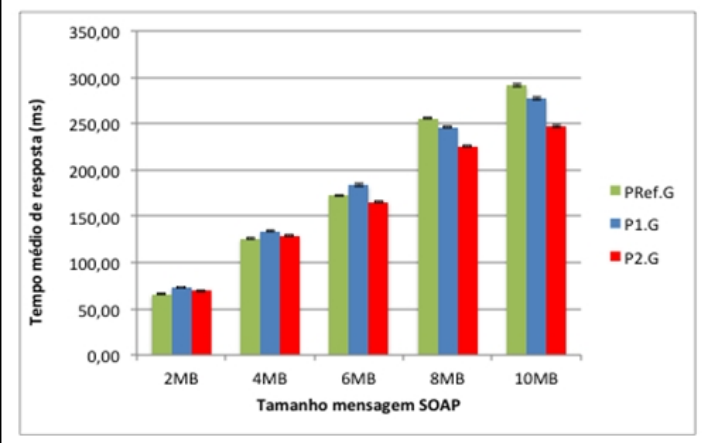

(c)

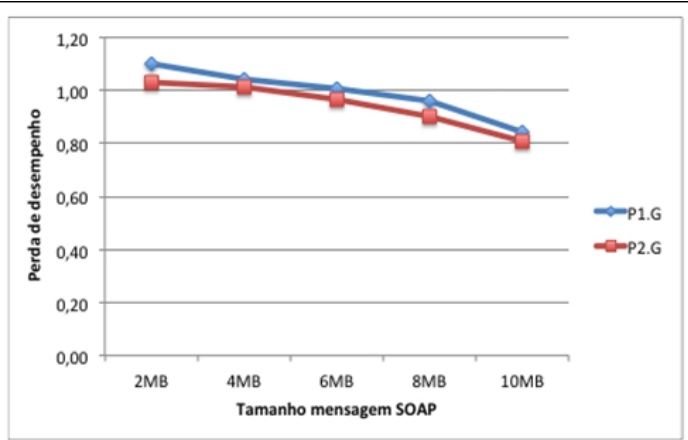

(b)

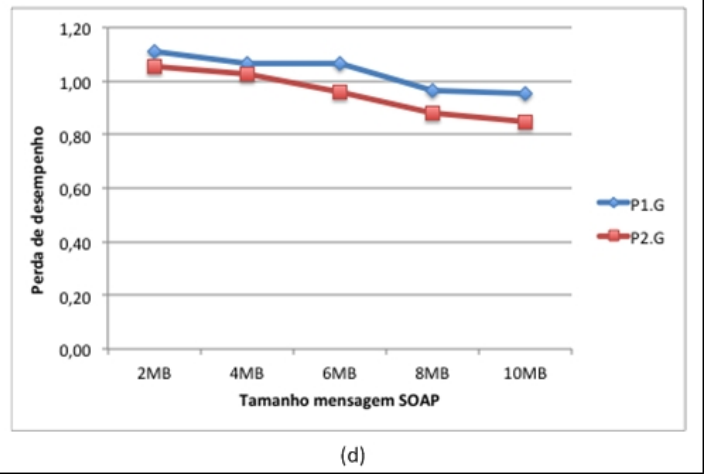

Figura 6.5: Resultados obtidos pelas plataformas baseadas em Glassfish durante as operações de unmarshalling de mensagens SOAP formada por elementos XML de cem caracteres: a) Tempo médio de resposta com $50 \%$ de utilização dos processadores, b) Perda de desempenho com $50 \%$ de utilização dos processadores, c) Tempo médio de resposta com $75 \%$ de utilização dos processadores e d) Perda de desempenho com $75 \%$ de utilização dos processadores.

DRAM, necessária para as operações de unmarshalling de mensagens SOAP, é preservada à medida que se amplia a taxa de utilização dos processadores. No entanto, a fração de memória alocada por intervalo de tempo é maior, já que há mais threads consumidoras executando em paralelo e os tempos médios de resposta das aplicações não apresentaram incrementos significativos para os valores de $S$ analisados, com exceção, quando $2 M B \leq$ $S \leq 4 M B$, como pode ser observado nos gráficos das Figuras 6.5.a e 6.5.c.

Para esse cenário, em que $2 M B \leq S \leq 4 M B$, todas as plataformas analisadas, baseadas em Glassfish, apresentaram incrementos nos tempos médios de resposta, uma vez que o servidor de aplicação necessita instanciar uma maior quantidade de objetos e threads nos pequenos intervalos de execução de cada requisição.

Ao incrementar a taxa de utilização dos processadores para 50\%, a plataforma PRef.G apresentou um aumento de $20 \%$ nos tempos médios de resposta, quando $S=2 M B$ e $12 \%$ quando $S=4 M B$. Já a plataforma P1.G apresentou incremento de $35 \%$ e $13 \%$, respectivamente, para os mesmos valores de $S$ analisados na plataforma de referência. Já a plataforma P2.G apresentou incremento nos tempos médios de resposta equivalente 


\begin{tabular}{|c|c|c|c|c|}
\hline \multirow{2}{*}{ Tamanho envelope SOAP } & \multicolumn{4}{|c|}{ Taxa de utilização das CPUs } \\
\cline { 2 - 5 } & $\mathbf{2 5 \%}$ & $\mathbf{5 0 \%}$ & $\mathbf{7 5 \%}$ & $\mathbf{1 0 0} \%$ \\
\hline $2 \mathrm{MB}$ & $130 \mathrm{MB}$ & $134 \mathrm{MB}$ & $136 \mathrm{MB}$ & $138 \mathrm{MB}$ \\
\hline $4 \mathrm{MB}$ & $256 \mathrm{MB}$ & $265 \mathrm{MB}$ & $264 \mathrm{MB}$ & $265 \mathrm{MB}$ \\
\hline $6 \mathrm{MB}$ & $383 \mathrm{MB}$ & $385 \mathrm{MB}$ & $385 \mathrm{MB}$ & $390 \mathrm{MB}$ \\
\hline $8 \mathrm{MB}$ & $507 \mathrm{MB}$ & $513 \mathrm{MB}$ & $517 \mathrm{MB}$ & $513 \mathrm{MB}$ \\
\hline $10 \mathrm{MB}$ & $630 \mathrm{MB}$ & $632 \mathrm{MB}$ & $634 \mathrm{MB}$ & $635 \mathrm{MB}$ \\
\hline
\end{tabular}

Tabela 6.3: Quantidade média de memória alocada em 25 iterações de consumo por taxa de utilização de CPUs, considerando mensagens SOAP com cem caracteres por elemento XML.

ao apresentado pela plataforma baseada em VMWare quando $S=2 M B$ e $20 \%$ quando $S=4 M B$.

Tais resultados levaram as plataforma virtualizadas a registrarem perdas de desempenho para esses valores de $S$. A plataforma P1.G obteve perda de desempenho de $10 \%$ para o menor valor de $S$ analisado e de $4 \%$ quando o tamanho da mensagem SOAP foi incrementado para $4 M B$, sendo que, para os mesmos valores de $S$, a plataforma P2.G apresentou perda de desempenho de, aproximadamente, $3 \%$ e 1\%, demonstrando, que apesar das perdas de desempenho sofridas, a plataforma baseada em Hyper-V é superior ao realizar a deserialização de mensagens SOAP.

Ao analisar a perda de desempenho de uma forma global, quando a taxa de utilização dos processadores é de $50 \%$, percebe-se que à medida que o tamanho da mensagem SOAP é ampliada, aumenta-se o ganho de desempenho, ou se reduz a perda de desempenho, das plataformas virtualizadas. Sendo que o maior ganho de desempenho obtido pela plataforma P1.G foi de $16 \%$ quando $S=10 M B$ e, para o mesmo tamanho de mensagem SOAP, a plataforma P2.G apresentou 19\% como o maior ganho de desempenho.

Ao ampliar a taxa de utilização dos processadores para $75 \%$, percebe-se, através do gráfico da Figura 6.5.d, que esse comportamento da perda de desempenho se mantém, sendo que a plataforma P1.G apresentou 5\% como maior ganho de desempenho e $11 \%$ como maior perda de desempenho, respectivamente, quando $S=10 M B$ e $S=2 M B$. Para esses mesmos valores de $S$, a plataforma P2.G registrou $15 \%$ como o maior ganho de desempenho, enquanto a maior perda de desempenho foi de $5 \%$.

É importante observar que à medida que a taxa de utilização deixa de ser $50 \%$ e passa a ser de $75 \%$, as perdas de desempenho foram ampliadas e os ganhos reduzidos, uma vez que, para todos os valores de $S$ analisados, ocorreram incrementos nos tempos médios de resposta, mas não na quantidade de memória necessária. Tal redução no desempenho global das plataformas virtualizadas só não é maior, uma vez que, ampliando a quantidade de threads consumidoras, amplia-se, também, o tamanho dos blocos de memória a serem alocados por cada intervalo de tempo.

Porém, essa tendência é alterada ao ampliar a taxa de utilização dos processadores de $75 \%$ para $100 \%$, sendo que, apenas quando $S=2 M B$ ocorre um aumento na perda de 
desempenho ao comparar os resultados obtidos com a taxa de utilização dos processadores de $100 \%$ com aqueles obtidos com a utilização de $75 \%$. Já para valores maiores de $S$, as plataformas virtualizadas apresentam aumentos nos ganhos ou reduções nas perdas de desempenho, sendo essa maior eficiência das plataformas virtualizadas ampliada à medida que se amplia o tamanho da mensagem SOAP.

Ao ampliar a quantidade de processadores utilizados, amplia-se, também, a quantidade de threads consumidoras e a quantidade de requisições a ser processada, aumentando o tamanho do bloco de memória alocado por intervalo de tempo. No entanto, essa característica não ocorre com taxas menores de utilização dos processadores, pois a quantidade de memória a ser alocada é reduzida, sendo que apenas para $100 \%$ de utilização dos processadores, o tamanho do bloco de memória a ser alocado é realmente significativo.

Esse fato pode ser confirmado ao se observar os resultados do gráfico da Figura 6.6.a, que contém os tempos médios de resposta quando a taxa de utilização dos processadores é de 100\%, e compará-los com os resultados do gráfico da Figura 6.5.c. Com essa comparação é possível perceber que para as plataformas virtualizadas, apenas quando $S=2 M B$ ocorre um aumento significativo nos tempos médios de resposta, sendo, em média, de 18\% para ambas as plataformas. Porém, para os demais valores de $S$, apenas a plataforma PRef.G apresentou aumentos significativos nos tempos médios de resposta.

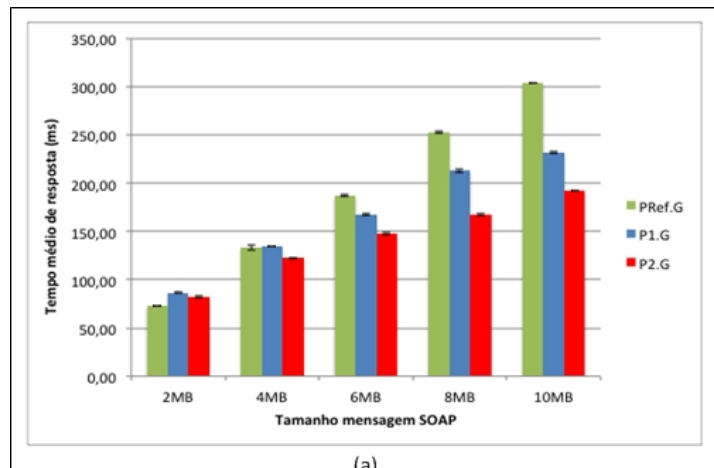

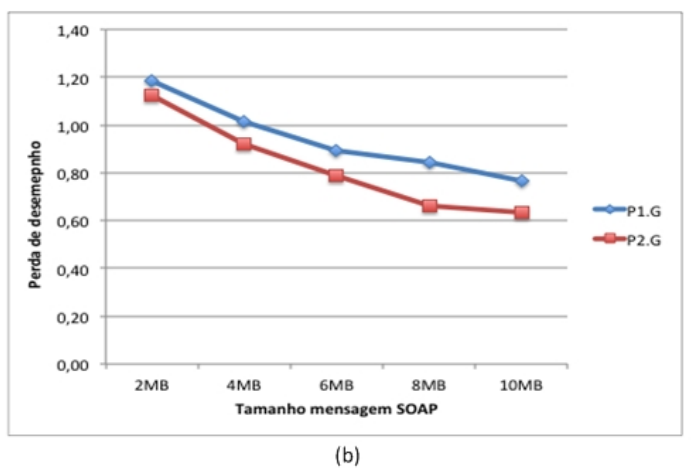

Figura 6.6: Resultados obtidos pelas plataformas baseadas em Glassfish durante as operações de unmarshalling de mensagens SOAP com cem caracteres por elemento XML e taxa de utilização de CPU de 100\%: a) Tempo médio de resposta e b) Perda de desempenho.

Com utilização de $100 \%$ dos processadores, o maior ganho de desempenho registrado pela plataforma P1.G foi de $24 \%$ quando $S=10 M B$, sendo que a plataforma P2.G, para o mesmo valor de $S$, apresentou ganho de desempenho, em relação à plataforma PRef.G, de $37 \%$, como pode ser observado no gráfico da Figura 6.6.b, que demonstra as perdas de desempenho sofridas pelas aplicações.

Ao analisar os dados da plataforma P1.G, percebem-se que os ganhos de desempenho obtidos pelo sistema de virtualização se inicia quando o tamanho da mensagem SOAP atinge $6 M B$, enquanto a plataforma P2.G apresenta ganhos de desempenho a partir 
de mensagens com $4 M B$ de tamanho. Sendo assim, é possível concluir que dentre as plataformas virtualizadas, a plataforma P2.G apresenta o melhor desempenho quando há cem caracteres por elemento XML, sendo, o desempenho da plataforma baseada em Hyper- $\mathrm{V}$, inferior ao da plataforma de referência apenas para pequenos valores de $S$, isso quando a taxa de utilização dos processadores supera $25 \%$.

Essa superioridade da plataforma P2.G, em relação à plataforma P1.G, mantém-se quando a quantidade de caracteres por mensagem SOAP é ampliada para mil, no entanto, em relação à plataforma de referência, há um aumento nas ocorrências de perda de desempenho, inclusive, há registros de desempenhos inferiores aos da plataforma PRef.G quando a taxa de utilização dos processadores é de apenas $25 \%$, como pode ser observado no gráfico da Figura 6.7.b.

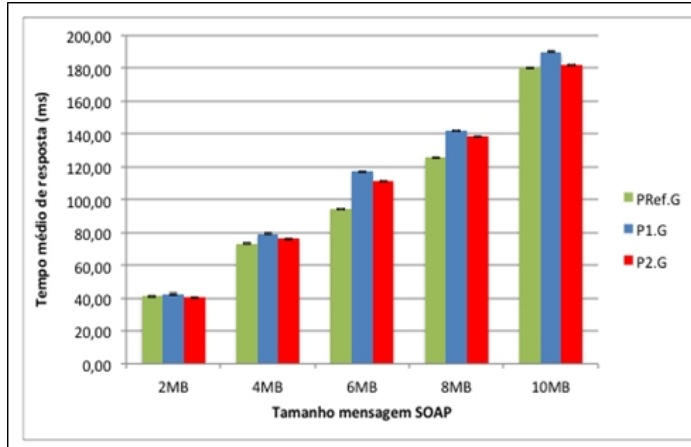

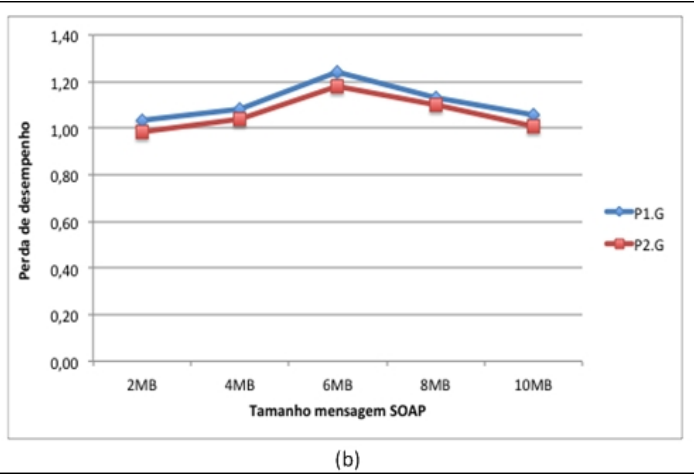

(b)

Figura 6.7: Resultados obtidos pelas plataformas baseadas em Glassfish durante as operações de unmarshalling de mensagens SOAP com mil caracteres por elemento XML e taxa de utilização de CPU de 25\%: a) Tempo médio de resposta e b) Perda de desempenho.

Ao analisar a Figura 6.7.b, pode ser observado que as perdas de desempenho se dividem em duas fases: a primeira fase, $\operatorname{com} 2 M B \leq S \leq 6 M B$, apresenta aumentos das perdas de desempenho, sofridas pelas aplicações executadas nas plataformas virtualizadas, à medida que se incrementa o tamanho da mensagem SOAP enviada pelo software consumidor. Nessa fase, a plataforma P1.G registrou perdas de desempenho variando entre $3 \%$ e $24 \%$, respectivamente, quando $S=2 M B$ e $S=6 M B$. Já a plataforma P2.G registrou ganho de desempenho de, aproximadamente, $2 \%$, quando $S=2 M B$ e perda de desempenho de $18 \%$ quando $S=6 \mathrm{MB}$. A segunda fase, por outro lado, apresenta redução na perda de desempenho à medida que se amplia o tamanho da mensagem SOAP, sendo essa fase observada quando $S \geq 8 M B$.

Na segunda fase a plataforma P1.G apresentou $6 \%$ como a menor perda de desempenho quando $S=10 M B$. A plataforma P2.G registrou, para o mesmo tamanho da mensagem SOAP, aproximadamente, $1 \%$ de perda de desempenho.

Esse comportamento, dividido em fases, é similar ao observado em cenários cujas mensagens SOAP possuem cem caracteres por elemento XML e taxa de utilização dos proces- 
sadores de $25 \%$. No entanto, ao se ampliar a quantidade de caracteres por elemento XML de cem para mil, percebe-se que há um aumento nas perdas de desempenho sofridas pelas aplicações. Com cem caracteres a plataforma P2.G apresentou ganhos de desempenho para todos os tamanhos de mensagem SOAP analisados, já ao ampliar a quantidade de caracteres, foram registrados ganhos de desempenho apenas quando $S=2 M B$. Nesse mesmo contexto, a plataforma P1.G apresentou ganhos de desempenho, com cem caracteres por elemento XML, quando $S=2 M B$ e $S=10 M B$, porém, ao ampliar a quantidade de caracteres, essa plataforma não registrou ganhos de desempenho para os valores de $S$ analisados.

Tal fato se deve às reduções nos tempos médios de resposta obtidos pelas plataformas ao ampliar a quantidade de caracteres, bem como a redução da quantidade de memória DRAM necessária para alocar os objetos instanciados. Ao analisar os dados do gráfico da Figura 6.7.a, que apresenta o tempo médio de resposta obtido com mil caracteres por elemento XML e com $25 \%$ de utilização do poder de processamento, e compará-los com os resultados apresentados no gráfico da Figura 6.4.a, que apresenta os tempos médios de resposta, para a mesma taxa de utilização dos processadores, mas com cem caracteres por elemento XML, percebe-se que ocorreu, em média, uma redução de $66 \%$ nos tempos médios de resposta das aplicações executadas sobre a plataforma de referência, $72 \%$ e $76 \%$ pelas aplicações executadas sobre as plataformas P1.G e P2.G, respectivamente.

Já a quantidade de memória DRAM consumida reduziu em, aproximadamente, 18\%, com pode ser observado ao comparar os dados da Tabela 6.4 com os dados apresentados na Tabela 6.3, com taxa de utilização dos processadores em $25 \%$.

\begin{tabular}{|c|c|c|c|c|}
\hline \multirow{2}{*}{ Tamanho envelope SOAP } & \multicolumn{4}{|c|}{ Taxa de utilização das CPUs } \\
\cline { 2 - 5 } & $\mathbf{2 5 \%}$ & $\mathbf{5 0 \%}$ & $\mathbf{7 5 \%}$ & $\mathbf{1 0 0} \%$ \\
\hline $2 \mathrm{MB}$ & $111 \mathrm{MB}$ & $110 \mathrm{MB}$ & $114 \mathrm{MB}$ & $115 \mathrm{MB}$ \\
\hline $4 \mathrm{MB}$ & $209 \mathrm{MB}$ & $209 \mathrm{MB}$ & $211 \mathrm{MB}$ & $215 \mathrm{MB}$ \\
\hline $6 \mathrm{MB}$ & $306 \mathrm{MB}$ & $312 \mathrm{MB}$ & $311 \mathrm{MB}$ & $309 \mathrm{MB}$ \\
\hline $8 \mathrm{MB}$ & $410 \mathrm{MB}$ & $409 \mathrm{MB}$ & $415 \mathrm{MB}$ & $413 \mathrm{MB}$ \\
\hline $10 \mathrm{MB}$ & $514 \mathrm{MB}$ & $513 \mathrm{MB}$ & $513 \mathrm{MB}$ & $512 \mathrm{MB}$ \\
\hline
\end{tabular}

Tabela 6.4: Quantidade média de memória alocada em 25 iterações de consumo por taxa de utilização de CPUs, considerando mensagens SOAP com mil caracteres por elemento XML.

Tais reduções fazem com que esse comportamento, dividido em fases, seja registrado, também, ao se ampliar a taxa de utilização dos processadores para $50 \%$, diferentemente do observado quando se utiliza cem caracteres por elemento XML, como pode ser observado no gráfico da Figura 6.8.b.

Ao analisar o gráfico da Figura 6.8.b, percebe-se que ao ampliar a taxa de utilização dos processadores de $25 \%$ para $50 \%$, há redução das perdas de desempenho sofridas pelas aplicações baseadas em SOA executadas sobre as plataformas virtualizadas, permitindo, inclusive, que para $S=2 M B$, o desempenho obtido na plataformas P1.G se tornasse 


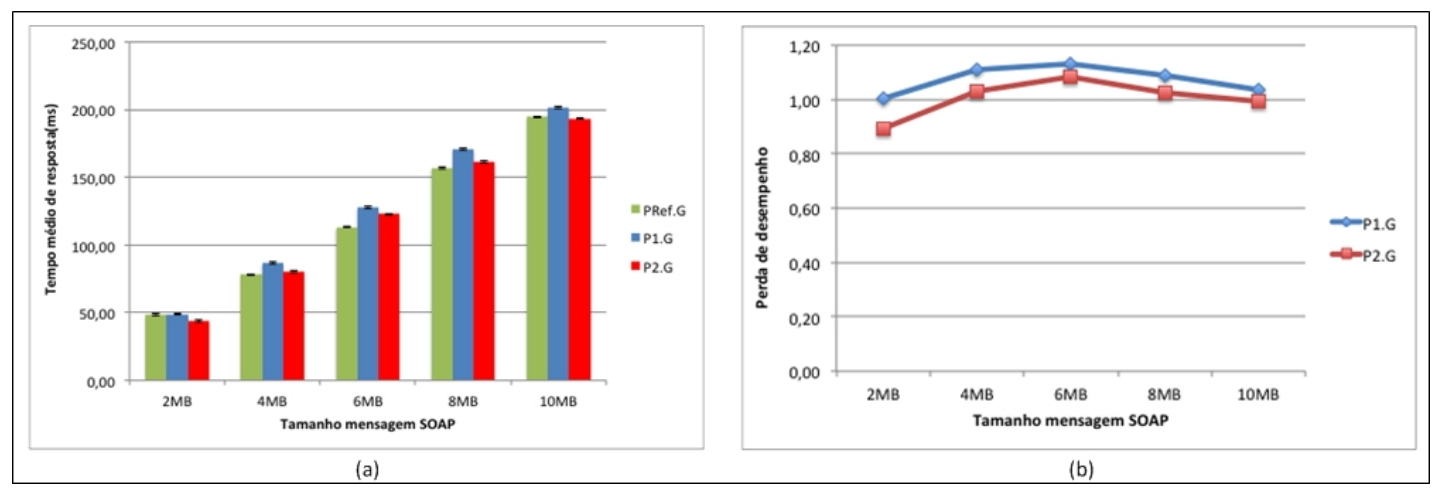

Figura 6.8: Resultados obtidos pelas plataformas baseadas em Glassfish durante as operações de unmarshalling de mensagens SOAP com mil caracteres por elemento XML e taxa de utilização de CPU de 50\%: a) Tempo médio de resposta e b) Perda de desempenho.

equivalente ao obtido pela plataforma PRef.G, uma vez que, para esse tamanho de mensagem SOAP, ocorreu sobreposição dos intervalos de confiança e das médias, como pode ser observado no gráfico da Figura 6.8.a.

Ao ampliar a quantidade de threads consumidoras, blocos maiores de memória são alocados em cada iteração de expansão do heap da JVM, permitindo que as plataformas virtualizadas ampliem seu desempenho através dos recursos destinados à gestão de memória, uma vez que a quantidade de memória, necessária para atender as requisições, não apresenta variação significativa ao aumentar a taxa de utilização das CPUs, como pode ser observado na Tabela 6.4.

No entanto, essa redução não apresentou resultados ainda mais expressivos, pois ocorreram aumentos nos tempos médios de resposta ao ampliar a taxa de utilização dos processadores de $25 \%$ para 50\%. Esse aumento se deve à necessidade do servidor de aplicação gerenciar uma maior quantidade de threads e recursos em um espaço curto de tempo, além da ampliação da quantidade de falta de páginas ocorridas por intervalo de tempo. Isso reduz o tamanho do bloco de memória a ser alocado, reduzindo, também, o impacto dos recursos de gerência de memória.

Nesse contexto, em média, os tempos de resposta da plataforma PRef.G apresentaram incremento de $16 \%$, sendo que, a maior ampliação registrada foi de $25 \%$ quando $S=$ $8 M B$, que corresponde ao momento em que ocorre a transição da primeira fase para a segunda. Para esse mesmo valor de $S$, a plataforma P1.G apresentou ampliação de $20 \%$, enquanto a plataforma P2.G de 17\%, sendo essas as maiores ampliações nos tempos de processamento registradas pelas plataformas virtualizadas, sendo que, em média, P1.G apresentou incremento nos tempos de resposta de $12 \%$ e a plataforma P2.G de $9 \%$.

A perda de desempenho dividida em fases deixa de existir à medida que se amplia a quantidade de processadores utilizados, passando para $75 \%$ e 100\%. Com essas configurações, as perdas de desempenho passam a ser decrescente à medida que se incrementa 
o tamanho da mensagem SOAP enviada pelo software consumidor, como pode ser observado nos gráficos das Figuras 6.9.a e 6.9.b, que apresentam as perdas de desempenho sofridas pelas aplicações distribuídas ao realizarem operações de unmarshalling em mensagens SOAP com mil caracteres por elemento XML, respectivamente, com $75 \%$ e $100 \%$ de utilização dos processadores.

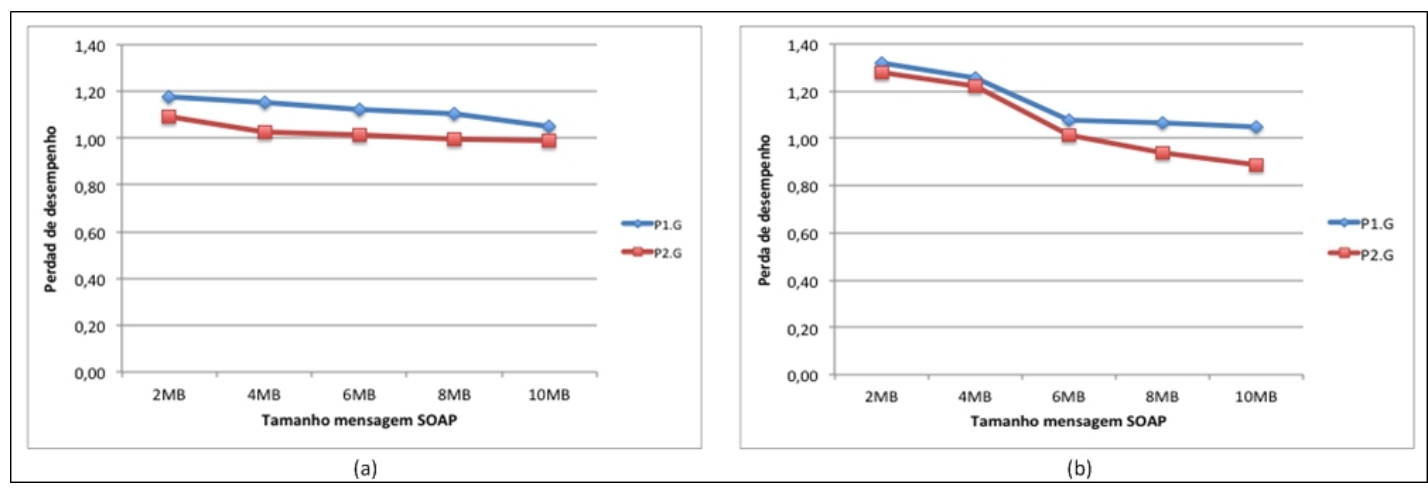

Figura 6.9: Perdas de desempenho sofridas pelas aplicações distribuídas ao realizar operação de unmarshalling com mil caracteres por elemento XML: a) $75 \%$ de utilização dos processadores e b) $100 \%$ de utilização dos processadores.

Ao ampliar a taxa de utilização das CPUs para $75 \%$, as plataformas virtualizadas apresentaram acréscimos nas perdas de desempenho sofridas pelas aplicações se comparado aos resultados obtidos, pelas mesmas plataformas, quando a taxa de utilização dos processadores era de $50 \%$, principalmente quando $S \leq 8 M B$. Nesse contexto, a plataforma P1.G apresentou $5 \%$ como a menor perda de desempenho e $18 \%$ como a maior, sendo tais resultados registrados quando $S=10 M B$ e $S=2 M B$, respectivamente. Já a plataforma P2.G apresentou ganho de desempenho de, aproximadamente, $1 \%$ quando $S=10 M$ e $9 \%$ como a maior perda de desempenho quando $S=2 M B$. Assim, para tamanhos elevados de $S$, a plataforma P2.G, através dos recursos de gerência de memória, não registrou variação na perda de desempenho ao ampliar a taxa de utilização dos processadores.

Esse incremento da perda de desempenho é proveniente do aumento de recursos que devem ser gerenciados pelo servidor de aplicação, uma vez que a quantidade de memória DRAM alocada para tratar as requisições não é ampliada à medida que se eleva a taxa de utilização dos processadores, como descrito anteriormente. No entanto, é importante observar que essa mesma característica reduziu as perdas de desempenho apresentadas pelas plataformas virtualizadas ao ampliar a taxa de utilização dos processadores de $25 \%$ para 50\%, diferentemente do comportamento obtido ao ampliar essa mesma taxa para $75 \%$. Isso indica que a quantidade de memória DRAM consumida deve ser elevada para permitir que o aumento da quantidade de threads, e, consequentemente, o tamanho do bloco de memória alocado por intervalo de tempo, reduzam as perdas de desempenho 
sofridas pelas aplicações.

Tal fato pode ser comprovado ao analisar os resultados do gráfico da Figura 6.9.b, que apresenta as perdas de desempenho registradas nas plataformas baseadas em Glassfish com 100\% de utilização dos processadores. Ao consumir todos os processadores disponíveis, há uma maior sobrecarga de recursos relacionada ao servidor de aplicação e, também, a concorrência pelo recurso de processamento entre as threads do servidor de aplicação e o próprio sistema operacional convidado, responsável pela gerência do hardware.

Nesse cenário, a perda de desempenho apresenta comportamento decrescente à medida que se amplia o tamanho da mensagem SOAP enviada pela software consumidor, sendo assim, a maior perda de desempenho registrada pelas plataformas virtualizadas foi de $32 \%$ e $28 \%$, respectivamente, para P1.G e P2.G com $S=2 M B$. Isso indica a superioridade da plataforma baseada em Hyper-V sobre a plataforma baseada em VMWare. Superioridade que se mantém à medida que se amplia o tamanho das mensagems SOAP processadas, uma vez que a plataforma P2.G apresentou ganho de desempenho de $11 \%$ quando $S=10 \mathrm{MB}$, diferentemente da plataforma P1.G que registrou perda de desempenho de $1 \%$.

Assim como descrito ao analisar os resultados com utilização dos processadores em $75 \%$, apenas para valores elevados de $S$, onde $S \geq 8 M B$, a quantidade de memória alocada é elevada o suficiente para permitir que os gerenciadores de máquinas virtuais reduzam as perdas de desempenho sofridas pelas aplicações distribuídas, como pode ser observado na Tabela 6.5, que apresenta a razão entre os tempos médios de processamento das plataformas baseadas em Glassfish, com 100\% e 75\% de utilização dos processadores.

\begin{tabular}{|c|c|c|c|}
\hline S & Plataforma PRef.G & Plataforma P1.G & Plataforma P2.G \\
\hline $2 \mathrm{MB}$ & 1,11 & 1,24 & 1,30 \\
\hline $4 \mathrm{MB}$ & 1,03 & 1,12 & 1,22 \\
\hline $6 \mathrm{MB}$ & 1,02 & 0,94 & 1,01 \\
\hline $8 \mathrm{MB}$ & 1,01 & 0,93 & 0,95 \\
\hline $10 \mathrm{MB}$ & 1,07 & 1,03 & 0,96 \\
\hline
\end{tabular}

Tabela 6.5: Razão entre os tempos médios de resposta com taxa de utilização de CPU em $100 \%$ e $75 \%$ ao processar mensagens SOAP com mil caracteres por elemento XML.

Ao analisar os dados da Tabela 6.5, percebe-se que, independemente do valor de $S$ adotado, a plataforma PRef.G apresenta incrementos nos tempos médios de resposta, sendo que esses incrementos são, em geral, reduzidos à medida que se amplia o tamanho da mensagem SOAP. Já as plataformas virtualizadas apresentam aumento nos tempos médios de resposta apenas quando $S \leq 4 M B$ ao considerar a plataforma P1.G e $S \leq 6 M B$ ao considerar a plataforma P2.G. A partir dos valores de $S$ descritos, as plataformas virtualizadas apresentam reduções nos tempos de resposta, sendo possível perceber que para mensagens com tamanho variando entre $6 M B$ e $8 M B$, a razão da plataforma P1.G é inferior ao apresentado pela plataforma P2.G. No entanto, a perda de desempenho registrada por aquela foi superior ao dessa. Esse comportamento distinto se deve ao 
maior incremento registrado pela plataforma baseada em VMWare ao se ampliar a taxa de utilização das CPUs de $50 \%$ para $75 \%$, o que indica que essa superioridade ao ampliar a taxa de utilização dos processadores de $75 \%$ para $100 \%$ não é suficiente para retirar, na totalidade, o incremento sofrido anteriomente, confirmando a superioridade da plataforma P2.G, dentre as plataformas virtualizadas, em todos os cenários analisados.

\subsection{Operação marshalling}

A operação de marshalling ocorre quando o Web Services obtém um envelope SOAP, armazenado na memória DRAM, e o envia, através de uma mensagem SOAP, para o software consumidor. Assim como a operação de unmarshalling é conhecida por deserialização de objetos, a operação de marshalling é conhecida como serialização. De maneira análoga ao utilizado na seção anterior, aqui o termo marshalling e serialização serão utilizados como sinônimos, uma vez que os dados enviados pelos Web Services são sempre compostos de mensagens SOAP, não havendo outro tipo de dados a ser trocado pelos softwares participantes do estudo.

De uma forma geral, as operações de escrita são mais lentas e "caras" que as operações de leitura. Nesse contexto de aplicações distribuídas baseadas em SOA, as operações de marshalling possuem tempos médios de resposta mais elevados que os obtidos ao realizar operações de unmarshalling, como pode ser observado ao comparar os resultados apresentados no gráfico da Figura 6.10.a, referentes aos tempos médios de resposta ao realizar operações de marshalling com dez caracteres por elemento XML e taxa de utilização de CPU em, aproximdamente, 25\%, com aqueles disponibilizados na Figura 6.1.a.

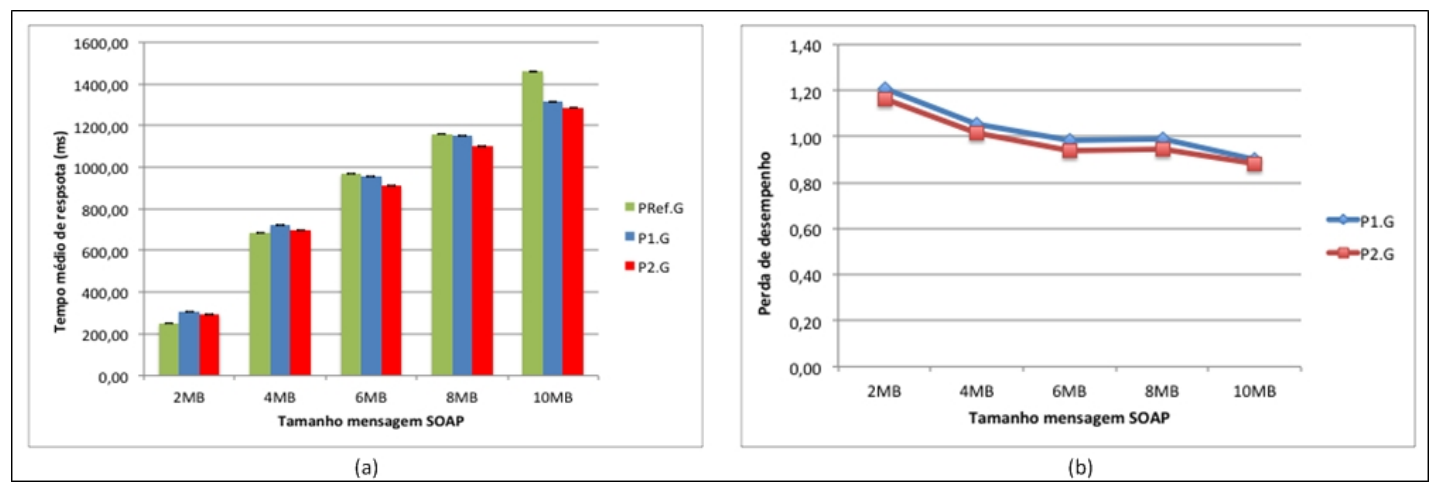

Figura 6.10: Resultados obtidos pelas aplicações distribuídas ao realizar operação de marshalling com dez caracteres por elemento XML em plataformas com taxa de utilização de CPUs em 25\%: a) Tempo médio de resposta e b) Perda de desempenho.

Ao comparar os resultados de ambas as figuras citadas, percebe-se que os incrementos nos tempos de resposta sofridos pelas aplicações distribuídas, executadas sobre a plataforma de referência, são inferiores à aqueles obtidos pelas aplicações executadas sobre as 
plataformas virtualizadas. Independentemente da plataforma considerada, o menor incremento, ao comparar os resultados das operações de deserialização e serialização, foi obtido quando $S=2 M B$, sendo registrado pela plataforma PRef.G, aproximadamente, $6 \%$ e pelas plataformas virtualizadas, respectivamente, $29 \%$ e $27 \%$ para P1.G e P2.G. Já o maior incremento nos tempos de processamento ocorreu quando $S=4 M B$ para todas as plataformas consideradas, onde a plataforma de referência apresentou $47 \%$ de aumento e as plataformas virtualizadas, P1.G e P2.G, apresentaram, respectivamente, $59 \%$ e $56 \%$.

No entanto, é importante observar que à medida que o tamanho da mensagem SOAP é ampliado, a diferença nos incrementos dos tempos de resposta ao comparar as duas operações, tendem a se tornar desprezíveis ao comparar os resultados das plataformas estudadas. Quando $S=10 M B$, o tempo médio consumido pelas aplicações executadas sobre a plataforma PRef.G, nas operações de marshalling, foi superior ao tempo consumido nas operações de unmarshalling em 41\%, sendo que a plataforma P2.G apresentou tempos superiores em, aproximadamente, $43 \%$, o que representa uma diferença de incremento de apenas $2 \%$. Já a diferença do incremento de P1.G e PRef.G foi inferior à $1 \%$.

Ainda analisando a Figura 6.10.a, percebe-se que, diferentemente dos resultados obtidos nas operações de unmarshalling, os tempos médios de resposta das aplicações executadas sobre as plataformas virtualizadas foram superiores àqueles obtidos pelas aplicações executadas na plataforma de referência, quando $S=2 M B$, como pode ser comprovado no gráfico da Figura 6.10.b, que demonstra as perdas de desempenho sofridas pelas aplicações distribuídas ao executarem operações de marshalling em ambientes com $25 \%$ de utilização dos processadores disponibilizados.

No gráfico da Figura 6.10.b, é possível perceber que à medida que o tamanho da mensagem SOAP é incrementado, as perdas de desempenho obtidas nas plataformas virtualizadas diminuem, impondo, às aplicações executadas, ganhos de desempenho quando $S \geq 6 M B$, sendo possível observar uma estabilidade dos ganhos de desempenho quando $6 M B \leq S \leq 8 M B$. Essa estabilidade ocorre devido à quantidade de memória, consumida pelo servidor de aplicação para processar os pedidos enviados pelo software consumidor, conforme pode ser observado na Tabela 6.6

\begin{tabular}{|c|c|c|c|c|}
\hline \multirow{2}{*}{ Tamanho envelope SOAP } & \multicolumn{4}{|c|}{ Taxa de utilização das CPUs } \\
\cline { 2 - 5 } & $\mathbf{2 5 \%}$ & $\mathbf{5 0 \%}$ & $\mathbf{7 5 \%}$ & $\mathbf{1 0 0} \%$ \\
\hline $2 \mathrm{MB}$ & $9 \mathrm{MB}$ & $11 \mathrm{MB}$ & $13 \mathrm{MB}$ & $15 \mathrm{MB}$ \\
\hline $4 \mathrm{MB}$ & $9 \mathrm{MB}$ & $11 \mathrm{MB}$ & $15 \mathrm{MB}$ & $18 \mathrm{MB}$ \\
\hline $6 \mathrm{MB}$ & $12 \mathrm{MB}$ & $14 \mathrm{MB}$ & $18 \mathrm{MB}$ & $22 \mathrm{MB}$ \\
\hline $8 \mathrm{MB}$ & $12 \mathrm{MB}$ & $14 \mathrm{MB}$ & $22 \mathrm{MB}$ & $23 \mathrm{MB}$ \\
\hline $10 \mathrm{MB}$ & $12 \mathrm{MB}$ & $14 \mathrm{MB}$ & $24 \mathrm{MB}$ & $25 \mathrm{MB}$ \\
\hline
\end{tabular}

Tabela 6.6: Quantidade média de memória alocada ao realizar operações de marshalling por taxa de utilização de CPUs, considerando 25 iterações e mensagens SOAP com dez caracteres por elemento XML. 
Ao observar os valores apresentados na Tabela 6.6, percebe-se que a quantidade de memória consumida pelo servidor de aplicação, especificamente com a geração Jovem e o heap Éden da JVM, uma vez que não ocorreram coletas de lixo, apresenta pouca variação à medida que o tamanho da mensagem SOAP é incrementado, sendo que há apenas dois valores de alocação com taxa de utilização de CPU em $25 \%$, sendo que para $S \leq 4 M B$ são consumidos $9 M B$ de memória e para mensagens de tamanho superior $12 M B$.

No entanto, o período de estabilização não se estende para o maior valor de $S$ considerado, uma vez que no gráfico da Figura 6.10.b se registra ganhos de desempenho superiores para o valor de $S$ considerado. Esse fato se deve à quantidade de memória que é alocada por intervalo de tempo. À medida que se amplia o tamanho da mensagem SOAP, mais memória DRAM deve ser reservada no heap para tratar a mensagem constituída. Assim, quando $S=10 M B$, aproximadamente, $83 \%$ da memória consumida é alocada em apenas uma requisição, enquanto com $S=6 M B$ apenas $50 \%$ é alocada.

A partir do momento que blocos maiores são solicitados por intervalos curtos de tempo, aumenta-se a eficiência dos recursos de gerência de memória disponibilizados pelo hardware e virtualizadores, principalmente a tabela dupla de mapeamento de memória e as long pages. Sendo, conforme descrito anteriormente, esse recurso ativo apenas na plataforma baseada em Hyper-V, o que justifica a superioridade dos resultados obtidos por essa plataforma ao compará-los com os obtidos pela plataforma baseada em VMWare.

Sendo assim, como destacado, o maior ganho de desempenho obtido pelas plataformas virtualizadas ocorreu quando $S=10 M B$, onde a plataforma P1.G reduziu o tempo médio de resposta em, aproximadamente, $10 \%$ e a plataforma P2.G em $12 \%$. Já a maior perda de desempenho ocorreu quando $S=2 M B$, cujos virtualizadores, VMWare e Hyper-V, impuseram, respectivamente, uma sobrecarga de, aproximadamente, $21 \%$ e $16 \%$.

No entanto, essa perda de desempenho para mensagens SOAP de tamanho reduzido é revertida para ganho de desempenho ao ampliar a taxa de utilização dos processadores para 50\%, como pode ser observado no gráfico da Figura 6.11.b, que apresenta as perdas de desempenho sofridas pelas aplicações distribuídas ao realizarem operações de marshalling com a taxa de CPU de $50 \%$.

Com essa configuração, as plataformas virtualizadas registraram ganhos de desempenho de $4 \%$ e 15\%, respectivamente, ao considerar os resultados obtidos por P1.G e P2.G quando $S=2 M B$. Ao ampliar a taxa de utilização dos processadores disponíveis para $50 \%$, a quantidade de memória alocada em um intervalo de tempo é incrementada, uma vez que um número maior de threads consumidoras são utilizadas.

Para essa mesma taxa de utilização de CPUs, é possível perceber pela Figura 6.11.b, que há uma estabilização nos ganhos de desempenho apresentados pelas plataformas virtualizadas quando $S \geq 4 M B$, sendo que a plataforma P1.G apresentou ganhos variando entre $88 \%$ e $93 \%$, enquanto a plataforma P2.G apresentou ganhos variando entre $76 \%$ e $78 \%$. 


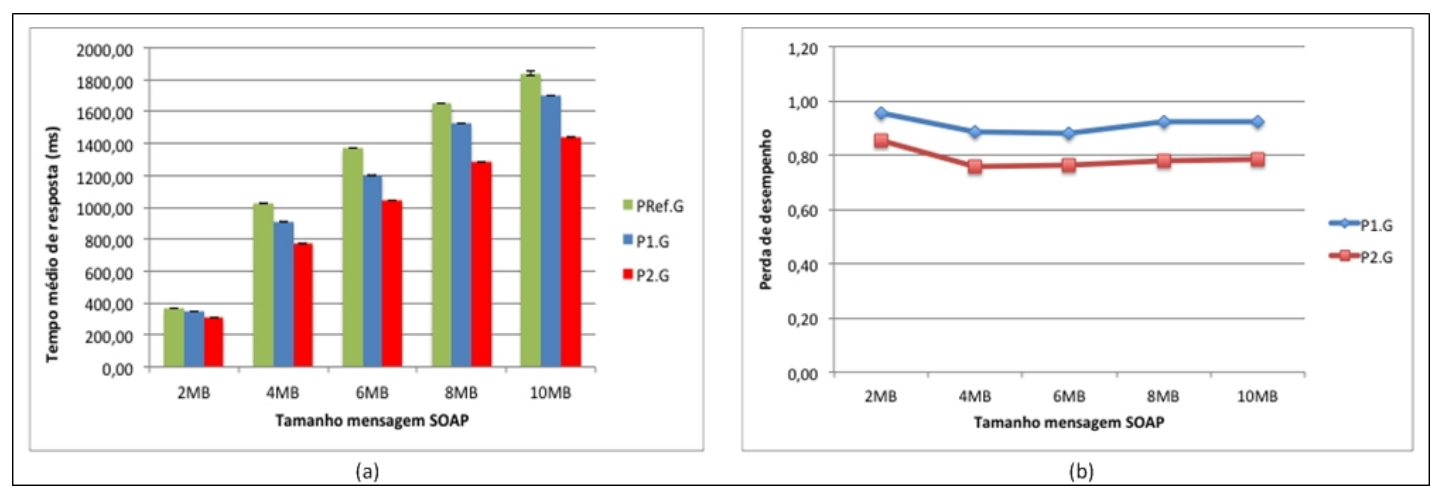

Figura 6.11: Resultados obtidos pelas aplicações distribuídas ao realizar operação de marshalling com dez caracteres por elemento XML em plataformas com taxa de utilização de CPUs em 50\%: a) Tempo médio de resposta e b) Perda de desempenho.

Essa estabilidade se deve ao aumento nos tempos médios de resposta obtidos pelas aplicações ao serem executadas sobre a plataforma de referência. Ao ampliar a taxa de utilização dos processadores, a plaforma PRef.G apresentou incrementos nos tempos médios de resposta variando entre $35 \%$ e $50 \%$, enquanto as plataformas virtualizadas apresentaram aumentos de, no máximo, $32 \%$ e $15 \%$ ao considerar as plataformas P1.G e P2.G, respectivamente, como pode ser observado ao comparar os resultados apresentados no gráfico da Figura 6.11.a com aqueles disponibilizados na Figura 6.2.a.

Ao ampliar a taxa de utilização dos processadores para 50\%, a quantidade de memória DRAM total necessária não foi ampliada significativamente, como pode ser observado na Tabela 6.6. Sendo assim, ao ampliar a quantidade de threads consumidoras, blocos maiores de memória foram alocados por intervalo de tempo, elevando a eficiência das plataformas virtualizadas, porém, ao ampliar o tamanho da mensagem SOAP e, consequentemente, o tempo de processamento, mais recursos são gastos com o gerenciamento das threads e o processo de escalonamento, o que reduz o desempenho das plataformas virtualizadas, fazendo, assim, que o ganho de desempenho apresentado por essas plataformas permaneçam estáveis à medida que se incrementa o tamanho das mensagens SOAP consideradas.

Apesar dos ganhos de desempenho apresentados pelas plataformas virtualizadas ao processar mensagens SOAP de tamanho reduzido, quando a taxa de utilização de CPUs era de $50 \%$, ao ampliar a taxa de utilização para $75 \%$ e $100 \%$ as plataformas baseadas em virtualizadores voltam a apresentar perda de desempenho, como ocorrido quando a taxa de utilização dos processadores era de $25 \%$, como pode ser observado nos gráficos das Figuras 6.12.a e 6.12.c.

Ao ampliar a taxa de utilização dos processadores para 75\%, amplia-se em, apenas, 18\% a quantidade de memória DRAM necessária, no entanto, amplia-se, consideravelmente, as operações de gerenciamento do servidor de aplicação, como escalonamento de 


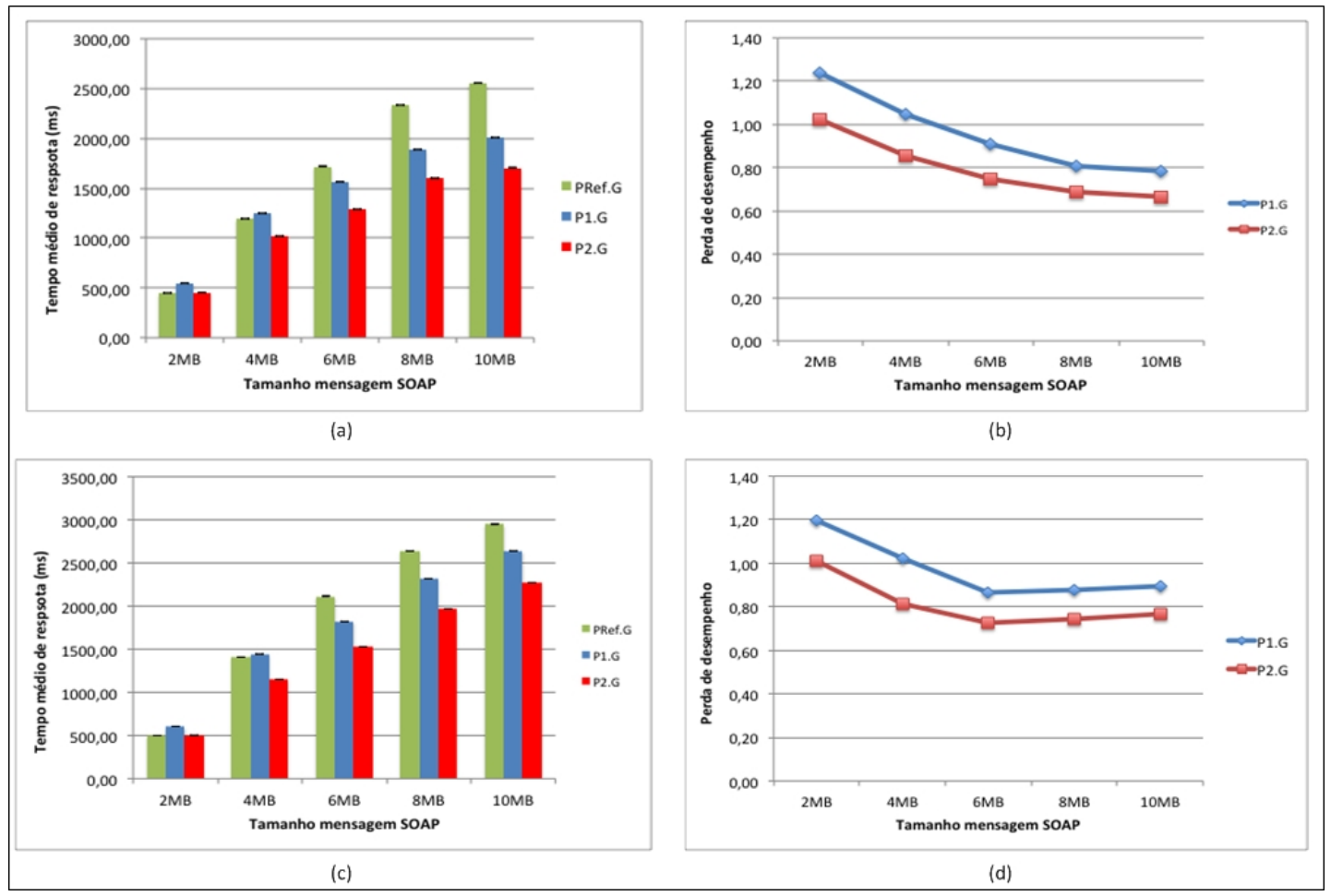

Figura 6.12: Resultados obtidos pelas aplicações distribuídas ao realizar operação de marshalling com dez caracteres por elemento XML: a) Tempo médio de resposta com taxa de utilização de CPUs $75 \%$, b) Perda de desempenho com taxa de utilização de CPUs de 75\%, e c) Tempo médio de resposta com taxa de utilização de CPUs 100\%, d) Perda de desempenho com taxa de utilização de CPUs de $100 \%$.

threads e a concorrência de escrita, fazendo com que os tempos médio de resposta das aplicações executadas sobre as plataformas virtualizadas sejam incrementados, em relação aos tempos obtidos com $50 \%$ de utilização dos processadores, em $57 \%$ e 43\%, respectivamente ao considerar as plataformas P1.G e P2.G. Para essa mesma configuração, a plataforma PRef.G apresentou incremento nos tempos médios de resposta de $21 \%$, demonstrando a sobrecarga gerada pelos virtualizadores, fazendo, assim, com que as aplicações executadas sobre as plataformas P1.G e P2.G sofressem perdas de desempenho de, aproximadamente, $24 \%$ e $2 \%$, respectivamente.

No entanto, como é possível perceber ao analisar a Figura 6.12.a, as aplicações executadas sobre a plataforma P2.G passam a apresentar ganhos de desempenho quando $S \geq 2 M B$, diferentemente da plataforma P1.G, cujas aplicações apresentam ganhos de desempenho quando $S \geq 6 M B$, sendo que, para ambas as plataformas, o maior ganho de desempenho foi registrado quando $S=10 M B$. Para esse tamanho de mensagem SOAP, a plataforma P1.G apresentou ganhos de desempenho de 78\%, enquanto a plataforma P2.G registrou ganhos de $67 \%$. Esse resultado demonstra que para uma taxa de utilização de CPUs de $75 \%$, as plataformas virtualizadas apresentam redução nas perdas de desempe- 
nho à medida que se incrementa o tamanho das mensagens enviadas pelo Web Service, transformando, assim, as perdas de desempenho em ganhos progressivos, como pode ser observado no gráfico da Figura 6.12.b.

Diferentemente dos resultados obtidos quando a taxa de utilização dos processadores era inferior ou igual à $50 \%$, ao ampliar a taxa de utilização para $75 \%$, ocorre um incremento na quantidade de memória à medida em que se amplia o tamanho da mensagem SOAP. Sendo que, à medida que se amplia a taxa de utilização dos processadores, também se incrementa a quantidade de threads consumidoras, permitindo que os recursos de gerenciamento de memória, presentes nas plataformas de virtualização, anulem e até revertam a sobrecarga gerada pelo gerenciamento do servidor de aplicação e do próprio sistema operacional convidado.

Esse fato, por si só, não permitiria que ao ampliar o tamanho da mensagem SOAP se reduzisse a perda ou ampliasse o ganho de desempenho, no entanto, à medida que se amplia o tamanho da mensagem SOAP, incrementa-se, ainda mais, a quantidade memória alocada por intervalo de tempo, fazendo com que valores elevados de $S$ apresentem melhores resultados em favor das plataformas virtualizadas.

Todavia, ao se ampliar ainda mais a taxa de utilização dos processadores, atingindo $100 \%$, percebe-se que, para tamanhos elevados de mensagens SOAP, onde $S \geq 8 M B$, ambas as plataformas virtualizadas impõem uma redução nos ganhos de desempenho obtidos pelas aplicações distribuídas executadas no servidor de aplicação Glassfish, como pode ser observado ao comparar os resultados dos gráficos das Figuras 6.12.b e 6.12.d.

Para os valores de $S$ descritos, ambas as plataformas apresentaram reduções nos ganhos de desempenho de, aproximadamente, $8 \%$ e $15 \%$, quando $S=8 M B$ e $S=10 M B$. Já para valores menores de $S$, percebe-se, através da Figura 6.12.d, que as plataformas ainda conseguem ampliar os ganhos de desempenho ou reduzir as perdas, sendo que, para $2 M B \leq S \leq 6 M B$, a maior perda de desempenho, registrada pela plataforma P1.G, foi de, aproximadamente, $20 \%$, quando $S=2 M B$, sendo, para esse mesmo tamanho de mensagem SOAP, a única perda registrada pela plataforma P2.G. Para mensagens SOAP com $2 M B$ de tamanho, a plataforma baseada em Hyper-V apresentou perda de $1 \%$.

Ainda com relação ao intervalo descrito, o único ganho de desempenho apresentado pela plataforma P1.G ocorreu quando $S=6 M B$, sendo de, aproximadamente, $9 \%$, enquanto a plataforma P2.G apresentou ganhos de desempenho com mensagens a partir de $S=4 M B$, no entanto, o maior ganho também foi registrado quando $S=6 M B$, sendo de, aproximadamente, $28 \%$.

Esse comportamento demonstra que para cargas elevadas de utilização de CPU, as perdas de desempenho obtidas pelas plataformas baseadas em virtualizadores apresentamse divididas em duas fases: a primeira ocorrem reduções nas perdas ou ampliações dos ganhos de desempenho, enquanto a segunda fase apresenta o comportamento inverso, registrando aumentos das perdas ou reduções dos ganhos de desempenho, sendo que, para 
as plataformas e cenários analisados, a mudança de fase ocorre quando $S=6 M B$.

\subsubsection{Variação no tamanho dos elementos XML}

De maneira análoga ao realizado na Seção 6.2, no estudo do impacto da virtualização nas operações de marshalling de mensagens SOAP, também foi realizado o estudo da influência da variação na quantidade de caracteres dos elementos XML que formam o corpo do envelope SOAP, sendo, no entanto, mantido o tamanho global da mensagem. Assim, a quantidade de caracteres foi ampliada para cem e mil sendo $2 M B \leq S \leq 10 M B$.

Ao ampliar a quantidade de caracteres para cem, percebe-se que os tempos médios de resposta das aplicações, executadas sobre as plataformas baseadas em Glassfish e com taxa de utilização dos processadores em $25 \%$, apresentam redução elevada, como pode ser observado no gráfico da Figura 6.13.a.

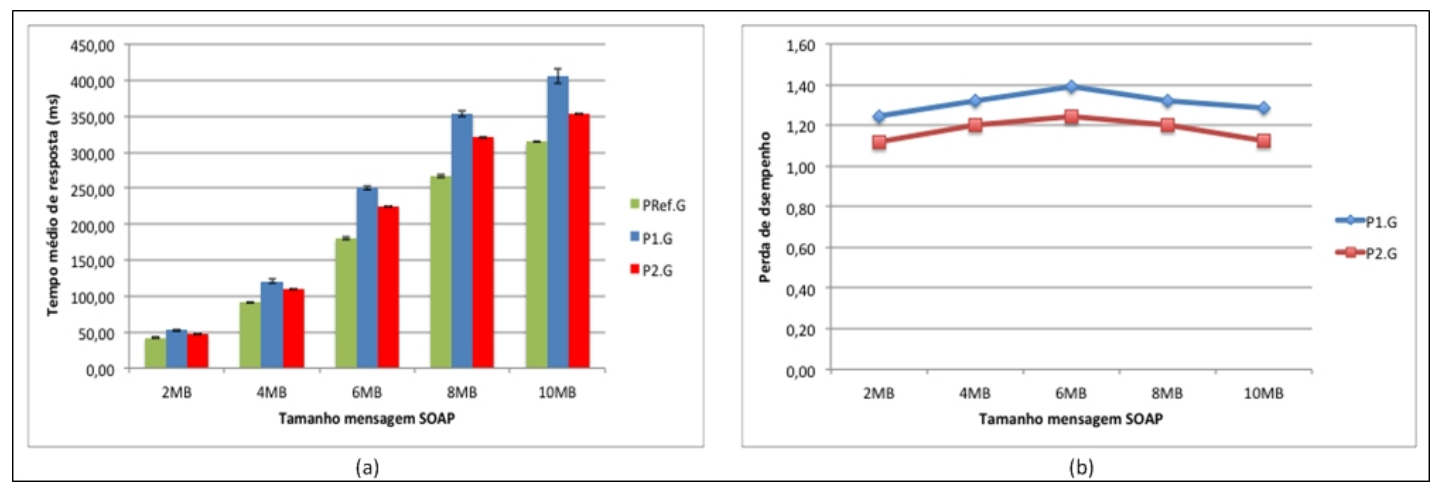

Figura 6.13: Resultados obtidos pelas aplicações distribuídas ao realizar operação de marshalling com cem caracteres por elemento XML e com $25 \%$ de utilização dos processadores disponíveis: a) Tempo médio de resposta e b) Perda de desempenho.

Ao analisar os dados da Figura 6.13.a e compará-los com os dados da Figura 6.10.a, percebe-se que ocorreu uma redução média entre $73 \%$ e $85 \%$ ao ampliar a quantidade de caracteres por elemento XML de dez para cem, sendo as maiores reduções observadas para os menores valores de $S$. Tal fato se deve à redução na quantidade de elementos XML que formam as mensagens, tornando as operações de escrita mais simples, reduzindo, inclusive, a quantidade de memória DRAM consumida durante as submissões em, aproximadamente, $66 \%$.

Esse cenário de reduções faz com que as plataformas virtualizadas percam desempenho em relação à plataforma de referência, uma vez que os recursos de gerenciamento de memória presentes nos virtualizadores e, também, no hardware utilizado, são pouco explorados, uma vez que ao reduzir a quantidade de elementos por mensagem SOAP, reduzindo a quantidade de memória a ser manipulada, também se decrementa a quantidade de faltas de páginas ocorridas. Desta forma, como pode ser observado no gráfico da Figura 6.10.b, 
as perdas de desempenho sofridas pelas aplicações distribuídas, executadas sobre as plataformas virtualizadas, apresentam duas fases: a primeira, quando $2 M B \leq S \leq 6 M B$, apresenta um incremento na perda de desempenho à medida que o tamanho da mensagem é ampliado, já a segunda fase apresenta o comportamento inverso, iniciando quando $S=8 M B$.

Diferentemente do registrado quando a quantidade de caracteres por elemento XML era inferior, quando as plataformas virtualizadas reduziram as perdas de desempenho, convertendo-as em ganhos e ampliando esses ganhos de desempenho à medida que o tamanho da mensagem SOAP era incrementado, quando se considera cem caracteres por elemento XML, percebe-se que, mesmo durante a segunda fase, as plataformas virtualizadas não convertem as perdas de desempenho em ganhos.

Assim, durante a primeira fase, a plataforma P1.G apresentou perdas de desempenho variando entre $25 \%$ e $39 \%$, já a plataforma P2.G apresentou perdas variando entre $12 \%$ e $24 \%$. Durante a segunda fase, a menor perda de desempenho sofrida pelas aplicações executadas sobre a plataforma P1.G foi de $29 \%$, enquanto a plataforma baseada em HyperV impôs uma perda de desempenho de, aproximadamente, $21 \%$ às aplicações distribuídas baseadas em SOA.

Tais resultados demonstram que os recursos da plataforma P2.G, principalmente o uso das large pages, evitam, em parte, as perdas de desempenho sofridas pelas aplicações, como pode ser observado ao ampliar a taxa de utilização dos processadores para $50 \%$, cujos resultados são apresentados no gráfico da Figura 6.14.b.

Ao ampliar a taxa de utilização dos processadores para 50\%, percebe-se, através do gráfico da Figura 6.14.a, que houve uma aproximação entre os resultados obtidos pela plataforma PRef.G e aqueles apresentados pela plataforma P2.G, permitindo que o desempenho desta plataforma seja superior à aquela para, praticamente, todos os tamanhos de mensagens analisadas, com exceção de mensagens com $6 M B$ de tamanho, onde o desempenho da plataforma P2.G foi equivalente ao apresentado pela plataforma de referência, uma vez que houveram sobrepsições das médias e intervalos de confiança.

Para essa taxa de utilização, ainda é possível perceber a existência das fases, cujo comportamento é semelhante ao apresentado quando a taxa de utilização dos processadores era de $25 \%$. Ao ampliar a taxa de processadores para $50 \%$, a plataforma P2.G apresentou $9 \%$ e 3\%, respectivamente, como o maior e o menor ganho de desempenho, sendo obtidos quando $S=2 M B$ e $8 \leq S \leq 10 M B$, uma vez que para valores elevados de $S$, o ganho de desempenho permaneceu estável. A plataforma P1.G, por outro lado, não registrou ganhos de desempenho para os valores de $S$ considerados, sendo registrado $12 \%$ e $38 \%$ como a menor e maior perdas de desempenho, respectivamente, quando $S=2 M B$ e $S=6 M B$, sendo que a maior perda de desempenho ocorre no valor de $S$ que indica a transição da primeira para a segunda fase.

É importante destacar que a presença das fases nas perdas de desempenho das pla- 


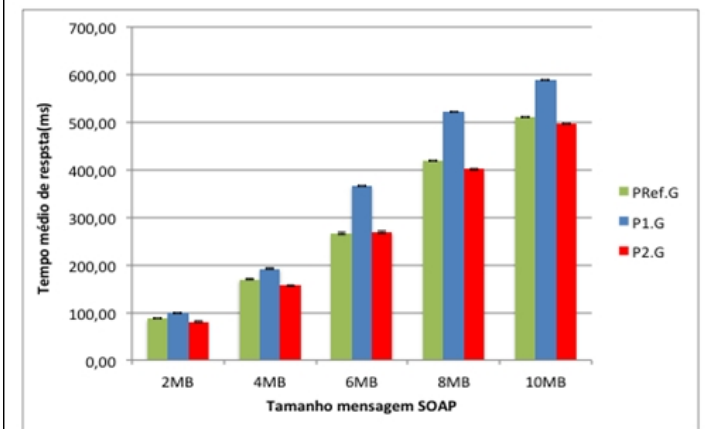

(a)

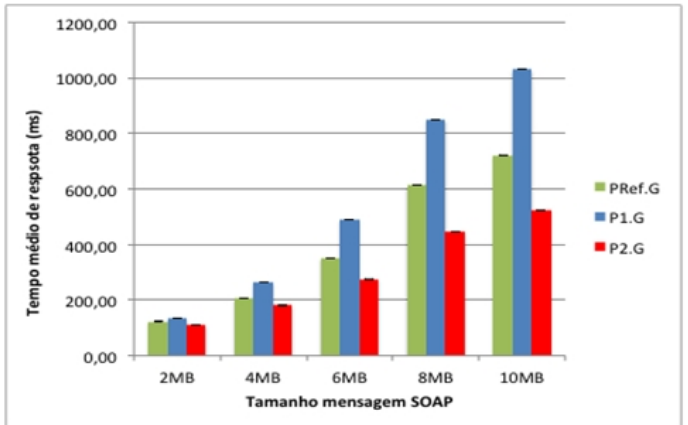

(c)

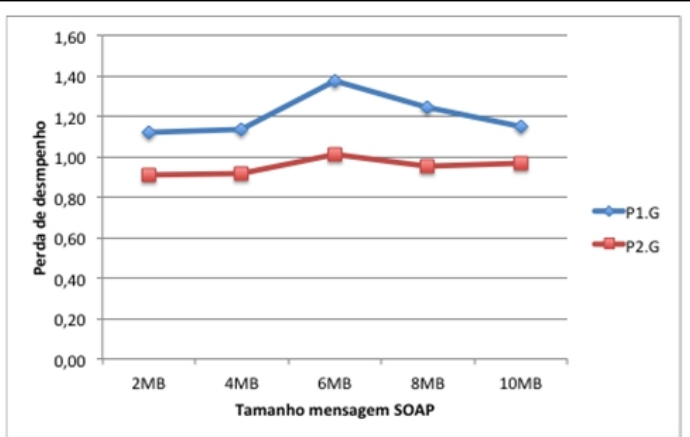

(b)

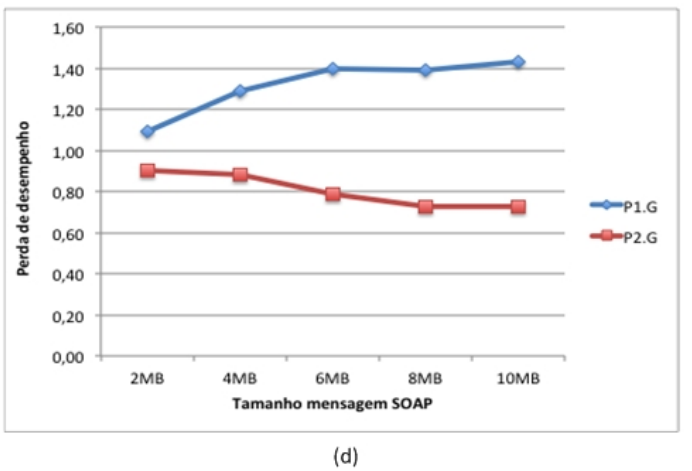

(d)

Figura 6.14: Resultados obtidos pelas aplicações distribuídas ao realizar operação de marshalling com cem caracteres por elemento XML: a) Tempo médio de resposta com taxa de utilização de CPU 50\%, b) Perda de desempenho com taxa de utilização de CPU de $50 \%$, c) Tempo médio de resposta com taxa de utilização de CPU 75\% e d) Perda de desempenho com taxa de utilização de CPU de $75 \%$.

taformas virtualizadas se deve ao aumento na quantidade de memória que é alocada, por intervalo de tempo, ao aumentar o tamanho da mensagem SOAP. Ao ampliar o tamanho da mensagem, um bloco maior de memória é alocado em um único intervalo de tempo, fazendo com que ocorram mais faltas de páginas, permitindo que a sobrecarga dos virtualizadores seja reduzida pelos processos otimizados de alocação de memória dessas plataformas.

De maneira similar, é possível perceber, ao comparar os resultados dos gráficos das Figuras 6.14.b e 6.13.b, que as perdas de desempenho sofridas pelas aplicações distribuídas foram inferiores às perdas sofridas quando apenas $25 \%$ dos processadores eram utilizados. De maneira análoga, ao considerar a plataforma P2.G, é possível perceber que ao ampliar a quantidade de processadores, os ganhos de desempenho apresentados pelas aplicações distribuídas, executadas sobre a plataforma P2.G, foram ampliadas. Esse fato se deve ao aumento na quantidade de threads consumidoras, que ao requisitarem memória em intervalos pequenos de tempo, de forma mais intensa, tornam a alocação de memória mais constante, permitindo que as plataformas virtualizadas obtenham melhores desempenhos se comparados aos desempenhos obtidos quando a quantidade de threads era menor. 
Assim, ao ampliar para $75 \%$ a taxa de utilização dos processadores, incrementando, também, a quantidade de threads consumidoras, percebe-se, através do gráfico da Figura 6.14.d, que os ganhos de desempenho apresentados pela plataforma P2.G são ainda maiores se comparados aos ganhos obtidos quando a taxa de utilização dos processasdores era de $25 \%$, bem como são menores as perdas de desempenho sofridas pelas aplicações distribuídas ao serem executas sobre a plataforma P1.G.

Ainda analisando o gráfico da Figura 6.14.d, percebe-se que apenas os resultados da plataforma P1.G ainda apresentam a divisão em fases, enquanto os ganhos apresentados pela plataforma P2.G são crescentes à medida que se amplia o tamanho da mensagem SOAP. No entanto, ao considerar os resultados da plataforma baseada em VMWare, percebe-se que não há mais um valor específico de $S$ que determina a transição de fases, mas sim um intervalo, sendo, nesse caso quando $6 M B \leq S \leq 8 M B$.

Nessa configuração, a plataforma P1.G apresentou $9 \%$ como a menor perda de desempenho sofrida quando $S=2 M B$ e, aproximadamente, $39,5 \%$ como a maior perda de desempenho, sendo essa perda registrada no intervalo de transição. Já para o maior valor de $S$ considerado, a perda de desempenho registrada foi de $29 \%$, caracterizando, assim, a troca de fase. Por outro lado, a plataforma P2.G apresentou o menor ganho de desempenho quando $S=2 M B$ e o maior ganho quando $S=10 M B$, sendo, respectivamente, $4 \%$ e $27 \%$.

A ausência das fases nas perdas de desempenho sofridas pelas aplicações ao serem executadas sobre a plataforma P2.G, caracteriza a inversão de desempenho entre a plataforma de referência e a plataforma baseadas em Hyper-V. Ao analisar os resultados das perdas de desempenho, quando a taxa de utilização das CPUs era de $25 \%$, a plataforma PRef.G apresentava o melhor desempenho dentre as plataformas, já ao ampliar a quantidade de processadores utilizados para 75\%, a plataforma P2.G passou a apresentar os menores tempos de resposta, diferentemente do ocorrido quando os elementos XML eram formados por apenas dez caracteres, onde, mesmo com baixa utilização do processador, a plataforma P2.G apresentou, para $S \geq 6 M B$, resultados mais eficientes que as demais plataformas, demonstrando que a redução na quantidade de memória e no tempo de processamento causada pela ampliação na quantidade de caracteres por elemento XML, apresenta impacto elevado nos resultados apresentados pelas plataformas virtualizadas.

Ao analisar os gráficos das Figuras 6.14.a e 6.14.c, e compará-los com os tempos médios de resposta obtidos ao utilizar dez caracteres por elemento XML, é possível perceber que ao considerar $50 \%$ de utilização dos processadores e cem caracteres por elemento XML, ocorrem reduções nos tempos de resposta variando entre $69 \%$ e $81 \%$, enquanto, ao considerar $75 \%$ de utilização dos processadores, ocorrem reduções entre $64 \%$ e $81 \%$, o que justifica o melhor desempenho da plataforma PRef.G em relação à plataforma P1.G com ambas as utilizações de CPU citadas e a similaridade de resultados obtidos entre a plataforma de referência e a plataforma P2.G ao considerar 50\% dos processadores 
utilizados.

No entanto, ao ampliar ainda mais a quantidade de processadores, chegando a uma taxa de $100 \%$, percebe-se que mesmo ampliando a quantidade de memória requisitada por intervalo de tempo, através das threads executadas paralelamente, as plataformas virtualizadas apresentam redução no desempenho global, fazendo com que as aplicações distribuídas apresentem aumento na perda de desempenho ou redução no ganho de desempenho, como pode ser observado no gráfico da Figura 6.15.b.

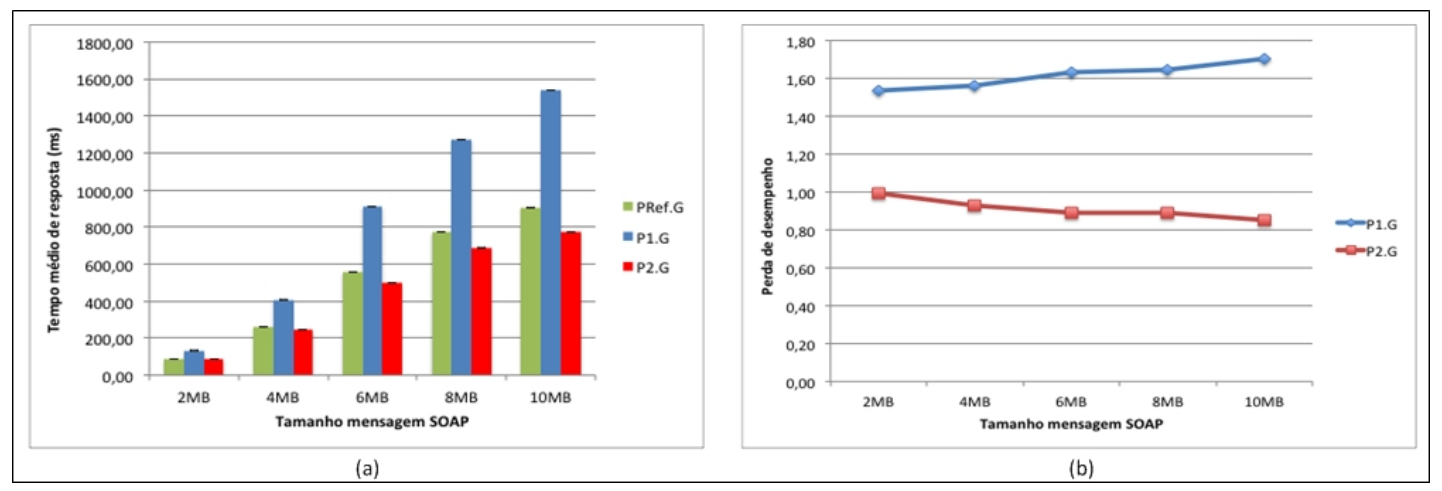

Figura 6.15: Resultados obtidos pelas aplicações distribuídas ao realizar operação de marshalling com cem caracteres por elemento XML e com100\% de utilização dos processadores disponíveis: a) Tempo médio de resposta e b) Perda de desempenho.

Ao analisar o gráfico da Figura 6.15.b, percebe-se que as perdas de desempenho sofridas pelas aplicações executadas sobre a plataforma P1.G, foram ampliadas se comparadas com as perdas registradas quando a taxa de utilização dos processadores era de $75 \%$. De maneira similar, os ganhos de desempenho, obtidos pelas aplicações executadas sobre a plataforma P2.G, também apresentaram redução.

Para essa taxa de utilização dos processadores, a plataforma P1.G não apresenta mais a divisão em fases, sendo a perda de desempenho incrementada à medida que se amplia o tamanho da mensagem SOAP analisada. Assim, a menor perda de desempenho registrada pelas aplicações nessa plataforma foi de $54 \%$ quando $S=2 M B$ e a maior de $70 \%$ quando $S=10 M B$, demonstrando que a plataforma P1.G possui uma grande sensibilidade ao aumento da quantidade de caracteres por elemento XML. Já a plataforma P2.G, apesar de apresentar resultados menos significativos do que aqueles obtidos quando a taxa de utilização dos processadores era menor, ainda apresenta ganhos de desempenho, variando entre $1 \%$ e $15 \%$, respectivamente, quando $S=2 M B$ e $S=10 M B$.

Apesar da maior quantidade de memória solicitada por intervalo de tempo, o incremento na quantidade de memória total, gasta ao ampliar a taxa de utilização dos processadores de $75 \%$ para 100\%, não é expressiva o suficiente para reduzir, significativamente, o impacto gerado pela sobrecarga dos processadores, sendo essa sobrecarga ocasionada pela concorrência entre as threads do Web Service e o próprio sistema operacional con- 
vidado. Ao ampliar a utilização dos processadores, a quantidade de memória consumida ampliou de $8 M B$ para $9 M B$ quando $2 M B \leq S \leq 6 M B$ e de $10 M B$ para $13 M B$ quando $8 M B \leq S \leq 10 M B$.

Essa desvantagem das plataformas virtualizadas é ampliada ao aumentar a quantidade de caracteres por elemento XML, reduzindo, ainda mais, a quantidade de operações de entrada e saída realizada pelo Web Service e, consequentemente, reduzindo a quantidade global de memória consumida.

Ao ampliar a quantidade de caracteres por elemento XML de cem para mil e considerar uma taxa de utilização dos processadores de $25 \%$, ocorre uma redução na quantidade de memória consumida de, aproxidamente, 14\%, uma vez que com cem caracteres por elemento XML são consumidos $6 M B$ de memória quando $2 M B \leq S \leq 6 M B$ e $8 M B$ quando $8 M B \leq S \leq 10 M B$. Já ao considerar mil caracteres por elemento, a quantidade de memória consumida foi de, aproximadamente, $5 M B$ e $7 M B$, respectivamente, quando $2 M B \leq S \leq 4 M B$ e $6 M B \leq S \leq 10 M B$.

Juntamente com a redução na quantidade de memória consumida, também ocorre a redução nos tempos médios de respostas, como pode ser observado na Tabela 6.7, que demonstra a razão entre os tempos médios obtidos pelas plataformas estudadas ao realizarem operações de marshalling com mil e cem caracteres por elemento XML e taxa de utilização de CPU de $25 \%$.

\begin{tabular}{|c|c|c|c|}
\hline S & Plataforma PRef.G & Plataforma P1.G & Plataforma P2.G \\
\hline $2 \mathrm{MB}$ & 0,61 & 0,53 & 0,54 \\
\hline $4 \mathrm{MB}$ & 0,46 & 0,38 & 0,39 \\
\hline $6 \mathrm{MB}$ & 0,33 & 0,26 & 0,28 \\
\hline $8 \mathrm{MB}$ & 0,29 & 0,23 & 0,25 \\
\hline $10 \mathrm{MB}$ & 0,30 & 0,25 & 0,27 \\
\hline
\end{tabular}

Tabela 6.7: Razão entre os tempos médios de resposta das aplicações distribuídas ao considerar mil e cem caracteres por elemento XML e taxa de utilização de CPU em 25\%.

Ao analisar os dados da Tabela 6.7, percebe-se que para todos os tamanhos de mensagens SOAP consideradas, as plataformas virtualizadas apresentam maiores reduções nos tempos de execução das aplicações, fazendo com que a diferença de desempenho existente entre as plataformas analisadas, quando os elementos XML eram formados por cem caracteres, seja reduzida ao ampliar a quantidade de caracteres para mil. Essa aproximação nos tempos médios, obtidos ao ampliar a quantidade de caracteres, pode ser observada no gráfico da Figura 6.16.a, que apresenta os tempos médios de respostas obtidos ao realizar operações marshalling com mil caracteres e taxa de utilização de CPU de $25 \%$.

Apesar da redução na diferença dos tempos de respostas, as plataformas virtualizadas ainda possuem desempenho inferior ao obtido pela plataforma de referência, em todos os tamanhos de mensagem SOAP analisadas, com exceção de mensagens de $2 M B$, sendo que para esse valor de $S$, a plataforma P2.G apresentou ganho de desempenho em relação 


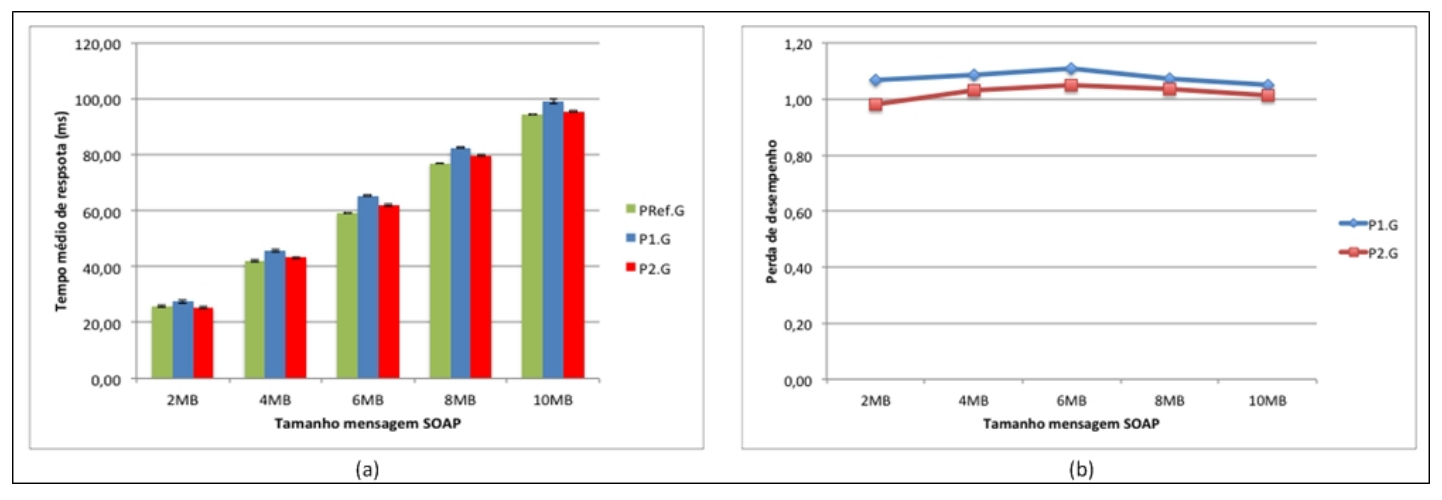

Figura 6.16: Resultados obtidos pelas aplicações distribuídas ao realizar operação de marshalling com mil caracteres por elemento XML e com $25 \%$ de utilização dos processadores disponíveis: a) Tempo médio de resposta e b) Perda de desempenho.

à plataforma PRef.G, como pode ser observado no gráfico da Figura 6.16.b.

Ao analisar os resultados apresentados no gráfico da Figura 6.16.b, percebe-se que a redução elevada no tempo de processamento, devido à menor quantidade de elementos XML para serem serializados, e a redução pouco acentuada na quantidade de memória, permitem que as perdas de desempenho sofridas pelas aplicações distribuídas, executadas sobre as plataformas virtualizadas, sejam inferiores àquelas registradas pelas aplicações ao serem executadadas sobre as mesmas plataformas, porém, com uma quantidade inferior de caracteres por elemento XML.

Nesse cenário, ambas as plataformas virtualizadas possuem as perdas de desempenho divididas em duas fases, como ocorre quando há cem caracteres por elemento XML. Da mesma forma, a primeira fase compreende os resultados obtidos quando $2 M B \leq S \leq$ $6 M B$, onde as perdas de desempenho aumentam à medida que se amplia o tamanho das mensagens processadas. A segunda fase, por outro lado, que compreende as mensagens cujo tamanho variam entre $8 M B$ e $10 M B$, apresenta reduções nas perda de desempenho à medida que se amplia o tamanho das mensagens SOAP consideradas.

Assim, durante a primeira fase, a plataforma P1.G registrou perdas de desempenho variando entre $7 \%$ e $11 \%$, sendo essa perda reduzida para $5 \%$ quando o tamanho da mensagem SOAP atinge $10 M B$. Já a plataforma P2.G registrou perdas de desempenho variando entre $3 \%$ e $5 \%$ quando $4 M B \leq S \leq 6 M B$, uma vez que, para mensagens com o tamanho mínimo considerado, as aplicações distribuídas, executadas sobre a plataforma baseadas em Hyper-V, obtiveram ganhos de desempenho, como descrito anteriormente. Durante a segunda fase, a plataforma P2.G apresentou perdas de desempenho variando entre $4 \%$ e $1 \%$, respectivamente, quando $S=8 M B$ e $S=10 M B$.

No entanto, ao ampliar a taxa de utilização dos processadores para $50 \%$, percebe-se que ambas as plataformas virtualizadas apresentam incrementos maiores nos tempos médios de respostas que os registrados pela plataforma PRef.G, como pode ser observado ao com- 
parar os resultados apresentados no gráfico da Figura 6.17.a com aqueles disponibilizados no gráfico da Figura 6.16 .

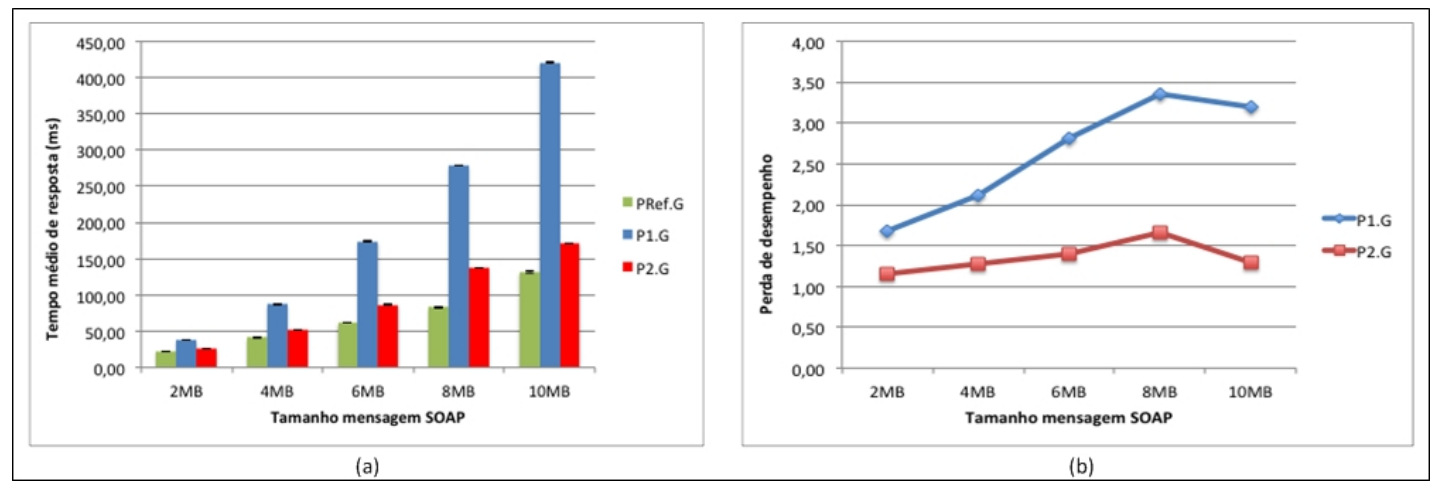

Figura 6.17: Resultados obtidos pelas aplicações distribuídas ao realizar operação de marshalling com mil caracteres por elemento XML e com $50 \%$ de utilização dos processadores disponíveis: a) Tempo médio de resposta e b) Perda de desempenho.

Ao analisar o gráfico da Figura 6.17.a, percebe-se que à medida que se incrementa o tamanho da mensagem SOAP, amplia-se, também, os tempos médios de resposta, sendo que, apenas a plataforma PRef.G apresentou reduções nos tempos de processamento quando $2 M B \leq S \leq 4 M B$. Para valores maiores de $S$, a plataforma de referência apresentou incrementos variando entre $5 \%$ e $39 \%$. Dentre as plataformas virtualizadas, a plataforma P1.G foi a que impôs incrementos maiores aos tempos médios de respostas obtidos, variando entre $26 \%$ e $424 \%$, o que demonstra a sensibilidade dessa plataforma ao cenário gerado com a ampliação da quantidade de caracteres por elemento XML. A plataforma P2.G, também, apresentou incrementos superiores aos registrados pela plataforma PRef.G, no entanto, muito menores que os apresentados pela plataforma P1.G, variando entre $2 \%$ e $79 \%$.

O incremento nos tempos médios de resposta são provenientes da concorrência nas operações de escrita geradas pelas threads paralelas, executadas no servidor de aplicação, e da sua própria gestão de recursos. Essa combinação de fatores ocasiona, também, incrementos nas perdas de desempenho sofridas pelas aplicações executadas sobre as plataformas virtualizadas, em relação àquelas executadas sobre a plataforma de referência. No entanto, ocorre a presença das fases de incremento e decremento das perdas de desempenho.

É interessante destacar que a presença das fases nos resultados de perdas de desempenho é formada pela característica dos tempos médios registrados pela plataforma de referência. No gráfico da Figura 6.17.a, é possível perceber que para $\geq 8 M B$, os tempos de resposta das aplicações executadas sobre a plataforma PRef.G são ampliados desproporcionalmente aos registrados para valores menores de $S$, sendo esse valor de $S$ o ponto de inversão da perda de desempenho, uma vez que os tempos médios de resposta apresen- 
tados pelas plataformas virtualizadas possuem o mesmo comportamento à medida que se amplia o tamanho da mensagem SOAP.

Nesse contexto, a plataforma P1.G apresenta perdas de desempenho variando entre $68 \%$ e $235 \%$ durante a primeira fase, respectivamente, quando $S=2 M B$ e $S=8 M B$ e $220 \%$ para o maior valor de $S$ considerado. A plataforma P2.G, no entanto, apresentou perdas, significativamente, menores que as registradas por P1.G, variando entre $15 \%$ e $65 \%$ na primeira fase e $30 \%$ na segunda fase quando $S=10 \mathrm{MB}$.

Essa dificuldade das plataformas virtualizadas para tratar mensagens SOAP com poucos elementos, compostos por um número elevado de caracteres, é ainda mais significativa ao ampliar a taxa de utilização dos processadores para $75 \%$ e 100\%, principalmente ao considerar a plataforma P1.G, como pode ser observado nos gráficos das Figuras 6.18.a e 6.18.c

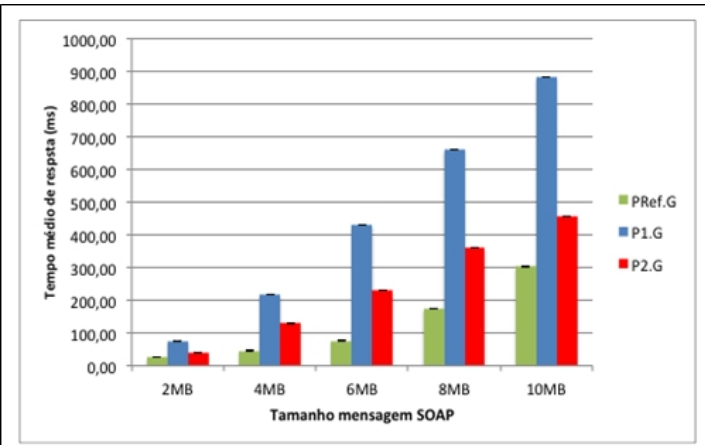

(a)

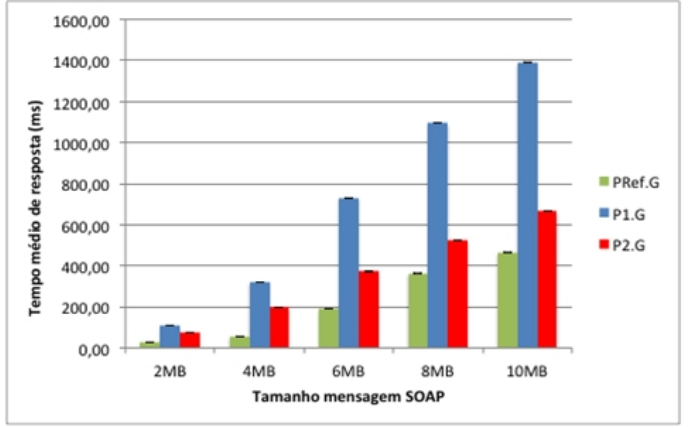

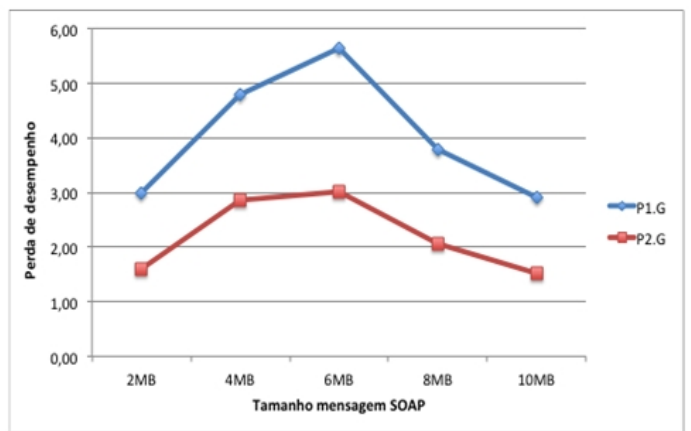

(b)

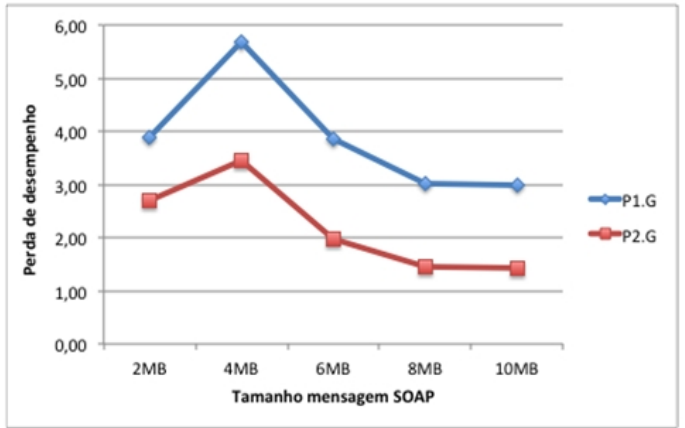

(d)

Figura 6.18: Resultados obtidos pelas aplicações distribuídas ao realizar operação de marshalling com mil caracteres por elemento XML: a) Tempo médio de resposta com taxa de utilização de CPU 75\%, b) Perda de desempenho com taxa de utilização de CPU de $75 \%$, c) Tempo médio de resposta com taxa de utilização de CPU $100 \%$ e d) Perda de desempenho com taxa de utilização de CPU de $100 \%$.

Observando os gráficos das Figuras 6.18.a e 6.18.c, percebe-se que os tempos médios de respostas obtidos na plataforma PRef.G apresentam um incremento significativo a partir de um determinado valor de $S$, levando a perda de desempenho das plataformas virtualizadas a apresentar as duas fases já descritas anteriormente. Quando a taxa de 
utilização dos processadores é de $75 \%$, a mudança de fase ocorre quando $S=6 M B$, já quando a taxa de utilização dos processadores é de $100 \%$, a mudança entre as fases ocorre quando $S=4 M B$, demonstrando que à medida que se aumenta a taxa dos processadores, a alternância de fases ocorre com valores menores de $S$, como pode ser observado nos gráficos das Figuras 6.18.b e 6.18.d.

Assim, quando a taxa de utilização dos processadores é de $75 \%$, a plataforma P1.G apresenta perdas de desempenho entre $198 \%$ e $364 \%$, respectivamente quando $S=2 M B$ e $S=6 M B$. Durante a segunda fase, as perdas são reduzidas para $191 \%$ quando $S=$ $10 M B$. De maneira mais eficiente, a plataforma P2.G apresenta perdas de desempenho variando entre $59 \%$ e $201 \%$ durante a primeira fase, e de $51 \%$ ao final da segunda fase.

Ao ampliar a taxa de utilização dos processadores para 100\%, fazendo com que não somente as threads concorram pelos processadores, mas, também, o próprio sistema operacional convidado, percebe-se que as perdas de desempenho sofridas pelas aplicações distribuídas executadas sobre os gerenciadores de máquinas virtuais é ainda mais elevado. A plataforma P1.G registrou $199 \%$ como a menor perda de desempenho e $467 \%$ como a maior perda de desempenho, respectivamente, quando $S=10 \mathrm{MB}$ e $S=4 \mathrm{MB}$, sendo este valor de $S$ o ponto de mudança de fase no gráfico de perdas de desempenho.

A ampliação elevada nas perdas de desempenho, registrada pelas plataformas virtualizadas, resulta da combinação de baixa memória DRAM consumida e pelos tempos elevados de vida das aplicações distribuídas. Com 100\% de utilização dos processadores, a quantidade de memória DRAM necessária para tratar as aplicações distribuídas é de $7 M B$ quando $S=2 M B$ e de $12 M B$ quando $S \geq 4 M B$. Assim, ao inserir múltiplas threads consumidoras concorrentes, o servidor de aplicação aloca rapidamente o bloco de memória DRAM necessário na geração Jovem da JVM, permanecendo o restante do tempo executando conversão de objetos em mensagem XML, cujo tempo é proporcionalmente maior que aquele gasto alocando memória, fazendo com que as plataformas virtualizadas possuam desempenho muito inferior ao obtido pela plataforma de referência.

\subsection{Considerações finais}

Este capítulo apresentou a influência da virtualização no desempenho de aplicações baseadas em SOA ao realizarem as operações de marshalling e unmarshalling de mensagem SOAP, incluindo mensagens de tamanhos variados e formadas por diferentes quantidades de caracteres, demonstrando que para tomar decisões sobre qual plataforma de virtualização implantar, faz-se necessário considerar tais características, pois como apresentado, na maioria dos cenários analisados, a plataforma baseada em Hyper-V apresentou resultados superiores aos obtidos pela plataforma VMWare, no entanto, ao considerar mensagens SOAP formado por pequenos elementos XML, constatou-se a superioridade desta plataforma em detrimento daquela. 
Este capítulo destacou que as plataformas de virtualização são capazes de ampliar ao desempenho das aplicações baseadas em SOAP, tanto nas operações de marshalling quanto de unmarshalling, principalmente em cenários onde a quantidade de memória consumida é elevada e o tamanho do bloco de memória solicitado pela JVM, em um determinado intervalo de tempo, é grande.

Por outro lado, essa avaliação demonstrou, também, que a virtualização pode impor perdas de desempenho extremamente elevadas às aplicações distribuídas baseadas em SOA, principalmente durante as operações de marshalling cujas mensagens SOAP são formadas por poucos elementos XML com uma grande quantidade de caracteres por elemento. Sendo, essas perdas, ampliadas à medida que se amplia a quantidade de processadores utilizados, sendo o pior desempenho obtido quando se atinge $100 \%$ de utilização das CPUs, uma vez que nesse contexto, há também uma sobrecarga gerada pelo sistema operacional convidado ao gerenciar processos e threads.

Assim, a partir das características apresentadas neste capítulo e no anterior, é possível analisar os principais modelos de desempenho existentes, permitindo concluir que tais modelos não representam, de maneira realista, as influências da virtualização no desempenho de aplicações distribuídas baseadas em SOA e da infraestrutura envolvida em sua execução. Assim, o capítulo seguinte apresentará uma análise crítica desses modelos de desempenho disponíveis, a fim de indicar as modificações necessárias para que representem as tecnologias abordadas neste trabalho. 


\section{Capítulo \\ 7 \\ Virtualização e os modelos de desempenho}

\subsection{Considerações iniciais}

Conforme destacado no Capítulo 1, uma das maiores dificuldades enfrentadas pelos profissionais de TI, ao disponibilizarem serviços na Web, consiste em dimensionar de forma adequada a infraestrutura, oferecendo a qualidade de serviço necessária para os clientes.

É neste contexto que se faz necessário o uso de modelos de desempenho que auxiliam no planejamento de capacidade, que pode ser definido como o processo de prever os níveis futuros de carga de um sistema, permitindo, através da solução mais econômica, adiar ao máximo a sua saturação. Para isso, a previsão precisa considerar a evolução da carga de trabalho e os níveis de qualidade desejados [MENASCE; ALMEIDA, 2003].

Este problema de adequação é agravado na presença de aplicações baseadas em SOA, principalmente quando executadas sobre plataformas virtualizadas, uma vez que o desempenho do sistema está relacionado não somente com a plataforma de desenvolvimento, mas, também, com a infraestrutura do gerenciador de máquinas virtuais, do hardware e da comunicação adotada.

Desta forma, considerando que os modelos de desempenho atualmente disponíveis na literatura não refletem, de forma realista, as plataformas consideradas, este capítulo apresentará as mudanças necessárias para adaptá-los a essa nova realidade. Assim, a fim de permitir um melhor entendimento sobre tais mudanças e a área envolvida, inicialmente será apresentado os conceitos de planejamento de capacidade e seu relacionamento com os modelos de desempenho, destacando o conceito de capacidade adequada e os modelos 
de carga de trabalho, de custo e de disponibilidade.

\subsection{Capacidade adequada}

O principal objetivo do planejamento de capacidade é fornecer informações que permitam a um determinado sistema ser executado em sua capacidade adequada, tanto em termos de software quanto de hardware.

Como capacidade adequada pode-se entender o dimensionamento ideal entre a capacidade do sistema e a quantidade de carga de trabalho submetida, de forma que a ociosidade da plataforma seja a mínima possível, sem, no entanto, deixar de cumprir os acordos de nível de serviço (SLA) e de garantir a satisfação do usuário.

A Figura 7.1 apresenta os três elementos necessários, juntamente com seus relacionamentos, para a correta definição da capacidade adequada em sistemas baseados na Web.

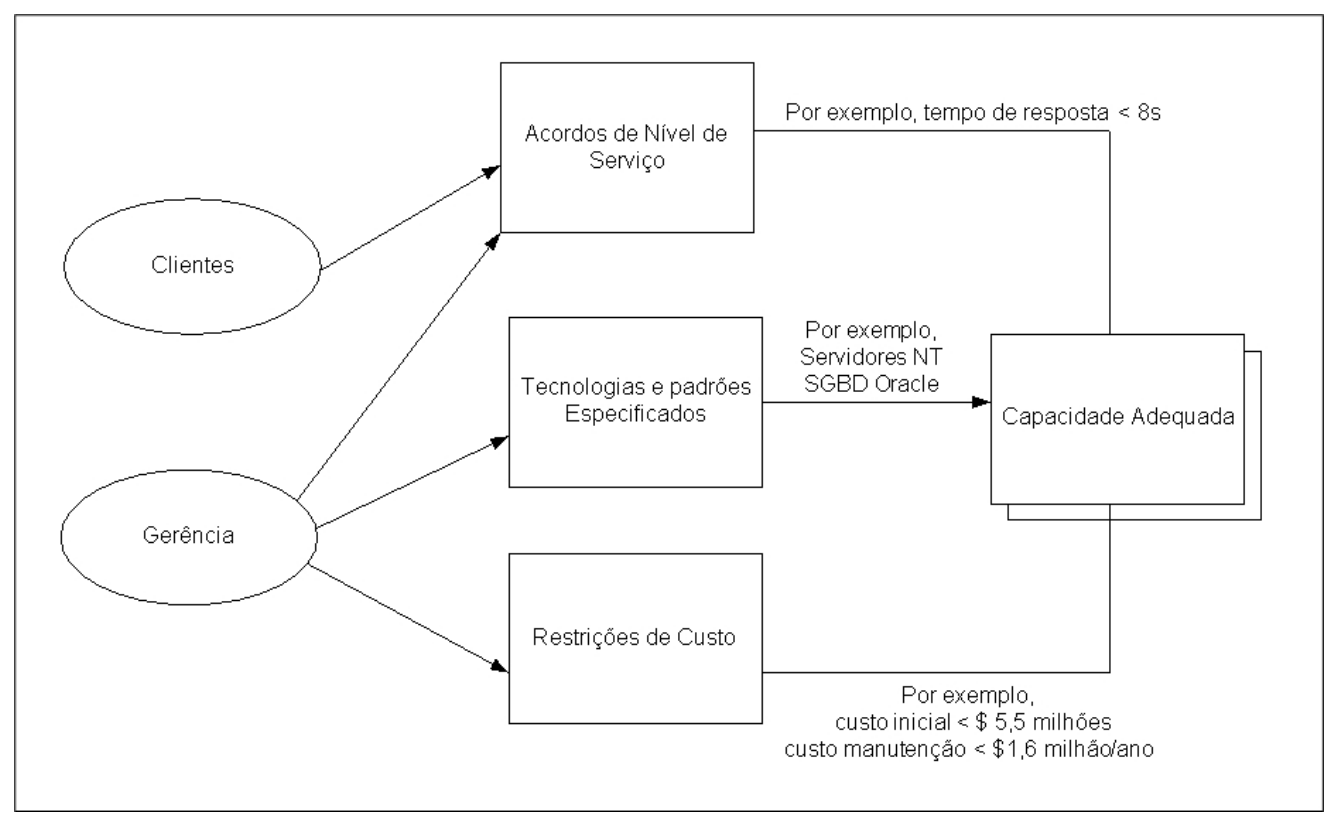

Figura 7.1: Definição da capacidade adequada [MENASCE; ALMEIDA, 2003].

Como pode ser observado na Figura 7.1, o cliente possui interesse apenas no SLA, que descreve como o serviço deve ser fornecido, especificando tempos de respostas e porcentagens de requisições completadas, enfim, características que refletem a qualidade do atendimento prestado. No entanto, para que a capacidade adequada seja atingida, a gerência precisa atender ao SLA contratado pelos clientes, através das tecnologias e padrões especificados, respeitando o orçamento disponibilizado.

É interessante observar que, não somente devem ser considerados os custos com equipamentos e softwares, mas também os envolvidos em treinamentos e suporte técnico. Por exemplo, é possível que uma solução utilizando um servidor de banco de dados Oracle, 
executando sobre um sistema operacional Linux, apresente desempenho adequado, assim como aquele obtido ao utilizar SQL Server em um sistema Windows Server. No entanto, os custos de manutenção e suporte para ambas as plataformas são diferentes, inclusive, há diferença no tipo de suporte prestado.

Mesmo que os custos sejam semelhantes, pode haver uma decisão dos responsáveis por uma plataforma ou outra, tomada por questões ideológicas, marketing, enfim, por outros motivos não dimensionáveis financeiramente. No entanto, nesses casos, é necessário que a evolução da plataforma seja analisada, evitando que mudanças de grande impacto tenham que ser realizadas no futuro.

\subsection{Planejamento de capacidade}

Para atingir a capacidade adequada, o planejamento de capacidade utiliza três modelos, cujos desenvolvimentos são decompostos em etapas, como demonstrado na Figura 7.2 .

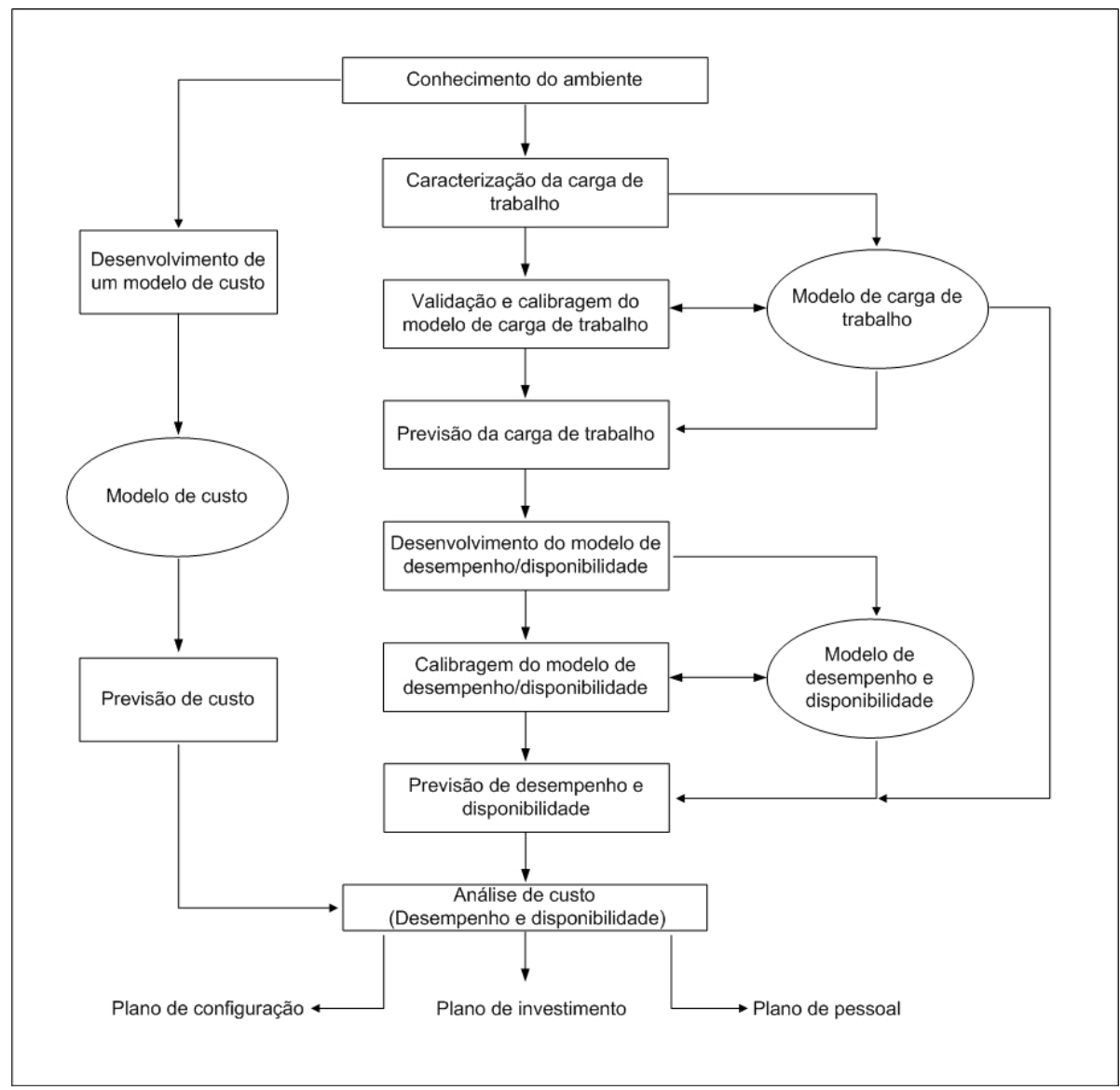

Figura 7.2: Metodologia para o planejamento de capacidade proposto em [MENASCE; ALMEIDA, 2003]. 
Tais modelos refletem os relacionamentos entre os elementos necessários para a obtenção da capacidade adequada, conforme apresentado na figura 7.1. Os modelos considerados são:

- Carga de trabalho: Modelo responsável por capturar as características principais da carga de trabalho do sistema, identificando os períodos de pico elevado, uma vez que o tráfego na Web possui comportamento em rajadas [CHEN; MOHAPATRA, 2003].

- Desempenho e disponibilidade: Responsável por representar o sistema, e com base na carga de trabalho descrita, dimensionar informações de desempenho, como tempo de resposta e taxa de processamento entre outros.

- Custo: Deve mapear os gastos necessários com software, hardware, telecomunicações, serviços de terceiros e de pessoal.

A partir do desenvolvimento dos modelos citados, espera-se, ao final do processo, obter um plano de investimento, que descreverá os custos envolvidos com as aquisições ou modificações na infraestrutura, detalhadas no plano de configuração. Espera-se também obter um plano de pessoal, que descreverá a mão-de-obra necessária para realizar as alterações propostas no plano de configuração.

Para um melhor entendimento da metodologia apresentada na Figura 7.2, as etapas envolvidas serão apresentadas em forma de seções.

\subsubsection{Modelo de carga de trabalho}

A partir do conhecimento do ambiente obtido, é possível desenvolver o modelo de carga de trabalho, cuja obtenção envolve as atividades de caracterização da carga e a validação/calibragem do modelo, o que permitirá caracterizar novas situações de carga imposta ao sistema.

Como carga de trabalho, pode-se considerar o conjunto de todas as informações de entrada que o sistema recebe em um determinado período de tempo [PRAPHAMONTRIPONG et al., 2007]. Todavia, torna-se difícil coletar e lidar com uma grande quantidade de informações, assim, é necessário reduzir e resumir tais informações, de forma que, as principais características da carga de trabalho real sejam mantidas. A essa síntese, dá-se o nome de modelo de carga de trabalho.

Uma técnica muito utilizada para avaliar sistemas, consiste em registrar as informações desejadas do sistema em arquivos de log, denominados trace. Assim, é possível desenvolver um modelo do sistema a ser analisado, e utilizar tais arquivos para solucionar o modelo proposto através de simulação.

No entanto, a abordagem por trace não permite empregar o planejamento de capacidade em sua totalidade, uma vez que não há a possibilidade de alterar parâmetros da 
carga do sistema, a fim de refletir possíveis mudanças futuras, objetivando prever o comportamento da plataforma. Adicionalmente, torna-se complexo obter as características que mais influenciam no desempenho do sistema, o que impossibilita otimizar o desenvolvimento das soluções avaliadas [JAIN, 1991].

Sendo assim, ao gerar modelos de carga de trabalho, adiciona-se um grau elevado de flexibilidade ao processo de planejamento de capacidade.

\section{Caracterização da carga de trabalho}

A caracterização da carga de trabalho pode ser definida como o processo de descrever, com precisão, a carga de trabalho global do sistema em termos de seus componentes principais [MENASCE; ALMEIDA, 2003].

Esses componentes devem ser decompostos em outros básicos, caracterizados por parâmetros que reflitam a intensidade da carga de trabalho e as demandas de serviços em cada recurso.

Para atingir tal objetivo, deve-se, inicialmente, escolher o ponto de vista envolvido no processo de análise, uma vez que uma mesma tarefa pode ser descrita de diferentes formas mediante o recurso que está sendo analisado, bem como do nível de abstração utilizado [CALZAROSSA; MASSARI; TESSERA, 2000].

Como exemplo, considere as solicitações a um Web Service. Elas podem ser caracterizadas a partir do ponto de vista do cliente, cujo fator mais importante é o tempo de processamento da solicitação ponta-a-ponta, ou seja, entre a solicitação do consumidor e a chegada da resposta ao mesmo. No entanto, se for considerado o ponto de vista do servidor de aplicações, a modelagem deverá retratar os tempos entre as chegadas das requisições, os tipos de requisições e os tempos de resposta dos servidores de aplicação.

Após realizar as fases de definição do ponto de vista da obtenção dos componentes básicos e seus parâmetros, deve-se executar a tarefa de coleta de dados, cujo objetivo é atribuir valores aos parâmetros de cada componente do modelo. Para tal, devem-se monitorar, através de monitores, as atividades do sistema durante intervalos de tempos previamente definidos, denominados janelas de tempo.

Os monitores são ferramentas que detectam eventos dentro de um sistema, identificando sinais predefinidos, podendo ser desenvolvidos em hardware ou software. Aqueles desenvolvidos em hardware são externos ao sistema e por isso são poucos invasivos, sendo muito utilizados para capturar dados de registradores, memórias e canais de entrada e saída. Esses monitores apresentam uma grande capacidade de adaptação, uma vez que são independentes do sistema operacional, no entanto, tornam-se inviáveis para obterem informações de aplicações [MENASCE; ALMEIDA, 2003].

Diferentemente, os monitores desenvolvidos em software são mais invasivos, uma vez que se apresentam como pequenas rotinas inseridas no sistema a ser observado, ocupando 
assim tempo de processador. Todavia, tais monitores são eficientes na obtenção de informações das plataformas de hardware e software [JAIN, 1991].

Até este ponto, a carga de trabalho encontra-se caracterizada de maneira global, a partir do ponto de vista escolhido. No entanto, é necessário particioná-la com o objetivo de dividi-la em um conjunto de classes, cujas populações são formadas por elementos homogêneos [CALZAROSSA; MASSARI; TESSERA, 2000]. Esse particionamento pode ser realizado de acordo com determinadas características como [MENASCE; ALMEIDA, 2003]:

- Uso de recursos: Categorizando a carga de trabalho de acordo com a intensidade de ocupação dos recursos, usando denominações como leve, moderada e pesada por exemplo.

- Aplicações: Podem-se utilizar as aplicações que geram o tráfego no sistema para dividir a carga em, por exemplo, requisições HTTP, FTP, SMTP, P2P ...

- Objetos: Especificamente em sistemas Web, podem-se caracterizar os objetos solicitados, como por exemplo, imagens, documentos HTML e vídeos.

- Funcional: Neste tipo de agrupamento, utilizam-se as aplicações, que dão origem a carga de trabalho, como parâmetros de classificação. Assim, poder-se-ia utilizar as seguintes classes: Oracle, Java, servlets ...

- Modo: Pode ser utilizado para agrupar os componentes da carga de trabalho em:

- interativos: Caracterizado por uma classe de processamento on-line, onde se faz presente um determinado tempo de pensar.

- Transação: Caracterizado por uma classe de processamento on-line, que agrupa componentes que chegam a um sistema com determinada taxa de chegada.

- Contínuo: Caracterizado por componentes executados continuamente, como tarefas em batch.

\section{Validação do modelo e previsão de carga de trabalho}

A partir da caracterização da carga de trabalho, o modelo já se encontra disponível, necessitando, porém ser validado.

O processo de validação consiste em comparar os resultados obtidos com o modelo de carga sintética, com aqueles registrados com a carga real, que foram previamente coletados. Caso os resultados apresentem diferenças percentuais pequenas, dentro de uma faixa aceitável para o sistema proposto, o modelo é considerado válido, caso contrário, será necessário calibrar o modelo, com ajustes na caracterização da carga, a fim de que seja possível validá-lo. 
A faixa de erro, que permite considerar o modelo válido, varia para cada caso analisado, dependendo da criticalidade e do nível desejado de precisão das previsões. No entanto, considera-se, em geral, que erros entre $10 \%$ e 30\% são aceitáveis [MENASCE; ALMEIDA, 2003].

Esse processo de validação se faz necessário, pois, ao construir modelos, algumas abstrações são realizadas, a fim de facilitar a coleta de dados e a caracterização da carga, uma vez que diminuindo o número de elementos considerados, torna-se mais fácil definir um perfil de carga. No entanto, ao abstrair informações, é possível que características importantes sejam excluídas, comprometendo o modelo.

A partir do momento em que o modelo de carga de trabalho está validado, é possível prever como as cargas reais oscilarão no futuro, necessitando apenas combinar o modelo de carga de trabalho, o histórico de evolução da carga real e os planos de negócios futuros [TAVARES, 2009].

\subsubsection{Modelo de custos}

O modelo de custo constitui uma parte crítica do planejamento de capacidade, uma vez que ampliações e modificações, tanto na estrutura de hardware, quanto de software, só podem ser concretizadas se estiverem dentro do limite estipulado no orçamento inicial.

O modelo de custo visa descrever os gastos financeiros envolvidos com a implantação do sistema e também em sua manutenção. Aqueles envolvidos com a implantação são denominados custos iniciais, e apresentam uma parcela única de investimento. Já aqueles envolvidos com a manutenção, denominados operacionais, são contínuos e buscam evitar a obsolescência e degradação da infraestrutura implantada [MENASCE; ALMEIDA, 2003].

Adicionalmente, o modelo de custos pode ser combinado com os modelos de desempenho e disponibilidade, a fim de verificar qual o cenário apresenta o melhor custo benefício, permitindo assim, que os acordos de nível de serviço sejam atendidos com o menor investimento possível.

\subsubsection{Modelo de disponibilidade}

Ao considerar a modelagem da disponibilidade, devem-se considerar, também, as questões referentes à confiabilidade. Uma vez que um sistema torna-se mais disponível à medida que a sua confiabilidade aumenta.

A necessidade de modelar a disponibilidade se torna um processo mais crítico em sistemas baseados na Web, principalmente aqueles envolvendo Web Services, uma vez que os serviços são disponibilizados, em alguns casos, em uma rede pública, cuja probabilidade de ataques é elevada. Adicionalmente, a grande quantidade de tecnologias envolvidas, juntamente com os prazos reduzidos para o desenvolvimento dos sistemas, torna-os mais susceptíveis a falhas, reduzindo a disponibilidade apresentada [MENASCE; ALMEIDA, 2003]. 
Ao analisar a disponibilidade, é importante conhecer a existência de alguns parâmetros utilizados para caracterizá-la. Tais parâmetros podem ser observadas na Figura 7.3.

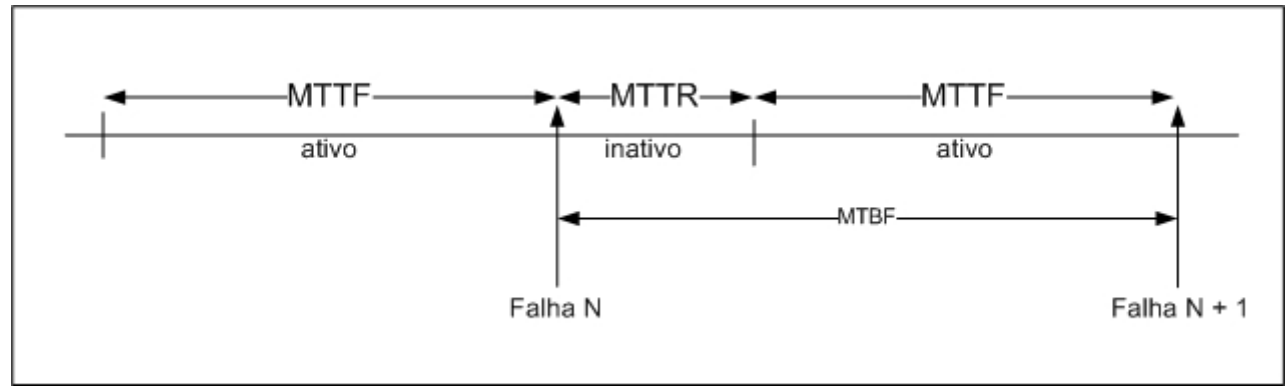

Figura 7.3: Parâmetros relacionados ao processo de modelagem da disponibilidade [MENASCE; ALMEIDA, 2003].

O MTTF(Mean Time To Failure) é uma média de tempo que um sistema leva para apresentar uma falha. Já o MTTR (Mean Time To Recover), compreende a média de tempo gasto para recuperar as falhas ocorridas. Finalmente, o MTBF (Mean Time Between Failures) é a média de tempo ocorrido entre falhas. A relação entre essas medidas é expressa na equação 7.1 .

$$
M T B F=M T T F+M T T R
$$

Juntamente com os parâmetros descritos, faz-se necessário, ainda, definirem-se quais os tipos de falhas devem ser consideradas ao desenvolver o modelo. Assim, em [MENASCE; ALMEIDA, 2003] é proposto uma taxonomia que divide as falhas em três dimensões:

- Duração: Classifica as falhas quanto ao MTTR, dividindo-as em:

- Falhas permanentes: Nesse tipo de falha não existe a possibilidade de recuperação do sistema.

- Falhas recuperáveis: Nesse caso há a possibilidade de recuperação de uma falha.

- Falhas transientes: São aquelas que apresentam MTTR reduzidos, cujas ações de recuperação são pouco dispendiosas.

- Efeito: Essa categoria classifica as falhas de acordo com efeitos causados ao sistema, sendo divididas em:

- Falhas funcionais: Esse tipo de falha não permite que o sistema desenvolva as suas funções corretamente.

- Falhas de desempenho: Este tipo de falha está intimamente relacionada ao modelo de desempenho, uma vez que o sistema realiza corretamente as suas funções, no entanto, com parâmetros como tempo de resposta, fora do limite desejado. 
- Escopo: Nessa categoria as falhas são classificadas de acordo com a abrangência atingida:

- Falha parcial: Neste caso, apenas uma parte do sistema é atingido, tornando-se indisponível, enquanto a outra parte permanece ativa e disponível.

- Falha total: Essa classificação engloba situações em que todo o sistema é comprometido, tornando-se indisponível. É importante observar que não necessariamente todos os componentes do sistema devem apresentar falhas, bastando apenas que o acesso a eles esteja indisponível.

\section{Classificação dos sistemas}

Ao modelar a disponibilidade, é importante observar o tipo de disponibilidade desejada, podendo categorizá-la de acordo com a quantidade de "9" envolvida no seu percentual. Essa relação pode ser observada na tabela 7.1.

\begin{tabular}{|c|c|c|c|}
\hline $\begin{array}{c}\text { Classe de } \\
\text { disponibilidade }\end{array}$ & Disponibilidade & $\begin{array}{c}\text { Indisponível } \\
\text { (min/ano) }\end{array}$ & Tipo de sistema \\
\hline 1 & $90 \%$ & 52,560 & Não controlado \\
\hline 2 & $99 \%$ & 5,256 & Controlado \\
\hline 3 & $99,9 \%$ & 526 & Bem controlado \\
\hline 4 & $99,99 \%$ & 52,6 & Tolerante a falhas \\
\hline 5 & $99,999 \%$ & 5,3 & Altamente disponível \\
\hline 6 & $99,9999 \%$ & 0,53 & Muito altamente disponível \\
\hline 7 & $99,99999 \%$ & 0,0053 & Ultradisponível \\
\hline
\end{tabular}

Tabela 7.1: Classificação dos sistemas de acordo com a disponibilidade [MENASCE; ALMEIDA, 2003].

A partir da decisão de qual o tipo de sistema desejado, é possível utilizar as equações 7.2 e 7.3, para obter as informações relativas às grandezas MTTF, MTTR e MTBF, onde $p_{\text {ativo }}$ indica a probabilidade de um sistema estar ativo, enquanto $p_{\text {inativo }}$ define a probabilidade dele estar inativo.

$$
\begin{gathered}
P_{\text {ativo }}=\frac{M T T F}{M T T F+M T T R} \\
P_{\text {inativo }}=\frac{M T T R}{M T B F}
\end{gathered}
$$

\section{Ampliando a disponibilidade}

A disponibilidade pode ser ampliada através da redução na quantidade de falhas, através da elevação do MTTF, ou da redução do tempo de recuperação, através do incremento 
MTBF. A redução do tempo de recuperação consiste na utilização de tecnologias direcionadas a rápida detecção da falha, bem como através da utilização de logs e sistemas de falhas recorrentes, a fim de reduzir o tempo gasto com a solução do problema.

Já a ampliação do MTTF apresenta-se de forma mais complexa em sistemas grandes, uma vez que as técnicas utilizadas para tal envolvem redundância dos recursos críticos e a clusterização dos mesmos. A redundância consiste em replicar elementos, de forma que, mediante a falha de um deles, o outro assume a tarefa de maneira automática. Essa solução, nas arquiteturas multicamadas, é muito empregada na camada de dados e na de distribuição.

Já a clusterização consiste na inserção de elementos em paralelo, a fim de que executem as tarefas direcionadas ao grupo de forma colaborativa. Assim, mediante a falha de um nó do sistema, é possível que outro assuma a tarefa interrompida. No entanto, para que esse comportamento seja atingido, é necessário que técnicas de migração sejam empregadas no nível de granularidade considerado [ALVES, 2008].

\subsubsection{Modelo de desempenho}

Ao considerar o modelo de desempenho, devem-se mapear os parâmetros que influenciam diretamente no desempenho do sistema, abstraindo aqueles que possuem menor impacto. Uma estratégia para atingir esse objetivo, consiste em analisar os parâmetros baseados em categorias [MENASCE; ALMEIDA, 2003]:

- Parâmetros do sistema: Abordam características gerais que afetam o sistema como um todo, como a disciplina de balanceamento, protocolos de rede e número máximo de conexões aceitas.

- Parâmetros de recurso: Descrevem as características peculiares de um determinado recurso, como o tempo de acesso a disco, largura de banda utilizada e o tempo para tratamento de ausências de páginas.

- Parâmetros de carga de trabalho: Refletem a caracterização da carga de trabalho. Tais características podem ser relativas à intensidade da carga, indicando o número de unidades de trabalho que disputam um determinado recurso, ou de demanda de serviço, que especificam a quantidade total de tempo de serviço, exigido por cada recurso, para atender a demanda de cada unidade de trabalho.

A partir dessa etapa, é necessário utilizar uma técnica de modelagem a fim de mapear o comportamento do sistema, frente aos parâmetros obtidos. Em sistemas Web, é comum utilizar a teoria de redes de filas [JAIN, 1991].

Na modelagem por rede de filas, a unidade básica utilizada é constituída de uma fila e um centro de serviço. O centro de serviço representa o recurso modelado, como 
por exemplo, disco, processador e memória. Já a fila é responsável por armazenar as solicitações destinadas ao recurso.

Um centro de serviço é caracterizado por uma função $S(n)$, que representa o tempo médio de serviço por pedido, quando existem $n$ pedidos na fila, sendo $n$ o tamanho da fila. É importante observar que a fila pode possuir uma capacidade máxima, sendo denominada finita, ou não, sendo então denominada infinita.

Ao modelar os recursos do sistema, deve-se observar que existem três categorias de recursos representados pelas redes de filas, conforme apresentado na Figura 7.4.

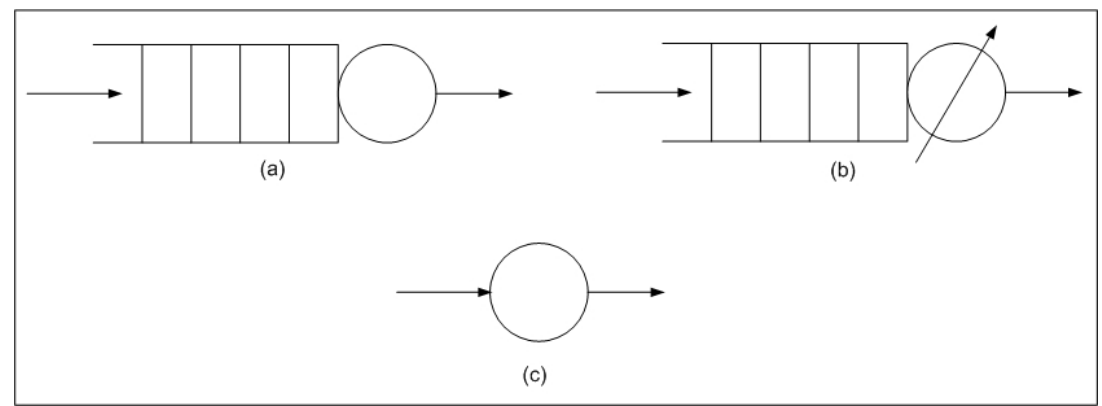

Figura 7.4: Categorias de recursos caracterizados em redes de filas: a) Recurso independente de carga, b) recurso dependente de carga e c) recurso de atraso. Adaptado de [MENASCE; ALMEIDA, 2003].

Os recursos independentes de carga, Figura 7.4.a, são aqueles que possuem enfileiramento de solicitações, no entanto, o tempo médio de serviço não depende da carga do sistema, sendo, portanto, constante. Da mesma forma, os recursos dependentes de carga, representados pela Figura 7.4.b, possuem enfileiramento de solicitações, no entanto, o tempo médio de serviço é influenciado pela carga. Assim, $S(n)$ é uma função arbitrária de $n$. Finalmente, os recursos de atraso, Figura 7.4.c, não possuem filas, por esse motivo, o tempo total gasto por uma solicitação é o tempo gasto para processá-la. Neste tipo de recurso, se um centro de serviço estiver alocado e receber uma solicitação, a mesma será automaticamente descartada.

Da mesma forma que descrito na seção 7.3.1, o modelo de desempenho precisa ser validado e se necessário calibrado, todavia, diferentemente da modelagem da carga de trabalho, tanto o modelo de desempenho, quanto o de disponibilidade, precisam ser resolvidos. Para tal, é possível utilizar duas alternativas: solução analítica ou simulação.

A solução analítica produz resultados exatos, não exigindo métodos estatísticos para validar a precisão obtida, uma vez que é baseada em um conjunto de fórmulas utilizadas para gerar medições de desempenho a partir de parâmetros do modelo. Todavia, essa abordagem apresenta-se como um método complexo, cujas soluções podem ser impossíveis de serem obtidas, se utilizado um alto grau de realidade na modelagem [JAIN, 1991].

Já a solução por simulação, apresenta-se como uma alternativa atrativa para sistemas complexos. Nesse tipo de abordagem, desenvolve-se um software que represente a mo- 
delagem do sistema, permitindo que as transações se desloquem pelos diversos recursos simulados [MENASCE; ALMEIDA, 2003].

Sendo assim, ao optar pela simulação, devem-se utilizar métodos estatísticos para validar os resultados obtidos, uma vez que se trata de uma solução numérica, cuja presença de erros é inerente [JAIN, 1991].

Nesse tipo de resolução, é preciso obter um nível de equilíbrio entre a precisão do modelo e a facilidade de uso. À medida que mais detalhes são modelados, maiores se tornam os requisitos de detalhamento da carga de trabalho, e mais complexo torna-se o programa de simulação. Por outro lado, à medida que se diminuiu a precisão desejada, diminuem-se também os requisitos de modelagem e a dificuldade de implementação.

\subsection{A influência da virtualização nos modelos de de- sempenho disponíveis}

$\mathrm{Na}$ literatura se encontram trabalhos que apresentam modelos de desempenho para aplicações baseadas em SOA, bem como modelos que tratam ambientes virtualizados e de computação em nuvem do tipo IaaS, como destacado no capítulo 1, no entanto, tais modelos não refletem em sua totalidade o impacto gerado pelo processo de virtualização de sistemas operacionais nos tempos de respostas das aplicações distribuídas baseadas em SOA. De maneira análoga, os modelos apresentados não permitem considerar a substituição do servidor de aplicação, uma vez que o processo de virtualização de aplicações, como o gerado pela JVM, não é considerado, excluindo, assim, a sobrecarga do processo de coleta de lixo existente nas principais linguagens e plataformas de programação.

Uma característica fundamental na análise de desempenho de aplicações baseadas em SOA é a divisão do software em múltiplas camadas, como abordado no modelo de desempenho denominado R-Capricio descrito em [ZHANG et al., 2007]. Nesse modelo, os autores consideram a divisão do software em três camadas, como pode ser observado na Figura 7.5.

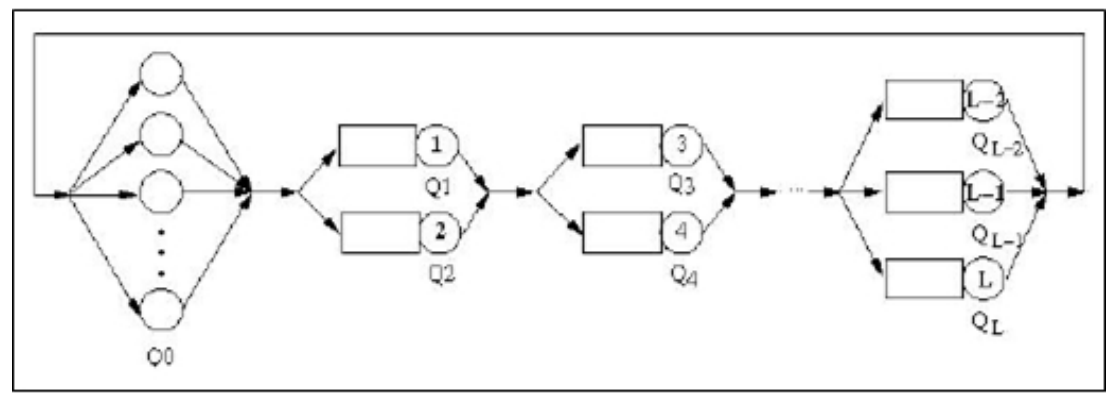

Figura 7.5: Modelo de desempenho R-Capriccio proposto em [ZHANG et al., 2007].

O modelo R-Capriccio, utiliza-se de um sistema fechado modelado através de redes de 
fila, em que o nível $Q 0$ representa os usuários que submetem requisições para a primeira camada do lado servidor, constituída de servidores Web. Esses servidores retornam para o usuário respostas HTTP compostas de páginas estáticas e encaminham para segunda camada de serviço onde se encontram os servidores de aplicação e, consequentemente, a implementação dos Web Services. Já a terceira e última camada é composta de servidores de banco de dados responsável pelo repositório de informações persistentes.

Apesar de sua aplicabilidade direta e de considerar o planejamento de capacidade de sistemas completos, envolvendo todas as camadas, o modelo R-Capriccio não considera a existência de threads, como apresentado em [LIU et al., 2008], cujo modelo pode ser observado na Figura 7.6.a

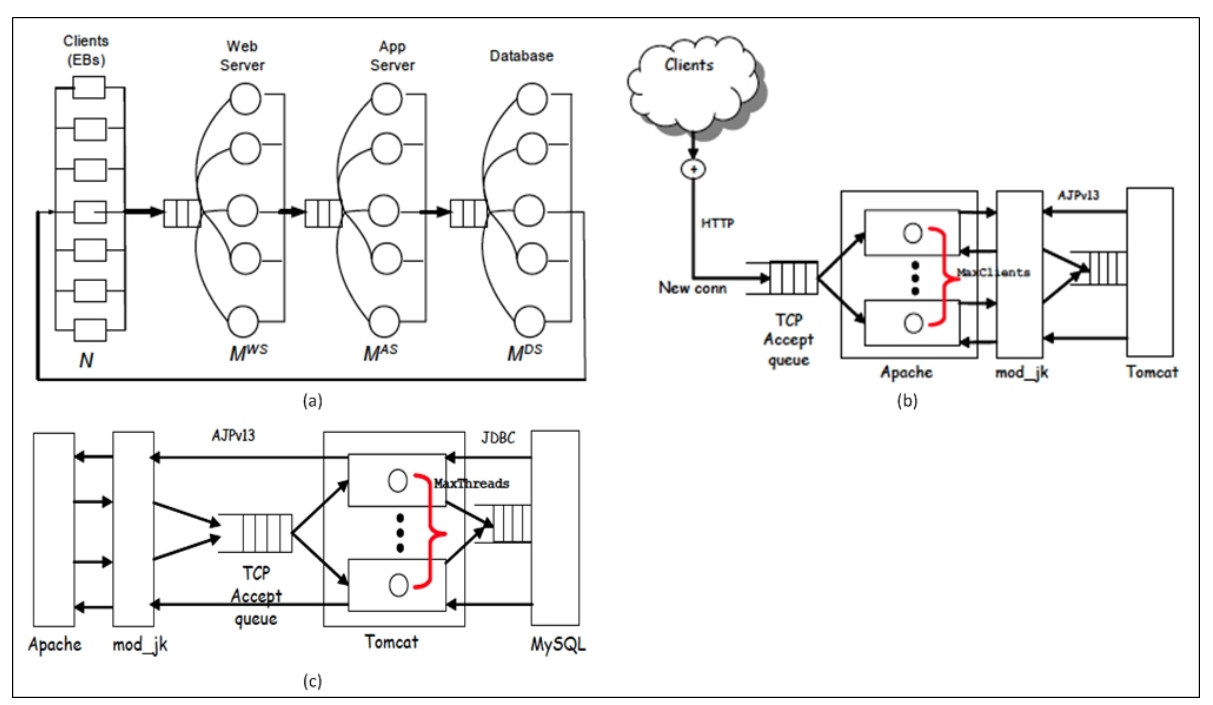

Figura 7.6: Modelo de desempenho apresentado em [LIU et al., 2008] considerando sistemas dividido em camadas e com múltiplas threads: a) Modelo de rede de filas e b) arquitetura de comunicação entre as camadas um e dois e c) arquitetura de comunicação entre as camadas dois e três.

Ao observar o modelo apresentado na Figura 7.6.a, percebe-se que as camadas consideradas são as mesmas apresentadas no modelo da Figura 7.5, no entanto, cada camada é composta de um único serviço composto de múltiplas threads, o que torna a representação de cada serviço mais realista, pois, como demonstrado nos capítulos 5 e 6 , a taxa de utilização dos processadores é caracterizada pela quantidade de requisições ativas simultaneamente, geradas pelas threads consumidoras, que ativam threads concorrentes no servidor de aplicação.

Nesse modelo, muitos detalhes de implementação, que geram sobrecarga, são conside-

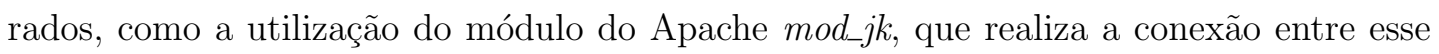
servidor Web e o contêiner de servlets Tomcat, como apresentado na Figura 7.6.b, bem como a utilização de drivers JDBC utilizados na conexão entre a segunda e a terceira camada no lado do servidor, como apresentado na Figura 7.6.c. 
Tais características impõem maior precisão na prospecção de desempenho de cenários futuros para o tipo de solução considerada, no entanto, o modelo proposto em [LIU et al., 2008] não permite que múltiplos servidores sejam disponibilizados como apresentado no modelo R-Capriccio.

Ao analisar ambos os modelos apresentados até esse momento, percebe-se que cenários virtualizados não podem ser considerados em sua totalidade. Como os modelos são baseados em traces, é possível utilizar os tempos de respostas obtidos pelas aplicações distribuídas ao serem executadas em um ambiente virtualizado em específico. Essa abordagem permite prever o comportamento da plataforma em situações em que mudanças nos componentes não são requeridas, como a ampliação na quantidade de clientes e, consequentemente, de requisições simultâneas. Porém, mesmo nesse cenário, a previsão não seria completa, pois os novos recursos de gerenciamento de memória disponibilizados pelos processadores, como a tabela dupla de endereçamento e as "large pages", fazem com que em algumas configurações de carga, o desempenho das plataformas virtualizadas sejam superiores aos obtidos pelas plataformas que não utilizam virtualização. Adicionalmente, as perdas ou ganhos de desempenho obtidos pelas aplicações baseadas em SOA oscilam juntamente com a variação na taxa de utilização das CPUs.

Adicionalmente, tais modelos não permitem prospectar o desempenho das plataformas através de troca de tecnologia, uma vez que, além de não tratar os recursos destacados anteriormente, presentes nos hardwares modernos, os modelos não consideram as características envolvidas na processo de virtualização de aplicações, como a sobrecarga gerada pela operação de coleta de lixo. Mesmo obtendo traces com tempos de respostas de diferentes servidores de aplicação, os modelos não mapeiam a relação entre a quantidade de memória consumida pelas estruturas de dados das aplicações, principalmente aquelas do tipo memory-intensive de carga moderada e elevada, e a quantidade de memória DRAM disponível para o sistema operacional virtualizado. Essa combinação, em conjunto com a taxa de alocação de memória, descreve a quantidade de execuções do garbage collector e, consequentemente, a sobrecarga gerada por essa operação.

Finalmente, os modelos propostos em [ZHANG et al., 2007] e [LIU et al., 2008], não permitem dimensionar a influência da virtualização nas bibliotecas de codificação e decodificação de envelopes SOAP, uma vez que, em tais modelos, o tempo de comunicação é ignorado, diferentemente do modelo proposto em [TEIXEIRA et al., 2009], onde os autores, através de redes de Petri [KARTSON et al., 1994], propõem um modelo cujos objetivos são analisar o consumo de recursos e a degradação nos níveis de serviços de aplicações baseadas em SOA.

O modelo desenvolvido em [TEIXEIRA et al., 2009] diferencia as operações de orquestração e coreografia de Web Services. No contexto apresentado pelos autores, orquestração é tratado como a maneira de combinar e recombinar serviços internos a fim de implementar uma regra de negócio, enquanto a coreografia se refere a comunicação externa com outros 
serviços disponibilizados, através de uma rede de comunicação, em servidores de aplicação externos.

Ao considerar a possibilidade de comunicação interna e externa, o modelo descreve, através da Equação 7.4, os custos envolvidos na atividade de invocação dos Web Services, sendo $\tau_{\text {comm }}$ descrito pela Equação 7.5

$$
\begin{gathered}
\tau[c]=\tau_{\text {intr }}+\tau_{\text {comm }} \\
\tau_{\text {comm }}=d[n]+\frac{h i[m]+h o[m]}{j[n]}+b[m]
\end{gathered}
$$

Na Equação 7.4, $\tau_{\text {intr }}$ corresponde ao tempo para processar a operação invocada pelo software consumidor acrescido do tempo de comunicação, denotado por $\tau_{\text {comm }}$. O tempo de comunicação é descrito pelo somatório da latência da rede, $d[n]$, acrescida do tempo de transmissão da mensagem SOAP e do tempo de computação da operação, $b[m]$, uma vez que a Equação 7.5 descreve uma invocação de uma operação síncrona. O tempo de transmissão da mensagem corresponde ao somatório do tamanho das mensagens SOAP de envio e retorno, denotadas, respectivamente, por $h i[m]$ e $h o[m]$ dividida pela vazão da rede ou taxa de transmissão, denotada por $j[n]$. Para invocações assíncronas, desconsiderase o processamento da mensagem de retorno e o tempo de processamento da operação invocada.

Ao considerar o tempo de transmissão de mensagens SOAP, é possível representar, no planejamento de capacidade de ambientes virtualizados, a existência de comunicação de dados sobre diferentes tipos de interfaces, bem como considerar uma rede estruturada sobre switches virtuais em um ambiente de computação nuvem do tipo IaaS, permitindo prever, assim, o impacto gerado pelas operações de marshalling e unmarshalling dos envelopes SOAP.

O modelo proposto em [TEIXEIRA et al., 2009] apresenta, também, a evolução dos modelos desenvolvidos em [ZHANG et al., 2007] e [LIU et al., 2008], uma vez que permite representar diferentes servidores de aplicação sendo executadas com múltiplas threads, conforme pode ser observado na Figura 7.7.

Ao analisar a Figura 7.7, percebe-se que o diagrama básico, utilizado para compor as diferentes organizações de sistemas baseados em SOA, prevê os seguintes lugares:

1. Lugar $W$ : Representa uma fila de consumidores aguardando pelo serviço;

2. Lugar S: Representa as requisições sendo executadas, sendo que $R_{k}$ contém os recursos necessários pela execução das operações, enquanto em $S, d_{\lambda}$ representa o atraso necessário para processar as mensagens de envio e recebimento, sendo constituída do tempo de envio e recebimento em operações síncronas e somente de envio em operações assíncronas, sendo denotadas em demais diagramas por $d_{r}$ e $d_{s}$, representando, 


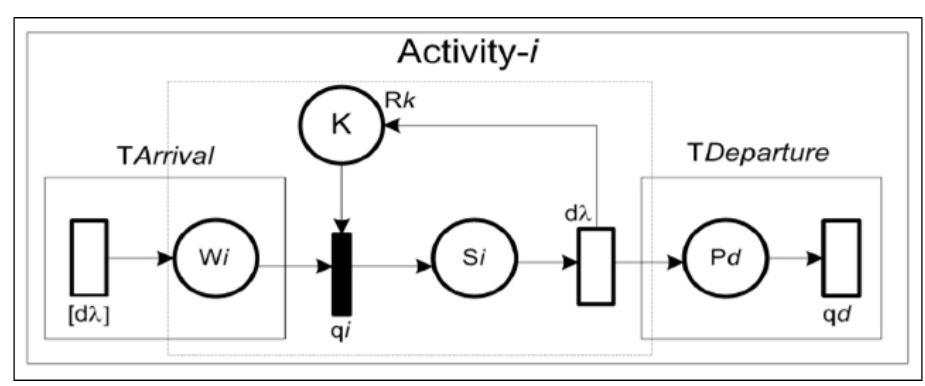

Figura 7.7: Processo básico do modelo de desempenho apresentado em [TEIXEIRA et al., 2009].

respectivamente, o tempo de envio e de recebimento;

3. Lugar P: Representa a fila de saída do sistema, cujas mensagens são enviadas para o consumidor.

A partir do diagrama básico apresentado, é possível compor os mais diferentes cenários em que os sistemas baseados em SOA são organizados, permitindo, inclusive composições paralelas. No entanto, mesmo permitindo representar mais características relacionadas ao comportamento de aplicações baseadas em SOA ao serem executadas sobre plataformas virtualizadas, o modelo descrito em [TEIXEIRA et al., 2009] não permite representar a taxa de utilização dos processadores, uma vez que o modelo prevê apenas a representação das threads do servidor de aplicação.

Como apresentado nos capítulos 5 e 6 , a taxa de utilização dos processadores possui forte influência no desempenho das aplicações baseadas em SOA ao serem executadas sobre plataformas virtualizadas, tanto no tempo de processamento das instruções do serviço implementado, quanto no tempo de processamento das mensagens SOAP pelas bibliotecas do servidor de aplicação. Assim, é possível perceber que o modelo considerado não permite mapear os recursos de hardware utilizados pelos virtualizadores do tipo bare-metal, assim como os modelos descritos anteriormente.

Adicionalmente, o modelo de [TEIXEIRA et al., 2009] não permite mapear a troca de servidor de aplicação, uma vez que o mesmo não mapeia a relação entre o consumo de memória DRAM pela aplicação, a quantidade de memória DRAM disponilizada para o sistema operacional convidado e o recurso de alocação garantida explorada pelos virtualizadores, principalmente, pelo VMWare. Assim, tal modelo não permite prospectar a ocorrência de coletas de lixo pelo Garbage Collector e consequentemente a quantidade de ausências de páginas maiores.

Da mesma forma, o trabalho apresentado em [KARGUPTA; BLACK, 2012] não permite descrever essa relação, no entanto, os autores desenvolveram fórmulas e padrões que permitem representar uma grande quantidade de características que envolvem as aplicações baseadas em SOA. Tais padrões relacionam o desempenho das aplicações às latências dos 
componentes e a carga de trabalho a partir de coletas prévias realizadas no sistema a ser avaliado.

Assim, as latências existentes entre os componentes são utilizadas para mapear tempo de processamento da memória, tempo consumido com entrada e saída, tempo de processamento de mensagens XML, entre outros. Desta forma, esse modelo permite descrever de forma mais precisa o impacto da virtualização nas bibliotecas de processamento de mensagens SOAP e nas interfaces de rede, uma vez que o delay total de cada operação é descrita pela equação 7.6 , onde $I_{G}$ se refere ao gradiente de impedância e $D L P i$ se refere à latência do ponto $i$.

$$
I_{G}=\sum i=1^{n} L_{D L P i}
$$

Uma vez que se trata de uma metodologia, a construção de frameworks se faz necessário para cada cenário a ser avaliado, como no exemplo apresentado pelos autores, apresentado na Figura 7.8.

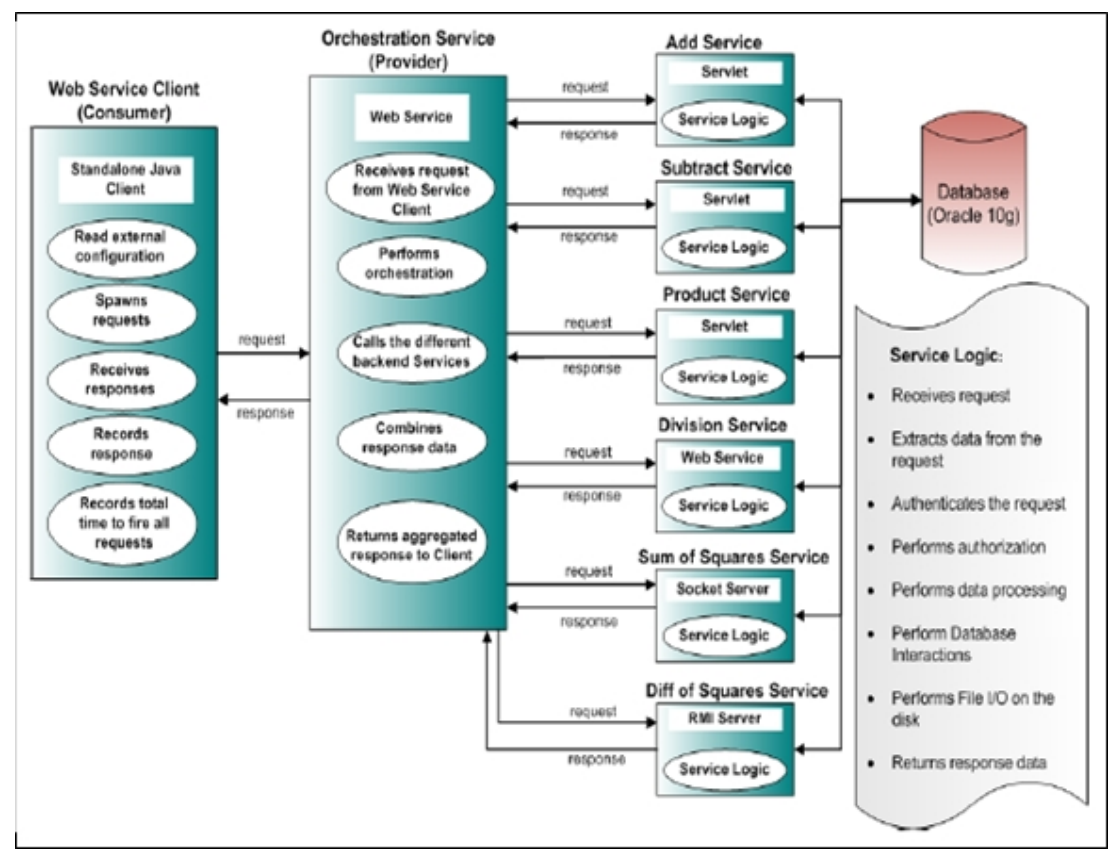

Figura 7.8: Framework de um modelo lógico de serviço [KARGUPTA; BLACK, 2012].

Como é possível perceber na Figura 7.8, a primeira camada do framework proposto consiste de um software consumidor desenvolvido na linguagem de programação Java, composto de múltiplas threads. Esse software é responsável por obter as informações do arquivo de configuração, incluindo o trace de submissão e, posteriormente, enviar as requisições para o serviço de orquestração contido na segunda camada, realizando, como última etapa, a escrita do relatório. O provedor localizado na segunda camada é responsável por receber as requisições do consumidor e realizar as chamadas aos serviços necessários que 
se encontram na terceira camada, retornando, para o software da primeira camada, os resultados obtidos durante o processamento, resultado esse que inclui os tempos de respostas. Os serviços na terceira camada representam operações reais disponibilizadas pelo sistema que está sendo avaliado, podendo, inclusive, envolver operações com transações em bases de dados.

É importante observar que entre as camadas há a representação das mensagens request e response, indicando que o atraso dessas mensagens devem ser computado no tempo total de processamento. Adicionalmente, ao observar o texto do trabalho, percebe-se que o tempo de codificação e decodificação das mensagens SOAP também são considerados separadamente, o que permite representar a diferença de desempenho nas operações de marshalling e unmarshalling destacadas nos capítulos anteriores.

Como destacado anteriormente, apesar do maior nível de detalhamento obtido com essa metodologia, os padrões e fórmulas apresentados em [KARGUPTA; BLACK, 2012] não permitem descrever as relações entre os virtualizadores, os servidores de aplicação e as operações de coleta de lixo. Da mesma forma, não permitem descrever os recursos de hardware como EPT, "large pages" e alocação garantida.

Por outro lado, o modelo interativo proposto em [KUNDU et al., 2010], destinado à ambientes virtualizados, permite representar, indiretamente, o impacto do servidor de aplicação no desempenho das aplicações distribuídas, uma vez que o modelo define a variável MOPS (Memory Operation per Second), que descreve a quantidade de operações realizadas por segundo. Nesse contexto, ao trocar o servidor de aplicação, o que altera a frequência do coletor de lixo e, consequentemente, o desempenho das aplicações, é possível reduzir a quantidade de operações de memória por segundo. Essa abordagem não trata o problema de forma direta, mas fornece uma aproximação melhor que as apresentadas pelos modelos anteriormente descritos.

De maneira análoga, o modelo define a variável IOPS (I/O Operation per Second), que descreve a taxa de competição por dispositivo de I/O, sendo que, quanto maior a taxa de competição, maior será a utilização dos mesmos pelas aplicações distribuídas. Ao considerar as operações de entrada e saída baseadas em disco, ao aumentar a taxa de competição, também, amplia-se a fila de espera ao processar faltas de páginas. Ao definir tal parâmetro, juntamente com o parâmetro MOPS, torna-se possível representar o recurso de alocação de memória garantido presente nos virtualizadores, reduzindo a quantidade de falta de páginas maiores. Também se torna possível mapear o recurso de "large pages", uma vez que na plataforma Hyper-V ele foi responsável pelo ganho de desempenho das aplicações em algumas configurações estudadas.

Já ao considerar as operações de entrada e saída baseadas em interfaces de rede, é possível mapear o meio de comunicação utilizado, no entanto, não é possível considerar a influência gerada pela virtualização nas bibliotecas de codificação e decodificação de envelopes SOAP, uma vez que não há variáveis destinadas a mapear um segundo ponto 
de sobrecarga no momento de comunicação a não ser aquele previsto nas interfaces de rede.

Finalmente, é possível perceber que o modelo proposto, mesmo descrevendo a variável CAP ( $C P U$ Allocation Percentage), que trata a porcentagem de CPU utilizada, não permite tratar a relação entre a taxa de utilização dos processadores e o desempenho das aplicações distribuídas, uma vez que tal desempenho se encontra vinculado a quantidade de memória DRAM alocada na geração jovem da JVM por intervalo de tempo, o que não corresponde, diretamente a quantidade de memória alocada pelo sistema operacional convidado.

\subsubsection{Modelo modular proposto}

A partir dos trabalhos analisados neste capítulo, percebe-se que novos modelos devem ser propostos e que aqueles atualmente em uso sejam adaptados para que reflitam, de maneira realista, os cenários estudados. Assim, a partir desse objetivo, o autor desta tese iniciou o desenvolvimento de um novo modelo baseado em redes de filas, no âmbito da Universidade Federal de Mato Grosso, cujo desenvolvimento se encontra na fase de validação e calibração, aquele através de simulação [JAIN, 1991].

A modelagem realizada se divide em três modelos fundamentais que, unidos, representam cenários em que aplicações distribuídas baseadas em SOA são implantadas em ambientes virtualizados, através de virtualizadores do tipo bare-metal, e, também, em ambientes sem a presença de um hypervisor.

\section{Máquina física}

O primeiro modelo fundamental, apresentado na Figura 7.9, representa uma computador executando diretamente sobre o hardware um único sistema operacional. Esse modelo foi definido originalmente em [ALVES, 2008] e expandido neste projeto para incorporar as características de processadores multinúcleos e, também, de diferentes tipos de discos rígidos e redes de blocos, tais como: discos SATA (Serial AT Attachment), discos SAS (Serial Attached SCSI), iSCSI (Internet Small Computer System Interface) e SAN (Storage Area Network).

No modelo apresentado na Figura 7.9 o processo é tratado como um token que circula pelo sistema, sendo processado pelos seguintes centros de serviço:

- RX: Representa o canal de entrada da interface de rede, uma vez que os canais de comunicação de entrada e saída devem ser tratadas separadamente, pois, é possível que o sistema operacional esteja implantado sobre uma estrutura do tipo blade, onde os servidores são fabricados em lâminas e acoplados em enclosures que disponibiliza, entre outros recursos, a possibilidade da comunicação entre lâminas ser realizada através de seu barramento interno, estabelecendo, assim, uma rede de alta velocidade 


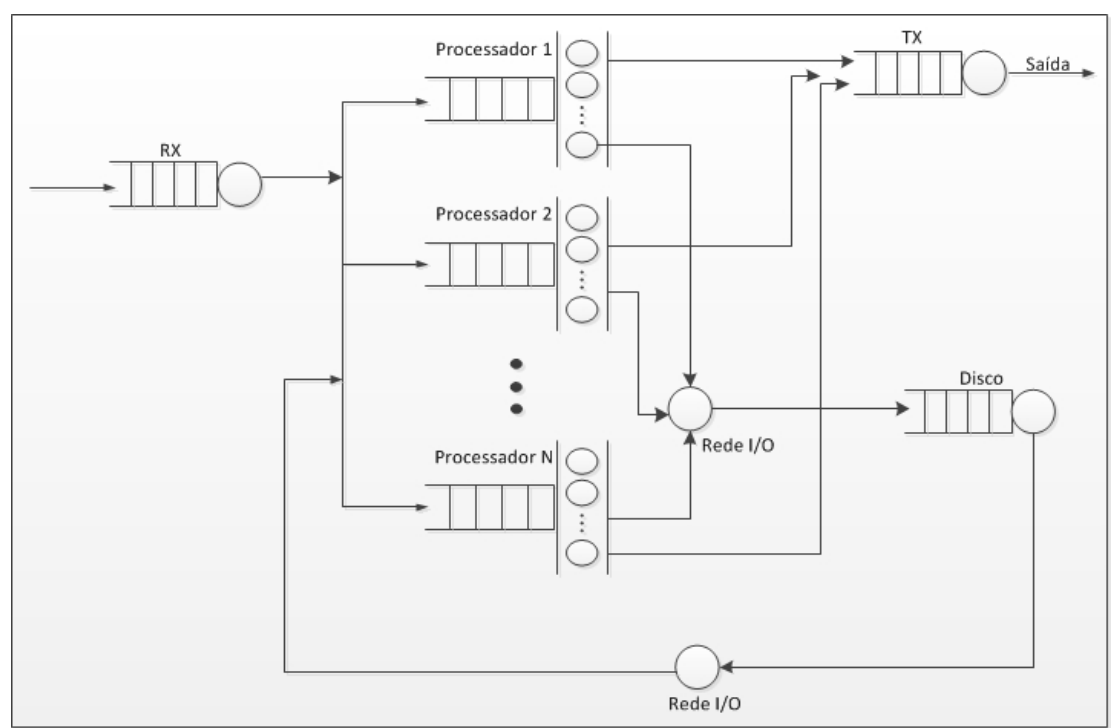

Figura 7.9: Modelo baseado em rede de filas que representa uma máquina física cujo sistema operacional é executado diretamente sobre o hardware.

de delay e jitter reduzidos. Por outro lado, é possível que uma ou mais lâminas precisem trocar informações com outros servidores localizados fora do enclausure, neste caso, as interfaces de rede são externalizadas através de portas de switches físicos, o que reduz a velocidade e a qualidade da comunicação. Desta forma, é possível perceber que uma requisição e sua resposta sejam realizadas por interfaces de redes com características distintas.

- TX: É o complemento do centro de serviço RX, modelando o tráfego de saída da interface de rede.

- Processador: Representa uma unidade de processamento contida em uma pastilha de silício, sendo composto uma única fila e múltiplos centros de serviço, onde cada centro de serviço representa um núcleo do processador. É importante destacar que ao implementar o simulador, deve-se considerar o fato do sistema operacional possuir uma fila de processos prontos independentemente da fila de entrada de cada processador.

Ao ser submetido a fila Processador, um processo executará por um quantum, normalmente de $20 \mathrm{~ms}$, podendo ser redirecionado para centro de serviço TX, indicando a sua saída do sistema, seja por finalização ou por uma comunicação necessária. Em se tratando de uma comunicação, ao seu término, o processo deve retornar pela fila RX, sendo, posteriormente, inserido no final da fila Processador. É possível, ainda, que o processo realize uma operação de entrada e saída em disco ou sofra uma ausência de página. Em ambos os casos o processo é redirecionado para o centro de serviço Rede I/O e, posteriormente, para o Disco, retornando, finalmente, para o 
processador que originou o seu trâmite.

- Rede I/O: Representa as redes de blocos e as diferentes tecnologias de discos presentes nos sistemas corporativos. Como destacado no início desta subseção, é importante observar que esse centro de serviço não possui uma fila anexada, uma vez que seu objetivo é ampliar o tempo de tratamento das operações de leitura e escrita, permitindo, assim, simular as diferentes tecnologias de comunicação de blocos.

- Disco: Representa o dispositivo disco rígido que, em conjunto com o centro de serviço Rede I/O, permite representar as diferentes tecnologias de comunicação em blocos. Ao deixar esse centro de serviço um processo retornará para o centro de serviço Processador através do centro Rede I/O.

No modelo apresentado na Figura 7.9, assim como aquele definido em [ALVES, 2008], a quantidade de ausências de páginas causadas por um processo é proporcional à diferença entre a quantidade de páginas alocadas a ele, e a quantidade de páginas necessárias para o seu working set, sendo dado definida pela Equação 7.7, onde mem. Solicitada $a_{i}$ é a quantidade de páginas solicitadas pelo processo $i$ e mem. Alocada $a_{i}$ é a quantidade de páginas alocadas ao processo $i$.

$$
\sigma * \frac{\text { Mem. Solicitada }}{\text { Mem. Alocada }_{i}}
$$

\section{Máquina virtual}

O modelo de redes de fila que representa uma máquina virtual, apresentado na Figura 7.10, é uma expansão do modelo de uma máquina física, sendo assim, os centros de serviço RX Física, TX Física, Rede I/O, Disco real e Processador físico, correspondem, respectivamente, aos centros de serviço RX, TX, Rede I/O, Disco e Processador do modelo descrito na Seção 7.4.1.

Nesse modelo, com o objetivo de representar a influência dos drivers de rede, normalmente presentes nos kits de integração dos virtualizadores, desenvolveu-se os centros de serviço RX virtual e TX virtual, que representam as interfaces de rede disponibilidades para as máquinas virtuais, que podem, ou não, estarem interligadas à placas físicas, representadas pelos centros RX física e TX física. Tal medida se faz necessária uma vez que em sistemas virtualizados é possível mapear as placas virtuais de rede em placas físicamente instaladas no sistema hospedeiro, bem como utilizar placas totalmente virtuais, que se conectam em switches virtuais. Tal característica permite impor taxas de comunicação diferenciadas para os tráfegos de entrada e saída, exigindo, assim, que ambos os canais sejam tratados independentemente.

No modelo apresentado na Figura 7.10 também é possível observar a presença de centros de serviços denominados Processadores Virtual, cuja quantidade é variável, de- 


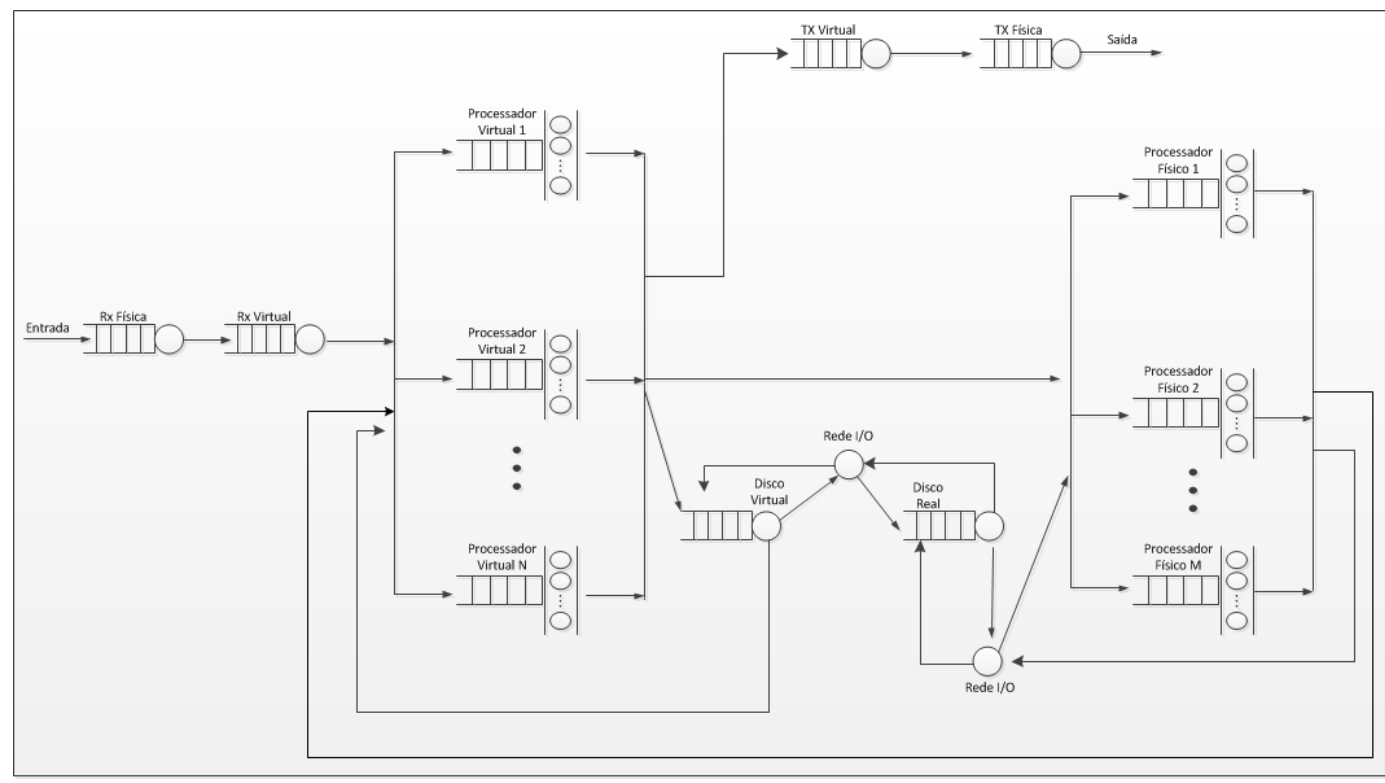

Figura 7.10: Modelo baseado em rede de filas que representa uma máquina virtual executando sobre um virtualizador do tipo bare-metal.

pendendo da quantidade de sockets disponibilizados pelo virtualizador para a máquina virtual. Esse recurso foi adicionado para permitir que a sobrecarga do sistema hospedeiro seja tratada separadamente do sistema operacional convidado, uma vez que os processos, após serem processados no centro de serviço Processador virtual, são encaminhados para o Processador físico, retornando, após a finalização do seu quantum, ou a partir de uma interrupção, para a fila dos Processadores virtuais. Através dessa abordagem é possível representar, de forma realista, a sobrecarga dos processadores nos sistemas operacionais convidados e nos hypervisores.

Assim como descrito na Seção 7.4.1, um processo em execução no centro de serviço Processador virtual pode sofrer uma falta de página, também descrita através da Equação 7.7, sendo, então, enviado para o Disco virtual para que a falta de página seja tratada. Esse centro de serviço foi desenvolvido para representar os diferentes recursos de terceira geração hardware destinados à virtualização, entre eles as large-pages e a alocação garantida, presentes, entre outros, nos hypervisores Hyper-V e VMWare estudados nesta tese.

Ao chegar no centro de serviço Disco virtual para o tratamento da ausência de página, interpretada pelo sistema operacional convidado como uma falta maior, se a mesma puder ser tratada pelo recurso de cache de páginas do virtualizador, o processo será redirecionado para a fila do Processador virtual que o enviou, indicando que a ausência de página já foi tratada e o endereço devidamente mapeado na tabela de páginas do sistema convidado. No entanto, caso essa ausência seja confirmada como uma falta maior também no nível do sistema hospedeiro, o processo será enviado para o centro de serviço Disco real, através do 
centro Rede I/O. Adicionalmente, o próprio sistema de virtualização pode sofrer ausências maiores de páginas, enviando, assim, o processo para o Disco Real através de uma Rede I/O, o que caracteriza o mesmo trâmite de uma máquina física.

Finalmente, quando um processo finaliza a sua execução ou realizada uma operação de comunicação em rede, o mesmo é enviado para o centro de serviço TX virtual, podendo, posteriormente, ser enviado para o centro de serviço TX Física.

\section{Servidor de aplicação}

O terceiro modelo desenvolvido, apresentado na Figura 7.11, representa um servidor de aplicação excluindo as características do sistema operacional. Essa abordagem se faz necessária por se tratar de um modelo modular, assim, ao executar o servidor de aplicação sobre um sistema operacional não virtualizado, o modelo apresentado nesta seção deverá ser combinado com aquele disponiblizado na Figura 7.9. No entanto, se o servidor de aplicação for implementado em um ambiente virtualizado, esse modelo deverá ser agregado àquele apresentado na Figura 7.10.

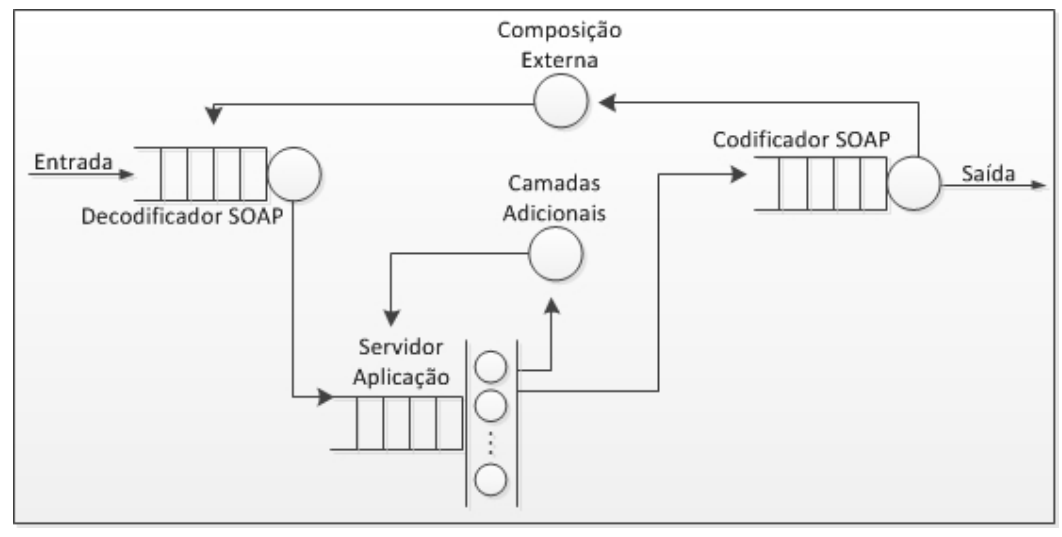

Figura 7.11: Modelo de um servidor de aplicação baseado em redes de filas.

De forma similar aos adotado nos modelos anteriores, a requisição é tratada como um token que circula pelo sistema, sendo esse composto pelos seguintes centros de serviço:

- Decodificador SOAP: Esse centro de serviço representa as bibliotecas de decodificação de envelopes SOAP, responsáveis pelas operações de unmarshalling das mensagens. A definição desse centro de serviço de forma independente dos centros de serviços relacionados ao tráfego de redes, permite representar o impacto das mensagens SOAP no tempo de processamento das aplicações distribuídas, como apresentado no Capítulo 6.

- Codificador SOAP: Esse centro de serviço é o complemento daquele apresentado no item anterior, sendo responsável pelas operações de Marshalling executadas pelos 
servidores de aplicação. Como destacado no Capítulo 6, as operações de codificação e decodificarão de envelopes SOAP apresentam diferentes impactos para os ambientes estudados, sendo assim, a separação dessas tarefas em dois centros de serviços visa representar essa característica.

- Servidor aplicação: Representa as threads instanciadas por um servidor de aplicação específico, sendo composto de uma fila única e múltiplos centros de execução. Essa caraterística se faz necessária uma vez que a fila de submissões pertence ao processo, enquanto a execução das mesmas são de responsabilidade das threads [TANENBAUM; STEEN, 2007]. Ao finalizar a execução de uma requisição, a mesma pode ser enviada para o Codificador de mensagens SOAP, caso não seja necessário representar camadas adicionais, como a WS-Security, ou para o centro de serviço Camadas adicionais que não possui fila, representando, assim, a sobrecarga de tempo gerado por cada camada adicionada.

- Camadas adicionais: Como descrito anteriormente, representa a sobrecarga gerada pelas camadas não fundamentais presentes na especificação dos Web Services.

- Composição Externa: Representa os processos de orquestração e coreografia de Web Services de maneira similar ao abordado em [TEIXEIRA et al., 2009]. A composição é retratada para o Web Services solicitante apenas como uma variação de tempo entre o envio da requisição, através do Codificador SOAP, e seu retorno através do Decodificador SOAP. Assim, caso o Web Services responsável pela execução da composição também faça parte do sistema a ser avaliado, é possível substituir o centro de serviço Composição Externa pelo modelo de redes de fila completo do servidor de aplicação. Desta forma, é possível realizar o planejamento de capacidade em todos os níveis do cenário considerado.

A partir da definição do modelo baseado em redes de filas do servidor de aplicação, é possível representar cenários compostos tanto por plataformas implantadas fisicamente sobre um hardware, quanto aquelas virtualizadas através de hypervisores do tipo baremetal.

A fim de exemplificar a composição dos modelos modulares, apresenta-se na Figura 7.12 o modelo resultante que representa um servidor de aplicação sendo executado em uma máquina virtual.

Analisando a Figura 7.12, é possível perceber que a chegada de uma requisição ocorre pela interface física de rede, sendo enviada, posteriormente, para a interface virtual, ambas através do canal de entrada RX, sendo, finalmente, entregue ao centro de serviço Decodificador SOAP. A partir dessa configuração, torna-se possível analisar o impacto da virtualização sobre as bibliotecas de codificação e decodificação de envelopes SOAP 


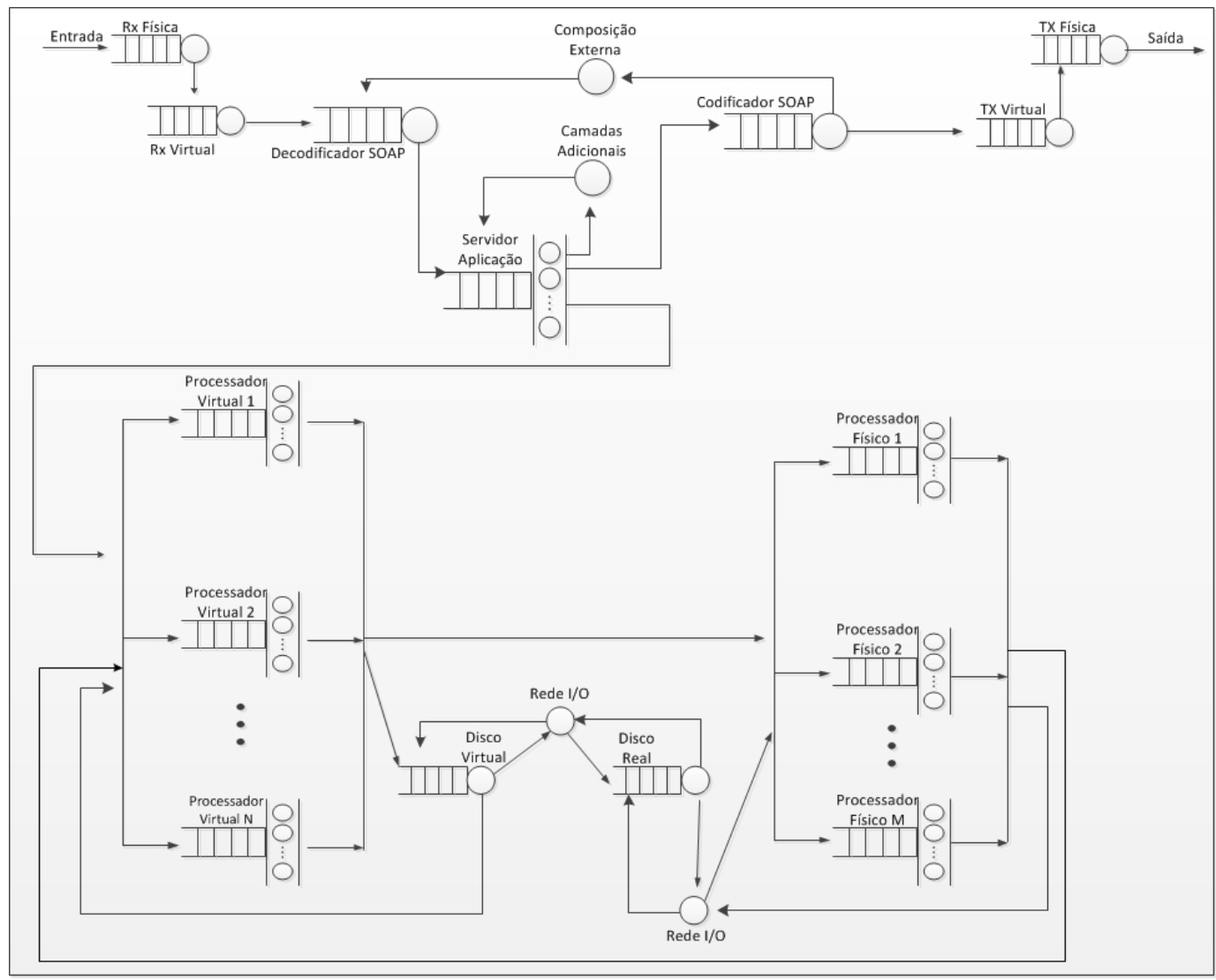

Figura 7.12: Modelo baseado em rede de filas que representa servidores de aplicação executados sobre ambientes virtualizados.

separadamente daquele sofrido pelas interfaces de rede instânciadas no sistema operacional convidado. De maneira análoga, a resposta de uma requisição também percorre três centros de serviços com o mesmo objetivo: Decodificador SOAP, TX Virtual e TX Física.

É importante destacar, também, que ao manter os centros de serviço Servidor Aplicação, Processador Virtual e Processador Físico, é possível analisar o impacto da taxa de utilização dos processadores, tanto físicos, quanto virtuais, bem como a sobrecarga da coleta de lixo realizada pelo Garbage Collector da máquina virtual Java, uma vez que quantidade de memória é representada separadamente para o servidor de aplicação e para os sistemas operacionais envolvidos, permitindo, ainda, analisar a influência do servidor de aplicação utilizado e, também, do virtualizador.

\subsection{Considerações finais}

Este capítulo apresentou os principais modelos de desempenho disponíveis atualmente na literatura, contextualizados no planejamento de capacidade e nos cenários envolvendo aplicações distribuídas baseadas em SOA executadas sobre plataformas virtualizadas. 
Ao realizar essa análise, percebeu-se que os modelos atualmente em uso, apesar de representar de maneira eficiente as aplicações baseadas em SOA e as plataformas virtualizadas de forma isolada, não descrevem, de forma realista, o comportamento ao executar essas aplicações em ambientes virtualizados, uma vez que tais modelos não consideram o relacionamento existente entre a quantidade de memória alocada pelo servidor de aplicação e aquela, efetivamente, reservada pelo sistema operacional hospedeiro, uma vez que não retratam os recursos de virtualização presentes nos hardwares de terceira geração e os recursos de gerência de memória implementado pelos hypervisores.

Ao não considerar o segundo nível de mapeamento de páginas de memória, os modelos estudados não possibilitam prever, entre outros fatores, a redução ou ganho de desempenho ao ampliar a quantidade de processadores utilizados. Adicionalmente, não abordam o impacto da reserva de memória pela JVM, uma vez que ao ampliar o tamanho do bloco alocado por intervalo de tempo, amplia-se o ganho ou se reduz a perda de desempenho imposta às aplicações distribuídas.

Neste contexto, apresentou-se nesta Seção um modelo modular, atualmente em desenvolvimento pelo autor desta tese no âmbito da Universidade Federal de Mato Grosso, sendo, tal solução, composta por três modelos fundamentais que, ao serem combinados, permitem representar as características e relacionamento supracitados. Esse modelo se encontra na fase de validação e calibração, tendo a simulação com ferramenta de solução do modelo. 


\subsection{Considerações finais}

Este trabalho abordou a influência da virtualização sobre o desempenho de aplicações distribuídas baseadas em SOA, destacando o relacionamento entre os recursos de hardware de terceira geração, destinados à auxiliar o processo de virtualização, a eficiência dos sistemas gerenciadores de máquinas virtuais e as características dos servidores de aplicações, principalmente no que tange ao sistema de "coleta de lixo" presente em muitas plataformas de desenvolvimento de software utilizadas na construção de Web Services.

Tais análises demonstraram que os hypervisores assistidos por hardware permitem que aplicações distribuídas baseadas em SOA apresentem resultados superiores aos obtidos pelas plataformas não virtualizadas, principalmente em ambientes em que o consumo de memória é elevado e dinâmico, o que demonstra pontos de falhas nos principais modelos de desempenho existentes na literatura, pois não permitem representar de forma adequada as plataformas consideradas nesta tese.

Assim, a partir de uma análise crítica, que identificou as principais características dos ambientes virtualizados executando Web Services, apresentou-se as modificações necessárias nesses modelos de desempenho para que reflitam as novas demandas no setor de tecnologia, o que permitirá que o planejamento de capacidade desses ambientes sejam corretamente executados.

Para avaliar as influências do processo de virtualização no desempenho das aplicações baseadas em SOA do tipo CPU-bound e memory-intensive, foram desenvolvidos Web Services que implementam os algoritmos de ordenação de vetores e de multiplicação de matrizes, sendo $100.000 \leq N \leq 500.000$, onde $N$ corresponde à quantidade de posições a serem ordenadas e $500 \leq O \leq 2.000$, onde $O$ representa a ordem das matrizes quadradas 
utilizadas no processo de multiplicação. Para representar as aplicações network-intensive, desenvolveu-se um Web Service que recebe e envia mensagens SOAP cujo tamanho varia entre $2 M B$ e $10 M B$. Assim, para esse tipo de aplicação, foram avaliados separadamente os impactos da virtualização nas operações de marshalling e unmarshalling. Adicionalmente, a fim de avaliar o impacto do tamanho interno dos elementos XML da mensagem SOAP, utilizaram-se mensagens formadas por elementos constituídos de dez, cem e mil caracteres.

Inicialmente, os Web services desenvolvidos foram implantados em três plataformas diferentes. A primeira plataforma, considerada a plataforma de referência, é isenta do processo de virtualização de sistemas operacionais, sendo o servidor de aplicação Glassfish instalado sobre o sistema operacional GNU/Linux. As demais plataformas possuem, também, o servidor de aplicação Glassfish instalado sobre o sistema operacional GNU/Linux, no entanto, esse sistema operacional é instalado sobre as plataformas de virtualização VMWare e Hyper-V. Assim, com o objetivo de facilitar a identificação, as três plataformas foram denominadas, respectivamente, PRef.G, P1.G e P2.G.

Em um segundo momento, com o objetivo de aferir o impacto do sistema de gestão de aplicações, substituiu-se o servidor de aplicação Glassfish pelo JBoss. Nesse contexto, alteraram-se os nomes das plataformas para PRef.J, P1.J e P2.J.

Finalmente, a fim de consumir os Web Services, foi desenvolvido um software cliente multithread responsável por enviar as solicitações para os Web Services, aferir os tempos de resposta e controlar, através das threads criadas, a quantidade de processadores utilizada.

Ao considerar as aplicações distribuídas do tipo CPU-bound e memory-intensive de carga baixa, percebe-se que apenas para altas taxas de utilização dos processadores, próximo de $100 \%$, as plataformas virtualizadas apresentam perda de desempenho. Tal fato se deve à sobrecarga gerada pelo processo frequente de escalonamento de threads, uma vez que os tempos de resposta são extremamente reduzidos.

No entanto, ao considerar as aplicações distribuídas memory-intensive de carga moderada e alta, percebe-se que, diferentemente do ocorrido com as aplicações cujo consumo de memória é reduzido, os recursos de gerenciamento de memória disponibilizados pelos hardwares utilizados, como o sistema de tabelas duplas (EPT), "large-pages" e a implementação dos virtualizadores, como a alocação garantida, permitiram que as plataformas virtualizadas apresentassem ganhos de desempenho em relação à plataforma de referência, principalmente quando a taxa de utilização dos processadores é baixa, em torno de $25 \%$.

Com essa configuração a plataforma P2.G registrou ganhos variando entre $6 \%$ e $28 \%$, quando $O=2.000$ e $O=500$, respectivamente. Esse comportamento indica que o ganho de desempenho aumenta à medida que se decrementa a ordem das matrizes. Tal fato está relacionado aos tempos médios de processamento das aplicações. Ao considerar aplicações com médio consumo de memória, quando $O=500$, o tempo de processamento é baixo, fazendo com que uma grande quantidade de objetos sejam alocados e removidos da geração 
jovem da JVM, em um curto espaço de tempo, gerando, assim, muitas faltas de páginas maiores. Isso obriga a plataforma PRef.G à acessar o disco rígido para tratar as ausências, enquanto as aplicações virtualizadas apenas reestabelecem os valores nas tabelas duplas de páginas, convertendo, assim, faltas de páginas maiores em menores.

Ao ampliar a quantidade de processadores utilizados se percebeu que os ganhos de desempenho obtidos pelas plataformas virtualizadas foram reduzidos e, em alguns casos, convertidos para perda de desempenho. No entanto, ambas as plataformas virtualizadas apresentam perdas de desempenho para todos os valores de $O$ considerados, apenas quando todos os processadores da plataforma foram ocupados. Nesse contexto, a plataforma P2.G, que até então era a mais eficiente dentre as plataformas virtualizadas, passou a apresentar perdas de desempenho superiores às registradas pela plataforma P1.G, atingindo $23 \%$ quando $O=2.000$. Esse fato demonstra a necessidade de considerar características específicas de cada virtualizador no processo de planejamento de capacidade, diferentemente dos métodos utilizados atualmente.

Com essa mesma taxa de utilização dos processadores, o mesmo comportamento ocorreu ao substituir o servidor de aplicação Glassfish pelo JBoss. Com todas CPUs utilizadas, ao processar aplicações memory-intensive de carga moderada e elevada, obteu-se perdas de desempenho para todas as ordens consideradas das matrizes. No entanto, os tempos médios de resposta das aplicações foram inferiores aos obtidos ao utilizar o servidor de aplicação Glassfish. De maneira análoga, essa configuração foi a única em que a plataforma baseada em Hyper-V apresentou desempenho inferior à plataforma baseada em VMWare.

Essa redução nos tempos médios de resposta, obtida ao substituir o servidor de aplicação e ao executar aplicações memory-intensive de carga moderada e elevada, foi registrada para todas as taxas de utilização dos processadores. Esse fato demonstrou que o recurso de carregamento paralelo e sob demanda de classes, presentes no servidor JBoss, influencia consideravelmente o desempenho das plataformas, apesar da máquina virtual Java utilizada ser a mesma para ambos os cenários estudados. Tal fato demonstra, também, que os ajustes realizados pelo servidor de aplicação na JVM, através de parâmetros, reduz a frequência de passagem do coletor de lixo, o que contribuiu para o melhor desempenho das plataformas baseadas em JBoss.

Tais reduções também foram obtidas ao se considerar aplicações CPU-bound e memory-intensive de carga baixa; no entanto, ao se comparar o desempenho das plataformas virtualizadas P1.J e P2.J com o desempenho da plataforma de referência PRef.J, percebeu-se que para uma utilização dos processadores entre $50 \%$ e $75 \%$, as perdas de desempenho sofridas pelas aplicações distribuídas, executadas sobre as plataformas virtualizadas, foram maiores que aquelas obtidas pelas aplicações executadas sobre as plataformas P1.G e P2.G. Isso indica que as reduções nos tempos médios de resposta, obtidos pela substituição do servidor de aplicação, diminuiu o impacto dos recursos de virtualização, 
disponibilizados, pelo hardware, utilizado nas plataformas.

Os recursos de hardware destinados a virtualização se apresentaram mais eficientes nas avaliações da influência da virtualização nas bibliotecas de codificação e decodificação de envelopes SOAP, principalmente nas operações de unmarshalling. Nessas operações, ao utilizar o servidor de aplicação Glassfish, as plataformas virtualizadas apresentaram ganhos de desempenho para todas as taxas de utilização de processadores. Sendo os menores ganhos de desempenho registrados quando $S \leq 6 \mathrm{MB}$ com taxa de utilização dos processadores em 25\%, uma vez que essa é a configuração em que a quantidade de memória DRAM necessária é a menor registrada, pois, ao ampliar a quantidade de threads consumidoras, ampliando a taxa de utilização dos processadores, amplia-se, também, a quantidade de memória alocada por intervalo de tempo, uma vez que a JVM reserva memória no espaço Éden em blocos, fazendo com que os recursos utilizados pelas plataformas VMWare e Hyper-V sejam mais eficientes.

Ao manter as páginas liberadas pelo sistema operacional convidado na memória do virtualizador VMWare, a plataforma P1.G reduziu consideravelmente o tempo de tratamento das faltas maiores de páginas geradas à medida que as solicitações, do software consumidor, são finalizadas e novas solicitações são recebidas. Vantagem semelhante é obtida pela plataforma P2.G ao utilizar o recurso "large-pages".

Já o maior ganho de desempenho foi registrado quando a utilização dos processadores se encontrava em $50 \%$ e com mensagens SOAP com $4 M B$ de tamanho, o que indica que o ganho de desempenho das plataformas virtualizadas são divididos em fases, sendo a primeira fase caracterizada pela redução da perda ou ampliação do ganho de desempenho à medida que o tamanho da mensagem SOAP é ampliado e a segunda caracterizada pelo incremento da perda ou redução do ganho de desempenho, demonstrando a influência do sistema de coleta de lixo da JVM, cuja frequência se amplia à medida em que se aumenta a quantidade de memória DRAM requisitada pelo servidor de aplicação por intervalo de tempo.

Ao ampliar a quantidade de caracteres por elemento XML, preservando, assim, o tamanho da mensagem SOAP, percebeu-se que a quantidade de memória DRAM necessária reduziu drasticamente, enfatizando o impacto da complexidade de deserialização da mensagem SOAP ocasionado pelo alto volume de elementos. Ao reduzir a quantidade de memória DRAM necessária, observou-se que os ganhos de desempenho obtidos pelas plataformas virtualizadas, no processo de unmarshalling de mensagens SOAP, são reduzidos e até mesmo eliminados.

Todavia, as plataformas virtualizadas voltaram a obter ganhos à medida em que se ampliou a taxa de utilização dos processadores e o tamanho das mensagens SOAP, diferentemente do conceito global, atualmente em vigor, em que à medida que se amplia a taxa de utilização dos processadores o desempenho de plataformas virtualizadas é reduzido. Nesse contexto, foram registrados ganhos de até $24 \%$ e $7 \%$, quando a taxa de 
utilização dos processadores é de $100 \%$ e $S=10 M B$, ao considerar as plataformas P1.G e P2.G, respectivamente. Tais valores revelam que ao ampliar a quantidade de caracteres por mensagem SOAP, a plataforma baseada em Hyper- $\mathrm{V}$ volta a apresentar os melhores resultados dentre as plataformas virtualizadas, uma vez que ao considerar mensagens SOAP com baixa quantidade de caracteres por elemento XML, a plataforma baseada em VMWare apresenta o melhor desempenho dentre as plataformas virtualizadas. Esse fato reforça a tese de que deve ser considerado nos modelos de desempenho as características específicas de cada hypervisor.

Essa superioridade da plataforma baseada em Hyper-V permanece ao realizar operações de marshalling de mensagens SOAP, independentemente da quantidade de caracteres por elemento XML, uma vez que para esse tipo de operação os tempos médios de resposta são maiores que aqueles obtidos pelas operações de unmarshalling, sendo a quantidade de memória consumida muito menor.

Nesse cenário, ao considerar mensagens com dez caracteres por elemento XML, foi comum as plataformas virtualizadas apresentarem perda de desempenho com mensagens de tamanho reduzido, principalmente quando a taxa de utilização dos processadores é baixa, chegando a registrar perdas de desempenho de $21 \%$ e $16 \%$, ao considerar as plataformas P1.G e P2.G, respectivamente, com taxa de utilização dos processadores em $25 \%$ e $S=2 M B$.

No entanto, à medida em que se amplia a taxa de utilização dos processadores e o tamanho da mensagem SOAP enviada pelo Web Service, fazendo com que a quantidade de memória DRAM necessária seja ampliada e, consequentemente, o tamanho do bloco reservado ao espaço Éden pela JVM, as aplicações executadas sobre as plataformas virtualizadas deixaram de registrar perdas e passaram a registrar ganhos de desempenho. Porém, assim como registrado na operação de unmarshalling, ao atingir 100\% de utilização dos processadores, o ganho de desempenho obtido pelos virtualizadores apresentou uma divisão em duas fases, sendo que na primeira há um incremento no ganho de desempenho à medida que se amplia o tamanho da mensagem SOAP e na segunda um comportamento inverso foi registrado, sendo que essa característica também não é retratada nos modelos de desempenho atualmente em uso.

Tais fases são consequência dos elevados tempos de processamento das operações de serialização de objetos, o que gerou uma estabilidade na quantidade de memória DRAM necessária para processar múltiplas requisições das threads consumidoras a partir de um dado valor de $S$. Ao atingir essa estabilidade no consumo de memória, a sobrecarga de gerência das threads em conjunto com a sobrecarga de gerência do próprio sistema operacional hospedeiro, fez com que a eficiência dos recursos de virtualização, explorados pelos virtualizadores bare-metal, seja reduzida, decrementando, assim, os ganhos de desempenho das aplicações executadas sobre essas plataformas.

Essa mesma redução na eficiência dos recursos de virtualização foram apresentadas 
ao ampliar a quantidade de caracteres por elemento XML nas operações de marshalling, onde os tempos médios de resposta são reduzidos significativamente. Ao ampliar a quantidade de caracteres para cem, percebe-se que a eficiência dos recursos disponibilizados pelo hardware só é recuperada, pela plataforma P1.G, quando a taxa de utilização dos processadores atinge 50\%, sendo a maior eficiência atingida quando a taxa de utilização foi de 75\%. Nesse cenário, a plataforma baseada em VMWare apresentou uma característica interessante, mesmo ampliando a taxa de utilização dos processadores e o tamanho das mensagens SOAP, a plataforma apresentou perdas de desempenho crescentes, demonstrando que sob certas circunstâncias, os sistemas hypervisores podem apresentar insuficiência na gestão do hardware.

Finalmente, no Capítulo 5, demonstrou-se que os modelos de desempenho atualmente em uso não estão preparados para tratar a influência da virtualização no desempenho de aplicações baseadas em SOA ao serem executadas sobre plataformas virtualizadas, como descrito anteriormente. O primeiro modelo discutido, denominado R-Capricio [ZHANG et al., 2007] apesar de tratar a divisão do software em camadas, não modela o uso das threads presentes nos servidores de aplicações modernos, como destacado em [LIU et al., 2008].

O modelo apresentado em [LIU et al., 2008] também trata a divisão dos sistemas em camadas, incluindo a sobrecarga de módulos adicionais de conexão como o mod_jk, entre as duas primeiras camadas e os drivers ODBC entre as duas últimas camadas. No entanto, esse modelo, assim como o R-Cappricio, precisa de modificações profundas para tratar sistemas virtualizados, uma vez que ambos não permitem representar os impactos gerados pela terceira geração de recursos de virtualização disponibilizados pelo hardware, entre eles a tabela dupla de páginas e as "large-pages", bem como os recursos presentes na implementação de alguns hypervisores bare-metal, como a alocação garantida e o impacto gerado pelo servidor de aplicação, especificamente pelo sistema de coleta de lixo, presente nos sistemas de virtualização de aplicações.

Outros modelos, destinados ao planejamento de capacidade de aplicações baseadas em SOA, apresentaram-se mais eficientes nessa tarefa de representar plataformas virtualizadas, como o apresentado em [TEIXEIRA et al., 2009] e [KARGUPTA; BLACK, 2012]. O primeiro permite modelar as comunicações considerando diferentes interfaces de rede separando, inclusive, o tráfego originado e recebido. Essa técnica permite prever os impactos da virtualização nas interfaces físicas de rede e nas interfaces de comunicação interna, como a loopback e o uso de switches virtuais. Essa característica também é tratada no segundo trabalho citado, que apesar de não definir um modelo completo, estabelece fórmulas e padrões baseadas em delay que representam pontos de perda de desempenho nos sistemas estudados.

Todavia, tais modelos, apesar de mais completos e de serem considerados a evolução natural dos modelos apresentados em [ZHANG et al., 2007] e [LIU et al., 2008], não permitem descrever a relação entre os recursos de terceira geração de virtualização, os servidores de 
apliação e os sistemas de coleta de lixo.

Já o último modelo estudado, destinado a prever o comportamento de plataformas virtualizadas, mas não de aplicações distribuídas baseadas em SOA, permite ponderar, de maneira aproximada, a influência do servidor de aplicação e dos recursos de terceira geração dos processadores. Todavia, por não ser destinado a Web Services, não permite representar a relação entre a taxa de utilização dos processadores e o impacto das coletas de lixo, uma vez que essa tarefa reflete diretamente na quantidade de memória alocada por intervalo de tempo.

Assim, concluiu-se que os modelos de desempenho atualmente em uso precisam ser modificados, para que incluam as características dos sistemas virtualizados ao executarem aplicações baseadas em SOA descritas nesta tese, pois, somente assim, tais modelos refletirão as plataformas utilizadas atualmente em ambientes de TI.

\subsection{Contribuições}

No decorrer deste trabalho algumas contribuições foram realizadas, destacando-se:

- Levantamento bibliográfico envolvendo trabalhos científicos publicados nas áreas de sistemas baseados em SOA e virtualização de sistemas operacionais. Ao abordar sistemas baseados em SOA destacou-se a sua estrutura e composição, o sistema de cooperação e as características das composições. Também apresentou-se a tecnologia de Web Services, que atualmente destina-se a concretização do SOA, destacando sua arquitetura, protocolos e padrões. Ao tratar de sistemas de virtualização, destacaram-se os recursos de terceira geração dos processadores destinados à sistemas de virtualização bare-metal, sendo que, tais recursos, possuem influência direta sobre a virtualização de processadores, memória e dispositivos de entrada e saída, também abordado neste trabalho. Isso constitui uma contribuição deste trabalho porque permite que pesquisadores iniciantes tenham uma boa referência introdutória na área de aplicações baseadas em SOA e sistemas de virtualização, tanto de sistemas operacionais quanto de aplicações, facilitando o desenvolvimento de futuros trabalhos na área;

- Apresentação e análise crítica da influência da virtualização no desempenho de aplicações baseadas em SOA do tipo CPU-bound e memory-intensive, com consumo de memória DRAM variando entre baixa e alta, ao serem executadas sobre plataformas virtualizadas. Nesse contexto, destaca-se a utilização dos virtualizadores do tipo bare-metal VMWare ${ }^{\circledR}$ e Hyper-V ${ }^{\circledR}$, que, de acordo com o grupo Gartner ${ }^{\circledR}$, são as duas principais plataformas de virtualização disponíveis. Ao estudar a influência da virtualização descreveu-se a relação entre o uso dos recursos de virtualização 
de terceira geração disponibilizadas nos processadores atuais e a eficiência dos virtualizadores ao utilizá-los. Descreveu-se, também, a relação entre o consumo de memória DRAM pelas aplicações distribuídas, o seu gerenciamento pelas plataformas de virtualização e o sistema de coleta de lixo existentes nas plataformas de desenvolvimento de software modernas.

A partir dessa análise, é possível que profissionais envolvidos em processos e estudos de virtualização selecionem, corretamente, a plataforma que apresenta o melhor desempenho mediante o tipo de carga de trabalho existente. Adicionalmente, tais análises permitem que esses profissionais prevejam o comportamento futuro da plataforma mediante o aumento da carga de trabalho ou, até mesmo, de sua mudança. Como confirmação dessa contribuição, encontra-se os resultados obtidos no âmbito do Tribunal Regional Eleitoral de Mato Grosso (TRE-MT) que, a partir deste estudo, optou por substituir a plataforma de virtualização Microsoft Hyper-V ${ }^{\circledR}$ pela plataforma VMWare VSphere ${ }^{\circledR}$.

- Apresentação e análise crítica da influência do servidor de aplicação e de seus recursos de gerência de conteineres de Web Services ao executar aplicações distribuídas do tipo CPU-bound e memory-intensive, de carga variando entre baixa e alta, em ambientes virtualizados. Nesse contexto, analisaram-se os servidores de aplicação Glassfish e JBoss. O primeiro é o servidor de aplicação de referência na implementação da especificação da plataforma JEE, enquanto o segundo é, também de acordo com o grupo Gartner ${ }^{\circledR}$, um dos líderes de mercado em servidores de aplicação. Ao realizar essa análise destacou-se a relação entre o consumo de memória DRAM pelas aplicações, sua gestão pelo conteiner e a ativação dos recursos de contenção de memória pela plataformas de virtualização, entre eles o converter as faltas de páginas maiores em menores.

Assim como no item anterior, essa análise permite que profissionais tomem decisões sobre as soluções a serem adotadas ou mantidas envolvendo os servidores de aplicação e prevejam o comportamento das plataformas utilizadas mediante mudanças na carga de trabalho ou, até mesmo, em sua natureza.

É importante destacar que através deste estudo, o TRE-MT optou por manter o servidor de aplicação JBoss, no entanto, ao descobrir que esse servidor de aplicação eleva a quantidade de coletas de lixo, a equipe de analistas, desse tribunal, optou por reduzir a carga de utilização de memória em cada hypervisor que constitui a plataforma.

- Apresentação e análise crítica da influência da virtualização nas bibliotecas de codificação e decodificação de envelopes SOAP, no momento em que as aplicações realizam as operações de marshalling e unmarshalling dos envelopes. Esse estudo demons- 
trou a relação entre os recursos de virtualização de terceira geração disponibilizados pelo hardware, a eficiência dos virtualizadores do tipo bare-metal em gerenciá-los e as operações de alocação de blocos na geração Jovem da JVM, mais especificamente no espaço Éden. Essa análise descreveu também a influência do tamanho das cadeias de caracteres que formam os elementos XML enviados no corpo dos envelopes SOAP. Tal resultado trata-se de uma contribuição ao permitir que profissionais de virtualização dimensionem corretamente as redes virtuais, principalmente em ambientes com elevada taxa de composição de serviços, além de permitir prever o comportamento da plataforma em momentos futuros;

- Apresentação e análise do impacto da taxa de utilização dos processadores em ambientes virtualizados na presença de aplicações CPU-bound e memory-intensive, com carga de memória variando entre baixa e alta, bem como nas operações de marshalling e unmarshalling de envelopes SOAP pelas bibliotecas de codificação e decodificação dos servidores de aplicação. Nesse cenário descreveu-se a relação entre a taxa de utilização dos processadores e o consumo de memória DRAM pelas aplicações, refletindo, diretamente, no tamanho do bloco reservado pela JVM por intervalo de tempo. Este item constitui uma das mais importantes contribuições desta tese, uma vez que permite aos profissionais de TI analisarem o comportamento futuro das plataformas implantadas mediante o incremento da carga de trabalho;

Assim, como nos itens anteriores, os analistas do TRE-MT também aproveitaram esse estudo verificando a necessidade de redistribuição da carga de trabalho de alguns sistemas críticos como o IPleno, responsável por gerenciar as audiências judiciais.

- Análise crítica de modelos de desempenho existentes, destinados ao planejamento de capacidade de aplicações distribuídas e de ambientes virtualizados, destacando as vantagens e, principalmente, os pontos em que modificações são necessárias para representar, de maneira realística, ambientes em que aplicações baseadas em SOA são implantadas em ambientes virtualizados. Este item constitui uma contribuição uma vez que permite aos autores de modelos de desempenho e pesquisadores da área adaptarem os modelos existentes ou até mesmo desenvolverem novos modelos, uma vez que as características fundamentais das plataformas virtualizadas já foram mapeadas nesta tese de doutorado;

- Desenvolvimento de um software consumidor multithread e de Web Services que representam aplicações CPU-bound, memory-intensive e network-bound, esta através das operações de marshalling e unmarshalling de envelopes SOAP. Uma vez desenvolvida, essa ferramenta pode ser utilizada por outros pesquisadores para estudar características das plataformas virtualizadas ainda não consideradas neste trabalho. 


\subsection{Sugestões para trabalhos futuros}

A área em que este trabalho está inserido é muito vasta, assim, trabalhos futuros são essenciais para o avanço da pesquisa. Dentre os mais importantes destacam-se:

- Realizar estudos analíticos considerando aplicações I/O-intensive em ambientes virtuais, uma vez que as plataformas de virtualização total permitem inserir no sistema operacional hospedeiro drivers que simulam as técnicas de paravirtualização. Adicionalmente, ao se utilizar storages e redes SAN (Storage Area Network), obtém-se velocidades superiores àquelas obtidas por sistemas RAID (redundant array of independent disks) instalados localmente;

- Realizar estudos analíticos considerando outras técnicas de virtualização, como a paravirtualização, muito utilizada pelo projeto XEN, uma vez que essa técnica elimina a necessidade de interpretação das instruções pelo kernel do sistema operacional hospedeiro, reduzindo a sobrecarga dos virtualizadores. Ao realizar esse estudo, é interessante destacar a relação da ocupação de memória DRAM pelas aplicações baseadas em SOA, pelo conteiner de Web Services e pelos recursos vinculados a paravirtualização;

- Expandir os estudos inserindo computação em nuvem do tipo IaaS, principalmente nuvens privadas, uma vez que nessa modalidade a migração das máquinas virtuais entre os gerenciadores ocorre em intervalos reduzidos de tempo, diferentemente do obtido em nuvens públicas, onde os tempos de migração são elevados;

- Realizar estudos comparativos nas plataformas abordadas neste trabalho com outras plataformas de desenvolvimento de software. Tal estudo permitirá relacionar a influência do sistema de "coleta de lixo" e de seu método de implementação;

- Adaptar modelos de desempenho existentes ou, se necessário, desenvolver novos modelos para que reflitam, de maneira realística, o comportamento de plataformas virtualizadas ao executar aplicações baseadas em SOA, permitindo, assim, a execução de planejamentos de capacidade mais adequados.

- Realizar estudos analíticos considerando a execução de múltiplas máquinas virtuais sobre um mesmo hypervisor, descrevendo a relação entre a memória consumida pelos sistemas operacionais convidados e hospedeiro e o desempenho global da plataforma.

- Realizar estudos analíticos considerando as técnicas de retomada de memória pelo hypervisor, descrevendo sua relação com o desempenho das aplicações baseadas em SOA executadas nos sistemas operacionais convidados. 


\section{Referências Bibliográficas}

ALVES, L. C. D. Políticas de escalonamento memory-intensive para aplicações distribuídas. Dissertação (Mestrado) - ICMC, USP, São Carlos, SP, Junho 2008.

ALVES, L. C. D. et al. CMGS - obtendo eficiência no escalonamento de aplicações memory-intensive em clusters. In: XXXV Conferência Latino Americana de Informática. Pelotas, RS, Brasil: [s.n.], 2009.

BAUN, C. et al. Cloud Computing: Web-Based Dynamic IT Services. 1st. ed. [S.l.]: Springer Publishing Company, Incorporated, 2011. ISBN 3642209165, 9783642209161.

BHATIA, N. Performance Evaluation of Intel EPT Hardware Assist. VMware White Paper, VMWare, Palo Alto, CA, 2009.

BITTMAN, T. J. et al. Magic Quadrant for x86 server virtualization infrastructure. Gartner Group, Stamford, CT, p. 1-9, 2012.

CALZAROSSA, M.; MASSARI, L.; TESSERA, D. Workload characterization issues and methodologies. In: Performance Evaluation: Origins and Directions. London, UK: Springer-Verlag, 2000. p. 459-481. ISBN 3-540-67193-5.

CHEN, H.; MOHAPATRA, P. Overload control in qos-aware web servers. Comput. Netw., Elsevier North-Holland, Inc., New York, NY, USA, v. 42, n. 1, p. 119-133, 2003. ISSN 1389-1286.

CHI, Y. et al. SLA-tree: a framework for efficiently supporting SLA-based decisions in cloud computing. In: Proceedings of the 14th International Conference on Extending Database Technology. New York, NY, USA: ACM, 2011. (EDBT/ICDT '11), p. 129-140. ISBN 978-1-4503-0528-0. Disponível em: <http://doi.acm.org/10.1145/1951365.1951383>.

CHIANG, J.-H. Optimization Techniques for Memory Virtualization-based Resource Management. Tese (Doutorado) — Stony Brook University, New York, NY, USA, December 2012. 
CHINNI, S.; HIREMANE, R. Virtual Machine Device Queues. Intel White Paper, Intel, Santa Clara, CA, USA, 2013.

COHEN, F. Discover SOAP Encoding's impact on Web Service performance. 2003. Acessado em 17 de Janeiro de 2010. Disponível em: $<$ https://www.ibm.com/developerworks/webservices/library/ws-soapenc/>.

DEITEL, H. M. et al. XML, Como programar. Porto Alegre, RS: Bookman, 2003. ISBN 85-363-147-3.

DEviCES, I. A. M. AMD-V Nested Paging. AMD White Paper, Advance Micro Devices, Inc, Sunnyvale, California, 2008.

E-COMMERCE. Evolução da Internet e do e-commerce. 2013. Acessado em 21 de Julho de 2013. Disponível em: <http://www.e-commerce.org.br/stats.php>.

ENDREI, M. et al. Patterns: Service-Oriented Architecture and Web Services. New York, NY, USA: IBM, 2004.

ERL, T. Service-Oriented Architecture: Concepts, technology and design. Vancouver, Canad: Prentice Hall, 2005.

ERL, T. SOA Princípios de design de serviços. Vancouver, Canadá: Prentice Hall, 2009.

ESTRELLA, J. C. et al. Diretrizes para avaliação de desempenho de web services. WPerformance, XXVIII Congresso da Sociedade Brasileira de Computação, Bélem, PA, p. 111-126, 2008.

GUO, F. Understanding memory resource management in VMware VSphere 5.0. VMware White Paper, VMWare, Palo Alto, CA, 2011.

HAU, T. et al. Where to start with soa: Criteria for selecting soa projects. In: HICSS '08: Proceedings of the Proceedings of the 41st Annual Hawaii International Conference on System Sciences. Washington, DC, USA: IEEE Computer Society, 2008. p. 314. ISBN 0-7695-3075-8.

HUANG, X. et al. An adaptive performance modeling approach to performance profiling of multi-service web applications. In: Proceedings of the 2011 IEEE 35th Annual Computer Software and Applications Conference. Washington, DC, USA: IEEE Computer Society, 2011. (COMPSAC '11), p. 4-13. ISBN 978-0-7695-4439-7. Disponível em: <http://dx.doi.org/10.1109/COMPSAC.2011.10>.

IOSUP, A. et al. Performance analysis of cloud computing services for many-tasks scientific computing. IEEE Trans. Parallel Distrib. Syst., IEEE Press, Piscataway, 
NJ, USA, v. 22, n. 6, p. 931-945, jun. 2011. ISSN 1045-9219. Disponível em: <http://dx.doi.org/10.1109/TPDS.2011.66>.

JAIN, R. K. The Art of Computer Systems Performance Analysis. 1. ed. San Francisco, CA, USA: Wiley, 1991. 720 p.

KARGUPTA, S.; BLACK, S. A novel approach for service performance analysis and forecast. J. Web Eng., Rinton Press, Incorporated, Paramus, NJ, v. 11, n. 2, p. 146-176, jun. 2012. ISSN 1540-9589. Disponível em: $<$ http://dl.acm.org/citation.cfm?id=2230896.2230900>.

KARTSON, D. et al. Modelling with Generalized Stochastic Petri Nets. 1st. ed. New York, NY, USA: John Wiley \& Sons, Inc., 1994. ISBN 0471930598.

KUNDU, S. et al. Application performance modeling in a virtulized environment. In: High Performance Computer Architecture (HPCA) 2010. [S.1.]: IEEE Press, 2010. p. 1-10. ISBN 978-1-4244-5658-1.

LARSON, R.; CARBONE, J. Windows Server 2008 Hyper-V Resource Kit. 1st. ed. Redmond, Washington, USA: Microsoft Press, 2009. ISBN 0735625174.

LIU, X.; HEO, J.; SHA, L. Modeling 3-tiered web applications. In: MASCOTS '05: Proceedings of the 13th IEEE International Symposium on Modeling, Analysis, and Simulation of Computer and Telecommunication Systems. Washington, DC, USA: IEEE Computer Society, 2005. p. 307-310. ISBN 0-7695-2458-3.

LIU, X. et al. Queueing-model-based adaptive control of multi-tiered web applications. IEEE Trans. on Netw. and Serv. Manag., IEEE Press, Piscataway, NJ, USA, v. 5, n. 3, p. 157-167, set. 2008. ISSN 1932-4537. Disponível em: $<$ http://dx.doi.org/10.1109/TNSM.2009.031103>.

LU, J. et al. Web service composition: A reality check. In: Web Information Systems Engineering - WISE 200\%. Heidelberg: Springer Berlin, 2007. v. 4831/2007, p. 523-532. ISBN 978-3-540-76992-7.

LU, L. et al. AWAIT: Efficient overload management for busy multi-tier web services under bursty workloads. In: Proceedings of the 10th international conference on Web engineering. Berlin, Heidelberg: Springer-Verlag, 2010. (ICWE'10), p. 81-97. ISBN 3-642-13910-8, 978-3-642-13910-9. Disponível em: $<$ http://dl.acm.org/citation.cfm?id=1884110.1884118>.

MARZULLO, F. P. SOA na prática. Inovando seu negócio por meio de soluções orientadas a serviços. São Paulo, SP, Brasil: Novatec, 2009. ISBN 978-85-7522-201-0. 
MATOS, J. d. Distribuição de carga flexível e dinâmica para provedores de Web Services. Dissertação (Mestrado) - ICMC, USP, São Carlos, SP, Março 2009.

MENASCE, D. A.; ALMEIDA, V. Planejamento de Capacidade para Serviços na Web: Métricas, modelos e métodos. Rio de Janeiro, RJ, Brasil: Campus, 2003. ISBN 85-352-1102-0.

MEZGHANI, E.; HALIMA, R. B. Drf4soa: A dynamic reconfigurable framework for designing autonomic application based on soa. In: Proceedings of the 2012 IEEE 21st International Workshop on Enabling Technologies: Infrastructure for Collaborative Enterprises. Washington, DC, USA: IEEE Computer Society, 2012. (WETICE '12), p. 95-97. ISBN 978-0-7695-4717-6. Disponível em: $<$ http://dx.doi.org/10.1109/WETICE.2012.81>.

NETO, A. T. et al. Interfaces multimodais dinâmicas utilizando j2ee. In: XIV Simpósio Brasileiro de Sistemas Multimídia e Web (Webmedia 2008). Vila Velha, ES: Webmedia/SBC, 2008. v. 1, p. 1-48. ISBN 9788576692003.

Peter Mell and Tim Grance. The NIST Definition of Cloud Computing. http://csrc.nist.gov/publications/nistpubs/800-145/SP800-145.pdf: [s.n.], 2011.

PEZZINE, M. et al. Magic Quadrant for enterprise application servers. Gartner Group, Stamford, CT, p. 1-17, 2011.

POTENA, P. Optimization of adaptation plans for a service-oriented architecture with cost, reliability, availability and performance tradeoff. J. Syst. Softw., Elsevier Science Inc., New York, NY, USA, v. 86, n. 3, p. 624-648, mar. 2013. ISSN 0164-1212. Disponível em: <http://dx.doi.org/10.1016/j.jss.2012.10.929>.

PRAPHAMONTRIPONG, U. et al. An analytical approach to performance analysis of an asynchronous web server. Simulation, Society for Computer Simulation International, San Diego, CA, USA, v. 83, n. 8, p. 571-586, 2007. ISSN 0037-5497.

RAO, J. et al. Self-adaptive provisioning of virtualized resources in cloud computing. In: Proceedings of the ACM SIGMETRICS joint international conference on Measurement and modeling of computer systems. New York, NY, USA: ACM, 2011. (SIGMETRICS '11), p. 129-130. ISBN 978-1-4503-0814-4. Disponível em: $<$ http://doi.acm.org/10.1145/1993744.1993790>.

ROCHA, C. A. Um estudo sobre os desafios de segurança na adoção da Arquitetura Orientada a Serviços (SOA). Dissertação (Mestrado) - IC, Unicamp, Campinas, SP, Julho 2006. 
ROY, N. et al. A capacity planning process for performance assurance of componentbased distributed systems. In: Proceedings of the second joint WOSP/SIPEW international conference on Performance engineering. New York, NY, USA: ACM, 2011. (ICPE '11), p. 259-270. ISBN 978-1-4503-0519-8. Disponível em: $<$ http://doi.acm.org/10.1145/1958746.1958784>.

SCHLIMMER, J. C. Web Services Description Requirements. 2002. Acessado em 15 de Janeiro de 2010. Disponível em: <http://www.w3.org/TR/ws-desc-reqs>.

SHIMIZU, S. et al. Platform-independent modeling and prediction of application resource usage characteristics. Journal of Systems and Software, v. 82, n. 12, p. 2117 - 2127, 2009. ISSN 0164-1212. Disponível em: <http://www.sciencedirect.com/science/article/B6V0N4WSHK0F-1/2/ff346dfe5baf22bafaed8e05cc1f5ad8>.

TANEnBAUM, A. S. Sistemas Operacionais Modernos. trad. 3 ed. São Paulo: Pearson Education, 2009.

TANENBAUM, A. S.; STEEN, M. V. Sistemas distribuídos: princípios e paradigmas. trad. 2 ed. São Paulo: Pearson Prentice Hall, 2007.

TAVARES, T. C. Caracterização de cargas de trabalho para avaliação de desempenho em Web Services. Dissertação (Mestrado) - ICMC, USP, São Carlos, SP, junho 2009.

TEIXEIRA, M. et al. Performance evaluation of service-oriented architecture through stochastic petri nets. In: Proceedings of the 2009 IEEE international conference on Systems, Man and Cybernetics. Piscataway, NJ, USA: IEEE Press, 2009. (SMC'09), p. 2831-2836. ISBN 978-1-4244-2793-2. Disponível em: $<$ http://dl.acm.org/citation.cfm?id=1732003.1732188>.

TEIXEIRA, M. et al. Planning service agreements in SOA-based systems through stochastic models. In: Proceedings of the 2011 ACM Symposium on Applied Computing. New York, NY, USA: ACM, 2011. (SAC '11), p. 1576-1581. ISBN 978-1-4503-0113-8. Disponível em: <http://doi.acm.org/10.1145/1982185.1982518>.

TROYER, J. Virtualization Overview. VMware White Paper, VMWare, Palo Alto, CA, 2006.

TROYER, J. Understanding Full Virtualization, Paravirtualization, and Hardware Assist. VMware White Paper, VMWare, Palo Alto, CA, 2007.

UENO, K.; TATSUBORI, M. Early capacity testing of an enterprise service bus. In: Proceedings of the IEEE International Conference on Web Services. Washington, DC, USA: IEEE Computer Society, 2006. (ICWS '06), p. 709-716. ISBN 0-7695-2669-1. Disponível em: <http://dx.doi.org/10.1109/ICWS.2006.57>. 
W3C. Lastest SOAP versions. 2007. Acessado em 17 de Janeiro de 2010. Disponível em: $<$ http://www.w3.org/TR/soap/>.

W3CSCHOOLS. SOAP Tutorial. 2010. Acessado em 17 de Janeiro de 2010. Disponível em: <http://www.w3schools.com/soap/default.asp $>$.

XIAO, L.; CHEN, S.; ZHANG, X. Dynamic cluster resource allocations for jobs with known and unknown memory demands. IEEE Trans. Parallel Distrib. Syst., IEEE Press, Piscataway, NJ, USA, v. 13, n. 3, p. 223-240, 2002. ISSN 1045-9219.

YU, Q. et al. Deploying and managing web services: issues, solutions, and directions.

The VLDB Journal, Springer-Verlag New York, Inc., Secaucus, NJ, USA, v. 17, n. 3, p. 537-572, 2008. ISSN 1066-8888.

ZHANG, Q. et al. A capacity planning framework for multi-tier enterprise services with real workloads. In: Integrated Network Management, 200\%. IM '0\%. 10th IFIP/IEEE International Symposium on. [S.l.: s.n.], 2007. p. 781-784.

ZIVIANI, N. Projeto de algoritmos com implementações em Pascal e C. 3st. ed. [S.l.]: Cengage Learning, 2011. ISBN 8522110506 , 9788522110506. 